
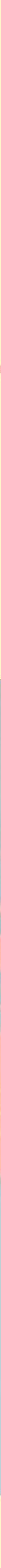

Leuven University Press 
Spatial Boundaries, Abounding Spaces 



\section{Spatial Boundaries, Abounding Spaces}

COLONIAL BORDERS IN FRENCH AND FRANCOPHONE LITERATURE AND FILM

Mohit Chandna 
Published with the support of the

KU Leuven Fund for Fair Open Acces

Published in 2021 by Leuven University Press / Presses Universitaires de Louvain / Universitaire Pers Leuven. Minderbroedersstraat 4, B-3000 Leuven (Belgium).

(C) 2021 Mohit Chandna

This book is published under a Creative Commons Attribution Non-Commercial Non-Derivative 4.0 Licence.

\section{(c) $(1)(9)$}

Further details about Creative Commons licences are available at http://creativecommons.org/licenses/

Attribution should include the following information:

Mohit Chandna, Spatial Boundaries, Abounding Spaces: Colonial Borders in French and

Francophone Literature and Film. Leuven, Leuven University Press. (CC BY-NC-ND 4.0)

ISBN 9789462702738 (Paperback)

ISBN 9789461663832 (ePDF)

ISBN 9789461663849 (ePUB)

https://doi.org/10.11116/9789461663832

D/2021/1869/16

NUR: 633

Layout: Crius Group

Cover design: André Klijsen

Cover illustration: RMN-Grand Palais (Musée du quai Branly - Jacques Chirac) / Hervé Lewandowski

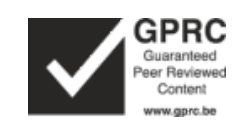


For Prem ...

These feet may be mine but I walk because of you 



\section{TABLE OF CONTENTS}

Note on Translations

Acknowledgements

Prologue

Chapter 1

Introduction: Charting Course

Anchoring Space

Doing Space

Geographies of Literature

Postmodern Spaces - Material Histories

Chapter 2

Around the World in Eighty (One) Days 45

Section 1. Understanding Verne: Laying the Groundwork 49

Verne and the World 53

Verne's Geography 56

Geography on Verne 60

Reading Verne's Geographies $\quad 66$

Rounding up the World 68

$\begin{array}{ll}\text { Capital Repetitions: Monghir } & 71\end{array}$ 
Section 2. Opium Silence and Nineteenth-Century French Literature 78

Colonizing Hong Kong 81

Illegal Opium and Colonial Wealth 89

Opium Cities $\quad 94$

Opium Race $\quad 98$

Chapter 3

Dislocating the Indian Nation: Ananda Devi's Homelands $\quad 107$

$\begin{array}{ll}\text { Global Pathways } & 109\end{array}$

Along a Local Road $\quad 111$

Dislocating Location $\quad 115$

$\begin{array}{ll}\text { Grounding Identity } & 118\end{array}$

$\begin{array}{ll}\text { Patriarchal Homelands } & 121\end{array}$

Tango with India $\quad 126$

Delhi's Underbelly 133

Antipodal Itineraries 136

$\begin{array}{ll}\text { Desert Safari } & 140\end{array}$

$\begin{array}{ll}\text { Producing Dissent } & 145\end{array}$

Rediscovering India $\quad 152$

Chapter 4

Martinique: Space, Language, Gender 155

Section 1. Contextualizing Texaco 157

Texaco and its Significations 157

A Spatial Metaphor $\quad 158$

Literary Margins: City and Language 159

Marie-Sophie as Texaco 163

$\begin{array}{ll}\text { Chamoiseau and Feminism } & 164\end{array}$

$\begin{array}{ll}\text { Reinventing the City } & 167\end{array}$

Section 2. Martinique's Literary Identity and French Borders 169

Martinique: Colonial History, Postcolonial Literature 169

$\begin{array}{ll}\text { French Borders, Martinican Text } & 174\end{array}$

Section 3. Text, Texaco and Landscape 177

Texaco: Space and Language 177

$\begin{array}{lr}\text { Rewriting l'En-ville } & 185\end{array}$ 
Section 4. France, Martinique and Marie-Sophie’s Body 188

$\begin{array}{ll}\text { Marie-Sophie and Texaco } & 188\end{array}$

$\begin{array}{ll}\text { Marie-Sophie's body and Martinique } & 197\end{array}$

Chapter 5

Out of Place: French Family at (Algerian) War 205

Immaterial Differences 206

Locating Caché $\quad 207$

$\begin{array}{ll}\text { White Lies } & 211\end{array}$

Hidden Agenda 213

Colonial Family; National Lies 216

Colonial Past; Cinematic Present 221

Escaping Images $\quad 228$

Deadly Images $\quad 232$

Epilogue: Interjecting Passages 239

$\begin{array}{ll}\text { Notes } & 253\end{array}$

$\begin{array}{ll}\text { Bibliography } & 287\end{array}$ 



\section{NOTE ON TRANSLATIONS}

Translations of quotations from literary works and films: English translations appear in square brackets and follow the original quotations within the main text.

Translations of critical writings: English translations appear in the main text whereas the original French quotations only appear in the notes. Occasionally, when necessary for the argument some of the translations follow the original in the main text.

Unless otherwise stated all English translations of French quotations are mine. 



\section{ACKNOWLEDGEMENTS}

Spatial Boundaries, Abounding Spaces: Colonial Borders in French and Francophone Literature and Film is the result of many years of hard work and is a book that has become possible only because of the help of several friends, colleagues and institutions. I would like to start by thanking Nelly Furman. She has been a constant source of support and friendship, both when I was a graduate student and later when I started my career as a colleague in the profession. I shall forever remain indebted to Nelly. My thanks also go to Kathleen Long, for her professional guidance, to Mary Pat Brady for her help with my theoretical arguments, and to Debra Castillo for her friendship. Thank you David Bodenhamer for helping me find a home for this book.

Without the supportive and professional environment at the Department of Romance Studies at Cornell University, and the Department of French and Francophone Studies at the English and Foreign Languages University (EFLU), this work could not have taken its current shape. Friends and colleagues from the Department of French and Francophone Studies at EFLU have contributed immensely to creating an environment conducive for research. Discussions with students and research scholars have helped me further refine my intellectual and theoretical positions. Rebecca Vedavathy B. very graciously agreed to read this manuscript. I owe Rebecca an unrepayable debt of gratitude for her remarks and suggestions.

Thank you very much Jayanti di, Javeed sahab, Manjari Katju, Aniket Alam, Sara Aparajita and Rewa Anahita. Hyderabad is home because of you. My deepest thanks to my family. Nabina and Spruha have generously tolerated the vagaries of this journey. Sarika and Rajiv, I cannot ever thank you enough. My parents are the reason I am where I am. I am grateful for their love and support. 
A Shastri Mobility Programme (SMP) Grant by Shastri Indo Canadian Institute (SICI) enabled me to consult research material and interact with colleagues in Canada. I would like to thank Centre d'études et de recherche sur l'Inde, l'Asie du Sud et sa diaspora (CERIAS), and the Département d'études littéraires, both located at the Université du Québec à Montréal (UQAM), for their support.

The generous grant by the Paul Druwé Fund and the KU Leuven Fund for Fair Open Access has made it possible for this book to be available in the open access format. My sincerest thanks to KU Leuven. I would also like to thank the acquisitions editor at Leuven University Press, Mirjam Truwant, who has always been very generous with guidance and help. Irina du Quenoy's editing skills have helped this manuscript take its current shape.

Several parts of this manuscript have been presented at conferences and published in English and French in edited volumes and journals. They are as follows: "Caché, Colonial Psychosis and the Algerian War," Interventions (2021); "Reading Devi's Poetry" in Ananda Dévi, When the Night Agrees to Speak to Me. Translated by Kazim Ali. Harper Collins. 2021; "Paris, Rue Descartes et la poésie de Czesław Miłosz," Caraivéti, Démarche de Sagesse. Jan-June 2019; "Produire le non-lieu: I'Inde à la dérive chez Ananda Dévi," Caraivéti, Démarche de Sagesse: Numéro Spécial Sur Récit de Voyage. July-December 2017; "Femme et dislocation nationale chez Ananda Devi," Interculturel Francophonies. Lecce: Alliance Française de Lecce, no. 28 (2015); "Time Is Money: Spaces of Colonial Desire and Jules Verne," Victoriographies: A Journal of Nineteenth-Century Writing, 1790-1914. 3.2 (2013); "Colonialisme sans frontières: L'Espace colonial dans la littérature de jeunesse," Littérature de Jeunesse: Réel et Imaginaire. Ed. Nalini Thampi. Pondicherry: Dept. of French, School of Humanities, Pondicherry University (2013); "Around the World in Eighty (One) Days," in Cartographies of Affect: Across Borders in South Asia and the Americas, eds. Debra Castillo \& Kavita Panjabi. Kolkata: Worldview Press, 2011; "Re-reading Postcolonial Women Authors," International Journal of Francophone Studies. 18.4 (2015); "Writing Colonial Spaces," Journal of Commonwealth and Postcolonial Studies. 1.2 (2013); Rev. of Rewriting the Return to Africa. by Anne M. François, International Journal of Francophone Studies. 15.2 (2012). 


\section{PROLOGUE}

One needs to rearticulate the colonial project of unending spatial expansion, with its fetish for acquiring and apportioning space, along the theoretical coordinates of the borders it engenders. Spatial Boundaries, Abounding Spaces: Colonial Borders in French and Francophone Literature and Film engages with narrations of spatial conflicts in nineteenth-century and turn-of-the-millennium French and Francophone literature and film, to analyze subject formations resulting from interaction with these colonial reconfigurations. This book examines key colonial and postcolonial moments to theorize: a) the role of ever-changing space and spatial grammar within the colonial project; b) the ongoing resistance to colonizing spatial practices as the omnipresent enforcers of citizenship; and c) literature and film as the sites that register colonial spatial paradigms and advance competing narratives that fracture their dominance.

This book provides ways of rereading the colonial story and its aftermath by juxtaposing spatial demarcations of colonialism alongside the plethora of connotations that production of space brings forth, evoking both the discourse on the enunciation of space as well as how space produces the colonial subject. This mutual intertwinement of space, discourse and the subject allows us to see spatial divides - whether they be geographical, literary or conceptual - both as agents of the colonial-capitalist narrative and as bearers of the counter and ante-narratives of postcolonial differences. As it examines spatial practices within colonial paradigms across the world, Spatial Boundaries, Abounding Spaces brings together the historical and material conditions of the colonizing mission alongside those of fictional characters in order to lay bare the spatial workings of colonialism. 
Central to this thesis is the territorial fetish of the colonial project that defined the world as an extension of European frontiers. I argue that the conventional colonial narrative disregards the collusion of colonially generated spatial paradigms in reducing all markers of plurality to a conquerable unit of spatial territory. Therefore, as it contends with imaginary histories of colonialism this book resituates postcolonial discourses alongside spatial analyses of literature and film. Located within these prevailing postcolonial discourses are spatial formulations that these discourses of nationalism and self-articulation either remain unaware of or underplay in favor of modernity-inspired enunciations of identity. I argue that uncovering these formulations dissolves the "authentic" enunciations of identities that these anti-colonial and ante-colonial discourses got mired in, in their haste to counter the colonizing discourses of modernity.

In particular, this book focuses on the colonized body. It is the site on which spatial reconfigurations are mapped and the site that subverts colonial topography. Displacement of peoples by whimsical borders, management of individual bodies for maximizing production, advancement of a paternalistic nationalism by sacrificing the reproductive body, erasure of the racialized body, are all different ways of exploiting the colonized body that are analyzed in this book. I foreground also how this body, whether in the form of an immigrant, raped domestic worker, or even as a dead body, subverts the workings of colonial spatial paradigms.

Space is an active component in the formation of colonial identity and nowhere is it more evident than in the proactive engagement and transformation carried out by everyday spatial practices of the colonial subject. Whether in overt headlong resistance against the powers that be, or in the act of survival of a domestic worker in unauthorized slums, creative works record such material interactions and uncover a discursive site that focuses on everyday spatial practices. These works understand divisions such as colony, metropolis, urban, rural, center and peripheries not as permanent designators of spatial hierarchy but instead as the result of material conditions of colonialism.

Each chapter of Spatial Boundaries, Abounding Spaces situates the negotiations of the colonial subject within the deeply ingrained spatial logic of colonialism. While the first chapter scaffolds the theoretical reasoning, the chapters that follow understand different moments of colonial spatiality by anchoring representative arguments alongside the works of one particular author. The second chapter discusses nineteenth-century literary perceptions of Asia, in particular that of India, as it follows Jules Verne's famous character Phileas Fogg around the world. The third chapter looks at the colonially generated geography of India in 
Ananda Devi's literature. Devi narrates alternatives to the India of modernity presented by Verne. In the fourth chapter, Patrick Chamoiseau's work allows us to engage with the relationship with the French borders that Caribbean writers unceasingly recall. The fifth chapter brings us back to Paris, or rather to its suburbs, where the famous film Caché foregrounds how France's large immigrant population is suffering the consequences of a colonial spatial logic. 



\section{CHAPTER 1}

\section{INTRODUCTION: CHARTING COURSE}

On Wednesday, 2 October 1872, predictably "suivant sa quotidienne habitude" ['in keeping with his daily habit'] (12; 10), Phileas Fogg, the protagonist of the famous nineteenth-century French novel Le Tour du monde en quatre-vingts jours (Around the World in Eighty Days), left at half-past eleven for the Reform Club. He reached his destination with calculated precision, taking 575 steps with his right foot and 576 with his left $(18-19 ; 15) .{ }^{1}$ Before delving into the Morning Chronicle, the distinguished English gentleman had already read the Times and the Standard, the latter keeping him busy from 3:45 p.m. until dinnertime. As he settled down for a hand of whist with his fellow club members, the discussion turned around to the contents of an article in the Morning Chronicle that were to alter, in many ways, the entire life of this mathematically exact, machinelike $\operatorname{man}^{2}$ leading a life regulated to the very last detail.

Provoked into a heated debate about the possibility of circumnavigating the Earth in eighty days, Phileas Fogg decides to disprove his fellow club members of their erroneous understanding of the expanse of the world and challenges them to a 20,000-pound bet. He sets out to prove that "la terre a diminué" ['Earth has shrunk'] $(23 ; 18)$. With his resourceful and loyal servant Passepartout (hired exactly at 11:29 a.m., a minute before leaving for his club the very same morning) in tow, Phileas Fogg embarks on a journey that would take him around the world and back to London in a matter of eighty days. Or, as Fogg takes the pains to point out, in 1920 hours or 115,200 minutes $(25 ; 20)$.

Following his departure on 2 October (at $8: 45$ p.m. to be precise), it is only by relying on his qualities of "sang-froid et d'exactitude" ['composure and precision'] $(301 ; 202)$ that Fogg is able to overcome the many dramatic tests 
that adverse circumstances throw his way along the geographically dispersed itinerary. Navigating his path, mostly through British colonies, he tides over often-encountered adversity by dipping into his generous purse to hire and at times even buy his transportation. ${ }^{3}$ Fogg returns, as one might expect of him: just on time - with the clock at the Reform Club striking exactly 8:45 p.m. on 21 December 1872 (299; 200). Given that most of his time on the journey is spent traveling in various modes of transportation, in many ways the victory was not only Fogg's but also that of the mechanization that made the journey possible.

One of the salient features of the journey of this phlegmatic hero is that he is rarely given to observing, being focused solely with chronometric rigidity on his objective. Appreciating the local scenery in the journey is a task left either to Passepartout or to the narrator in the novel's background. While traveling by ship, for example, Fogg could not be worried to explore the wonders of the Red Sea. ${ }^{4}$ However, the reader does notice that, from Suez to Bombay to Calcutta to Hong Kong, the novel is in many ways an excuse for putting on display the vast British colonial empire. No wonder that at times the journey takes the adventurers into locales that are nothing but exact replicas of British counties. At other times, the level of savagery or civilization of the stopovers is a function of their relationship to the colonizer. Oblivious to the scenery, uninterested in people, what then had the eccentric gentleman gained on his quest? Nothing, the novel tells us, except a "charmante femme" ['lovely wife'] (301; 202), Aouda, a woman from British India whom Fogg and his servant had saved from being forcefully consigned to the flames of her husband's funeral pyre. For Phileas Fogg, who spent 19,000 pounds of the 20,000-pound $s^{5}$ bet on the journey itself, the material gains might have been insignificant, but for this book this net gain of zero, which proves that the Earth has shrunk, has accrued a whole wealth of discourse about a globe aligned along new geopolitical axes.

Simply put, the contention at the heart of this journey is: Time is money. What is at stake in the bet is not Fogg's financial future. It is rather a discourse on the planet Earth. Set in a period where accrual of capital was increasingly becoming a function of clock time, could there be a better metaphor for the commodification of global geography than a 20,000-pound bet that negotiates global space in a fixed period of eighty days? This swift passage over space in fixed time, led by a character who is the very embodiment of a clock, critically reduces the status of the globe by reproducing it within the constraints imposed by a mechanism responding to a 20,000-pound investment. 
Among the first works to take the nineteenth-century reader around a globe configured in cartographic terms, Phileas Fogg's circumnavigation of the world rescales global geography along a matrix of colonial capitalism. There is a dramatic resemblance between this journey and the production process that dominated much of the late nineteenth century. What one witnesses here is global spatiality being prepared to fulfill the demands of an abstracted time: colonial structures produce a universally homogenized global network of infrastructure necessary to encash the commodity of time. Spatial structures and geographies in the novel gain their relevance by the degree to which they are rooted in a market economy organized to accommodate the needs of a fast-paced system of transportation - a spatial abstraction that only reinforces the temporal abstraction of clock time.

Fogg's quest for a shrunken Earth might seem a failed mission if one takes the statement at its literal value, but this was the very guiding principle for steam-based transport that was, in many ways, diminishing Earth. For Verne's novel, the early nineteenth-century topos of "[a]nnihilation of time and space," still seems operational and indeed even shows how "[m]otion was no longer dependent on the conditions of natural space, but on a mechanical power that created its own new spatiality" (10). ${ }^{6}$ Engrossed as he is in himself, Fogg's indifference is in fact the validation of the very paradigm that reformulates this Earth. Instead of appreciating the local landscape, he single-mindedly focuses on the speed of his journey.

Structured by a Western European industry that invades local landscape and practice, Verne's novel is replete with borders and spatial markers that deploy a blinkered colonial vision to empty the world of its peoples and cultures, reproducing it into an assemblage of rationalized spaces. As active tools in the propagation of a capital-infused colonial spatiality, these abstracted spaces operate as empowered agents that transmit through self-replication the commercial essence that made them, revealing in the process an entirely different globe.

This spatial encounter, in turn, critically reduces all markers of human subjectivity to coordinates familiar to the self-proclaimed racially superior colonizer. Verne repeatedly presents Aouda as a Europeanized native woman. Fogg, the benevolent colonial adventurer taking Aouda back to London after rescuing her from the clutches of the native barbarians, serves as a transparently racial metaphor for the kind of racial clustering that such rationalized spaces insist on. 


\section{Anchoring Space}

Assessing colonial spaces, questioning the parameters they impose, and bringing forth their constant presence, both in the subjugation by the colonizer and as a point of resistance by the colonized, has occupied much of literature written on colonialism. Yet, within the context of Francophone literature and film, despite the overwhelming presence of everyday negotiations with the kind of abstracted spaces that the example above demonstrates, most discussions of the definitions of space have centered on what constitutes the expanse of national geography.

Even Léopold Sédar Senghor's version of Négritude, for example, situates his movement's geographical origins in Africa and thus advances the same old colonizing model of defining identity through the paradigm of the nation. In his haste to set up normalizing identities, Senghor is among those early writers who advanced simplistic definitions of history as well as geography that work on the basis of exclusion. Senghor's is a twofold move that involves establishing the African as essentially different and then setting one's self up according to "la francité," the universal indicator of "clarity, order, harmony of ideas" (459).?

Instead of seeing how nationalism itself (with physical geographical boundaries as one of its essential prerequisites) is a spatial product of the European quest for newer territories, the debate about Francophone literature has invariably been about setting up competing geographical nationalisms that remind us of the colonial paradigm, ${ }^{8}$ as Senghor's conception of Négritude does. At the same time, Francophone literature has concerned itself with finding alternatives to this very idea of a fixed nationalism. Anne François, for example, in her work on Francophone women authors, Rewriting the Return to Africa and the Caribbean, ${ }^{9}$ displays how the women authors under study negotiate their identity and presence between Africa and the Caribbean. Simultaneously these authors respond to the clear misogynist leanings of those like Senghor who founded their identity in a mythically created Africa.

A work like Joseph Diémé's De la plantation coloniale aux banlieues: La Négritude dans le discours postcolonial francophone, ${ }^{10}$ through its very title (I translate roughly: From the Colonial Plantation to the Banlieues: Négritude in Postcolonial Francophone Discourse), signals the juxtaposition of two different spatial entities - the slave plantation of early French colonialism and the twenty-first century banlieues. The title itself underscores the need to reckon with the role spatial divisions play in creative production. When Diémé shows how contemporary creative production - music, film, literature - in the spatial 
margins of the French banlieues is linked to the practices of the plantation, he is creating the grounds for exploring the causal links between these spatial divisions and the creative production that they engender. Indeed, as scholars like Diémé and François, through what I have elsewhere called "co-incidental spatial analyses," 11 are making capital contributions toward a better understanding of Francophone literatures, they are also bringing forth spatial anxieties that need further examination.

Beyond identitarian debates located around the physical spaces of nations, even conceptual understandings of colonial interactions resort to spatial metaphors, only further underscoring the need to understand the spatial paradigm that undergirds the world. Édouard Glissant's usage of his signature term relation from his seminal work Poétique de la relation (Poetics of Relation) speaks of the globe as an interconnected space. Without the awareness of the plethora of theoretical discourses that elucidate the spatial nature of colonialism, Glissant's "étendue" ['expanse'] offers a move to overcome the debilitating definitiveness that a colonizing modernity had imposed upon the world. "Étendue" encapsulates the interconnections that bind the globe together as it also allows articulating various histories that populate it: “L'étendue n'est pas d'espace, elle est aussi son propre temps rêvé." 12 ['Expanse [extending] is not merely space; it is also its own dreamed time.'] ${ }^{13}$ The dictionary definition of the word "étendue" presents it as a property of bodies placed in a larger space and occupying a part of it. ${ }^{14}$ "Étendues" are unique perspectives that define physical space in such a way that each "étendue" understands the world and its own placement within it differently. At the same time, these various divergent "étendues" overlap as they delineate each other from their respective points of view.

Apart from the territorial conquests, colonization presented another spatial monopolization - by fashioning a world focalized through and revolving around the European perspective - thereby scripting a unipolar discourse that spreads outwards as an extension of the European frontier. Jacques Coursil ${ }^{15}$ explains how Glissant already spatializes the colonizer-colonized relationship when he explains colonization as a function of "étendue" ['expanse'], according to which the "[o]ccident ne peut se concevoir sans la maîtrise de l'étendue" ['the West cannot think of itself without mastering the expanse'] (95), and as such, describes the world from its own rigid perspective.

There have been attempts at understanding the functioning of space in Francophone literature, as is evidenced by the collection of essays titled Geo/graphies: Mapping the Imagination in French and Francophone Literature and Film. ${ }^{16}$ This is an exploratory collection of essays resulting from a conference, which 
attempts to display "the number of approaches possible" while analyzing "representation of place in a variety of texts" (ix) in both French and Francophone literature. Given its genre, this volume is unable to engage in a sustained manner either with the issues of importance in Francophone literature, or with theoretical concerns for the discipline of geography, and more importantly with the interaction between these bodies of knowledge.

One notable exception is Eric Prieto's Literature, Geography, and the Postmodern Poetics of Place. ${ }^{17}$ In this monograph, Prieto brings together literary and theoretical conceptualizations of place "in a way that highlights points of resonance between them" (10). Divided into three sections, the monograph looks at "the phenomenological experience of place"; "place-bound identities"; and "place in the larger geopolitical context of postcolonial studies" (10). The third section, comprising the fifth and the sixth chapters, is particularly relevant for my work. This third section discusses "postcolonial place identities" in the context of Martinique and Guadeloupe and is directly related to this book's discussion of Martinican literary tradition. Prieto first charts out the evolution of postcolonial theory in relation to the nation, the neighborhood and the niche in the fifth chapter. In the sixth chapter, Prieto reads these three in the works of Aimé Césaire; Patrick Chamoiseau and Maryse Condé; and Glissant.

Underlying Prieto's larger work is the idea that humans have a "long history of environmental co-evolution between us and our environment," which has "played a long and active role in determining the kinds of cognitive abilities we have and don't have" (63). ${ }^{18}$ It is within such an understanding that Prieto discovers how Glissant's work underlines the "importance of relationality" (Postmodern 180) and displays an interplay between what is immediately accessible and the distant. More precisely, it helps understand the "mechanisms through which our (often indirect) experiences of the wider world impinge on our understanding of the local environment" (Postmodern 180).

Prieto has faced criticism for his humanist approach toward literary geography, which critics recognize as being on the wane. ${ }^{19}$ Still, the juxtapositions that Prieto brings forth between postcolonial theory on the one hand and Caribbean literature on the other display the underlying spatial urges within postcolonial Francophone traditions and are particularly useful for understanding the various spatial forms identitarian assertions have taken, both within postcolonial theory and Francophone literary tradition.

In privileging the biological metaphor of niche (Postmodern 184-6), Prieto is not claiming to present an overarching theoretical model to explain the totality of multiple spatialities that have emerged from the postcolonial Francophone 
canon's engagement with capitalism, colonialism and decolonization. In another article, Prieto has made the call for recognizing and respecting various levels of analysis and exploring the "explanatory potential" of all discursive positions ("Phenomenology" 67). Prieto recognizes other potential ways of looking at literary geography. While discussing Jameson, Prieto categorically states that his intention is not to "deny the importance of political economy." Nor is it to "argue for the foundational authority" of other forms of analyses, like the placebased analyses Prieto himself privileges ("Phenomenology" 66). Prieto has set different theoretical objectives for his monograph and he is aware that the "biological, evolutionary model" (Postmodern 186) he presents does not directly engage with colonial and financial equations of centers and margins whose effects are visible in the material unevenness that persists across the globe. Prieto ends the third section of his 2013 monograph with a suggestion to use the metaphor of niche, borrowed from evolutionary biology, to approach and understand "the homogenizing pressures of commodity capitalism" (186).

For Spatial Boundaries, Abounding Spaces colonial exploitation and the accompanying uneven global economic development are central to the analyses of literary spatiality. The need for examining the effects of "commodity capitalism" that Prieto gestures toward in his analyses of Martinican literature, along with the need to register the effects of colonialism, provide the basis for this book, as it extends its enquiry to geographical areas other than those discussed by Prieto. Spatial Boundaries, Abounding Spaces also approaches literary geographies differently. This book, as I discuss below, privileges Marc Brosseau's idea of literary texts being geographers in their own rights. Nonetheless, it is important to recognize that Prieto's is one of the rare works to engage very self-consciously with space in Francophone literature. Largely, Francophone literary analyses' engagements with space mirror what Edward Soja reminds us about Michel Foucault: although "understanding of spatiality was at the center of all his writings," Foucault "never developed his conceptualizations of space in great self-conscious detail" (146-9). ${ }^{20}$ This gap of undeveloped spatiality in Francophone liteature and film is where Spatial Boundaries, Abounding Spaces: Colonial Borders in French and Francophone Literature and Film hopes to situate itself.

The interactions of spaces and powers that Foucault recognizes but does not enumerate have been articulated in greater detail by others like Doreen Massey, whose engagement with spatiality extends over decades and several book-length arguments. Massey addresses more rigorously what Glissant's work intuitively refers to: colonialism as a product of the European desire to master the étendue. 
Étendue is to be understood here both as the physical expanse of the world and as the knowledge that defines this global expanse. Massey writes:

Once understood as more than the history of Europe's own adventures, it is possible to appreciate how the previous way of telling the story (with Europe at its centre) was powered by the way in which the process was experienced within Europe; told from the point of view of Europe as the protagonist. Spatialising that story enables an understanding of its positionality, its geographical embeddedness; an understanding of the spatiality of the production of knowledge itself. $(63)^{21}$

Massey's comment about the importance of geography in knowledge creation contrasts a world defined by unidirectional linear time - of "History" - against one that exists in a multiplicity of spaces, highlighting the focus on space in recent years. Massey's prismatic view defies the earlier urge to flatten differences and accepts a multidimensional subjectivity. This

is a move away from the imagination of space as a continuous surface that the colonizer, as the only active agent, crosses to find the to-be-colonised simply "there." This would be space not as smooth surface but as the sphere of coexistence of a multiplicity of trajectories. (For Space 63)

With its attention to a multiplicity of influences on spatiality, its demand for taking into consideration numerous histories, Glissant's coincidental engagement with space needs to be further enriched within a larger framework. Massey's assertion reveals how geography plays a vital role in defining the knowledge that shapes the colonized subject as someone who is "simply 'there." This assertion also provides reason to reassess within a spatialized understanding why Glissant in his colonial countermove to this colonial "continuous surface" is so insistent on a "coexistence of a multiplicity." Seeing that the same reductive paradigm dictates Verne's spatial reconfiguration and the creation of artificial lines dividing the colonies from the metropolis, both having profound meanings for human lives, one would have to assert that "if time unfolds as change then space unfolds as interaction. In that sense space is the social dimension" (For Space 61). Massey constructs a matrix wherein spaces exist in interrelation with each other: "Such a way," Massey says, "of conceptualizing the spatial, moreover, inherently implies the existence in the lived world of a simultaneous multiplicity of spaces: 
cross-cutting, intersecting, aligning with one another, or existing in relations of paradox or antagonism" (3).22

In fact, Michel Foucault offers a rather uncomplicated lament that scaffolds the central argument of this book. One needs to interpret space as anything but "the dead, the fixed, the inert." 23 "A whole history," Foucault writes, "remains to be written of spaces - which would at the same time be the history of powers (both these terms to be plural) from the great strategies of the geo-politics to the little tactics of the habitat, institutional architecture from the classroom to the design of hospitals, passing via economic and political installations" (49). We are all part of a global community populated with omnipresent spatial power structures (both meanings intended) that make available the application of "great strategies" as well as afford "little tactics." Foucault's comment reminds us that space remains an all-pervasive influence in our lives and it participates in "economic and political installations" as these installations shape space. Glissant and Verne highlight the urgency with which one needs to reassess these spaces alongside a growing list of scholars engaged in deciphering their workings.

And it is only in charting out a historical account that one can understand the links between a nineteenth-century novel like Le Tour du monde en quatre-vingts jours and a twenty-first-century film like Caché. Caché is a film that chalks out the links between the Algerian war and the life of an underprivileged man of Algerian descent who lives on the margins of urban modernity. The readings in this book focus on the everyday negotiations that fictional characters carry out with these colonially generated spatial divides, which include, but are not limited to, national borders.

I am not claiming that these works, or their authors, are directly talking to each other or responding to each other's work. This book foregrounds how even today our understanding of the world operates within and responds to processes that shaped the globe as a colonial capitalist entity. In looking at those moments where spatial manifestations that result from colonialism interact with human identity, the focus is on how colonial spatial processes continue to shape relations of power. Through readings of Verne's literature, Spatial Boundaries, Abounding Spaces locates the colonial reconfigurations of spaces, communities and identities that have given rise to new equations that human beings share with spatial arrangements. If Verne's literature registers changes brought upon by colonialism, then the spatial contestations in the works by Devi, Chamoiseau and Haneke display that a new understanding of belonging and citizenship can be forged to resolve our relationship with colonial spatiality and to work toward a more just and equal society. 


\section{Doing Space}

Even though reflections on geography as a discipline have been present ever since the nineteenth century, ${ }^{24}$ the kind of multiplicity of spaces that Massey talks about has taken a long time to come about. Massey's capital contributions to the field of geography have had a significant influence on recent scholarship. Over the last few decades, an ever-increasing number of scholars have started rethinking the world in spatial terms. Expressions like landscape, space, place, location, nation, communities, local, global, center, periphery, core, margin, inside, outside, the First World, the Third World, the world, and its many worlds, are spatial references used in abundance both metaphorically and literally, making space and spatiality nodal points of reference. In these few decades, human geography has undergone profound changes that have "transformed it into one of the most dynamic, innovative and influential of the social sciences" (1). ${ }^{25}$ The current thinking on spatiality started taking roots in the last few decades when a number of researchers, almost simultaneously, focused their attention on the way geography was organized and narrated, and the way it had been responding to forces of capital. Henri Lefebvre has clearly been central to this shift toward space as the defining vector, a shift often described as the spatial turn. ${ }^{26}$

One need only look at the reproach in Kahisnka Goonewardena et al.'s statement that citing Lefebvre "is now de rigueur for anyone trained with even a homeopathic dose of critical theory in geography, planning, or architecture" $(5)^{27}$ to understand the importance of Lefebvre in the field of critical geography. Goonewardena et al. provide an interesting survey of how the Anglo-American academic circles have "produced" (2) Lefebvre. Broadly dividing Lefebvre's reception into a "debilitating dualism," they attribute the two broad categories of his readings of "political economy" and "cultural studies" (3) to David Harvey and Edward Soja respectively. Both the "'postmodern' appropriations led by Edward Soja that followed the 'urban political-economic' renderings centered on David Harvey" are understood by the authors as "a significant abstraction from Lefebvre's self-understanding of his own interventions in revolutionary theory and practice" (Goonewardena et al. 3). When I attest to the fact that Lefebvre "has been, and is, read in often contradictory ways" (3) ${ }^{28}$ I only do so to point to great opportunities and possibilities that his thoughts offer those working on space, as they do for this project as well.

For indeed, it is only in taking stock of the varying connotations that the terms space and place constantly evoke that one can truly understand the 
possibilities that such a reading engenders, especially because of the polemics that the terms have generated. Even if one uses Tim Cresswell's simplified definition of space in Place: A Short Introduction ${ }^{29}$ as something that is "seen in distinction to place as a realm without meaning [...] when humans invest meaning in a portion of space [...] it becomes a place" (10), this definition can only act as a placeholder. ${ }^{30}$ Advancing a little ahead into Cresswell's account, one discovers that de Certeau is one among others who have complicated these definitions. Creating confusion among geographers is how "de Certeau uses space and place in a way that stands the normal distinction on its head." ${ }^{31}$ Similarly, one points out that Massey "uses the terms of space and spatiality sometimes interchangeably, and sometimes she makes a distinction between the two." ${ }^{32}$

In the context of Lefebvre's Production de l'espace $e^{33}$ (translated as Production of Space $^{34}$ ), which functions as the mainstay of the readings for this book, Soja points out that after the first chapter "everything that follows seems to float independently or else seems to contradict erratically what has gone before. Certain concepts clearly defined at one point either seem to disappear or become confusingly redefined in another way elsewhere" (Thirdspace 58-9). One sees this constant shifting of parameters, the need to identify meaning, as an integral part of the dynamism, "radical openness and polyphony" (Thirdspace 60) of Lefebvre's entire oeuvre: a radical openness that this book shall constantly refer to as it examines similar negotiations with the meaning of space in literature and film.

The colonially produced borders under discussion in this book are encompassed by what Lefebvre calls "l'espace social" or 'social space'; the interactive phenomenon that demonstrates that "production of space is a continual process, and that space is always changing as conceptions, perceptions, and lived experiences change." 35 "La pratique spatiale" 36 or 'Spatial Practice' refers to the underlying principles that define our practices and answers the question: "What is the relationship of space and ideology and social formations?" (Shields 162) "Les représentations de l'espace" or 'Representations of space' refers to space that the organizers of a society, its planners, its architects and its technocrats conceive, and which becomes the dominant space of a society.

On the other hand, "Les espaces de représentation" or "Spaces of Representation' refers to the subterranean and clandestine aspect of social life. "This is the dominated - and hence passively experienced - space which the imagination seeks to change and appropriate" (Production, trans. NicholsonSmith, 39). While the first, "Representations of space," in search of "order" reigns with its graphs, charts, numbers, maps, drawings and prints, the latter expresses adaptation to, or the resistance against, this imposed spatiality. 
Through the tussle between the imposed space and the subject who inhabits it, this book hopes to bring forth human space as a process. In other words, one can only analyze spaces by taking into consideration the processes that shape them, the social realities that interact with them and the manner in which they are perceived and experienced. It is this dynamic nature of spatiality that the current academic "spatial turn" has been insistently signaling toward, and to which this research hopes to contribute. Spaces inflect people; people inflect spaces. Only once we understand that human identities, desires, histories and perceptions of the world are all formed within and with a spatial interface can we understand the productive process that spatiality entails. The complicity, the opposition, the manipulation, the domination, the rebellion, the submission in human relations is influenced and carried out through, with and most certainly within spaces.

If Foucault is right in demanding that power "must be analyzed as something which circulates, or rather as something which only functions in the form of a chain" and that power "is employed and exercised through a net-like organization" (Power/Knowledge 98), then within the spatial matrix these works act as narratives that also produce a discourse of space. As they expand on the meanings and practices of space by demonstrating the various spatial usages, within this "net-like organization" these works present opportunities where the counter forces to dominating spaces can also be exercised with alternative conceptions of space.

Crucial to such an understanding is that spaces do not exist in seclusion from the human subject or even from each other. Lefebvre insists that if one discusses "the daily life of a tenant in a government-subsidised high-rise housing project" it does not mean "that motorways or the politics of air transport can be left out of the picture" (Production trans 38). ${ }^{37}$ Lefebvre clearly points out that no part of the world is in isolation and that what began as the colonial project of spatial expansion needs to be, and is being, understood spatially. Any discussion of space, spatiality, place, geography and landscape, among other terms, is already fraught with complications. Adding literature and film to the mix makes things even more challenging.

Elaborating on the spatial turn that the last few decades of contemporary theory has engendered, Sara Upstone in Spatial Politics in the Postcolonial Novel insists on not qualifying this turn as a replacement of time with space. The "study of geography does not result in the need for an alternative hierarchy" that replaces time. "To reassert spatiality," Upstone says, "is therefore to privilege it as a context that must be read alongside temporality as a factor of equal significance" 
(3). In other words, this current turn needs to be seen as the opening up of a much larger and richer domain of knowledge that allows to grasp better the contours of the lived human experience via a spatiotemporal analysis. To reread Glissant's quotation in the light of my above statements: "Expanse [extending] is not merely space; it is also its own dreamed time. ${ }^{38}$ I would like to study these various "étendues" - sites at which geography is formed as a function of both space ("espace") and time ("temps rêvé"); the historical circumstances that go into their making; and how they interact with each other and influence the geographical world.

What exactly does it mean when I establish my intentions of studying the confluence where space intersects with social relations? One can answer this question by understanding the production of space. I use the term production of space in a rather deliberate manner to speak of Lefebvre's landmark work, The Production of Space. The title itself encapsulates space as a process when it communicates both the idea of producing (on the ground and through discourse) space as well as the production carried out by space. Certainly, it is important to recognize the creative works examined in this book and the common colonial background they discuss, but these works also present spatial instances of a social reality.

\section{Geographies of Literature}

Over the last half a century the idea that space serves as a passive backdrop for narrative action or that literature (or any other creative work) serves as a passive container where the author has the unique ability to evoke the "feel or essence of a place" $(328)^{39}$ has been thoroughly reconfigured. Until the early nineteen nineties, as Marc Brosseau shows, spatial readings of literary geography were not really about literature. They were limited to a "triangular tug of war between 'facts', 'experience' and 'ideology"' (10)..$^{40}$ The objective of literary geography was limited to understanding if the geography represented was factually correct. Within the humanistic tradition, the thrust was on a fuller understanding of the human experience within a spatial context. For radical geographers, literature was a "means of showing what reality could or should be or, more appropriately, of offering a critical interpretation thereof" (343)..$^{41}$ This tug of war had little to do with literature per se. It corresponded "to an internal debate within 
geography, literature simply being another terrain in which to wage the dispute" (Brosseau, "In" 10). For these studies, literature was relevant only to the extent to which it reproduced geography's relationship with the world.

In a recent essay, Brosseau notes with satisfaction that given all the "review papers, chapters in cultural geography textbooks, entries in human geography dictionaries or encyclopedias, and the publication in 2015 of the first issue of the journal Literary Geographies," the relationship between geography and literature can no more be considered a "disciplinary oddity" ("In" 9). Brosseau, along with Sheila Hones and Robert T. Tally Jr., are only some of the scholars whose analyses of the intersection where space and literature meet have brought out its vibrancy and dynamism. They have also invested significantly in resolving many of the intellectual challenges accompanying this fast-expanding field.

The particularly formative moment that literary spatiality is passing through currently will influence future research in significant ways. As the discussion that follows will show, this intersection has become richer, both in terms of the numbers of scholars it has attracted and in terms of the range of academic approaches deployed and intellectual hypotheses explored. Such is the diversity that Hones finds the need to identify common academic stakes in relation to which one could define one's work. The framework (discussed below) that Hones proposes does not intend to dissolve ideological and methodological differences; rather, it intends to identify intellectual coordinates in relation to which one could place one's work. In engaging with contemporary debates surrounding the challenges involved in bringing together literature and space, I hope to have prepared the groundwork for explaining why this introductory chapter holds off from imposing fixed contours on the meaning of space, place or geography, all of which have been used synonymously in different contexts.

The challenges involved are discernible in the various terms used to identify this intersection where literature and space meet: "referred to as spatial literary studies - whether it operates under the banners of geocriticism, geopoetics, literary geography, the spatial humanities, $[. .$.$] [or] any approach to the text that$ focuses attention on space, place, or mapping" (3). ${ }^{42}$ The discussion that follows helps to prepare the backdrop to explain better my own understanding of the relationship between literature and space via Brosseau's articulation of an "alternative geographic epistemology" ("In" 10). As is obvious, Brosseau anchors arguments around the term "geography." In this proposition, the terms place and space find their meaning in relation to the idea of literary geography. For instance, when reading Dionne Brand's What We All Long For, Brosseau, along with coauthor Tavares, discusses the novel's "potential to shape the geographical 
imaginary of informal urban citizenship in the multi-cultural city" (30). ${ }^{43}$ To understand this "geographical" imaginary, they discuss both the identities of specific "places across Toronto" and the role that general "everyday urban spaces" play in Brand's novel (29 my emphases). Since Spatial Boundaries, Abounding Spaces finds its larger understanding in Lefebvre's work, in particular Production of Space, this project favors the term "space" as a broad placeholder. Space, instead of geography as the anchor term, becomes particularly useful in Verne's context, wherein I discuss the discipline of geography with its much narrower definitions as they existed in the nineteenth century. At the same time, in contending with arguments or juxtaposing analyses within certain intellectual trajectories, Spatial Boundaries, Abounding Spaces is also constrained to deploy simultaneously some of the terms Tally lists above.

Tally's intellectual engagement with space has spanned over several monographs, edited volumes and articles. If one would recommend Brosseau's work for a historical survey of the field, ${ }^{44}$ it is Tally's work, in particular, Spatiality, that one would need to read for engaging discussions on the spatial relationship that the author and the reader have with literature. ${ }^{45}$ In chapters three and four of Spatiality, Tally shows how the "literary author projects a map onto the often chaotic world" and how the reader or the critic then makes "sense of the literary map" (8). Very broadly speaking, these two discussions from chapters three and four of Spatiality also form the basis of two edited volumes by Tally: Literary Cartographies: Spatiality, Representation, and Narrative (2015); and Geocritical Explorations: Space, Place, and Mapping in Literary and Cultural Studies (2011). ${ }^{46}$ The former shows how the "writing of the literary texts is itself a cartographic endeavor" (Literary Cartographies 4), and the latter is a collection of essays that focuses on reading literature spatially. When taken together, the two volumes (respectively on the author and the reader) testify to the diverse and innovative ways that space and its various literary engagements are pressed into visibility; at the same time, the essays contained therein also testify to how key terms remain unstable signifiers. Of course, Tally is aware of the accompanying intricacies and celebrates the fact that "not all scholars engaged in the spatial humanities will have the same idea of what such engagement entails." ${ }^{47}$ In the debut issue of the journal Literary Geographies, Neal Alexander also recognizes the "general disagreement over what literary geography means, as both paradigm and practice" (5). While these remarks celebrate the vibrancy, dynamism and the potential of the growing scholarship in this field, they also point to the underlying need, identified by those like Hones, for a common intellectual ground where scholars of all hues can come and agree upon what to disagree upon. The 
establishment of Literary Geographies in 2015 itself is a testament to the need to answer the basic question of what it means to bring together literature and space in this field, which is essentially a cross-disciplinary one.

The differences between the two disciplines of geography and literary studies already make it "difficult to think of academic criticism as one form of public consumption” acceptable to both the disciplines (Hones, "Text" 1307). It is not just the "broad disciplinary differences between geography and literary studies" that pose a challenge (Hones, "Text" 1308). Disagreements over ideological positions and academic approaches would only be welcome. There is a more foundational problem of where to meet and what to talk about. Given the differences in the two academic fields, the exact same piece of academic research bringing together literature and geography, when presented at two different forums, one specializing in literature and the other in geography, "would quite likely lead to miscommunication if not mystification in one or both locations" (Hones, "Text" 1308).

Within such a context, how does one truly create a common ground where one can productively interact? The challenges become further compounded if one looks at the innovative ways in which one can imagine the interaction between space and literature. ${ }^{48}$ Miles Ogborn and Charles W. J. Withers write about the geographies of the book and discuss the production, distribution and the consumption of its physical and the material object. One of the questions that they set out to answer is about exploring "the local places in which written materials were produced, and their impact on the nature of books as material and signifying objects" ${ }^{49}(11)$. The actual content, the written text itself, cedes place to the physical movement of the book.

At the same time, it has been pointed out that the humanist understanding of space has been on the wane since the 1980s. Yet, Prieto nudges us toward "the need to rethink traditional (humanist) conceptions of self and world [...] to re-examine some deeply entrenched assumptions about the nature of place, with an eye to refining and improving it" ("Phenomenology" 62). Powered by the belief of "co-evolution between us and our environment" (63), Prieto makes a persistent case for refining our understanding of phenomenological place in light of recent findings.

These are engaging ways of reading literature spatially. They also underline the challenges literary geography faces in attempting to bring all these approaches within the same interrelated context. For instance, Hones comments on Prieto's monograph, Literature, Geography, and the Postmodern Poetics of Place and observes how Prieto engages primarily with humanistic geographers, whose influence has been on the wane, while overlooking the majority of the influential 
work by contemporary critics like Brosseau (175-8)..$^{50}$ To follow from Hones, it is not just about approaching literary geography from different locations, but instead about reading literary geography at disconnected locations such that participants remain intellectually removed from each other's intellectual preoccupations. In order to find "a broad metadisciplinary framework within which various kinds of academic difference could themselves be theorized and worked with in spatial terms," Hones, following from Massey's work, makes the argument for understanding fiction as an inherently spatial event (1313). ${ }^{51}$ After all, a creative product is the result of a spatial interaction between the author, the text and the eventual reader, all of them being situated in relation to each other. Simply stated, space is the "dimension that renders fiction possible" (Hones, Literary 23).

In the book Literary Geographies: Narrative Space in Let the Great World Spin, Hones details how such a spatial understanding presents the "event of the text as a contingent achievement" that produces a "range of readings that is less concerned with evaluation" (31). Hones is proposing forever evolving contextual readings of literature that are never fixed. This relational understanding of literature could involve analyzing geographies of production, like geographies related to "inspiration, creativity and authorship" (31). Alternatively, they could involve analyzing readers' geographies and the "spatialities of reception" (15). This inclusive theoretical umbrella that Hones spreads not only expresses the desire to find common intellectual ground but also indicates the vastness of the research taking place in the growing field of literary geographies.

This all-encompassing understanding of literary spatiality, which attempts at articulating fiction spatially from the moment of conception until its various moments of readership and which Hones explores more fully in her 2014 book, has been in the making for a long time. In a 2008 article, "Text as It Happens: Literary Geography," Hones sketches out the initial contours of this "text-based spatial interaction" (1301), which presents the "writing-reading nexus as a contextualized and always emerging event" (1302). In a later thought-provoking analysis of Alice Walker's short story "Petunias," Hones shifts the focus to the reader's agency while concentrating on the "the micro-geographies of narrative style and text-reader interaction" (474). ${ }^{52}$

Spatiality for Spatial Boundaries, Abounding Spaces is not about simply delineating the fictional representation of real-world spaces invested in colonialism. Nor does it serve to justify, confirm or reiterate hypotheses more pertinent to the discipline of geography. For a student of literature, such approaches would create an awkward coexistence, wherein literature plays a secondary role to the definitions that the discipline of geography generates. Instead of presenting 
literary space as something that can be described in isolation as a discrete entity, this book seeks to understand the literary processes that are involved in giving spaces their valence. The spaces resulting from the colonial project that Spatial Boundaries, Abounding Spaces analyzes encompass different aspects of what Hones calls fiction as an event. The inclusive openness that Hones' literary spatiality proposes provides me with a spatial paradigm within which to situate the spatial relationship between the viewer and the screen in the last chapter, wherein I read a cinematic work. In addition, when juxtaposed against preoccupations of postcolonial theory, the spatial manifestations analyzed in this book reveal valuable opportunities for understanding how complex layered spatial legacies of colonialism are embedded in and contested by creative works.

Spatial Boundaries, Abounding Spaces addresses creative spaces by noting their presence within a global colonial structure to see how the spatial interrelationships that emerge present "alternative geographic epistemologies." 3 Brosseau's work is a fuller example of how, more recently, for critics interested in literary spatial analyses the focus has shifted "onto the text itself $[. .$.$] to ac-$ knowledge its ability (a form of agency) to define its reader" ("In" 10). In this book, while analyzing literary works, in paying attention to "the materiality of the linguistic form, its paradigmatic differences, the tangible dimension of signs, the narrative composition and the different styles" (99) $)^{54}$ what one discovers is that a novel (and any creative work in general) can be understood as "a subject that becomes a geographer in its own right" "City" 92). For the purposes of this book, close analyses reveal these works as creative geographers of colonialism.

In the 1980s, Kristin Ross was among the earlier critics to have explored the potential of the text to present geographical articulations in conversation with the changes happening in the larger spatial paradigm. In reading the French poet Rimbaud's poetry, Ross shows how the transformations taking place in the nineteenth century manifested themselves on the space of the human body, which became a site where "developed technology is fused with the natural, living creature [...] permeated with apparatuslike elements" (55). Much as in the example of Ross' spatial conclusions, I lay special stress on understanding the knowledge that shaped both the colonizing and the colonized subject in order to decipher the operations that provoke and sustain the conception of such a temporally defined geography as moments of "synchronic history" (37).55 These spaces manifest the "displacement of the political onto seemingly peripheral areas of everyday life - [which could be] the organization of space and time, changes in lived rhythms and social ambiances" (Transformation 39). Ross evokes Marx's idea of "displacement" to see everyday spaces in Rimbaud's poetry as "adjacent 
- side-by-side" (Transformation 39) sites on which the transformations in larger spatial usages are displaced. Similarly, the spatiality presented in this book also demonstrates "synchronic history." Ross' work deals with space and spatial usage as belonging to a larger paradigm of social relations. This "social space" puts on display a "synchronic history" of contemporary political practices and becomes an active element in its own perpetuation. Decidedly "not a static reality" (Transformation 42), Ross' "social space" (Transformation 36), chiming in with Massey's idea that "space unfolds as interaction," is clearly an invitation to conceive of space as "active, generative $[. .$.$] space [\ldots]$ as created by an interaction," and as "something that our bodies reactivate, and which through this reactivation, in turn modifies and transforms us" (Transformation 42). When read alongside contestations and debates proper to postcolonial identity, the spaces analyzed in this book exhibit colonial legacy at multiple levels. Close attention to interconnections and interactions between these spaces reveals how these creative works keep in productive tension the relationships between the local, global and nation-based identities as they have emerged out of colonialism.

Jules Verne belonged to the nineteenth century. The other two writers, Ananda Devi and Patrick Chamoiseau, and the filmmaker Michael Haneke are contemporaries and have been attracting critical attention to their work over the last quarter of a century or so. Broadly speaking, this monograph organizes chapters in the chronological order of the appearance of the works analyzed therein. However, claiming an absolute temporal succession between them would be difficult. The analyses in this book have had to move back and forth between several works that have appeared over the last three decades.

I have chosen to interrogate colonial and anti-colonial spatial discourse in works that mediate questions of belonging and identity spatially. Analyses of colonial geographies, and the alternative geographies that emerge as a response to colonialism, show a nuanced engagement with important theoretical questions of space in these works. In Verne's case, this spatial engagement takes a self-conscious form. Verne creates in his writing a world whose understanding he drew from the nascent discipline of nineteenth-century geography. The interconnections that emerge from other works contest and accommodate struggles against narratives of spatial impositions. Each of these works helps highlight key questions related to space.

These chapters follow a geographical and thematic logic and take the reader on a trip around interconnected colonial geographies across the world. The chapters juxtapose interrelationships that emerge between spaces against debates and issues of relevance to postcolonial theory. The thematic and spatial analyses 
link up like a chain, such that one folds into the next. For instance, Verne's text takes us to the colony of India and Devi evokes modern-day India to present the woes of those displaced by French colonialism to islands like Mauritius and Martinique. Chamoiseau's work is set on the island of Martinique and negotiates Martinican identity in relation to the French nation. The very last chapter deals with a film based in Paris, the capital of the French nation and the heart of the French colonial empire.

To outline briefly the interconnections analyzed in the chapters that follow: the second chapter presents the establishment of colonial spatiality. The chapter discusses how a string of nascent urban spaces marks Verne's colonial-capitalist world. Verne's work, in particular Le Tour du monde en quatre-vingts jours, reveals a web of interconnected, mathematically abstracted spaces that facilitate the easy movement of opium and simultaneously produce a facile reduction of colonial identity. Written at the height of the colonial project, Le Tour du monde en quatre-vingts jours abundantly displays the role a colonial spatial paradigm played in colonial expansion.

The third chapter analyzes Devi's feminist assertions in relation to the modern postcolonial nation-state of India that resulted from colonialism. The transnational political and economic interconnections and the accompanying inequities of economic development that emerge in Devi's text are reminiscent of the network whose nascent version is present in Verne's work. The works analyzed in this chapter allow exploring how the origin-obsessed postcolonial nationalism works in tandem with capitalism to structure global spaces and feeds on the human body for its existence.

The fourth chapter on Chamoiseau looks at the interactions between the physical topography of the disorganized hutment of Texaco, the human body and the text. A detailed analysis of this interaction in the novel Texaco displays that any understanding of colonialism must attend to questions of gendered citizenship. Chamoiseau's work gives occasion to discuss the role of the French language in the island's identity as it looks at Martinique's relationship with the political boundaries of the French nation. As this chapter analyzes discussions about language through the form of the text, it also opens up to the postmodern readings of difference, which come to the fore in the last chapter.

Caché is a film about negotiating postcolonial identity in twenty-first century France. This film allows us to reflect on the way a spatial vocabulary has become intrinsic to defining human relationships within the colonial context. The last chapter moves to the French capital of Paris, where Georges and Majid are living the consequences of French colonialism and trying to resolve their 
relationship with each other as well as with the colonial past. This chapter looks at the interrelationship of the nonmaterial spaces of identitarian difference in Caché. It analyzes the correlations between the space of difference that connects the colonizer and the colonized on the one hand, and the viewer and the viewed object on the other. The cinematic techniques deployed to bring these spaces together furnish a potential solution to the conundrum of defining one's relationship to the colonial past.

It is by extending Brosseau's articulation about literature to the interconnections between the cinematic structures that I am able to comment on the spatial relationship that the viewer shares with the viewed object in the context of cinema. The exact spatial dynamics of each creative expression as they emerge from different historical and cultural traditions and the accompanying theoretical and ideological questions need the same meticulous attention that the geographies of the novel and the short stories have attracted. At the same time the uneven attention accorded to spatiality in cinema (and other creative forms) does not rule out the ability of structures inherent in these creative works to register the larger spatial changes. I am hopeful that the readings that I offer in the last chapter will serve as a starting point for furthering other spatial cinematic analyses pertinent to postcolonial cinema.

Hones presents the idea of a text as an event to explain the spatialization of literature from the moment of inspiration to its eventual readership. Similarly, this book begins its journey with how Verne draws inspiration from the emerging nineteenth-century discipline of geography. The very last chapter focuses on the relationship of the reader with the subject under study. The spaces studied in Spatial Boundaries, Abounding Spaces: Colonial Borders in French and Francophone Literature and Film exist as part of a process implicated in the creation of social relations. Study of these colonial spaces allows a better understanding of the processes that map social relations.

Le Tour du monde en quatre-vingts jours abstracts human identity by presenting a uniform spatial image of the entire colonial world. Chamoiseau, Devi and Haneké highlight the relevance of race, gender, colonial definitions and capitalism to space. The works studied here show that literature and film do not just simply reflect and represent spatial structures. Rather, they present an acute awareness of the historical processes that produce and define space. The spaces in these works are not just "there" as depicted background. Instead, through their contested presence, these spaces demand the contextual articulation of a history that resulted in their creation. 


\section{Postmodern Spaces - Material Histories}

Within the postcolonial context, my intention of discovering spaces - tangible and intangible, metaphoric as well as well as literal - clearly necessitates a determination of my own positioning within this extremely vibrant current leftist thought on postcolonial literature, in particular, between the partisans of materialist thinking - interested in a historical analysis - and those that prefer language-inspired critical approaches. In analyzing, for example, the colonial-capitalist infrastructure in Le Tour du monde en quatre-vingts jours, I trace the creation of the opium-related network in the novel to relate it to the Opium Wars. Does this historical analysis preclude me from approaching questions of "postcolonial" identity apparent in Caché? In the words of Benita Parry, at stake in this materialist versus textual debate when analyzing colonialism is

whether the imperial project is historicized within the determining instance of capitalism's global trajectory, or uprooted from its material ground and resituated as a cultural phenomenon whose intelligibility and functioning can be recuperated from tendentious readings of texts. $(8)^{56}$

In its analyses, this book has assiduously aimed at collating views of colonial literature and investigating questions of identity predicated both on: a) the (post) colonial thinking current to the present poststructuralist world; b) and the historical and material contexts in which these works were written. Therefore, testifying to a clear-cut division between the "historicized" and "readings of texts" would be an impossible task, one that would only end up condoning the hierarchy inherent in "procedures which subordinate the real to the cultural and the semiotic" or the other way round. Instead, I have looked at Texaco (and other creative works analyzed in this book) from a perspective that takes "full account of both the cultural and the semiotic as social practices" while paying attention to the historical reality of slavery and colonialism that preceded the current dialogue (Parry 5).

This is not to say that Spatial Boundaries, Abounding Spaces remains innocent of the antagonism between postmodernism and a more material analysis in contemporary theory. Given that this monograph draws inspiration from the literary works it discusses for its conceptual paradigm, it seeks to understand space as a function of the Francophone creative production. Texaco, the title of 
Chamoiseau's award-winning novel, is the name of an American oil company, the ultimate symbol of capitalism. The fight between the residents of a shantytown and the oil company over a piece of land serves as a metaphor for the linguistic tussle between the two languages, French and Creole. If this book were to limit itself either to a materialist reading or to an analysis of the postmodern language-based assertions that the novel is making, would it not then, when studying the spatial ramifications in Texaco, be going against the grain of the literary context that this novel represents?

By setting my sights on the site of resistance that Texaco (the novel and the piece of land) offers, I have discovered a proleptic acceptance of Chandra Talpade Mohanty's call for a localized response to the ever-growing forces of globalization. The point here is that the Creole idiom and the resultant space that Texaco highlights, and most critics have focused on, should not take away from the "transnational feminist practice" (509) $)^{57}$ whose possibility becomes real in reading the novel through the character Marie-Sophie's body.

When Mohanty says since "women are central to the life of neighborhood and communities they assume leadership positions in these struggles" (515), she might as well have been literally describing Marie-Sophie's position within her hutment. More importantly, Mohanty becomes relevant because her theoretical stance allows me to understand better the localized nature of MarieSophie's struggle. "Place consciousness," in Grace Lee Bogg's words, "encourages us to come together around common, local experiences and organize around our hopes for the future of our communities and cities" (quoted in Mohanty 515). This "place consciousness" in turn implicates my reading of the novel, and Marie-Sophie's fight, within a global dynamics of resistance - connected to other similar colonial literatures. Texaco's struggle against colonial structures is also a local struggle, whose global interlinkages are present in Verne's, Devi's and Haneke's works. One needs to juxtapose these works against Marie-Sophie's spatial sojourns, if true appreciation is to be had of her experiences that she shared in common with many other unacknowledged women participants in the colonial struggle across the globe.

The guiding principle of "interconnectedness of the histories, experiences, and struggles" (522) in Mohanty's proposed pedagogy ${ }^{58}$ of feminist scholarship - "comparative feminist studies model" - has tied together texts from all over the world dealing with colonialism. Works by Patrick Chamoiseau, Michael Haneke, Ananda Devi and Jules Verne still remain linked within a spatial matrix, even as they belong to different colonial contexts (linguistic, geographical, and historical). ${ }^{59}$ All of them respond to a spatial anxiety that through its own particular 
historical and cultural experience also allows an understanding of other similar experiences existing in "interconnectedness." In other words, just as one cannot study the "British Victorian novel for example, without at the same time considering what the flowering of cultural wealth in England owed to events taking place in India and elsewhere" (Ross, WL 670-1), so is it impossible to appreciate "in isolation" from each other the colonial spatialities of this book. Beyond just the obvious, palpable colonial context that forms the backbone of this book, the interconnectedness of the capitalist context (central to the Vernian universe and to the title of Texaco), the (fuzzy) nation-state boundaries of Devi's work and Caché and the questioning of identity are just some of the ("conceptual, material, temporal, contextual" ${ }^{60}$ ) links that have brought together colonial contexts related to Africa, South Asia, the French Caribbean, Paris and indeed the entire globe if Phileas Fogg's journey around the world is taken at its literal value.

Notwithstanding the potential criticism that Mohanty - with her materialist and real view antithetical to "postmodernist relativism" (511) is likely to level against a concept like rhizome, I still find it very useful to evoke the mutually influencing space that these chapters constitute together. As a metaphor, "rhizome" allows me to experience these works, their characters, the underlying colonial issues and defining power paradigms all acting together, as no doubt scattered geographical elements that are nevertheless tied together and speak the (sometimes incoherent) language of colonial history within the same complex network of interconnectedness.

If I have appropriated Glissant's relation (inspired from rhizome) and other similar postmodern identitarian concepts to explain the rationale behind this book, it is not as a rejection of the materialist mode that Parry and Mohanty advocate. On the contrary, the very coming together of geographically and temporally distanced works in this book communicates how this study could become part of a "curricular strategy [that] is based on the premise that the local and the global are not defined in terms of physical geography or territory but exist simultaneously and constitute each other" (Mohanty 522). Or, in other words, it is imperative for us to see how Caché, in conspicuously underplaying a colonial connection, is equally implicated in the colonial process described in Le Tour $d u$ monde en quatre-vingts jours and the struggle outlined against it in Texaco.

But the negotiation that results in the choice of these texts exceeds the one between the materialist understanding that has been central to my own political leanings and the epistemic urge that is the hallmark of the poststructuralist era; it is also between my own personal experiences and my academic trajectory. After India's independence, my grandparents, much like many of their 
generation, were forced to migrate from the "other side" (now Pakistan). Their personal stories, of this new border's devastating power and the unspeakable human tragedy it imposed, had weighed heavily upon my formative years long before the subcontinent's border narratives made these questions important to me. Even as a young boy, dealing with the confusion associated with my uncertain Punjabi identity, unquestioningly accepting the linguistic peculiarity of my parents, living in Delhi among many other such culturally uprooted families, I had already begun questioning the fixity of identity. Theoretical terms that explore the reverberations between Chamoiseau's multilayered novel on Créolité and the human identity's response to colonialism in Verne's and Haneke's works have allowed me a comprehensive space of articulation that accommodates not only my academic interests but also my personal trajectory. These reflections result, I suspect at least in part, from my upbringing in a postindependence India, where I had to juggle between English and other Indian languages and reflect, unbeknown to myself, on these issues.

My academic training, first (to the pride of my parents) in an Englishmedium school in postcolonial India and then in French at the university level, has seen me gravitate toward the colonial commonalities across the globe. This is not to portray a particular advantage in understanding the complexities of the questions raised in this book. Instead, it is in the spirit of full disclosure that I lay out a genealogical map through a familial lineage. I am sure that my place as a privileged male member of India's vibrant academic community is a direct result of my doctoral studies in the US academe as much as it is linked to my grandparents' personal history. They were among those "populations who cannot and might not choose to migrate" (308). ${ }^{61}$ Through this disclosure, I also wish to reveal the personal negotiation - and the inevitable linkages - between the material history of colonization (that my grandparents lived through) and the constant questioning of identities (which I undertake) within this book.

To truly achieve Mohanty's academic exercise where "each historical experience illuminates the experiences of the others" (522), or in other words to understand Devi's negotiations between Mauritius and India, and Majid's self-immolation in a film that challenges national identities, I would have to continually retrace the colonial trail that resituates global geography within the vocabulary of nation-states. 



\section{CHAPTER 2 \\ AROUND THE WORLD IN EIGHTY (ONE) DAYS}

As spatial barriers diminish so we become much more sensitized to what the world's spaces contain. ${ }^{1}$

-David Harvey

The title of Jules Verne's famous novel Le Tour du monde en quatre-vingts jours (Around the World in Eighty Days) promises a journey in eighty days. Yet, the culminating moments of this adventure reveal that Phileas Fogg takes not eighty but eighty-one days to reach his destination. As Fogg goes around the world in a precisely calculated, or rather an almost precisely calculated journey, the route he takes and the tools he uses - graphs, charts, numbers and maps - are the very devices of abstracting spaces that lead to his victory at the end of the adventure. ${ }^{2}$ I say almost precisely calculated because the climactic moments actually defy the careful calculations that form the basis for the adventure, as well as the subsequent victory, which surprises both Phileas Fogg and the reader.

During the entire journey across the world, Inspector Fix follows Fogg. Fix has confused the former with a robber responsible for robbing the Bank of England of 55,000 pounds. Lacking a proper warrant, Fix is able to arrest Fogg only once back in Great Britain, at Liverpool. The novel craftily persuades the reader that due to his mistaken imprisonment Fogg had lost the bet by a delay of five minutes. Finally, when the misunderstanding is sorted out and Fogg is released the narrative states: "Il avait perdu" ['he had lost'] (284; 191). There is no intervening explanation for the confusion that follows when, a couple of chapters later, in what Timothy Unwin calls a "whipcrack ending,"3 on the twenty-first of 
December Phileas Fogg runs into the Reform Club at eight forty-five p.m. with the clock striking the fifty-seventh second and exclaims: "Me voici, messieurs" ['Here I am, gentlemen'] (295; 199). It is to be understood that he won the bet.

The last chapter reveals the literary ruse. One finds out that Fogg's victory is a result of a collusion - as would befit such a novel - between the units of time and global geography. In traveling eastwards around the globe, Fogg and his companions had gained a day without realizing it. On disembarking at Liverpool, they had arrived not on the final day of the bet, as they had thought, but instead a day before. It was Edgar Allan Poe's famous story "Three Sundays in a Week" that furnished the mechanism of introducing this surplus day, ${ }^{4}$ or, the "phantom day" (Unwin Le tour; 4 ), in the novel. To be fair to Verne's literary talents, this was a carefully planned "sleight of hand of an accomplished storyteller" (47). Unwin shows how via a "series of devilish ticks," (46), Verne leaves plentiful clues, sometimes in plain sight, to prepare the reader for this surprising conclusion, such that this "phantom day" becomes a "perfectly obvious consequence of the information which has been provided earlier" (42-3).

The intervening day also allows Fogg and Aouda to reveal their affection toward each other. It is while making necessary arrangements for Fogg and Aouda's wedding that Passepartout, Fogg's servant, realizes that they can still win the bet. It is interesting that the earnestness of this declaration of love toward Aouda, perhaps Fogg's only display of human emotions, takes place at a moment when the novel reveals his mathematical error. As much as this episode gives us grounds to claim a relationship of conflict between the emotional and the calculative, ${ }^{5}$ even more revelatory is the role of this new spatiotemporal paradigm that trumps the clock-like mathematical Fogg. Here is the novel's explanation of the calculation of the twenty-four hours that the mathematically accurate Fogg did not account for:

Or, on compte trois cent soixante degrés sur la circonférence terrestre, et ces trois cent soixante degrés, multipliés par quatre minutes, donnent précisément vingt-quatre heures, - c'est-à-dire ce jour inconsciemment gagné. (299)

[Now there are 360 degrees on the Earth's circumference, and this 360, multiplied by 4 minutes makes exactly 24 hours - in other words the day gained unconsciously. (201)]

Fittingly, the "phantom day" that accounts for his victory is the product of the crossing of the spatial understanding of Earth's surface in terms of its meridians 
with a temporal consciousness measured in hours and minutes. The resultant territorial circumference ("circonférence terrestre" ['Earth's circumference']) is not just literally the topographical span but is rather a collectivity of three hundred and sixty homogenized degrees, all of which have been rendered uniform by the equal time gained of four minutes in crossing them. Placed against the backdrop of a remapped Earth that responds to the temporal demands of a nascent capitalistic thinking, this calculation is the final blow to all ideas of alterity. In moving from the other calculation that initiated the journey of eighty days at the beginning of the novel, it represents the ultimate abstraction of global spatiality. ${ }^{6}$ Earlier calculation acknowledged the existence of a spatial multiplicity (London, Bombay, Yokohama, New York, etc.) that had to exist for the voyage around the world to take place. In contrast, the new world that emerges at the end of the novel is literally flattened out into a universal familiarity of numbers, both temporal as well as spatial. This newly created reality of the globe is a space that institutes a numerically defined understanding of the world and encompasses within itself a redefinition of human subjectivities.

The eventual marriage between Fogg from civilized London and Aouda from a savage unregulated part of India is a biological union that connects two disparate units of the British Empire, perpetuating a new order that is the direct result of this new spatiotemporal paradigm. ${ }^{7}$ Indeed, as Ross Chambers points out, a white man bringing back to London a "thoroughly assimilated Aouda" (a Europeanized woman) could only be yet another example of "reduction of alterity to sameness." Instead of leading the narrative action, as they have until this point, the couple find themselves submitting to the possibility of financial failure. Just as they prepare to fight the resulting indigence by combining forces, ${ }^{9}$ the spatiotemporal collusion reveals itself, declaring Fogg to be the winner of the bet. Appearing concomitantly as they do, the numerical explanation and the marriage reinforce each other. The very enabling actors demonstrate by example their subservience to the new order. The reality of the all-powerful forces of this colonial-capitalist globe is no longer in question for them; as its components, their acceptance of defeat validates the power of the paradigm that had propelled their journey across the globe.

In analyzing Fogg's near mythical journey, this chapter assesses the relevance of similar spatiotemporal matrices that relate to time taken to traverse global space. Susan Hanson attests that since the 1950s experts have started theorizing that the "commodification of space means that a unit of travel time has a money value" (471). ${ }^{10}$ Fogg, through his strictly timed journey with its monetary implications, traversing over the globally interconnected colonial infrastructure, 
was already displaying that speed can be increased "via networks and technology" (Hanson 471). ${ }^{11}$ Writing about the space-time compression characteristic of modernity in The Condition of Postmodernity, David Harvey analyzes French writers and painters like Baudelaire, Flaubert and Manet. Harvey discovers "signals" of a break "of cultural sentiment that reflected a profound questioning of the meaning of space and place, of present, past and future, in a world of insecurity and rapidly expanding spatial horizons" (263). Had he studied Verne, instead of hunting for "signals" indicating how the literary world was symbolizing ${ }^{12}$ the changing dynamics, Harvey would have discovered a much more obvious and at the same time more nuanced enunciation of a "world where both time and space are being absorbed under the homogenizing powers of money and commodity exchange" (263). This chapter makes visible the process that rearticulates the globe as an imperial commodity.

As stated in the introductory chapter, analyses in this chapter shall serve as a backdrop for later chapters, in which I discuss postcolonial works that resist this spatial imperialism. This is not to state that the newer spatialities that emerge in the process respond directly to Verne. Instead, it is to present Verne as exemplifying the dominant spatial logic of nineteenth-century colonialism and capitalism, whose effects later works contest. The discussion below presumes similarities in the numerous expressions of French and European modernity, resulting from various cultural, historical and political contexts. While in-depth study of these expressions and the colonial effects they had across the globe is essential to highlight the differences between them, it is also beyond argument that their shared colonial commonalities produced a totalizing vision of the world. What follows is a "periodizing hypothesis," to borrow Jameson's term (3), ${ }^{13}$ in which I present the dominant traits of a colonizing spatial narrative that the postcolonial imagination challenges. Verne's iteration of the world evokes not only the prevailing power equations in colonial terms but also modernity's rationalization of spaces of belonging and Otherness as spaces of production and consumption. Emerging forms of geographical knowledge embed into Verne's aesthetic production, an ideology of ordering and managing territorial occupations from the center.

A clear tension is present in Verne's work between the principles of geography that dominate the ninenteenth century and the "alternative geographic epistemology" (Brosseau, "In" 10) that emerges when we analyze the workings of the colonial-imperial structures of his writings. The geography that Verne purposefuly intends to incorporate into his fiction is distinct from the literary geography in his work that responds to the colonial reorganization of the world. 
In order to display the workings of Verne's literary geography, I have divided this chapter into two major sections. The first prepares the grounds for understanding how Verne's final textual result is complicit in a spatial paradigm wherein capitalism and the Western concept of national borders sought to empty the global landscape of its local meaning to reinscribe it within an industrialized mechanics. In addition to displaying how, exactly, Verne participates in the nascent nineteenth-century discipline of geography, whose objective at that time was to describe landscapes and national territories, this section also contextualizes Verne by looking at studies that have analyzed his geography. The objective is double: firstly, to account for the widely held critical beliefs about Verne, in particular related to his use of geography; secondly, to show how these studies have laid the important groundwork for the discovery of far more complex workings of geography. In the last part of this section I demonstrate, through a brief reading of the Indian landscape, how Le Tour du monde en quatre-vingts jours reinscribes the planet in a newer spatial paradigm.

This reading will serve as a backdrop for understanding the workings of the opium economy in the second section, which records how Verne's literature both displays the clandestine workings of an opium economy and becomes a site of its concealed principles. Opium first proliferated in China because of imperial smuggling. Later, when faced with an increasingly determined China committed to keeping opium away from its boundaries, the British imperial war machine smoothened the territorial creases to ensure opium's free movement across colonial space. This early capitalism would one day become a part of the kind of "financescapes" (34-5) $)^{14}$ that spread all across the world to overwhelm nation-states. In the next chapter on Ananda Devi's work, I shall take up this relationship between the nation-state and global economy.

\section{Section 1. Understanding Verne: Laying the Groundwork}

Le Tour du monde en quatre-vingts jours belonged to a series of novels, Voyages Extraordinaires (Extraordinary Voyages), whose fictional journeys, enabled by technological possibilities and knowledge emerging toward the end of the nineteenth century, presented the world and its physical expanse to the readers. Verne's characters cut through the air in a balloon (Cinq semaines en ballon; 1863), delved deep into the ocean (Vingt mille lieues sous les mers; 1869), 
burrowed their way to the centre of the earth (Voyage au centre de la Terre; 1864), and even flew through the infinite extraterrestrial space (De la terre à la lune; 1865). In addition to displaying modernity's thirst for newer mechanical innovations and the desire to discover new locales of Otherness, ${ }^{15}$ these adventures across various geographies displayed how Verne "systematically and patiently" marked out "the globe into its different regions"16 (28). The four elements earth, air, fire and water - whose presence Julian Gracq analyzes in Verne's work serve to give mythical proportions to his writings. ${ }^{17}$ Much like the varied spatial exploits of his characters, Verne's literary profusion also effortlessly transcended genres, charting new literary territories. The enviable critical attention that his oeuvre, boasting of scores of novels, short stories, plays and poems, has attracted is a testament to his exceptional artistic acumen.

From a writer with "defective" inspiration to a "man who foretold the future," ${ }^{18}$ Verne's critical reception has varied considerably over the last century and a half. Even though he attracted worldwide attention, he spent his life yearning for respect as an accomplished littérateur. One observer has called Verne a "prophet" for having predicted several scientific discoveries. ${ }^{19}$ Verne's work might have even challenged the Bible in popularity ${ }^{20}$ and triggered a slew of ongoing worldwide academic interest, ${ }^{21}$ but he lamented the lack of recognition as a literary equal by his peers. Lucian Boia commences his book on Jules Verne with an often-quoted note of regret by the legendary author: 'The biggest disappointment of my life is that I have never been considered a part of French literature. ${ }^{22}$ The disappointment accentuates the irony of Verne's literary career. One of the most read French authors and "the most translated of all French writers," ${ }^{23}$ he only found praise from a few of his peers. French literary canon largely ignored the value of his literary contributions during his lifetime.

It is only recently that critics like Unwin have convincingly argued for a more sustained interest in "the self-conscious literary skills and compositional practices which went into" (Journeys 1) Verne's writing. The "complexity and the sophistication of Verne's approach to the writing of novels" (2) completely belie Zola's gross underestimation of Verne's literary talents. Zola had infamously characterized Extraordinary Voyages as 'without any importance in the contemporary literary movement. ${ }^{24}$ If anything, Verne was breaking new literary ground with his writing, while at the same time questioning what it meant to write in the nineteenth century. Indeed, Verne "expanded the very concept of what literature is or might be" (5). ${ }^{25}$

Unwin sees Verne's writings as analogous to the adventurous journeys that are their subject matter. One of the crucial questions that Unwin's monograph 
Jules Verne: Journeys in Writing sets out to answer is about "the metaphorical relation between his [Verne's] own fictional and experimental journey - the 'journey of writing' [...] and the actual physical 'journeys' that are so often the subject of his novels" (3). One need only look at the "processes of writing and the literary techniques" to discern profound underlying debates in Verne's writing about "what the novel is, or might be, or could become." The discovery of unknown spaces, experimentation and scientific progress, then, are not just subject matters of Verne's fiction: in certain ways they are "re-enacted in the writing itself" (216).

In order to counter Roland Barthes' derisive opionion of Verne as being an armchair traveler, Unwin asserts that Barthes fails to understand that for Verne's writing, "travel is text, that text is travel" (217). ${ }^{26}$ The synonymity between writing and travel that Unwin signals functions metaphorically as well as at a more literal level in Verne's writing. The "textual negotiation" during travels not only involves using texts, as Vernian travelers do in the form of written documents as navigation tools, but also involves reading and rereading the world as a text, to give it meaning (217).

The literary readings in my study, then, set out to find the meaning that Verne produces of a world that he defines uniquely in geographical terms. These readings follow Unwin's claim that for Verne nature has to be "verbalised and articulated if it is to have any 'meaning' at all" (217). If we are indeed to believe that Verne's writing proclaims that "it is through text that we are able to understand and make sense of the world" (217), then surely it is incumbent upon us as readers of literature to just do that: make sense of the "meaning" of this world that Verne textually negotiates in topographical and national terms. As one sets out to understand how Verne's writings register the pervading spread of newer technologies across the world, one discovers that they also record the accompanying coordinates that define the changing meaning of the worldscape.

As the colonial enterprise and the nascent capitalist market, aided by technological and scientific novelties, spread all across the word, they also began to reconfigure the very idea of the world as already defined by social relations produced by a colonial-capitalist dynamics. The "meaning" of the world that Verne creates is mediated through these dynamics, which, as they were offering access to the yet unknown geographies, were also already rendering them into homogenized commodities. More importantly, Verne's text reduces the colonial subjects to the demands of these new geographical arrangements, defined in terms used to prop up the process of distribution and consumption in the capitalist economy and its emerging global contours. 
Within the context of this book, this chapter serves to establish the kind of extreme rationalization of geography that creative works of the twentieth and twenty-first century respond to. The reason these postcolonial works insist on foregrounding colonial bodies; on analyzing language's interaction with space; on focusing our analytical attention on the ever-evolving relationship between the colonizer and the colonized, is that they seek to present an alternative to the naturalization of the colonized subject as a passive entity interchangeable with the conquered geographical landscape.

While this study responds to the lack of textual analyses of Verne's work in English, ${ }^{27}$ it also complements the kind of readings that Unwin presents in Journeys in Writing about Verne's literary place in nineteenth-century French literature. For Unwin, in order to show how Verne is opening a novel literary space, it is important to "return to the literary and cultural context in which the Voyages extraordinaires were composed" (2), and to analyze how Verne assembles his texts within the nineteenth-century literary and cultural conventions. In order to appreciate "the complexity and the sophistication" of these texts and to see how Verne "achieves his own uniqueness and originality as a novelist" (3), Unwin focuses on "Verne's approach to the writing of novels." ${ }^{8}$ Unwin's nuanced macroanalyses of Verne's writing process prepare the grounds for my analyses focusing on the textual result of that process. For Unwin, understanding this "approach" involves analyzing the intertextual environment that Verne worked in $^{29}$ and the kind of textual sources he used; it also involves understanding how Verne's apprenticeship in theatre contributed to the "sheer theatrical quality" (96) of his writing and ensured "that the textual world he creates is an artificial and unreal one" (108).

While Unwin analyzes the process of the creation of the Vernian text, I am more interested in the implications of the final product. Journeys in Writing covers an amazing breadth of Verne's work, in order to comment upon the literary characteristics of the entirety of Extraordinary Voyages. My study dives deep into select moments of Le Tour du monde en quatre-vingts jours to discover how this foremost of French authors was rearticulating the world as a geographical extension of the colonial empire's expansionist project. If Vernian writing is about writing and rewriting this world, about giving it "meaning," then for my study it is important to see how the end result of this writing process, the actual text, produces "meaning." I am interested in finding out how the syntactical structures, the vocabulary used and the historical references create Verne's fictional world; I also ask what insights do Verne's textual predilections offer about the 
conceptions of global spatiality in the late nineteenth century, and the implications they have for the "meaning" of the world?

\section{Verne and the World}

It is well established that Verne was among those nineteenth-century authors writing in the presence of the "split personal subject" inhabiting the end of the century (8)..$^{30}$ The need to travel and the need to write about discoveries of newer lands and cultures across the globe were central to nineteenth-century literature's attempts at "discovering, exploring, and connecting such divides" (Youngs 2014; 8). This desire for an elsewhere was the result of "a subliminal unease with changes" in the metropolitan center that nineteenth-century writers "thought they knew so well."31

In Exotic Memories: Literature, Colonialism, and the Fin de Siecle, Chris Bongie reads time and space in Verne's work as a confluence that sets up exoticism (7). Central to this view is a superior past, whose lost values one has to revive elsewhere in the future. Confronted with the discovery of the masses in the aftermath of the French Revolution, the subject of modernity finds its individuality subjugated to a gathering of indistinguishable individuals. Exoticism seeks to rediscover this lost individual, whose existence has become possible, ironically, with the discovery of its loss. This "post-revolutionary individual is in his very essence an afterimage, always alienated from experience and tradition" (Bongie 13). Unlike an imagined past in which an original subjectivity had the possibility of an authentic experience of fellow beings, for the nineteenth-century European subject, advancing modernity, with its mechanization and its social institutions, appeared to be eliminating all prospects of going back to the past. Far-away locales offered an escape route from this annihilating modernity. In its flight the subject sought to relive the original experience in locales far removed from continental Europe, untouched by the spreading peril of mechanical capitalism, where individuality had not been eroded and one could still revive the imagined glorious times of an invented history with the hope of reliving them in the future. Exoticism prospects across global space for a temporal confluence of the past and the future. It is a circular move of temporality that one realizes in spaces of Otherness.

This presentation of the world presumes it to be divided along the lines of technology, with human subjectivity a function of the spreading industrialization. Such a world is made to order for realizing the dreams of its onlooker where the Other's existence is justified in its utility for the self. Human subjectivity is 
presumed to be the same all over the world, such that traversing space makes it possible for one to assume a predetermined essence. History in this equation is a fiction responding to the desires of its reader and serves only to contort further the unipolar presentation of the world. It is a selectively chosen image of the past highlighting those reference points that validate the vantage point of the present. The search for an original individuality is one such strategy of an insecure subject that responds to the obliterating pressures of modernity. Desirous of rediscovering itself, it looks toward the past to seek a more stable subjectivity. ${ }^{32}$

Written in 1872, at the height of colonial expansion, Le Tour du monde en quatre-vingts jours abounds in discursive practices that rearrange political and social boundaries. Jules Verne's writings represent the dominant bourgeois worldview of his time, in which time and space were to provide a sense of order. Ironically, while it might seem that these fictional journeys were an escape from the advancing rationalization, the world that they describe is refracted through the prism of its mathematical modernity. The fact should be evident from the title of the novel itself, which tells us of the world understood as a quantifiable entity, measured in the units of time (eighty days) taken to traverse it. The very same well-measured mathematically exact movements with which Fogg negotiates the private space of his home and traverses London, the heart of the largest colonial empire, ${ }^{33}$ are then deployed to present the geography of the entire world as already conquered in its consumable finite geographical limits.

History and geographical space fell into the same paradigms of methods of production and consumption, which were rationalizing the time and spaces of infrastructure. Related to these mechanisms of organizing spaces of citizenship and belonging, of demarcating limits of civilization, was a rise in newer institutions like disciplinary geography, and tools for investigating and measuring the world, such as cartography. Verne's work responds to the need to organize and access the world, to manage and control the unwieldiness of alterity within the bounds of the written word. Narratives such as Verne's are invested in, and powered by, the growing need to conquer space, be it in terms of colonial territories or newer markets. When such narratives as Phileas Fogg's mathematically link domestic spaces, the topography of London and the entire colonial empire, they participate in the material conditions of the latter and reiterate its political ambitions. For us, they also necessitate a deeper examination of such links.

At the same time, it is interesting to note that Verne insisted on his work not being political. If politics means avoiding everything that would attract controversy at the end of the nineteenth century, then yes, one could argue that Verne's work does not overtly lead into acrimonious debates. Pierre-Jules Hetzel, Verne's 
editor, proactively edited out any portions that could have been potentially controversial. ${ }^{34} \mathrm{He}$ even went to the extent of consulting with the "Russian embassy in Paris to make sure it [the novel Michel Strogoff] would not cause offence to tsarist readers" (59). ${ }^{35}$ In light of Hetzel's editorial efforts to ensure that Verne's work remained generally palatable and marketable, one understands why Verne would want to claim while referring to Twenty Thousand Leagues Under the Sea that "politics has no place in the book." ${ }^{36}$ In accepting this argument today, one runs the risk of eternalizing Verne's understanding of himself and foreclosing the very possibility of alternative readings. ${ }^{37}$

As an author who was crossing boundaries - both geographical as well as literary - Verne's popularity and the pedagogical objective of his work were also influenced by and at the same time shaping and influencing the ideological framework of the society within which he lived. Boia presents Verne's literature as one about spatial exploits and devoid of any political overtones:

Jules Verne had two passions in his life: theater [...] Second passion: geography $[\ldots]$ traveling $[\ldots]$ traveling on the map, traveling via books, traveling by writing. [...]

All of Jules Verne can be found there. Everything for him was a pretext for geography and for a plot bringing together individual destinies, and much less or not at all social or national problems. ${ }^{38}$

As I shall show in the sections that follow, the academic attention devoted to spatial organization in Verne's work validates Boia's recognition of the importance of geography in the author's work. However, to share Boia's assessment about the absence of the social and national realm risks missing out on the full nuances of Verne's literature. When Boia notes that the 'study of the society is not one of Verne's strong points, ${ }^{39}$ and bases this argument on a correspondence between Verne and Hetzel, where Verne is defending his literature, the critic succumbs to Verne's intentions and his definition of himself and thus universalizes the author's understanding of his own work.

While Boia presents layered and complex representations of Verne's place in nineteenth-century literature, his usage of geography, in being limited to a grammar of cartography ("la carte" ['the map']) that facilitates travel, concurs with Verne's spatial appropriation of a world divided along topographical and national lines. In contrast, I contend that instead of being nonexistent, these social realms actively claim relevance in the Vernian universe. In fact, a more just representation of Verne's fiction would communicate the social and political 
enmeshed within geography and subsumed by it in such a way that the spatial, while retaining prominence, acts as a marker of social relations.

I am interested in showing how Vernian space is a register of social equations and, even more importantly, how it participates in perpetuating the political ambitions of the colonial project. It is important to understand the circumstances under which the Vernian space was created, the way it was communicated, and how his literature - born under the frenetic glare of industrialization and determined by the industrial outlook of modernity - perceived and used global space as a tool of colonialism.

Verne's writing contributed to stabilizing the identity of the modern subject within the dominant spatial givens and perpetuated the identitarain limits imposed upon a world defined along national, and by extension, imperial lines. Analyses that bring together literature and geography have grown exponentially over the last few decades. They attempt to understand the myriad ways in which humans and their surroundings, both built as well as natural, interact with each other. Such analyses now provide the vocabulary to exploit unexplored nuances of Verne's work, which is self-consciously geographical in nature.

\section{Verne's Geography}

Scholars have documented how Verne privileged geographical knowledge in his writing. In a special volume ${ }^{40}$ published in 2005 to commemorate Verne's death centenary, Jean Bastié, the president of the Societé de Géographie (Society for Geography), notes with pride that the author had vigorously participated in the society's meeting, and that starting from 1865, he even belonged to it for more than three decades. ${ }^{41}$ To highlight Verne's enthusiastic involvement in the nascent, yet fast growing discipline of geography, it has often been pointed out that, although limited in number, Verne did publish articles on geography. Ian B. Thompson concludes that it "would be an exaggeration to state that Verne made a significant contribution to geography as a discipline." ${ }^{2}$ Verne’s Géographie de la France (Geography of France) followed the "standard descriptive form of the day" $(47)^{43}$ and one could describe his attitude toward geography as that of an eager, engaged, and a well-informed learner. Commenting on the geographical dimensions of Verne's work, Dao Humeau finds that the author does evoke "a geography with social connotations;" at the same time, in his view Verne "can't be considered as a geographer, because he doesn't think as such" (21). ${ }^{44}$ To summarize Humeau's argument in Thompson's more succinct formulation: "It is more appropriate to think of 'Verne and geography' rather than 'Verne the Geographer." 
Verne was writing at a time when the disciplinary boundaries related to geography were still being established. While at present, increasing stress is being laid on understanding spaces as a social product, and in particular on seeing aesthetic art forms as sites where everyday spatial negotiations are most visible, Verne was working within a spatial environment where describing landscapes and countries was seen as geography's primary function. More importantly, despite lively debates within the Society for Geography, the "narrowly conceived scientific conceptions that presided over the university institutionalization [...] [ensured that] geography was quite effectively separated from literature for a long time" (Berdoulay 47). The academic definition of geography was structured to exclude even those like Verne who actively participated in the Society for Geography, and were, in their own way, also producing a conception of the discipline. To what extent this academic positioning of the university discipline, which led to literature's exclusion, might have both impoverished geography and influenced Verne's engagement with it, is difficult to state. Nonetheless, the discussion above does speak to Verne's desire to mirror the preoccupations of geographers contemporary to him and to participate in, and follow, the normative understanding of geography: the "standard descriptive form of the day" (Berdoulay 47). The "obsession for plenitude" 45 and the extreme realism that are described as the defining characteristics of Verne's writing were determined by the dominant geographical thinking of the time, at least as far as the author's engagement with spatial manifestations (local descriptions, urban centers, or the entire world) was concerned.

As a member of the Society for Geography, Verne would interact with "some of the great geographers of the day, such as Kropotkin, and Elisée Reclus" (Thompson), and even source inspiration for his literary works from fast growing geographical research and findings. In order to highlight Reclus' influence on Verne, Lionel Dupuy entitles the book Jules Verne, l'homme et la terre: la mystérieuse géographie des Voyages extraordinaires ${ }^{46}$ after Reclus' posthomous work titled L'Homme et la Terre. ${ }^{47}$ Dupuy also goes to some length to detail the similarities between Verne and Reclus. Both men, according to Dupuy, shared the common ambition of 'representing Earth in its entirety' ${ }^{48}$; furthermore, both display 'a form of human ecology much before its time. ${ }^{39}$ However, what Dupuy details are coincidences related to their lives and careers, ${ }^{50}$ and not methodological similarities in their attitude toward the discipline of geography.

It is the differences between Verne and Reclus, more specifically political differences between the two, that one needs to consider in order to understand their individual attitudes toward geography. ${ }^{51}$ During the Paris Commune, 
they stood on opposite sides of the political divide. While Verne supported the status quo, Reclus' active participation in the Commune led to his exile to Switzerland. ${ }^{52}$ His "constant preoccupation was the problem of the state and its relation to the individual" (Ross, "Rimbaud" 60). Beyond a facile landscapism, it was the human element that Reclus laid stress on in his engagement with geography. He was among the first to have used the term "social geography" (Ross, "Rimbaud" 61); to have understood space as a social product and as an entity that is produced as a result of its interaction with human beings. While Verne did consult Reclus' work, ${ }^{53}$ and both Verne and Reclus expressed the desire to understand the world in its totality, the kind of geography that the author of fiction deployed ran counter to geography as a social product that Reclus was exploring. Reclus' work was "anticipating many of the more modern theories of unequal development" (Ross, "Rimbaud" 61). Had Verne actually followed the methodological approach of this "anarchist geographer" (Ross, "Rimbaud" 60 ), he would have undoubtedly engaged with how changing spatial definitions under the influence of imperialism were affecting human beings and their place in the world. Instead, in presenting the world as available for discovery, as an entity that can be grasped, enumerated and textually narrated, Verne followed a version of geography that was closer to Vidal de la Blache's ${ }^{54}$ conception of the discipline.

For Vidal de la Blache, the human sense of sight was the privileged tool and the role of a geographer was "to detail a region's physiognomy and show how its traits result from a harmonious and permanent interaction between natural conditions and old historical heritages" (Ross, "Rimbaud" 56). In other words, the aim of geography was to describe and enumerate with as many details as possible the regions and physical features of the planet. One cannot forget that Verne was writing immediately after France's defeat at the hands of Germans in the FrancoPrussian War. As a way of reclaiming lost national pride France was expanding its colonies across the globe, and acquiring elsewhere, territory lost to the Prussian army. Vidal de la Blache was a historian by training, and it is pointed out that his "conversion to geography was tied in with France's recent defeat at the hands of Germany"55 (147). Vidalian geography, much like Verne's own understanding of geography, was greatly invested in France's nationalist mission. In particular, "the teaching of French geography appeared to be essential as a means of strengthening people's attachment to their national territory" (Mercier 148).

Geographical societies, themselves interested in expanding the reach of their discipline, served as pressure groups advocating colonial expansion (Berdoulay 51). These societies furnished the tools of charts, maps and geographical data 
needed for colonial expansions, and at the same time, because of these expansions, they gained in terms of easier access to newer territories. The nascent discipline of geography that Verne followed so closely was deeply invested in the cause of French nationalism. As a result, it embedded territorial expansion and colonialism as the guiding principles of Vernian literature.

Verne was not in favor of all aspects of colonialism. However, overall, he remained a supporter of the practice. Jean Chesneaux rightly notes that Verne's "description of colonial expansion and the national movements opposed to it is very contradictory" (116). This contradiction no doubt reflects how, on the one hand in Verne's Extraordinary Voyages there are "idealist views about the superiority of 'a state of nature'; [and] on the other hand, [...] racist and ethnocentric prejudices [...] [that serve as] convenient justification for colonial expansion" (112). Despite his "secret sympathy" for the cause of the colonized Verne nonetheless recognizes colonialism as an "unavoidable and accomplished fact" (122). Colonization was less about some peoples exercising authority over others. It was, rather, "one of the methods by which man can achieve mastery over the globe" (123).

At a textual level, this desire of mastery over the world took on Faustian proportions. Indeed, beyond just expansion, it was the desire to possess within the bounds of his text, to describe in absolute detail the nooks and crannies of the Earth and its beyond, that marks Verne's writing through the end of his writing career. This "yearning for totality - total knowledge, total coverage, total possession" (Unwin 29) - especially when talking of the expanse of the Earth - is what Unwin calls part of a larger "metaphysical, Faustian ambition to possess the infinite" (Unwin, Journeys 29). Roland Barthes calls this "an obsession for plenitude" (Barthes 65). This is a world of "numerable and contiguous objects" (Barthes 65), and betrays a presumption that the world can be exhaustively catalogued. One has recognized this presentation of the world as an example of the nineteenth century's realist desire to capture in words a world that one understands to be finite. This landscape-based definition of geography aimed at discovering new territories was an inherent part of the principle of expansion, which was the "defining principle of his [Verne's] approach" (Unwin "Negotiating" 13).

Unwin concludes that it was no doubt because Verne's novel Paris au XXe siecle (Paris in the Twentieth Century) lacked this expansion of literary and physical boundaries that Hetzel rejected the manuscript in 1863. The novel, after all, recounts the story of a "garret-dwelling hero" named Michel Dufrénoy, inhabiting a world of "art and poetry for their own sake." How could such spatial stasis 
and the unquestioning acceptance of literary boundaries be condoned? Such a "view of art and of the modern world was radically opposed to the whole thrust of Voyages Extraordinaires" (Unwin "Negotiating” 13).

One cannot help seeing a faint reflection of Dufrénoy, a man in search of literature, in Verne the author himself. While not quite a garret-dweller, Verne's explorations of the world, for a nineteenth-century author writing about travel, were limited. Verne was writing at a time when travel literature was undergoing foundational transformations. Irrespective of whether they were actually travel writers or not, "a remarkable number of novelists and poets were travelling writers"56 (73). Ironically, Verne, for whom geographical presentation of the world was extremely important, and who through his detailed research created at times a geographical hyperrealism, was not himself very well traveled across the world. ${ }^{57}$

Verne relied heavily on resources collated and analyzed by scientific societies and expert geographers to render his adventurers' destination. He also "did not hesitate to exploit guide books to add local colour and detail" (Thompson). Gracq names Verne a "discoverer of routes and revealer of worlds." 58 To adapt liberally this comment to the current argument about Verne's borrowed geographical knowledge, it would be more pertinent to call Verne a re-discoverer of routes and re-revealer of worlds. Verne was unquestioningly transporting geography's methodological presumptions into his work, accepting this conception of geography as a given. Similarly, critical analyses too, have followed Verne's treatment by uncritically accepting Verne's geography as a passive backdrop against which the narrative unfolds.

\section{Geography on Verne}

Rare would be the study on Verne that addresses the author's literary exploits relating travels across the world without evoking his penchant for geography. One has strong reasons to classify all critical readings of Extraordinary Voyages as geographical analyses. After all, Verne was writing about journeys across the world, and any criticism would, by default, be a commentary on Verne's engagement with geography. Yet, despite the passage of more than a century after his death, barring a few exceptions, sustained geographical readings that juxtapose Verne's works to emerging understandings of space are difficult to find. There have been numerous studies about stereotypes associated with nationalities and ethnicities; differences between continents; characteristics of flora and fauna; descriptions of landscape, topography and national territories, among other 
aspects of Verne's work. All such arguments furnish coincidental spatial analyses about the organization and perception of space in his oeuvre.

Let us take, for instance, studies that examine Verne's association with Scotland. In rich and nuanced analyses, Ian Thompson notes "Verne professed an affection for Scotland to an almost obsessive degree." On a similar note William Butcher and Sarah Crozier show that "Verne's understanding of Scotland and Scottish society went far deeper than has been appreciated to date." ${ }^{.59}$ In an article about nineteenth-century Scotland, Thompson points out that Voyage a reculons en Angleterre et en Écosse (Backwards Journey to England and Scotland) "reflects the writings of the Romantic period in France and the search for the exotic." Butcher and Crozier insist, while commenting on Les Indes noires (The Black Indies), that nowhere "else in his 200 works does he demonstrate such detailed and accurate knowledge of his mother's homeland [Scotland]." One infers through terms designating geographical belonging, like Scotland and France, that the arguments are operating in a critical environment that presumes a world divided along political boundaries as Verne himself imagined.

There have been similar in-depth studies that examine the extent to which Verne was invested in different political and territorial divisions of the world. ${ }^{60}$ This scholarship tries to understand, for instance, how Verne was "enamored with America and all things American"61 (35); how the geography of colonial India was marked by the presence of 'savage unbridled nature ${ }^{\prime 62}$; and how "Verne subtly aligns the geography of Central Africa with outer space in order to prepare his audience for their imminent, and allegorical, 'departure' into the realm of the outlandish" (109). ${ }^{63}$ If there is a geographical argument to be made about how Verne fictionalizes continents and countries, there is also another to be made about how literary cultures across the world ${ }^{64}$ perceive Verne differently. In Victorian Britain, one primarily read Verne as a "writer of juvenile literature"65 (Costello 16), which has contributed to keeping Verne from being regarded as a "literary" author across the English-speaking world.

The intention here is not to hold these studies up for criticism because they do not furnish the definition of space that this study furnishes. For my study, literature serves as a historical record of the evolving spatial preoccupations of its time, whose dynamics one can excavate through an analysis of its syntax, vocabulary and literary structures. In contrast, for these studies, it is important to analyze how Verne understands geography, and they are conducted in the awareness that for Verne geography meant describing countries and topographies. Butcher and Sarah Crozier, as well as Thompson, examine the effects of Verne's travels to his "mother's homeland" (Butcher and Sarah), to explain the image of Scotland 
that emerges in the author's work. When Verne traveled to his "mother's homeland" and subsequently deployed that personal experience into his literature, he was engaging with the politically defined spatial entity of Scotland.

Thompson rightly points out the irony in Verne's stand. On the one hand, "Verne regarded Scotland as being downtrodden by the English, linking the history of Scotland to his anti-British imperialist views," and yet on the other hand he "sympathised with the view of Scotland founding its own colonies overseas and in Les Enfants du Capitaine Grant." For us, this irony also displays that Verne's political stand, his personal affinities, and his views toward colonialism and empire were all operating within a nineteenth-century political economy. Such theorizations of Verne's literary journeys recognize Verne's geographical engagement in terms of national identities and physical features. Further, they also account for ways in which late nineteenth-century geographers were tracing political and natural divisions. The latter quarter of the nineteenth century saw an explosion of scientific observations, experimentations and travels transmuting the world from a collection of faraway lands to knowable entities that one could access through books, journals and magazines, and discuss in schools and bourgeois living rooms as verifiable facts.

Just as writers like Baudelaire were fetishizing the streets of Paris, recording their experiences of negotiating the constructed urban landscape, there were those like Verne whose writings represented the split subject of nineteenth century going in search of locations not yet touched by mechanisms of modernity.

It is thus easy to see why Verne would write about the polar region. Such a geographical presentation of a faraway land also fulfilled Verne's pedagogical objective of introducing the young readers to a geographical region they would not have access to otherwise. It would then also be natural for critics to discover, as Edmond-P. Gehu does, in a three-part series about Verne's writings on polar regions, that Verne had 'the soul of all the pioneers of the white desert.' Verne 'contemplated within himself, the gloomy hyperborean solitude; heard the voice of ice floes; pondered over the polar night [...] He had the soul of all the pioneers of the white desert [...] He put this soul into his writing. ${ }^{66}$

In presenting Verne's 'soul', it is almost as if Gehu illustrates how the endof-the-century author seeks solitude, whether it be within the 'soul' or in the faraway, unknown, undiscovered lands, and then invests writing with this solitude. These faraway lands had to be inaccessible, the irreducible unknown geographical Other, to function as the site of expression for the collective fin de siècle literary melancholy. 
That 'ruins, locations of decrepitude and decay, would have a special place as a literary metaphor in Verne's writing dominated by solitude is not surprising. It is interesting to note, firstly, that in this search for places of Otherness, ruins function as 'the expression of a veritable poetics of space that reveals a geographical imagination where man, confronted with time, experiences the vulnerability of his life and work. ${ }^{67}$ Secondly, as if Verne's work was not already highly geographical in nature, it is interesting that even the metaphors used to describe natural features are those associated with physical dilapidation that result from human beings' interaction with space.

Moreover, this interplay between the text and geographical space does not just stop at one particular metaphor of ruins. As Unwin's thorough analysis has shown, there is also a parallel relationship between the entirety of Extraordinary Voyages, that is, Verne's "fictional and experimental journey - the 'journey of writing' $[. .$.$] and the actual physical 'journeys' that are so often the subject of his$ novels" (Journeys 3). Verne's coverage of the entire world is a metaphor for understanding his writing. In a different context, Butcher has also discovered an interplay between geographical linearity and narrative linearity. This "linéomanie," as Butcher calls it, refers to the simultaneous spatial as well as chronological linearity in Verne's writings. Verne as the author need only follow the linearity of the river and the narrative linearity takes care of itself. The river, a character in its own right, provides plenty in terms of geographical information, and in terms of obstacles and opportunities of adventure, to fulfill the needs of the fictional content of the narrative. The straight line, in all its manifestations, represents the desire to 'occupy the immense expanse of the physical or conceptual space. ${ }^{38}$

Thus far, in the attempt to show the different definitions of geography that emerge from critical works on Verne, apart from exemplifying the presentation of political and topographical divisions, I have also shown how Verne's writings mirror the geography they represent. There is also reason to invert the relationship between Verne's literary discoveries and the territorial expansion they depict. Verne plagiarized copiously and it is easy to see how "there is often a surprising boldness and openness about his re-use and reworking of other texts" (Unwin, Journeys 178). One can also see how in "proclaiming its derivative qualities" Verne's writing style "challenges and subverts notions of originality" (Unwin, Journeys 178). Would not this copious plagiarism, practiced routinely in nineteenth-century literature, ${ }^{69}$ allow us to see how it is Verne's textual colonization that gets reflected in his manner of depicting territorial expansion? Might one not say, that when Verne boldly presents as his own other people's writing, he is laying out, at a textual level, the principle that guides his occupation of 
geographies of Otherness; that it is through the template of appropriation practiced at the textual level that Verne refracts his understanding of geography?

To continue with the example of a river furnishing the linearity needed for the narrative: Verne had used the works of Jean Chaffanjon and Élisée Reclus to create the backdrop for his Venezuelan adventure, Le Superbe Orénoque (The Mighty Orinoco), a novel that takes place along the river Orinoco. While relying on Chaffanjon and Reclus, Verne did cite his sources at times by name and did use appropriate quotation marks to ensure that the text of the source author stands out, but he also very liberally plagiarized entire chunks of text. ${ }^{70} \mathrm{At}$ other times, Verne extrapolated, orienting geographical data from Chaffanjon's writings toward the needs of his fictional narrative: increasing the number of inhabitants, or making a village seem more somber than what Chaffanjon's text furnished (Dupuy "Superbe Orénoque de Jules Verne"). In other words, Verne's appropriation of texts, his manner of adapting textual information to suit the disposition of his narrative, could also be seen here as the dominant template that determines how he appropriates geography. The world he presents can only appear as colonized because it results from textual colonization. Of course, in hypothesizing about textual colonization as the dominant principle, I am only making a rhetorical point to display how existing studies have opened up numerous possibilities of research about Verne's association with geography.

How physical structures are fictionalized, and how the narrative and the geography mirror each other's structures are certainly important questions to be dealt with. The question of Verne's geographical sources in particular is inextricably linked to the historical context that was providing access to newer places. While fast-growing research was making it possible for Verne to set up his adventures in newer territories, the literary conventions of his times allowed him to own the geographical information without citing those like Louis Figuier, ${ }^{71}$ Jean Chaffanjon and Élisée Reclus as the sources for his writings. An engaged discussion of these questions shows how geography is inextricably linked to all forms of research about Verne. Given Verne's popularity, one can be sure there is a lot more to come.

The definition of space and spatiality that serves as the backdrop for these analyses accepts as given the broad continuities in Verne's understanding of geography and modernity's spatial rationalization. The crucial difference is that Verne very consciously foregrounded geography, whereas for his critical reception, with a few exceptions, the excessive geographical details have slipped into the backdrop, belying their status as Verne's principal preoccupation, a part of his writing style and a literary innovation. They have become stabilized within 
definitions that Verne himself was borrowing from the nationalist colonial outlook of the discipline. It is the literary result of these broad methodological continuities between these secondary sources of geographical knowledge on the one hand, and Verne's work on the other, that needs a deeper examination. Verne's articulation of geography superimposes imperial notions of identity and nation building onto colonies and glosses over alternative geographical conceptions.

A few notable studies have read Verne within emerging paradigms of geography. Dupuy's engagement with Verne's geography extends over two monographs and several scholarly articles, many of which have already figured in discussions above. How to understand better Verne's deliberate usage of geography is the question that undergirds Dupuy's extensive examinations. For instance, in the monograph En relisant Jules Verne (Rereading Jules Verne), Dupuy assumes the 'point of view of a geographer, ${ }^{72}$ and analyzes different notions of space and time (18) in Verne's work. Voyage au centre de la Terre (Journey to the Center of the Earth), is not only a journey into the entrails of the planet but also a way of understanding Earth's history and evolution over time as recounted by the various geological layers. ${ }^{73}$ Time in this equation refers to both the time taken for the journey as well as a historical reference that evokes the various stages of Earth's evolution. $^{74}$

While not claiming that Verne was a geographer, Dupuy nonetheless identifies geographical and ecological preoccupations in Verne's work to argue that the nineteenth-century author was much ahead of his times. A century before our current pressing concerns about the relationship between human beings and their surroundings, Verne, according to Dupuy, was already displaying a deep awareness about such questions (En relisant 102). For instance, Dupuy reads Twenty Thousand Leagues Under the Sea as a 'magnificent ecological metaphor'75 and places analyses of the novel within the transdisciplinary stance of human ecology. Nemo's surroundings offer him shelter while he protects them from exploitation and abuse. This coexistence serves as an ecological metaphor for a thought process much ahead of its times (En relisant 126). It shows us how Verne's work was making a case for reasonable use of resources that respects nature.

Dao Humau also discovers a 'new social geography ${ }^{36}$ in the context of Nemo's society and highlights the presence of a 'coherent geographical space in osmosis with nature. ${ }^{17}$ Through this social geography, Humeau articulates geography as distinct from nature and raises questions that help understand the relationship between spatial arrangement and human beings. However, given its limited scope, this short study does not go beyond making a brief presentation of 'some of the geographical dimensions in Verne's work. ${ }^{78}$ One of the questions 
that Dao Humeau poses is about how Verne's work 'underlines the subtle differences between ${ }^{79}$ the two geographical notions of determinism and possibilism. While analyzing Verne's La Maison à vapeur (The Steam House), Frédéric Landy debates a similar question. Landy comments on the colonial dimension of Verne's work to discover a possibilist geographical outlook underlying which is the belief of human beings' power and their 'progressive mastery over natural forces. ${ }^{90}$ This outlook corresponds to Verne's larger belief that 'human societies are capable of dominating the most extreme of natural surroundings. ${ }^{\text {.81 }}$

These readings have quite rightly made Verne's engagement with geography their subject matter. In addition to showing how Verne reflects the preoccupation of modern geography, they have made a strong case for a deeper investigation of the relationship between human beings and their surroundings. I shall show how analyzing representations of this geography further opens up a complicity between Verne's outlook - invested in spatial rationalization - and the colonial project, which was also intent on flattening the globe out for easier imperial and capitalist expansion. Unlike some of the readings above, what follows takes a less sympathetic view of Verne's perception of the world. The cartography of Verne's globe, even as it privileged swift movement - propelled by the growing availability of an imperial infrastructure - also created new social relationships and political hierarchies. This geography is definitely more than a simplistic description of natural locales.

\section{Reading Verne's Geographies}

Cinq semaines en ballon (Five Weeks in a Balloon), the very first of the Extraordinary Voyages, was also where Verne tested for the very first time detailed descriptions as the defining narrative tool that would dominate the rest of his writing. This novel, which recounts the westward journey across Africa of three Englishmen, was based on real-life expeditions along the Zambezi river, the Kalahari and Sahara deserts. Verne read about these expeditions in research journals and reviews such as L'Année Géographique (Geographical Year) to source material for his novel. Such was the importance and the influence of geography as a discipline in Verne's writing that figures of scientific authority exhibit traits proper to a geographer. As Dr. Samuel Fergusson travels across Africa in Cinq semaines en ballon, he records the features of the places he is crossing, just as a geographer would. ${ }^{82}$

That Fergusson, in his ethical attitude toward nature and planet, and through his criticism of the plundering ways of Kennedy, his traveling companion, might 
be acting as Verne's alter ego, is not lost on the informed reader. ${ }^{83}$ More importantly, Fergusson embodies exactly the kind of geographical expert whose writings become the source of Verne's literature. Verne's character records the kind of geographical information that the author will use as source information for this character to record. Verne is the mediating conduit who participates in a self-fulfilling textual loop that displays the process of writing wherein the world is contained in the text that contains the world.

To imagine Fergusson as Verne's reflection one has to look for literary clues. But Verne is also very consciously inserting his presence within the literary spatial rationalization via one of his favored tools: maps, which "emphasize their complex relations to his texts in support of the spatial imaginaries of his heroes' adventures" (Harpold 19). ${ }^{84}$ In Voyages et aventures du capitaine Hatteras (Voyages and Adventures of Captain Hatteras), the reader discovers a map drafted by someone named Jules Verne. Is this Jules Verne a part of the fictive world, or does it refer to Jules Verne the author of the Extraordinary Voyages? There is a "calculated interleaving of fictional and nonfictional realms - 'Jules Verne,' the expedition's cartographer, doubles 'Jules Verne,' the author" (Harpold 21). For the purposes of my study this interleaving raises important questions about the world's presentation within the textual realm. While Harpold presents this "interleaving" as homologous with the way this fictional map incorporates real-world spaces along with fictive imagined spaces, for me this also presents a world whose contours are already prefigured within a closed and predictable geometry. Verne the author imagines Verne the map-drafter who charts out spaces that Verne the author incorporates in his narrative. If by "stepping outside of the diegetic process [...] Verne deliberately draws attention to the literary framework," ${ }^{\prime 5}$ then this play with the image of the hidden geographer is certainly to be read as drawing attention to the process of imagining geography. The geography of Extraordinary Voyages is a self-fulfilling prophecy whose fictional coordinates are prefigured in the mathematical principles that lay at the basis of Jules Verne's (both as author and the mapmaker) map-based rationalizing knowledge. None of these two Jules Verne figure as active characters in the narrative. Yet, it is their geographical eye that furnishes the backdrop for the fictional narrative where modernity's abstraction of the world renders it coherent, homogenous, and a textually representable physical terrain. This abstraction glosses over the differences and the accompanying global inequality inherent to this spatial abstraction.

If writing about the elsewhere was somehow linked to finding subliminal answers about the split nineteenth-century subject, then, what does one make of Verne, fusing himself with his fictional characters in a text representing an elsewhere? 
These are characters who, with information supplied by Verne, communicate this elsewhere within the text, such that Verne is both within and outside the diegetic process. Answer to this rhetorical question is outside the purview of this current study. However, the readings that follow will help better situate Verne's literature within the context of an imperial system that imposed uniformity of local, national and global political divisions. These analyses, that show modernity taking aesthetic forms in Verne's literary rendition of spatiality, will also, hopefully, ensure that all debates that reckon with the relationship between the elsewhere and the author inhabiting the end of the nineteenth century, have to engage necessarily with spatial abstraction and the urban form it takes. In addition, the discussions that follow will reinforce arguments by scholars interested in analyzing the nineteenth-century author's need for writing about an elsewhere, and the textual representations that this elsewhere assumes. I am also hoping that these close textual analyses will bolster the work of scholars like Richard Phillips and Indra Mukhopadhyay who give primacy to the reader and discover in Verne's work an anti-imperialist stance. They read Verne's work as a "site of resistance" (Phillips 137) and identify in it a "literary alternative to colonial historiography" (Mukhopadhyay 118). ${ }^{86}$

\section{Rounding up the World}

The discussion that follows not only reinforces the important role that Verne's titles play ${ }^{87}$ but is also a testament to the perception of space under modernity. This reading serves as a specific example of how the textual structures and vocabulary betray Verne's rationalization of geography. To look closely, the title of the novel under discussion is Le Tour du monde en quatre-vingts jours (translated as Around the World in Eighty Days). It is a title centered literally on the world. The word monde - French for world - falls at the center of the three-part, seven-word French title. The other two parts, Le tour $d u$ and en quatre-vingts jours, encapsulate monde and summarize within themselves how the novel envisages the world. The world, it is to be noted, is le monde. The connotations of this definite article go beyond its grammatical function of presenting the unique physical reality of le monde. It tells us that the novel visualizes the world solely from the point of view of its geographical space, and secondly, it introduces us to a conception of the world as being one that does not allow for plurality and forecloses the existence of multiplicity. This "world," as the novel proves, is not a world of cultures, of languages. It is one where all markers of plurality get incorporated within, defined by, and subjugated to, the expanse of physical space. 
The French word tour encapsulates within it the idea of both a measurement of a circular body ${ }^{88}$ and a movement around a circular body. ${ }^{89}$ When the title talks about a "tour" of the world, it presents not only a world that one circles around in a matter of eighty days but also a world that is measurable in eighty days. Tour is a unit of measurement quantifying and capturing the world. The number eighty stands in clear contrast and opposition to the unitary aspect endowed to the space of this world. This number miniaturizes further the contours of the world by assigning a finite figure to the project. Since it is in traversing only the physical expanse of the world that one completes the journey in eighty days, quatre-vingts reinforces the presentation of the world solely as a physical reality defined by its geographical spread.

It is also important to point out that the idea of going "around" the world tells, first, of an agglomeration of technological and scientific advances that allowed the world to be measured and mapped; and, second, of a synchronization of scientific accomplishments that made possible a feat demanding dominance over land and water. Presenting a world of technological advances, the novel's title ties in closely with the explosion of technological inventions at the end of nineteenth century and instantly necessitates a look at the influence of these advances. Contrasting the spatially defined unitary world against the carefully arrived at sum of eighty days speaks of space quantifiable in measures of time. ${ }^{90}$

It is such a quantifiable world that a mathematical Fogg, himself known for his exactitude and precision, sets out to traverse. Suvin points out that Fogg is the very embodiment of the novel. "Fogg of Anglo-Saxon coolness and chronometric precision in traversing time and space" reminds us that "Verne's protagonists are passionate incarnations of the story's theme" (61). Only an eccentric such as Fogg could have traversed the planet in the given time and only someone named Passepartout, whose very name suggests passeport (the French word for passport), connoting international mobility, could have accompanied Fog in his quest to cross borders. Need one be reminded that in French, passepartout literally means a master key that opens every lock? ${ }^{91}$

The combination of these near polar opposites, where Fogg's sometimes purposeful indifference is contrasted with Passepartout's near intrusive interest in the local, ${ }^{92}$ brings together "the two halves of man." ${ }^{\text {"3 }}$ This combination of two halves is also conjoined in their other identity as colonizers, such that both the Englishman and his French servant go around the world reinscribing its definitions in parameters of colonization. 
This becomes clearer in Passepartout's conversation with Fix in the following exchange. In his attempts to ascertain the exact location of India, Passepartout divulges the computing matrix used to reckon with spatial alterity:

- Est-ce loin Bombay ? demanda Passepartout.

- Assez loin, répondit l'agent. Il vous faut encore une dizaine de jours de mer.

- Et où prenez-vous Bombay?

- Dans l'Inde.

- En Asie?

- Naturellement.

- Diable !

$[\ldots]$

- Mon bec de gaz que j'ai oublié d'éteindre et qui brûle à mon compte. Or, j'ai calculé que j'en avais pour deux shillings par vingt-quatre heures, juste six pence de plus que je ne gagne, et vous comprenez que pour peu que le voyage se prolonge ... (51-2)

['Is Bombay very far?' asked Passepartout.

'Quite far. About ten days away by sea.'

'And where do you find Bombay?'

'In India.'

'Which is in Asia?'

'Of course

Good Lord!’

$[\ldots]$

'My gas burner. I forgot to turn it off, and so have to pay the bill myself. I've worked out that it's costing me 2 s. every 24 hours, or $6 \mathrm{~d}$. more than I earn. So it's easy to calculate that if the journey goes on for any length of time ...' (36-7)]

Interrogation regarding the distance to Bombay, the question about Bombay's location, and finally the doubt about India, are queries that, while supposedly displaying Passepartout's ignorance, reiterate many times over the instability of their destination - the colony of India. This dialogue literally raises questions about India's existence. Passepartout's ultimate concern for a few shillings over the colony's existence gives away the colony's triviality. This calculation revolving around a gas burner, combined with the reduction of India to the urban center 
of Bombay, suggests the importance of the role of money and urban centers in this vision. What defines and sustains the vision of these distant, undefined locales of Otherness is the calculative concerns. This operation of rationalizing alterity, minimizing it to known coordinates, becomes clearer through the descriptions of how the travelers move through the British colony of India.

\section{Capital Repetitions: Monghir}

In what follows, I shall show how the novel grapples with the unknown landscape of the Indian subcontinent, giving us the beginnings of the formation of the colonial landscape. In discovering how industry invades the local landscape and practice, I will prepare the scaffolding for a discussion about its role in reinforcing the presentation of the local as savage. As the travelers' train cuts across the Gangetic plane from Benaras to Calcutta, the description of Bihar from within a train compartment privileges a technologically advantaged perspective. Apart from the ready cliché of technology working the raw, indigenous land, corresponding to the rapid movement of the train, the description accumulates other numerous details typifying the quintessential fetish objects associated with the presentation of the subcontinent, especially the particular attention paid to Hindu spirituality. With the holy city of Banaras and the "eaux consacrées" ['sacred water'] of the river Ganga as the backdrop, the peppering of names of Hindu divinities completes the perfect ensemble for the pious to live in. This landscape is synonymous with the religion of its inhabitants.

The two quotations that follow, both part of the same description, register the change in the paradigm that defines space. Of the binary opposition in the description - the train against untamed nature - the former is gaining in force. Conscious of the power of technology and its dominating relationship with the metamorphosing landscape, the description exploits all these elements by bringing them together in a hypothetical question that reiterates the power equation:

Mais de quel œil Brahma, Shiva et Whishnou devaient-ils considérer cette Inde, maintenant 'britannisée', lorsque quelque steam-boat passait en hennissant et troublait les eaux consacrées du Gange, effarouchant les mouettes qui volaient à sa surface, les tortues qui pullulaient sur ses bords, et les dévots étendus au long de ses rives! (107)

[But what must Brahma, Shiva, and Vishnu have thought of this India, now 'Britannicized', when some steamboat passed on the Ganges: neighing, churning up the sacred waters, and frightening the seagulls 
skimming over the surface, the tortoises swarming over its banks, and the devout stretched out along its shores. (74)]

Establishing the historical change, "cette Inde" ['this India'] as it stands in its present state brings to light another India, by default an earlier India not "britannisée" ['Britannicized'], a change of state marked by the presence of the steamboat. As the passing train records a moment of transition, the Hindu trinity (Brahma, Shiva, and Vishnu) associated with the earlier India is reduced to helplessness, and the steamboat becomes a historical milestone that records the passage to the mechanical age. The extent to which its movement over water can disturb the seagulls, the tortoises and the devotees all at the same time communicates the spread of the steamboat's power and the power the state of being Britannicized stands for.

With this, for the very first time in the description, a challenge to the native landscape is alluded to and this scene of gentle disturbance of the quaint scenario that remains literally over the surface - it troubles the waters ("troublait les eaux" ['churning up the sacred waters']) - changes to a more aggressive and an overt challenge to the local scenery. The following quotation reveals the ease with which the train overpowers the geography of the colony of India:

Tout ce panorama défila comme un éclair, et souvent un nuage de vapeur blanche en cacha les détails. À peine les voyageurs purent-ils entrevoir le fort de Chunar, à vingt milles au sud-est de Bénarès, ancienne forteresse des rajahs du Béhar, Ghazepour et ses importantes fabriques d'eau de rose, le tombeau de Lord Cornwallis qui s'élève sur la rive gauche du Gange, la ville fortifiée de Buxar, Patna, grande cité industrielle et commerçante, où se tient le principal marché d'opium de l'Inde, Monghir, ville plus qu'européenne, anglaise comme Manchester ou Birmingham, renommée pour ses fonderies de fer, ses fabriques de taillanderie et d'armes blanches et dont les hautes cheminées encrassaient d'une fumée noire le ciel de Brahma, - un véritable coup de poing dans le pays du rêve! (107)

[This whole panorama flew past like a flash, although often a cloud of white steam masked the details. The travelers hardly saw the fort of Chunar, twenty miles south-east of Benares; nor the ancient fortress of the rajahs of Bihar; Ghazipur with its important rosewater factories; 
Lord Cornwallis's Tomb, which stands on the left bank of the Ganges; the fortified town of Buxar; and the large industrial and business city of Patna, where the principal opium market in India is held. They could hardly glimpse Monghyr, a town which is more than European, being as British as Manchester or Birmingham, renowned for its iron foundries and its factories for edge tools and knives, and whose tall chimneys choked the sky of Brahma with their black smoke - a veritable punch delivered to the land of dreams! (74)]

The two extremes of the passage allow for discussion on the nature and importance of the visual in the strengthening of industry. As the steam power provides locomotion to the train, it is muddying up the view ("un nuage de vapeur blanche en cacha les détails" ['cloud of white steam masked the details']). Toward the end, this view has been completely taken over by the violence of the factory smoke: "les hautes cheminées encrassaient d'une fumée noire le ciel de Brahma - un véritable coup de poing dans le pays du rêve !' ['tall chimneys choked the sky of Brahma with their black smoke - a veritable punch delivered to the land of dreams!'].

As the scene fluctuates between the locales and industry, one becomes conscious of the priority given to sight. Be it the movement of the water, a description of the tortoises ("les tortues qui pullulaient" ['the tortoises swarming']) or the people ("dévots étendus" ['the devout stretched out']), the presentation, detailed from behind a train window, prepares for the eventual challenge industry holds out to the traditional organization of the landscape in the novel. Initially presented visually, it is a landscape described solely from the point of view of the religious everyday practices of the inhabitants. They are living in a contourless space, undefined by any capital-based markers or political boundaries. Moving from a clear view of the inhabitants to a view hampered by the vapor of the train, the advancing description, as if to demonstrate the power of industry it presents, progressively cedes that place to industry.

A sky already covered by the overreaching chimneys is completely dominated by the smoke emanating from them. While speaking volumes about the importance of the privileged human faculty of sight in the advancement of industry, it demonstrates how the industry obscures sight itself, such that it only makes allowance for a view conducive to its own growth.

One can better perceive this aggression in the interplay between the Hindu divinity, Brahma, and the factories. It is a moment of spatial transition in which 
the latter muscle their way in, destroying the earlier serenity and introducing violence into the landscape. Although identified as "le maitre suprême des prêtres et des législateurs" ['the supreme master of the priests and legislators'] $(107 ; 73)$, Brahma is better known as the creator of the universe in Hindu mythology. In receiving "un coup de poing" ['a punch'], Brahma's sky is forever transformed by the chimney smoke, and with it the text signals an alternate conceptualization of the universe, aligned to the matrix of these factories. The world of the creator is forever changed.

As a precursor to the impending cartographic move of reconfiguration, this unveils a new space, scaled by and for the proliferation of capital. Lefebvre states: "A further important aspect of spaces of this kind is their increasingly pronounced visual character. They are made with the visible in mind: the visibility of people and things, of spaces and of whatever is contained in them" (Production 75). With the eye as the primary tool of delineation, this space currently devoid of any territorial signs - is to be mapped for the growth of industry. ${ }^{94}$ From Passepartout's worries of a few shillings to an aggressive industry, these are all strategies of abstraction that empty space of its qualitative characteristics, reducing it to universally quantifiable coordinates. Hampered visibility is a symptom underscoring the increasing transparency of this evolving space, which in turn ignores the varied human experience inhabiting it. "Sight and seeing," in Lefebvre's words, "have turned into a trap: the means whereby, in social space, diversity may be simulated and a travesty of enlightenment and intelligibility ensconced under the sign of transparency" (75-6).

As the party traverses the colony of India, the description is associated with the reach of the railway line, and the regions served are directly implicated within the colonial economy. With factories as its points of reference, the movement of the train evokes the movement of the colonial industry, recording the milestones of its economic prosperity as it also tries to grapple with spatial alterity. In this movement of the adventurers, one perceives a distinct opposition between the aggressive industry and a quaint local landscape. As a precursor to the impending cartographic reconfiguration, Monghir is only an example of this new space, scaled by and for proliferating capital. This aggressive industry is only one of the many strategies of abstraction that empty out space of its qualitative characteristics reducing it to universally quantifiable coordinates.

For the moment, I turn to another strategy of annihilation of social spaces: repetitious spaces. Monghir, with foundries and factories as its sole coordinates, also assumes the identity of a British city - a self-multiplying 
space in the novel, which in its many appearances demonstrates the transparency of world space. Apart from the unfolding of the city as a comparison of Manchester and Birmingham, since what makes this city of Monghir in the Indian subcontinent English ("anglaise") is its industrial nature, one also infers the relationship of synonymity that exists between being English and being industrial, which forces us to consider the interdependence between colonialism and capitalism. To understand this connection, a further exploration of Monghir's identification as a colonial city ("ville") and that which makes it a city is necessary.

At a time when "the geographical description of any country consists of presenting and describing the regions that make it up," of describing the "natural 'givens" (Ross "Rimbaud" 51-52), Monghir exists solely as a colonial space. In homogenizing the colonial world and making it one with the colonizer's world through technological coordinates, the alterity has most definitely been negated. Monghir cannot even exist as a natural "given," which would allow it a unique existence in India. It now exists as a replication of the colonizer. Wiped clean is the old world where borders designated difference and prevented incursions.

Crossing borders functions as the mainstay of this novel about free movement across the world, where the existence of international frontiers furnishes the very basis of the adventure. Despite the protestations of the card players with whom he has struck the wager, and who assure Fogg of believing his word of a gentleman, Fogg promises to come back with visas stamped on his passport $(30 ; 24)$. Stamped passports that verify travel across borders testify to their importance in this adventure. Given the ease with which the travelers can go around the world also paradoxically prepares the ground for theorizing the ineffectiveness of these borders. What emerges when Monghir exists as one of many similar entities is the obvious corollary it produces of borders in crisis. While they do maintain the illusion of separation, the similarity between locations across the world constitutes these borders as impossible entities. Even before the journey from London began, one could already predict what Monghir - existing elsewhere - held. If the technology-based paradigm was to display Monghir as a reflection of Birmingham and Manchester, the British consul at Suez, right before Fogg was to enter India, was already putting a question mark on the validity of borders and their mechanisms. In this meeting, the consul affirms to Fogg that passports and visas are unnecessary $(46 ; 33)$. Whereas this insistently reminds readers of the spread of imperialist hegemony, figuring Egypt as another outpost of British colonialism, it also 
preemptively presents the colonized world as indistinct from that of the colonizers. No visas and passports are needed in a world where technologically triggered replication holds sway and locations are indistinguishable from each other. As the adventurers will soon discover, Monghir has been absorbed into the body of the colonial project. It has become a part of what the title of the novel had from its very outset predicted - the singular le monde. Since the world has been rendered the same all over - a replication of British counties the borders serve no purpose.

In today's fast-globalizing world, we are trying to understand how the global economic structure "invites compliance from states, corporations, and other organizations." 95 One can see that "state actions and the global economy are causing one another"; that is, they are complicit in each other's existence. The mathematical calculations in Le Tour du monde en quatre-vingts jours breaking down the distinctions between Birmingham and Monghir, Europe and Asia, empire and colony in favor of the colonial economy were already making these borders obsolete. They are not frontiers to alterity but serve as facile conduits to sameness.

Or, are these borders obsolete? Instead of defining the inhabitants of India and other colonies, they now facilitate unhindered movement for the colonizers. Their existence lies in furthering the colonizing mission. They do not limit boundaries but are now themselves limited to the colonial design. With technology as the locus, this is both a moment of change in spatial use as well as a moment of reinscription of the role of boundaries. Their submission has now given them a unidirectional aspect and their purpose lies in allowing Fogg to pass through India in order to validate his travels as well as to lock the native in for the discovery and the perusal of the colonizer. However, this paradigm where ineffective borders serve as exotic containers cannot function without simultaneous consequences for the larger definition of space. Monghir remains only a symptom of the construct that has taken over this interconnected world, whose regions are progressively becoming alike as the world is shrinking.

This novel that literally takes the readers through the vast British Empire provides numerous examples of the work of this power on colonial spatiality, by showing how boundaries are created and how colonial essences are first constructed, then assigned and then emptied out and replaced by the means of capitalistic structures. Be it Singapore, Bombay, Calcutta, Yokohama or Hong Kong - cities in the novel are deployed as colonial recreations. Presented solely using structures of commerce and a colonial temporality, they all adequately 
model the prevalent pattern of representing alternate spatial identity during this voyage. In Harvey's words, this post-1850 world is one where the "world's spaces were deterritorialized, stripped of their preceding significations, and then reterritorialized according to the convenience of colonial and imperial administration" (“Condition" 264).

Until this point, I have touched upon the interweaving influences of temporal and spatial components onto colonial territories that rearrange these alterities into an infrastructure necessary for the accumulation of capital. Moving through unknown territories, at times even in violation of local conventions, Fogg's forays are never transgressions, for they always anticipate, and indeed actively participate in, the creation of a spatial "sameness" through the operations of a capital-induced colonialism. To explore this space means accepting a model of production that not only allows uniquely self-profiting transactions but also completely ignores all ideas of alternate subjectivity. In this paradigm, spatial entities like international borders function more as spatial tools in colonial service, resulting, as I have been trying to argue, in a complete effacement of the Other. To experience this space means constantly living at the cost of the Other, to find validation by inserting the self into emptied-out definitions of the Other.

In what follows I look at the presentation of Hong Kong as an illustration of how colonial cities are formed with capitalism as the operating force. This will allow appreciating how the seemingly innocuous reference to the opium market makes Monghir part of a larger constellation of geographically dispersed cities, all implicated in an opium economy, interconnected as parts of a machinery. It helps establish colonial cities under nascent capitalism as abstracted spaces, globally homogenized and presented with industrial markers that render them universally similar. They are set in place with the sole objective of increasing colonial capital. The reading records the novel rearticulating the indigenous landscape into a colonially familiar spatiality. 


\section{Section 2. Opium Silence and Nineteenth-Century French Literature}

L'opium agrandit ce qui n'a pas de bornes,

Allonge l'illimité,

Approfondit le temps, creuse la volupté,

Et de plaisirs noirs et mornes

Remplit l'âme au-delà de sa capacité.

$$
\text { - "Le Poison," Baudelaire" }
$$

[Opium extends that which has no bounds

Stretches the limitless

Deepens time, hollows out delight

And pours dark and mournful pleasures

To fill up the soul beyond its measure

$$
\text { — "Poison," Baudelaire" }{ }^{97}
$$

Baudelaire's writings present numerous instances of his experiences with opium. His fascination for the drug is more than evident in his much-quoted three-hundred-page volume, Les Paradis artificiels: Opium et haschisch (Artificial Paradises: Opium and Hashish, 1860). The extent of his addiction was such that opium and alcohol would cause his eventual financial ruin later in life. Much earlier though, in 1841, when he was around twenty years old, his family decided to send him on a voyage to the city of Calcutta in India, hoping to cure him of his wayward lifestyle. ${ }^{98}$ Baudelaire did start the journey, but right before reaching India, he took a boat back to France from the Indian-Ocean island of Mauritius. Had Baudelaire continued, he would have discovered that Calcutta was where the English colonizers had set up the nerve center of their opium trade. Baudelaire's family was, ironically, sending him to the very colonial roots of his addiction and subsequent ruin. Baudelaire's journey, in having opium as one of its instigators and failing to reach its colonial destination, is symptomatic of most nineteenth-century French literature. Despite the fact that opium trade "had become the largest commerce of its kind in a single commodity in the world," erature records opium's presence without recognizing the capitalist colonization it imposed on India and China for the drug's production and transportation. 
The epigraph above is from Baudelaire's four-stanza poem titled "Poison," where love is presented as a poison more potent than opium. It is neither the thematic of love, nor the vocabulary of death and despair ("creuse" ['hollows']; "noirs" ['dark']; and "morne" ['mournful']) that interests me. Rather, I am interested in the discourse on an opium space that this poem displays. This stanza is a perfect example of the absence in nineteenth-century French literature of opium's pivotal colonizing role.

Based on Baudelaire's treatment of opium with no references to a colonized Hong Kong or Calcutta, one would have no reason to probe its link with these cities. In fact, much like Calcutta, Hong Kong too was central to transporting opium. In 1842, just a year after Baudelaire's failed journey to India, Great Britain won what is famously known as the First Opium War against China. Opium, as the center of the three-word term - "The Opium War" - designates the cause of the conflict as well as its centrality to the interconnected global economy that the drug created. After their victory, not only had the British won the right to sell opium in China, but with China's concession of the island of Hong Kong the British Empire had also attained the logistical maritime means of making the drug a commercial success. The East India Company cultivated in India the drug destined for China, which led to opium becoming the central link between disparate geographies. Beyond China, Hong Kong, France and Great Britain, the effects of opium were felt across the globe as it turned around the economy of the colony of India and became the capitalist fuel for imperial colonial expansion.

Even as opium acquired new politicoeconomic significations, no longer remaining just a signifier for the hallucinatory drug, Verne's novel, Around the World in Eighty Days effaced any overt mention of opium's centrality to global interconnections. Indeed, by disguising its presence Verne's writing sanitized opium's effects to make it more palatable, or, as Baudelaire would have us believe - less of a poison.

Yet, as hard as it might try to occlude colonialism, Baudelaire's poetry nonetheless betrays the changing face of spatial discourse. When the poem urges us to investigate spatialities and temporalities of interconnectedness that have opium as their center, it is calling for an analysis of this ever-expanding new space. Of course, one cannot take literally the powers of opium to stretch spatial and temporal boundaries ("agrandit" ['extends']; "allonge" ['stretches']; "bornes" ['bounds']; "illimité" ['limitless']). Nonetheless, the poem is a site of articulation, associated with opium, that contains within it definitions of temporal and spatial boundaries as well as challenges to the limits of these definitions 
("pas de bornes" ['has no bounds']; "Allonge l'illimite'” ['Stretches the limitless']; "Approfondit le temps" ['Deepens time']; "Remplit l'âme au delà de sa capacité" ['To fill up the soul beyond its measure']). This poem prepares the ground for an entire discourse that demands a closer scrutiny of opium's presence and investment in history and the formation of global spatiality. The poem stretches space and history, evoking opium's presence in a network of influences to help us understand the dynamics that generate colonial space. It helps understand how opium is both a product of as well as an instigator of significant changes in colonial space and the history of India and China, and how Baudelaire as a consumer of opium creates the demand for the drug in the colonial metropolis. The poem, when read alongside Baudelaire's fascination for the drug, contextualizes opium's historical presence in France and traces the invisible route that led it from Calcutta to Hong Kong to Europe. Most importantly, it helps understand the transformation that opium, as a colonial-capitalist element, brought about in our spatial grammar.

Baudelaire presents opium without its supporting colonial infrastructure. On the other hand, the phlegmatic hero Phileas Fogg, in his forays from London to Bombay to Calcutta to Singapore to Shanghai, relies on a colonial infrastructure established by and for the opium economy, but never takes stock of opium as the driving force behind this infrastructure. By the term "opium silence," I intend to show how, through its absence, opium operates surreptitiously at an intersection of financial and colonial forces. Jules Verne's literature is implicated in the opium-driven nascent capitalist economy that reconfigured indigenous landscape into universally homogenized urban spaces such that they had to imperatively resemble colonial entities. Imperatively, so that English opium might pass unnoticed through this colonial economy. Much like the opium that was initially smuggled into China, an opium apparatus forms the clandestine backdrop of such nineteenth-century French literature. A juxtaposition of opium's historical economic strength with its paradoxical absence in literature allows us to understand the reasons for this silence and its larger implications for colonial subjectivity.

Verne's spaces and the spatial arrangements are all part of the changing spatial grammar that Verne was actively transporting into his literary works. It is not just about showing how the details and descriptions that the author so meticulously collected about countries and landscape find a place in his work. It is also about showing how spatial rationalization and homogenization, the mainstay of the changing discipline of geography, became the very guiding principles of Verne's spatial engagements. A French author writing the story of an 
Englishman who traverses global colonial-economic space speaks to the kind of cross-national interconnections in which the local and the global are intertwined and constitute each other.

\section{Colonizing Hong Kong}

The following is a detailed reading of Hong Kong's description. The centrality of Hong Kong's role in the novel's colonial opium economy shall become self-evident in this analysis. It is important to minutely parse Hong Kong's presentation to establish how capital-induced colonial coordinates and the associated vocabulary have completely taken over the presentation of urban landscape. Reproducing itself, this space becomes the main motor of colonialism.

The quotation below enunciates Hong Kong's "meaning" within a colonial geography that can only locate spatial coordinates associated with territorial expansion. Given the kind of geographical apparatus Verne was working with, it is not surprising to discover that all spatial details are invested in enhancing the city's colonial character. Spatial details abound, but only those that connect this city to the colonial-capitalist power structure. Additionally, the only historical moment available in the description is the year 1842, the year when Hong Kong became a colonial possession. The spatial and temporal structures that mark the island's geography are in themselves fictional creations, set into place by a colonizing vision that privileges only those temporal and spatial milestones that are consistent with its project of expansion. This blinkered vision exemplifies the matrix the novel deploys to render the world into a geography of abstraction.

Understanding Hong Kong's portrayal in the novel as a colonial geography would facilitate the task of showing the island's relevance to a colonially organized global narcotic economy. One never overtly mentions opium's role in Hong Kong's establishment. However, when, after the 1842 Opium War, it was responsible for Hong Kong's creation, opium stood as an example of the larger financial apparatus in Le Tour du monde en quatre-vingts jours. The novel displays colonial capital abundantly without any elaboration of its acquisition. Exactly in the same manner as the island of Hong Kong is described using selective coordinates, so is the description of the world that Hong Kong participates in limited to the economic operation of the colonial empire. What are the implications for the definition of the colonized, and how the novel allows only a particular kind of colonized subject to be at the center of this geography? This is what I examine next. 
While the first paragraph below is an example of what Michel Foucault calls a "voix sans corps" ['body-less voice'] (discussed below), an absent narrative voice, the second is from Passepartout's point of view. Together, they describe Passpartout's impressions about Hong Kong as he disembarks on the island and perceives it as a rearticulation of other English cities:

Hong-Kong n'est qu'un îlot, dont le traité de Nanking, après la guerre de 1842, assura la possession à l'Angleterre. En quelques années, le génie colonisateur de la Grande-Bretagne y avait fondé une ville importante et crée un port, le port Victoria. Cette île est située à l'embouchure de la rivière de Canton, et soixante milles seulement la séparent de la cité portugaise de Macao, bâtie sur l'autre rive. Hong-Kong devait nécessairement vaincre Macao dans une lutte commerciale, et maintenant la plus grande partie du transit chinois s'opère par la ville anglaise. Des docks, des hôpitaux, des wharfs, des entrepôts, une cathédrale gothique, un 'government-house', des rues macadamisées, tout ferait croire qu'une des cités commerçantes des comtés de Kent ou de Surrey, traversant le sphéroïde terrestre, est venue ressortir en ce point de la Chine, presque à ses antipodes.

Passepartout, les mains dans les poches, se rendit donc vers le port Victoria, regardant les palanquins, les brouettes à voile, encore en faveur dans le Céleste Empire, et toute cette foule de Chinois, de Japonais et d'Européens, qui se pressait dans les rues. À peu de choses près, c'était encore Bombay, Calcutta ou Singapore, que le digne garçon retrouvait sur son parcours. Il y a ainsi comme une trainnée de villes anglaises tout autour du monde. (139-40)

[Hong Kong is but a small island, which the Treaty of Nanking transferred to England after the war of 1842. Within a few years Great Britain's genius for colonization had founded an important city there, and created a port, Victoria Harbour. The island is situated at the mouth of the Canton River, only 60 miles from the Portuguese city of Macao on the opposite shore. Hong Kong was bound to overtake Macao in a commercial battle, and now the majority of Chinese imports and exports pass through the English city. Docks, hospitals, wharves, godowns, a Gothic cathedral, a Government House, and surfaced roads - everything made you think that one of the many market 
towns in Kent or Surrey had passed right through the terrestrial sphere and popped out at this point in China, almost at the antipodes. Passepartout, hands in pockets, headed for Victoria Harbour, examining the palanquins, the wind-driven wheelbarrows still in use in the Celestial Empire, and the large crowds of Chinese, Japanese, and Europeans filling the streets. With a few exceptions, it was Bombay, Calcutta, or Singapore all over again, that the worthy fellow was finding on his route. There is a trail of English cities right round the world. ${ }^{100}$ ]

The end of the quotation - "autour du monde" ['round the world'] - distinctly reminds of the desire projected by the title of the novel, and talks about the space of the 'world' the cities conquer. As "villes anglaises" ['English cities'] tell us - it is the cities that go around the world transporting the "trainée" ['trail'] of Englishness.

Presented as a product of Great Britain's "génie colonisateur" ['genius for colonization'], the description depicts Hong Kong as a locus of an enumeration of constructions that remind of Great Britain and its commercial prowess in the counties of Kent or Surrey. Hong Kong's definition above reaffirms its presence as another in the chain of colonial cities, and by acknowledging its position of mercantile superiority in the region, it also evokes a city's necessary association with business for it to be a successful British city. This association is further reinforced by the commercial nature of the numerous spatial constructions ("port Victoria" ['Victoria Harbour']; "docks, des hôpitaux, des wharfs, des entrepôts" ['docks, hospitals, wharves, godowns']; "government-house” ['Government House']; "rues macadamisées" ['surfaced roads']). Additionally, references to a "lutte commerciale" ['commercial battle'] and "transit chinois" ['Chinese imports and exports'] only enrich this business-related semantic field.

Colonial essence condenses in structures related to capital and commerce, and multiplies itself through the spatial reproduction of cities. As reproduced spaces, cities also operate as active tools in the further propagation of this capital-infused spatiality through self-replication. They are empowered agents that transmit the commercial essence that made them. While Hong Kong itself is portrayed as under the command of, and as a carrier of, colonial identity, it is the generic city that emerges victorious. Hong Kong as the stake between two empires highlights its importance as a space of desire and extends its dimensions of a city much beyond its administrative boundaries. Being of a collectivity that circulates around the world stretches Hong Kong's scope to the entire world: 
a world already inscribed using the coordinates of urban space. The following sentence exemplifies the relative power of these commercial entities through the example of the counties of Kent and Surrey:

une des cités commerçantes des comtés de Kent ou de Surrey, traversant le sphéroïde terrestre, est venue ressortir en ce point de la Chine, presque à ses antipodes.

[one of the many market towns in Kent or Surrey had passed right through the terrestrial sphere and popped out at this point in China, almost at the antipodes.]

The combined usage of "traversant" ['pass right through'] and "ressortir" ['popped out'] accentuates the action of cutting through the globe to emerge at the "antipodes" ['antipodes'] of the Earth, which incidentally is designated only using the physical expanse - "sphéroïde terrestre" ['terrestrial sphere'] of the planet. Antipode articulates the ability of urban spaces to establish themselves at the two geographical extremes, showing their vast reach and power, and the extent of their growing spatial domination over the planet. The image of cities that can cut through to pop out on the other side of the planet communicates a veritable notion of geographies in movement propelled by capitalism in a controllable physical world. Their respective sentence positions also address the power equation: the cities are in an active subject position with the world as their object. Combined with the adventurers' movement across the surface of land and water, the cities' momentum establishes complete authority over Earth. There is a distinct parallel between the two movements, which goes beyond the obvious use of "autour du monde" ['round the world'] for both the cities and the adventurers. It is the study of this other parallel movement that holds the key to understanding the adventurers' voyage around the world. When this spatial "world tour" of urban spaces is described as already accomplished during Passepartout's visit, it points to the fact that the spatial movement has preceded the adventurers: commercially propelled and long time in motion, these spaces have outrun the competitors in going around the world. In addition to enumerating constructions (docks, etc.) that represent colonial and business power in Verne's work, this section also tries to establish the interrelationship between spatial entities. Verne's world is a geography of colonial-capitalist spaces in movement that are carving out newer spatial hierarchies in the world according to changed coordinates. 
As much as the above discussion highlights the power of urban spaces, it also shows how Passepartout and his fellow travelers follow a route set up by the very same commercial infrastructure used to maintain a stronghold over colonies. This infrastructure also ensures that cities from different parts of the world resemble each other: be it Hong Kong or Kent or Surrey, or even Bombay, Calcutta, or Singapore.

It is a world that is shrinking as the commercial infrastructure is gaining in expanse. At least, this is the contention that triggers the voyage at the center of the novel. Fogg, during a card game with his fellow club members, counters a claim about Earth being vast: "Elle l'était autrefois" ['It used to be'] (22; 18), he contends - that Earth was vast in another time. As important as it is to take into consideration the two temporal references of a present and a juxtaposed past, even more significant is the question raised about the size of Earth. As Andrew Stuart rightly queries: "Comment, autrefois! Est-ce que la terre a diminué par hasard ?" ['What d'you mean, 'used to be'? Has the Earth suddenly got smaller by some chance?'] $(23 ; 18)$.

Stuart's skeptical interrogation about Earth's size receives a reply in the positive and the reason for this shrinkage is attributed to the speed of travel that allows one to cover distances much faster. The geographical expanse is inversely proportional to the increasing velocity of travel. This speed of means of transport becomes the historical marker differentiating the "autrefois" ['used to be'] of a larger Earth from the present. This temporal distinction with technology at its root is a recurrent trope in the novel and its prevalence becomes evident when Gauthier Ralph, another card player, joins his voice with Fogg's:

La terre a diminué, puisqu'on la parcourt maintenant dix fois plus vite qu'il y a cent ans. (23)

[The Earth has shrunk because it can be covered ten times as quickly now as a hundred years ago. (18)]

The proportional logic - between the decreasing size and the increasing speed crystallizes in the interrelation expressed between the increasing speed and the reduction of Earth's dimensions. In this case, with the increasing speed "dix fois plus vite" ['ten times as quickly'] as the only separation between the present and the past, the rate of velocity is literally a designator of history. What Ralph refers to is the significance of the new faster means of travel to a world contemporary to them, the infrastructure for which is being set up by the self-replicating 
urban space. In fact, it is the establishment of the railway-network in the English colony of India that triggers Fogg's journey. Following the publication in the Morning Chronicle of a hypothetical calculation claiming possible a trip around the world in eighty days, Fogg challenges the skepticism of his fellow card-playing club members and wagers half of his wealth to the project:

- En quatre-vingts jours seulement, dit Phileas Fogg.

- En effet, messieurs, ajouta John Sullivan, quatre-vingts jours, depuis que la section entre Rothal et Allahabad a été ouverte sur le 'GreatIndian peninsular railway', et voici le calcul établi par le Morning Chronicle. (23)

['Eighty days', interjected Fogg. 'Yes indeed, good sirs', confirmed Sullivan. 'Eighty days, now they've opened the section of the Great Indian Peninsular Railway from Rothal to Allahabad. This is the calculation done by the Morning Chronicle'. (19)]

The simultaneity between the setting up of the infrastructure and the world's shrinkage is clear. As a necessary precedent to the bet, the railroad is an example of colonial infrastructure as an essential precursor to the changing discourse of the planet. This is a moment of incorporating the world within a terminology of technology. The completion of the railways is the final piece of a global "meshwork" ${ }^{101}$ of dominated spaces.

The simultaneous conclusion of the railways and the beginning of the adventure around the world is not a coincidence. It is rather a predictable corollary for a journey that could potentially change the "meaning" of global space, imposing on it instead an essence that can be calculated. What the Morning Chronicle then presents through its calculations of the global distance is an example of dominated space. These calculations reduce the globe to an achievable number. In the novel, the colonial encounter with the Other is determined by the increasing role of the infrastructural "meshwork." Hong Kong illustrates the dynamics of such a mapping process and a study of the articulation of its means of transportation uncovers a matrix deployed toward dominating not only the colonized but also other competing colonizers.

Already valorized many times over, the supremacy of the British Empire in the region takes on a mercantile character when Hong Kong is presumed victorious over Macao in a hypothetical commercial battle: "Hong-Kong devait nécessairement vaincre Macao dans une lutte commerciale" ['Hong Kong was bound 
to overtake Macao in a commercial battle']. Having arrived first, the Portuguese were the ones to set up Macao - the oldest European port in China - in 1557. ${ }^{102}$ Eventually when the British did get to China, despite being the later entrants, they surpassed the other colonizers (Portuguese and the Dutch), "becoming the dominant European country trading with China" (Grasso 28).

Situating Hong Kong vis-à-vis Macao's inadequacy and putting the two in a commercial conflict brings to the fore an entire colonial history, wherein Hong Kong is a reminder of Great Britain's simultaneous victory over China and rival Portugal in a battle of territories. The distance of sixty miles offered by the Canton River between the two cities is more than just a physical separation. The waterway evokes the maritime prowess of Great Britain that navigated it into a position of advantage in the region.

For, during the Opium War the Chinese "military was no match for the steam powered ships and superior firepower of the British" (Grasso 38). Given that the very same waterway also propelled Britain to the position of commercial leader, it is little wonder that the infrastructure of Hong Kong is also replete with constructions that support this maritime movement: "des docks" ['docks']; "des wharfs" ['wharves']; "des entrepôts" ['godowns']. As a result, one sees the novel remarking that a majority of Chinese commerce transits through Hong Kong.

Serving as the foundation stone for the British colonial expedition, the river as separation aggrandizes the colonizer's position. While the constructions serve to anchor Hong Kong into an image of the colonizer, this image is fixed into a state of perpetual greatness by the means of a "constructed" distance, which, as it becomes the basis of Hong Kong's continued mercantile success, also serves to isolate Macao on the other bank of the river. This "other" side ['l'autre rive'] should also be understood as the other side of the prosperity the river signifies, and also, the humbled side of this commercial battle, not endowed with tools of maritime commerce.

While it might seem separated by a physical distance, Macao is inseparable from Hong Kong and its colonial greatness. Macao's presence in inferiority is a necessary corollary for anchoring Hong Kong's glorification in constructed structures. What Hong Kong and Macao in their hierarchy establish is the subservience of the local geography that has been carved to the demands of a commercially defined colonial essence.

The means of transport described in Hong Kong serve to draw a binary opposition. The association of nonmechanical palanquins and wind-driven wheelbarrows with an ancient name for China ("céleste empire" ['Celestial Empire']) that evokes divinity ${ }^{103}$ is clearly in contrast to modern infrastructure in Hong Kong, conducive to the movement of mechanized transport. This association 
of temporal opposition of the means of transport simultaneously exoticizes and relegates to the past all that is nonmechanical and celebrates all that reinforces Hong Kong in the hypothetical commercial battle. This preference for mechanization stands as proof for Ralph's (Fogg's fellow card player's) earlier stated contention about the interrelation between Earth's size and the changing face of transportation. Additionally, it also displays how means of transportation are the shaping mechanism of a new Earth. Not only means of displacement over space that reduce travel time, they are also temporal milestones that document the passage to a new Earth of reduced dimensions.

"[E]ncore en faveur" ['still in use'] crystallizes the temporal separation between the two kinds of transports. Where Hong Kong's current commercial prosperity is ascribed to British-type transport, "encore" ['still'] establishes a chronology of superiority where manual labor predates and eventually cedes place to the mechanical force - associated with the "génie colonisateur" ['genius for colonization']. This is an ameliorative history, where the two oppositional transports are designators of a past and a colonial present. As their host, Hong Kong finds itself suspended in a state of anachronism; its landscape witnesses the coexistence of two distinct moments of history on the same temporal plane such that its presence becomes an excuse for the colonizers' aggrandizement. Alternatively, this is a dehistoricized Hong Kong, disengaged from its own historical trajectory and in motion toward the colonizer's temporal plane.

The amplification of nouns illustrates the colony's dependence on the progress carried out by the colonizing genius. It is "Angleterre"104 ['England'] that takes possession of Hong Kong designated by the diminutive "îlot" ['small island']. But it is the subject of the second sentence, "Grande Bretagne" ['Great Britain'] ${ }^{105}$ and its "colonial genius" that transform the "îlot" ['small island'] of Hong Kong into an "île" ['island'] by establishing and creating an important city.

If Macao was indispensable to prove Hong Kong's superiority, then Hong Kong now serves to explain the power of Great Britain. From a small island, Hong Kong is transformed into an island at the same time as England becomes Great Britain. With the increase of the influence of colonial power, the physical dimensions used to refer to the colonizer also increase, only dwarfing further the contours of the "îlot" ['small island']. In the new interconnected colonial world, Hong Kong's transformation by Great Britain is a sign of latter's global influence. While this draws out the growing colonial interconnections between two disparate geographies, it also aptly demonstrates the indispensability of Hong Kong's existence as a diminutive that in its juxtaposition augments further Great Britain's contours of a larger island. 
This hierarchy of size is only one part of the equation of colonial spatiality; the other part draws out the necessity of viewing the colonized territory as conquerable and secondary to the colonizer. Colonial landmarks, enumerated as plural forms ("Des docks" ['docks']; "des hôpitaux" ['hospitals'] etc.), attest to the enormity of the growing colonial influence and to the reproducibility of such spaces. The plurality of these common nouns takes over the uniqueness of Hong Kong. These lexical items are easily replicable from the location of one proper noun - Kent or Surrey - to another - Hong Kong. Thus, the colonized space resembles Kent or Surrey - rendering the island a site of recreation of British nationhood. Instead of digressing further into how this also typifies the way most colonizing literature sees colonies as either units for the spread of religion ("cathédrale gothique" ['Gothic cathedral']) or governance ("government-house" ['Government House']), let us get back to the very first moment of contact between Hong Kong and its colonizer.

\section{Illegal Opium and Colonial Wealth}

Before I continue to discussing how this equation typifies much of the novel's desire in projecting the colonized territory, a quick word about the narrator-like voice in the background that creates through the literary structure its own sense of temporality and temporal understanding. Foucault assesses Verne's text as made complete by different speakers recounting the narrative in the background. The elaborate unfolding above of details regarding Hong Kong - both spatial and temporal - reminds us of one of these "voix sans corps" ['body-less voices']. It links the novel to the world of the reader as it enumerates details and events from the reader's world. ${ }^{106}$ The "body-less voice" presents Hong Kong via coordinates that recall Great Britain. From historical signposts of 1842 and the "treaty of Nanking" to the spatial reminders of a colonial city, all locate a universe familiar to the reader.

This alternative chronology that serves as a background to the narrative puts the author in a tacit understanding with the reader regarding a mutually accepted sense of historical occurrences that Foucault calls a "chronologie objective" ['objective chronology']. In acknowledging one of the author's historical moments of 1842 , the reader is in direct conversation with Verne; both agree about a time frame exterior to the fictional narrative.

This piggybacking by the fictional of the historically verifiable scaffolds Benedict Anderson's notion of "empty time," one of the principal ideas of nationalism. A perceived temporal simultaneity forms the backdrop of the nationalistic 
feeling shared by individuals identifying themselves with, and living in, the same political boundaries of a nation. ${ }^{107}$ Anderson explicates empty time through the example of fictional literary texts that present historical details verifiable by the reader. This, he says, creates "empty time," a common chronology where both the fiction and the reader coexist alongside a fictional backdrop. By analogy, according to Anderson, the very same idea is manifest in a nation where the nationalistic feeling claims the right to a common temporal unfolding for all its citizens. In the present case, "empty time" demonstrates a nineteenth-century sense of nationalism as it clearly postulates the island of Hong Kong as an extension of British history and political boundaries.

The very first sentence of the long quotation I have been discussing has two place names at its extremities, where the first - Hong Kong - is subordinated to the latter - "Angleterre" ['England']. All that the novel tells us about Hong Kong's origins is:

Hong-Kong n'est qu'un îlot, dont le traité de Nanking, après la guerre de 1842, assura la possession à l'Angleterre.

[Hong Kong is but a small island, which the Treaty of Nanking transferred to England after the war of 1842]

Apart from the net of spatial markers that ties Hong Kong to its colonizer, it is the "war of 1842" in between the two ends of this sentence that clarifies Hong Kong's status as a possession. As it mediates in this sentence between the two colonial entities, this war (and its ensuing consequences) is at work in much of this novel's knowledge of Hong Kong. In fact, it is the understanding of not one but two conflicts that allows us a better comprehension of the island. It is the second, a hypothetical commercial battle where Macao would have lost, that sustains the results of the first war by maintaining Great Britain's supremacy and Hong Kong's existence as a port of commerce. It is the first - the bloody battle of 1842 culminating in the Treaty of Nanking - that is of interest to us because it forced China to cede Hong Kong to the British, who turned it into a commercial port. Beyond just exhibiting the superior British force, this conflict laid the groundwork for the eventual shape the region would take.

More than in the exact dynamics of the colonial victory, my interest lies in opium, the trigger of this war. In the way the novel unproblematically relays the Hong Kong-Great Britain connection by omitting the role that opium played in the war that led to the island's transfer from China to Great Britain, 
one would have no reason to probe the link. When Aouda's passage from India to Europe too is marked by and even facilitated by an itinerary prepared by an opium economy, the importance of analyzing the role the drug plays in this voyage around the world becomes self-evident. While it apparently criticizes opium as a colonial vice, the novel itself is thoroughly implicated in its propagation: a proliferation that is never overtly accounted for and that always operates in the surreptitiousness of "opium silence." I hope to illustrate, firstly, that the silence of opium is the founding principle in operation in the novel's description of Hong Kong. Secondly, that this silence is nothing but a parallel of the opium-related historical reality at play in the region. What I wish to demonstrate is that opium could only have been present in the novel through its conspicuous absence. This paradoxical manifestation of opium, the reasons for its silence and its implications for colonial subjectivity is what I chart out in the discussion that follows about Hong Kong's origins.

In the given quotation, Hong Kong is indistinguishable from any of the other urban centers in the counties of Kent or Surrey. With a list of over dozen place names ${ }^{108}$ and an even more copious enumeration of spatial markers, ${ }^{109}$ the quotation successfully establishes Hong Kong's credentials as a British space. However, how the island came to be colonized and the exact beginnings of this association have been relegated to a single historical event: the war of 1842, a date that stands out in its sketchiness.

If there were any doubts about the power equation between the two entities of the colonizer and the colonized, then this date puts them to rest as its interests in Hong Kong go only so far as the island's association with the British Empire. For the purposes of this novel, Hong Kong's origins lie in the moment when it came in contact with the colonizer. Interestingly, the war that resulted in the treaty of Nanking actually started in 1840 and it is its culmination date of 1842 that figures in the quotation. Curiously enough, while this date privileges only the year of contact between the two entities, it also raises the question of why apart from the result of the British emerging as victors, no further details regarding the reasons for the commencement of hostilities or its continuation are forthcoming.

Of the many consequences of this war, the only one brought to light is the concession of Hong Kong to the British Empire. In this construction-heavy reference to Hong Kong, the sole temporal reminder of the island's history too has been presented as a reference to a spatial takeover. While it speaks volumes about the spatial obsession of the colonial project, Hong Kong's presentation is a case in particular of temporal subversion to suit the demands of a spatial venture. The war of 1842 as a point in history is important only in so much so as it allows 
for an explanation of spatial supremacy over the island. This way Hong Kong's spatiality and history both exist as replications of the colonial identity.

The war of 1842 is in fact better known as the first of a set of two opium wars that changed the shape of the colonial map in the region. As the name suggests, opium was at the root of this war and thus was instrumental in the formation of the island. Yet, in a quotation about Hong Kong's foundation, in a move symptomatic of this novel, not only has its role been overlooked, the word "opium" itself has been omitted from a name - the Opium War - in which it has earned a permanent place. Opium was the one product that was clearly fiscally more important to the British government (and the colonial project, one might add) than even the health of its subjects.

Before England definitively regulated opium's use in the early twentieth century, profits accrued from it overshadowed any considerations of restricting the drug's usage in the British society. So much so that during "the nineteenth century opiates were probably more extensively employed in England than in any other European country." 110 While China's first edict banning the usage of opium "appears to have been issued in 1729,"11 Britain continued ignoring the drug's harmful effects despite the fact that "opium and its preparations were responsible for more premature deaths than any other chemical agents" (Lomax 168).

Looking at the praise the medical journals were heaping on opium, one might think that the medical community was unaware of its ill effects. On the contrary, these journals also carried "almost as many references to the toxic nature of opium” (Lomax 168). It was not the lack of resistance against opium that allowed its proliferation; it was rather the business interests of the pharmaceutical community that prevailed. Despite the loss of human lives, nobody wanted to restrict a drug whose exceeding popularity was the cause of an increasing pharmaceutical business: "Even the government was not disinterested, since it supported the lucrative opium trade between India and China, without regard to the health of people of either country" (Lomax 176).

The government was slow to recognize the fallout of an unregulated drug that, as was to be expected, caused many deaths, with a particularly devastating effect on the infant population. Elizabeth Lomax explains how ignorant and poor working mothers from manufacturing districts liberally employed opium as an infant sedative. If the 1839 coroners' returns from England and Wales are anything to go by, of the 182 people who died of opium poisoning in 1836 and 1837,72 were children. The legislature did present a bill in 1857 , and passed a much watered-down version in 1868 , but the final legislative reprieve was to come later in the form of the Pharmacy Act of 1908. 
Nineteenth-century Britain used economics as the sole guide while dealing with opium domestically and adopted the same approach overseas in relation to its colonies. ${ }^{12}$ The British government had assumed "a monopoly over the sale of opium in their dominions" and the production of opium in India, "in Bengal directly under the aegis of a Governmental administrative monopoly" (Greenberg 105). It also forced the Chinese to buy the drug. Almost to the very moment the above statistics on opium-related infant deaths were being collected, Great Britain was preparing the groundwork for the beginning of the First Opium War in 1840. When one sees that William Jardine (in the same year, 1840) defended his character "as the leading opium merchant" by citing how declarations in both Houses of Parliament were repeatedly asserting that "it was financially inexpedient to abolish the trade," 113 one can well imagine the devastating effect opium might have had on British colonies.

Opium's significance should be obvious from the fact that the map-altering First Opium War was a direct result of the illegal opium trade by British traders in China. ${ }^{114}$ June Grasso et al. point out how initially they were restricted to the port city and forced to trade with the Chinese on their terms. The lopsided trade dynamics worked against the British: "while there was a large British demand for Chinese goods - especially tea - there was little Chinese interest in British goods." But as their position strengthened, the foreign traders, taking advantage of the weak political situation in China, compensated for their loss by trading in illegal opium. The "opium trade probably had become the largest commerce of its kind in a single commodity in the world" (Grasso 29).

Throughout the course of these business dealings the battle lines were drawn, not so much on territorial boundaries but along the right to sell opium. In the run up to the $1840 \mathrm{war}$, tired of increasing restrictions by China on the opium traders, Jardine repeatedly exhorted the British government to act militarily in order to secure favorable commercial conditions. Implicit was the demand for an imposition of the traders' interest on Chinese sovereignty. The government, however, would have none of it. In a letter sent out as reply in 1835 to one of Jardine's entreaties, it was made clear, not surprisingly, that the government was "not prepared to take such a step so long as the revenues which derived from the China trade continued to be provided" (Greenberg 197). However, once it became clear that opium trade was at a risk of coming to a standstill and in turn paralyzing the entire trade with China, the government had to step in and assert for dealings on its own terms. Over time, the "[i]llicit opium traffic" combined with the "British insistence on regulating trading relations on the basis of Western law, became an internal political issue" (Grasso 36-37), which 
would later result in a military conflict that the British forces won. One identifies the treaty of Nanking (the treaty the above quotation refers to) that followed the war as one of the "unequal treaties' that opened China to imperialist exploitation." Some of the clauses "were particularly injurious to China and were accepted only because the mandarins were at the wrong end of the gun." More importantly, for the purposes of my argument, it is noteworthy that "[ $\mathrm{f}]$ ive ports were opened for trade, gunboats and foreign residence [...] [and] Hong Kong was ceded to the British and was made a free and open port" (Grasso 39).

This treaty is a perfect example of colonial capitalist machinations conquering the space of the world. The very existence of Hong Kong as a part of the British Empire took place using force, and with an eye on the balance sheet. After its acquisition, the island played a pivotal role in opium trade. The British made sure that "Hong Kong remained the first port of call for vessels from India and the center from which the drug was relayed to the mainland." 115 What followed as Hong Kong's success story the novel has already relayed to us. Of all the consequences of a colonial Hong Kong, the most significant was the opium-generated economic turnaround of British India. By the time the crown assumed control of India in 1858, "the opium revenue, next to that from land and salt, was the largest single increment to the Indian treasury, aggregating something over one-seventh of its total income" (Owen 282-3).

In the entire discussion, what is of interest is that the representation of Hong Kong, dedicated to the colonizing genius, glorifies abundantly its great advances and conspicuously ignores opium's role in describing both Hong Kong's origins and its economic transformation. That Hong Kong played the clinching role in assuring the colony of India a substantial portion of its income would have furthered glorified the British colonial genius; yet, all mention of opium in this topographical rearrangement has been omitted. Or, has it?

\section{Opium Cities}

The above description could be uncritically read as a positive presentation of the British Empire: by presenting the effortless triumph over Hong Kong it ignores all opposition and advances the image of an unopposed colonizer. That it is no doubt the case, but there is more to it.

Similar to the secretive yet rampant opium contraband that led to the colonization of the region, this novel too creates an invisible spatial net held in place by the silent colonial opium. Apart from the obvious reference to the opium-triggered 1842 war, what entrenches the above description, and the novel, 
further into a drug related economy are the colonial cities it references - all of them (Hong Kong, Calcutta, Bombay and Singapore) directly enmeshed in proliferating the British trade of opium in China.

As mentioned, after the "emperor's edict of 1729, the East India Company decided not to jeopardize its lucrative role in the tea trade by continuing to carry opium to China." And although opium "could be grown in India only with the Honorable Company's permission" (Janin 37), it was "private 'country' traders (often Parsees or Scots) based in India or Western firms based in China itself [that] bought the drug at government auctions in Calcutta and arranged for its onward shipment to China" (Janin 57). While Hong Kong, occupied by the British, was extremely significant to the trade, it remained second to the Indian city of Calcutta (Le Failler, 44). ${ }^{116}$

Calcutta is the city that Baudelaire was headed toward, but that he never reached. As a spatial benchmark this demonstrates its importance - the city boasted the advantage of a seaport facilitating the shipping from India - a distinction it shared with Bombay. Of the two major varieties, the "opium produced in Bengal [...] was sent to Calcutta to be auctioned off" and the Malwa opium from the "native states of central and western India," after "it had reached Bombay [...] was transshipped to China" (Janin 38-9). While it drained China of its resources and caused an outcry on grounds of morality, ${ }^{117}$ for British India, opium brought a much-needed economic boom. In other words, 'China went in to deficit for India's profit ${ }^{\text {'118 }}$ Even Karl Marx pointed out how opium-generated money resulted in a richer colonial population capable of buying the increasing British exports. ${ }^{119}$ Singapore, the fourth and the final English city, with its location on the opium route between Calcutta and China, was only a logical stop for clippers of the drug trade: 'The fleet of clippers doing the Calcutta-SingaporeChina doubled between 1842 and 1858 [...] interval between the Opium Wars was the golden age for big traders.'120

While Singapore's contribution, as is obvious, was significant to the trade, opium's benefits to the island were not insignificant either: 'It won't be an exaggeration to consider the opium traffic as the founding business of the colony.'121 This all-around economic success was the product of a mandatory passage of opium through these cities. The unmentioned, the unspoken, even as it turned around the British Empire's economic health (Le Failler 33-4), opium trade was always carried out surreptitiously.

Establishing Hong Kong as a result of the 1842 war allows to understand how the spatial indicators enumerated above are all implicated in opium's production and transportation. Juxtaposing multiple locales and reading them in 
relation to their contribution to the clandestine opium trade brings forth their mutual interaction. Dispersed over an empire, when assembled together, the interplay between these cities illustrates the making of space articulated as a process, where one contributes to the other, much like each link making up the totality of a chain. So, when Hong Kong is described as yet another element in a series - "encore Bombay, Calcutta ou Singapore" ['Bombay, Calcutta, or Singapore all over again'] - the idea is also to understand these cities as implicated in Hong Kong's creation as much as the latter is another link of the chain they comprise. This network of cities, as it describes the spread of a colonial capitalism, presents also the attendant spatial abstraction. This is a globe that can be measured and scaled. These cities are appropriated into a matrix of hierarchy that reorganizes them in terms of their relevance to the opium trade and the fiscal demands of the colonizing power. Hong Kong reminds of the point of origination of this trade - Kent and Surrey - and not the other way round.

This is a classic example of a moment at which the production of a space Hong Kong - dominoes into the creation of a new subjectivity. The description continues unceasingly to reconstitute alterity when it recognizes the existence of different identities (Chinese, Japanese, European), but also empties them of all meaning by presenting Hong Kong as resembling very closely ("à peu de chose près" ['with a few exceptions']) a string of indistinguishable spaces. If, despite their existence, it is the island's dissimilarity that is accentuated, then it goes to say that the sum of their individual differences remains subservient to the unproblematic similarity at the global scale imposed by this "trainée de villes anglaises" ['trail of English towns'], of which Hong Kong is an indistinguishable part. This paradoxical identity creation exemplifies the dislocation carried out by abstract spaces on human subjectivities. While Chinese, Japanese and Europeans might exist on the island of Hong Kong, what matters is their contribution to the enhancement of overarching British capitalism. Similarly, as it attests to the existence of Hong Kong's uniqueness in the two means of transport palanquins and wind-driven wheelbarrows not found elsewhere, the description almost instantaneously finds a means of dislodging this alterity by articulating identity in terms of structures of Britishness.

Apart from demonstrating the economic transformation of the region, this depri(a)vation of identity through structures underscores the relevance of spatial markers to subjectivity formation while revealing the beginnings of abstraction of space, where spaces, and in turn subjectivities, are homogenized into an exchangeable similarity. One can be replaced by another and understanding one entails the understanding of all. ${ }^{122}$ This apparent contradiction of a simultaneous 
homogenization and hierarchy of locales provides an eloquent instance of the paradox of abstract spaces. For in resembling closely with "a few exceptions" and not exactly, this displays how abstract space "is not homogeneous; it simply has homogeneity as its goal, its orientation, its 'lens'” (Lefebvre, Production; 287). Hong Kong illustrates the coming into being of an alternate matrix, which, as I have shown, aims at endowing the world with "the flatness of a mirror, of an image," ordered "under the absolute cold gaze" (287) of Passepartout. Passepartout walks in a manner that it is his "lens" (both vision and perspective) that orders Hong Kong into an accumulation of constructions.

With the neutralizing of each annexed spatial component such an operation sets into motion the intrinsic repetitiveness of spaces of capitalism. As a new entrant into a world organized around urbanity, Hong Kong displays all the characteristics of a modern city. Belonging to a growing imperial capitalism that centers on opium, through their similarity, the constructions on the island, and the island itself, reproduce the inherent repetition associated with such spaces of abstraction. ${ }^{123}$ It was much later in the first half of the twentieth century that Walter Benjamin would discuss the loss of aura in works of art that were reproduced mechanically. ${ }^{124}$ For sure, Jules Verne's serial fiction is a classic example of a mechanically enabled, mass produced literature, that "paralleling nineteenth-century capitalism" was institutionalizing "delayed gratification." 25 More importantly, just like his literature that both speaks of and is a product of mechanization, these cities too, are produced by and situated through mechanical markers. These cities are already in the process of losing their aura, not in the sense of losing an authentic essence that would reduce these locales to an identifiable anchor, but in the sense of being incorporated into a spatial grammar of replication; existing as enablers of the process of mass production, they are themselves mechanically produced realities. Or, at least, that is how I would understand Hong Kong, and these cities, being produced discursively by a grammar of docks, wharfs and roads.

To recapitulate, the silence on opium's relevance in the articulation of these cities redeploys its conspicuous presence in every aspect of the region: without opium there would be no basis for colonial cities; they would not exist, let alone existing in interrelation with each other. If opium were any other product, its omission would hardly be a cause of concern, but the silence in this matter, as I have been insisting, remachinates the dynamics of opium's absence. Always the motor that propels business in the region, it is never recognized, and even as it causes the war, opium retains its silence. 


\section{Opium Race}

To end the First Opium War in order to avoid further loss and to "end hostilities, the Chinese were forced to sign the unequal Treaty of Nanking," 126 which, as the above discussion reminds, was responsible for the formation of a colonial Hong Kong. One knows that "the treaty never mentioned opium, however, the war effectively protected drug interests" (Marez 24). It would be safe to read Verne's novel as a literal enunciation of the politicogeographical language of silence that defined opium historically in relation to Hong Kong. The literary, in obfuscating opium's presence, is in fact performatively playing out opium's correspondence to real life. Verne's novel, through its silence, reminds us that while opium and the Opium War would perpetuate what Immanuel C. Y. Hsu calls China's "semicolonial status" ${ }^{27}$ (192), opium itself always moved unacknowledged through Hong Kong.

To be fair, it is not as if the novel is completely oblivious of the nefarious effects of opium. Describing a smoking den in Hong Kong, Le Tour du monde en quatre-vingts jours exclaims how the colonial business was selling hundreds of millions of francs worth of opium. The novel also holds the drug squarely responsible for the health of "millions" - all of whom were affected by "un des plus funestes vices de la nature humaine" ['one of the deadliest vices of human nature]' $(143 ; 98)$. Although an apparently genuine criticism of opium, this does not in any way contradict its workings in the formation of Hong Kong.

In a novel where the overall portrayal of colonial superiority presents a predictable corollary of Verne's beliefs that colonization "is one of the aspects of progress," ${ }^{28}$ this seeming criticism of opium reflects the true nature of the paradigm that Verne utilizes to deal with ideas of colonial Otherness. Despite all its ills - opium most likely included - colonialism for Verne presents the opportunity of taking "possession of nature, to exploit new territories in the interests of economic and technical progress" (Chesneaux 26). Hong Kong in this equation becomes an unavoidable and imminent product of this opium-generated colonialism.

The above reasoning is still insufficient for one crucial reason: the two mutually disparate presentations - the ills of opium and the formation of Hong Kong - are laid out in the novel with nothing mediating between them. That they are complementary products operating as part of the same mechanism that created Hong Kong is unproblematically relayed, with no attempts at making the connections. In a restricted presentation, Verne's novel completely discounts the colonial process by only partially acknowledging opium's presence. This way, 
Hong Kong remains a colonial accomplishment having no apparent relation to the opium trade. Opium in the novel must necessarily be portrayed as an unrelated detail. What, might one ask, provokes such a presentation?

It should not be a matter of surprise that Verne's novel, published in serialized form, documents colonial victory without mentioning the opium wars. Not only Verne but even his literary colleagues experimenting with serialized literature in England were representing the triumphant march of civilization in Asia without any reference to those historical events. Marez points out how, instead of reckoning with the historical reality, opium den narratives in the English mass culture circumvent the associated violence by almost never mentioning the Opium Wars. Two worldviews come to meet in the opium den narratives, where facts become acceptable through their transformation into fiction. This striking omission then falls into a pattern defining the enabling condition of literary works contemporary to Verne. Much like the opium den literature, Verne's novel "exists side by side with" the knowledge of British conquest, "but it denies the history of conquest by splitting from it" (Marez 69). It fits into the larger picture of literature devoted to the colonial project. The Opium War of 1842 as a key moment that fashions the colonial map that is responsible for Hong Kong's colonial character is not only conspicuous by its absence; it is through its absence that it displays the exact dynamics of the colonial undertaking in the region.

In these dynamics, Inspector Fix enacts the colonial control over opium as he intoxicates Passepartout, hoping thus to delay his departure from Hong. As a victim, Passepartout plays a fixed script. He cannot counter the monopoly of the inspector over the usage of opium in Hong Kong. After all, Fix was a representative of imperial authority. ${ }^{129}$ Situated in colonized Hong Kong, this opium den reanimates opium's history and its silent literary representations. As if to remind us that opium always acts in silence, Fix too - clandestinely - "en glissa une dans la main de Passepartout" ['slips a pipe into Passepartout's hand'] 130 (149) - thus effectively separating the servant from his master, at least for a part of the journey. The power dynamics of the region demand that the empire's power, working through this officer who manipulates opium surreptitiously, be on display and in effect on the island of Hong Kong. This apparent linkage between opium and Hong Kong could have been passed off as a literary coincidence, had it not been for Aouda's liberation - not only from the superstitious fury of the indigenous people but also from the grasp of opium. The political power structure both assures Fix a command over opium and also imposes a racial hierarchy. In what follows I discuss how Aouda rises further along a racial ladder by purging herself of opium. Hong Kong plays the decisive role in launching her toward Europe. 
Marez provides the beginnings of a racial equation associated with opium that explains Aouda's evolution from the exotic. What is at stake is a clear racial division imposed by opium. As if affirming Marez's conclusion, there is Inspector Fix who, just like the other colonial observers in these narratives, keeps his distance from opium consumption and symbolically recoils "from direct participation in the imperial system the opium den represents" (Marez 64). Yet, colonial authority benefits from imposing opium on unwilling victims: the British gain fiscally at the cost of the Chinese, and Fix benefits by delaying Passepartout.

Continuing with the same logic, Aouda is rescued not only from death but also from opium. As the adventurers are moving across the colony of India, they come to know of a woman of noble background, who, after the death of her husband, is to be consigned to fire along with her husband's body on the funeral pyre. Summoned to his gentleman's duty, Fogg decides to rescue Aouda, and after futile attempts to locate her family, he brings her back to London. As in several other literary works written during colonization, Aouda's rescue too could be read as an excuse to put on display the white man's inherent moral superiority: Fogg saves from the clutches of native barbarians a native woman, who otherwise would have been dead. But Aouda isn't after all a typical native woman. She is a "charmante femme dans toute l'acception européenne du mot" ['an attractive woman in the full European meaning of the word'] $(103 ; 71)$. So much so that one would have taken her for European ("l'eut crue Européenne" ['thought her a European'] [91;63]).

On her initial introduction, Aouda displays the racial characteristics associated with white women exposed to opium. In the opium den narratives, white women "seem especially prone to Asian capture." Falling for opium is a sure way for white women to be denigrated into fulfilling the vices of Chinese men. It would seem that their association with the drug is inversely proportional to the loss of their racial status: "cohabitation with opium-smoking Asian men caused certain women to shed their whiteness and assume a degraded new 'Oriental' visage" (Marez 65). In Aouda's case, however, this journey is carried out in the opposite direction, such that in moving away from opium's effects she finds her companion in a white man.

As a sati, before being consigned to the flames of her husband's funeral pyre, she was subjected to the fumes of opium and hashish. Aouda can barely support herself and makes her appearance as an intoxicated woman in the clutches of the Brahmins. To set her free would mean not only liberating her but also bridling the power of opium. This happens when the opium-induced intoxication of the Indians allows the adventurers to make possible Aouda's rescue: 
Suivant leur habitude, ces Indiens devaient être plongés dans l'épaisse ivresse du 'hang' - opium liquide, mélangé d'une infusion de chanvre -, et il serait peut-être possible de se glisser entre eux jusqu'au temple. (92)

[As was their custom, these Indians were lost in a haze of hang - liquid opium mixed with an infusion of hashish - and it was perhaps possible to slip through them and reach the temple. (63)]

Her introduction in the novel happens at a moment when she, as well as her relatives, are under the influence of opium. These white men take advantage of Aouda's relatives' opium-induced intoxication to rescue her. This display of opium in the cause of whiteness does not of course surprise, for that has been the underlying theme of what I have already said. This backward movement away from opium and toward civilization shows how the indigenous are easily categorizable human beings who exist in hierarchies. They are a blundering savage people who celebrate the idea of human sacrifice and then display their complete ineptitude in carrying it out. There is no doubt that these practices, and many others of such order, did plague the Bundelkhand region during the period described in the novel. Regardless of their veracity, what interests us is the interrelation drawn between the absence of English control and the presence of these practices. Below is an exchange between Fogg and Sir Francis Cromarty about the practice of sati in India:

- Comment! [...] ces barbares coutumes subsistent encore dans l'Inde, et les Anglais n'ont pu les détruire?

- Dans la plus grande partie de l'Inde, répondit Sir Francis Cromarty, ces sacrifices ne s'accomplissent plus, mais nous n'avons aucune influence sur ces contrées sauvages, et principalement sur ce territoire du Bundelkund. (88)

['Can it be?' [...] 'These barbaric customs survive in India, and the British still haven't been able to put an end to them?'

'Sacrifices don't happen any more in most of India, [Sir Francis Cromarty replied,] but we have no influence over these wild kingdoms, especially in the State of Bundelkhand.' (61)]

In turning to a country where the scale of civilization (in this case, savagery) is a function of the British control, Verne's novel posits a worldview whose operation 
is already manifest in the presentation of other locales. Much like Hong Kong's success is a product of English control, Bundelkhand's savagery results from the absence of such control. This, no doubt, is emblematic of much of exoticizing colonial literature, which while perceiving the uncontrollable and the inexplicable as a threat also appreciates all that is suitably white - as happens with Aouda's whiteness.

Throughout the course of her rescue and her eventual marriage proposal to Fogg, it is by distancing from opium that she achieves affinity with Europe. Needless to say, her fundamentally European physical characteristics and upbringing tipped the scales in her favor. She was after all, as has already been stated, "une charmante femme dans toute l'acception européenne du mot" ['an attractive woman in the full European meaning of the word'] (103; 71).

A product of and changing toward Europe, Aouda is the embodiment of transformation in process, ${ }^{131}$ who, in responding to the pushes and pulls of colonial opium, follows its geographic trajectory toward her ultimate Europeanization in London. She comes to be part of a power paradigm that disallows contact with subjectivities beyond its realm, and accounts only for a Fogg-Aouda-like self-reinforcing union. Instead of losing whiteness because of the drug, she gains Europe as she is liberated from opium, and thus verifies the correlation between racial identity and opium.

Her parentage reinforces her apparent superiority. She is related to the wellknown Parsi, ${ }^{132}$ Sir James Jejeebhoy, who was accorded his title by the colonial government. In fact, she accompanies Fogg to Hong Kong, hoping to seek help from a cousin of Jejeebhoy. This small island of Hong Kong occupies a disproportionately large space in the novel's topography. In Hong Kong, where she hopes to find support from her relative, she learns of him having shifted base to Europe - Holland. It is thus in Hong Kong that Aouda's decision to continue to England is taken for her, doubly underscoring the city's relevance to the opium map.

The possibility of this adventure presupposes a centrifugal world, moving away from the center; its every move verifying the center's existence. In this case, Aouda's itinerary passes through Hong Kong to London. As the island displays signs of its determining matrix, Hong Kong also justifies its own role within the grid. If Hong Kong had been an isolated creation, Aouda's passage would have generated little thought, but Hong Kong as an agent of the British Empire, as shown in our discussion, is an exercise in infectious mutation and thus has to garner reinforcing elements. This would explain why Aouda's decision in favor her onward journey to Europe is made for her in Hong Kong. As events prove, instead of being a temporary stop, London, where the besotted Fogg stays, becomes her future home. 
Identified already as superior among the indigenous people, Aouda, instead of just remaining "like" European, now justifiably owns her European identity. Hong Kong, presented this far as a mediated identity - a construct - becomes a mediator between a dangerous India and London, where a stable subjectivity emanates. In between the two ends are located not only the sojourns of this journey but also a definition of the process that triggers their creation. The journey animates a center that, while redefining these spaces, also pushes them to a state of abstraction, institutionalizing its own relevance. So, in moving up (or perhaps being pulled up) the spatial ladder toward London, Aouda retraces and reinforces the flow of the power of the center.

In this entire equation, as much as Hong Kong holds a justifiably substantial position, it models the prevalent pattern of representing alternate spatial identity during this voyage. In other instances, too, the novel furnishes yet other spatial Others who exist as extensions of the colonizer. Yokohama, for example:

une cité absolument européenne, couvrait de ses rues, de ses places, de ses docks, de ses entrepôts, tout l'espace compris depuis le promontoire du Traité jusqu’à la rivière. Là, comme à Hong-Kong, comme à Calcutta... (174)

[an absolutely European city: houses with low fronts adorned with verandas on top of elegant colonnades. Its streets, squares, docks, and warehouses covered the whole area between the Treaty Promontory and the river. As in Hong Kong and Calcutta... (119)]

With "européenne" as its key trait, this presentation situates the Japanese city with a nearly identical enumeration and establishes it via other colonial cities, reproducing the Hong Kong paradigm. Monghir too, more than European, as seen earlier in India, recalls the importance of colonial industry, and is articulated - once again - as a replication of the English cities:

Monghir, ville plus qu'européenne, anglaise comme Manchester ou Birmingham, renommée pour ses fonderies de fer, ses fabriques de taillanderie et d'armes blanches. (107)

[Monghyr, a town which is more than European, being as British as Manchester or Birmingham, renowned for its iron foundries and its factories for edge tools and knives. (74)] 
At the risk of overstating the obvious, Monghir's presentation, with its factories, displays all of Hong Kong's symptoms. Not to mention that the reason for the city's importance is its opium market, which assures it also a place in the silent opium economy.

Verne's novel demonstrates through this spatial wealth the predominant genius for colonization, and puts on display the changing geographical "meaning" of the world. What emerges from the above discussion is the consistent pattern of a mathematical European identity - defined commercially - that provides the template for apprehending the "meaning" of spatial alterity. The homogenized features of this template serve to configure these locales according to a global matrix of spaces rendered interchangeable for the smooth passage of opium. It is thus that Hong Kong, having achieved technical as well as financial progress as defined by the coordinates of this matrix, becomes an obvious example of the colonizer's power.

In order for this perceived mimicry to glorify the colonial power, these spaces need to be almost, and not completely, like the spatial self ("À peu de choses près" ['With a few exceptions']). This expectation of colonial mimicry from the Other is "the desire for a reformed, recognizable 'Other', as a subject of a difference that is almost the same, but not quite" (Bhabha 235). Not quite because this "desire" postulates the colonized subject as a "partial" presence within the colonizer's construct, which confronted with unfamiliar coordinates can only reckon with the known, treating the slippage as an undesired sedimentation. ${ }^{133}$ This spatial Other, which in this equation is "not quite" the same, becomes a site of lack. This spatial Other exists in a process of colonization that leads to a reformed state resembling the image that one has of the self. While such a move celebrates the familiar in Hong Kong as proof of colonial accomplishment, all that escapes comprehension is relegated to an "autrefois," another time associated with an antiquated China. Identity is redistributed along an axis that, while desiring a familiar, forever disarms the spatial Other of its difference. ${ }^{134}$

Arjun Appadurai speaks about how, in the contemporary world, globalization exists as a "definite marker of a new crisis for the sovereignty of nation-states" (4). ${ }^{135}$ Literary geography in Verne's work attests to the formative moments of this global network when nation-states and the accompanying nationalisms, working in consonance with capitalism, were laying the groundwork for a system whose hegemonic nature would assume the overwhelming proportions of contemporary twenty-first century fiscal globalization. This chapter, through its readings of the literary geographies associated with the colonial opium economy in Le Tour du monde en quatre-vingts jours, lays out the warning signs of the crisis Appadurai talks about. What one witnesses are the operations of a nascent network, invested 
in the market forces of opium's demand and supply that would eventually impose homogenization and rationalization on the entire planet. It is such imposed geographies that literary works discussed in later chapters of this book respond to.

Although Fogg himself might claim no apparent capital accumulation, in returning back to London - the point of departure - having gained nothing financially, he displays through his journey not only the path taken for the accrual of imperial capital and the acquisition of colonies but also represents a literary colonization of geographies. Just as the choice of locales in which Verne placed his narratives was determined by what was available in texts on geography, so do the manner of configuring these locales, their mutual interaction, their raison d'être and their association with human beings also get filtered through a geography of colonization. Written at the height of colonization, with a worldview that colonially apportions the globe, the novel displays how the entire planet has become a commodity. As dispersed nodes of trade routes, the relevance of these colonies is a function of their contribution to the interconnected financial network that transports production as well as ploughs capital back to London, further buttressing the colonizer.

Verne wrote at a time when traveling to discover, or writing about traveling to discover, the unknown elsewhere and its inscrutable mysteries was a means of escaping the advancing modernity. Yet clearly, Fogg embodies a paradigm of predefined quantifiable literary geography that already knows what it is looking for and how it will define its encounter with the spatial Other. Nowhere is this clearer than in the confidence with which Fogg accepts the wager. Fogg knows, without ever having done this before, that the world is measurable. Instead of presenting the new, Fogg's journey exemplifies the inscription of the world within known coordinates. This mathematical and mechanical man is both the witness and the agent responsible for measuring out the entire world in the same manner as he has been doing in his daily life by taking exactly 575 steps with his right foot and 576 with his left, to reach his club. ${ }^{136}$

Even the adjective "eccentric," perhaps the most used to describe Fogg, serves as the very proof of the workings of this new entity. ${ }^{137}$ In a discussion about spatial and temporal connotations of Fogg's eccentricity, following one definition of "eccentric,"138 P. Schulman argues that the hero undertakes two voyages:

one that is purely mathematical ( 80 days) $[\ldots]$ and the real voyage, that is the one filled with discoveries of exotic countries far from the centre, London, characterized by the act of enlarging his own sense of geographical space. ${ }^{139}$ 
Schulman offers a connection of some significance when London as the center is opposed to the larger geographical space, the exact locales within which are important only to the extent that they contribute to enriching Fogg's knowledge base. For, this is exactly what the journey is proof of: a world reconfigured in relation to, and according to the desires of the metropolitan center. Eccentric also means moving 'away from the point considered as the center. ${ }^{140}$ For this chapter, Fogg is eccentric because he is the bearer of this decentered literary geography: he deflects his eccentricity onto these locales by defining them in relation to the metropolitan center and thereby decenters them, dislodging these locales from their axes.

In reading a novel written at the height of the colonial quest for spatial domination, this chapter has tried to assess the influence of spatial homogenization in the narration of encounters with hitherto unknown spatial alterity. If colonial space needs to be rationalized, so would colonial subjectivity need to be refashioned to suit its expansionist desires. That is why in this novel, where the local and the global are created in the image of the empire, Fogg can only exist as a mathematical entity, and Aouda as thoroughly Europeanized. 


\section{DISLOCATING THE INDIAN NATION: ANANDA DEVI'S HOMELANDS}

rien à faire rien à foutre des images désarrimées de nos terres

-Ananda Devi ${ }^{1}$

[to hell with all the disarrayed images of our homeland -Ananda Devi]

Le lieu est incontournable.

-Edouard Glissant ${ }^{2}$

[sense of place is uncircumventable

-Edouard Glissant]

Disneyland is there to conceal the fact that it is the "real" country, all of "real" America, which is Disneyland (just as prisons are there to conceal the fact that it is the social in its entirety, in its banal omnipresence, which is carceral) Disneyland is presented as imaginary in order to make us believe that the rest is real, when in fact all of Los Angeles and the America surrounding it are no longer real, but of the order of the hyperreal and of simulation. It is no longer a question of a false representation of reality (ideology), but of concealing the fact that the real is no longer real, and thus of saving the reality principle.

-Jean Baudrillard ${ }^{3}$ 
Unlike Phileas Fogg, who spent only the briefest time in India, scurrying back to Europe with Aouda in tow, Ananda Devi's recent characters travel toward India to stay, to enjoy, and to amble like tourists through its temple towns and crowded streets. Literary geographies of her work register how, during the intervening hundred and fifty years since Fogg's visit, capitalism has grown unbridled, passage across Earth's surface has continued becoming swifter, and India, now a nation-state in its own right, participates in a network that forges human subjectivities according to its overwhelming nationalistic logic.

Much like with the opium network, contemporary financial workings are not readily discernible. This is not due to an operational infancy that relegates capitalism to a surreptitious silence as one sees in Verne's work. By the time the millennium has turned, the forces of globalization have permeated each nook and cranny of human existence. Capitalism exists as a white noise, hardly noticeable in its pervasiveness, yet available, loud and clear, if you press your ear to the writings of those like Devi whose recent literature has expressed an aesthetics of resistance to this new order. This is an order whose contours remain undefinable, and the origins of whose gossamer-like spread remain unidentifiable. Literary geogaraphies of Devi's work reveal how it is on the human body that the complicated nationalistic and financial articulations of space collude to generate the corporeal alienation particular to this current epoch.

Devi has always written about India. Realizing that she was neither a Creole writer nor an Indian writer, after much questioning Devi might have finally discovered that it is in a Mauritian identity that she was able to find herself and locate a 'process of synthesis and syncretism, ${ }^{3}$ but India and her Indian origins have played an important role in Devi's writings. For her earlier characters in works based in Mauritius, like Le Voile de Draupadi (1993)5 and L'Arbre fouet (1997), ${ }^{6}$ India was a faraway land whose religious stories regulated everyday lives; a site that one evoked as a place of mythical tales and as the origins of quotidian taboos. Eventually though, in later works like the novel Indian Tango $(2007)^{7}$ and the short story collection L'Ambassadeur triste (2015), ${ }^{8}$ the narratives moved to the streets of a twenty-first-century India, where her women characters continue defying social norms and breaking moral and religious taboos. If in one of her earlier works based in Mauritius, Rue la Poudrière (1988),', it was a father-daughter incest that took center stage, in Indian Tango, placed against the backdrop of a conservative Indian middle-class milieu, it is a lesbian encounter that serves to liberate the woman protagonist from her patriarchal chains.

Along the literary road on which her characters move from the streets of Mauritius to the streets of Delhi lies also the varied map of her spatial encounters 
with India: a) the faraway mythical India that the diasporas imagine; b) India as a nation-state designate that, in its subservience to the global economic order, confines human existence; and finally, c) a nonhierarchical, processual India that Devi's own text produces. As Devi's work has moved out of Mauritius, whether to London in Les Jours vivants $(2013)^{10}$ or to Delhi in Indian Tango, it is almost as if her work in visiting these newer locales is becoming aware of their interconnectedness. Throughout, India is present as part of an overpowering global network of capital.

If the second chapter of this book followed the setting up of an infrastructure that pulverized the world into entities revalorized according to the functioning of a market economy, this chapter deals with changing spatial anxieties in Devi's works. As these anxieties pivot from the local community of a Mauritian road to a reconfigured globe, the spatiality-related identitarian matrices that they negotiate simultaneously furnish plentiful insights into the changing locations that undergird Devi's literary arc, as well as the strategies that have been the mainstay of a politics of location within the context of postcolonial literature.

\section{Global Pathways}

Illustrating the changing dynamics of Devi's spatial anxieties are the titles of three of her works. As they register Devi's evolving spatial engagements with the formation of a human subjectivity, they also chart out the spatial anchors that this chapter analyzes. In no particular order, in this chapter I shall go back and forth between: the city; a global body politic conceived in terms of nation-state boundaries; and lastly, India, a particular nation-state.

I shall be talking about Devi's other works as well but for the moment let us place in order of chronological appearance her two novels: Rue la Poudrière and Indian Tango, as well as her collection of short narratives, L'Ambassadeur triste. Devi's literary engagement moves from the local of a Mauritian road in an earlier work, Rue la Poudrière, to a globe recalibrated as a function of national boundaries and capitalism, as it happens in L'Ambassadeur triste. Ambassadors in the twenty-first century function as indispensable links between nation-states that serve as nodes of this global body politic. Between the two works, India of Indian Tango serves as a constitutive example of the global logic of nations 
that comes up in L'Ambassadeur triste. Later, this chapter will show how Devi dismantles this logic of India.

Rue la Poudriere is the oral rendition of the Creole form of an actual Mauritian road called Rue de la Poudrière. ${ }^{11}$ This real-life road, much like in the novel, was where prostitutes practiced their profession. Human identity is configured according to the oral linguistic practices of the island and is located within a specific real-life quarter of the island that conjures up a specific cultural and material signified. ${ }^{12}$ Unlike her predecessors who, Ritu Tyagi points out, asserted a "unified identity located in [...] clear geographical confines of their island territory," Devi in her work transcends "cultural and regional boundaries" to present "new models and possibilities" $(2011,106)$. Despite the contributions that she has made to the cause of women from the Indo-Mauritiun community, ${ }^{13}$ even when Devi is "representing the Indo-Mauritian society" (2011, 106) it is with the intention of exposing "nationalist notions of identity as limiting" $(2011,106)$. Thus, one can see and understand why Tyagi sees in Devi's work an "openness to the universal" $(2011,106)$. It is through an analysis of Devi's treatment of the dynamics of the local community that one reaches the conclusion that Devi embraces not "the insularity that the island can impose on Mauritians," as her literary predecessors did, but "the expanse of the sea" (2011, 106). Rue la Poudriere, through its precise locatedness, allows seeing Paule, the protagonist, as part of a larger global dynamics.

However, in the later works both the literary stimulation as well as the conclusion arrived at are based in a much broader global space. In a way, Devi's characters have crossed the sea, both metaphorically as well as literally, to deploy the local dynamics in order to discover a global space. This is where the unlocatable sites, available in the title of the collection as well as in the narratives that make LAmbassadeur triste, help us understand this explicit denouncement of the nation-based global divisions.

While the majority of this collection recounts the touristy experiences of foreigners in India, the title story "L'Ambassadeur triste" is about a homesick ambassador stationed in Delhi "depuis dix ans déjà" ['already since a decade'] (10). Both the title of the collection as well as of the short story, "L'Ambassadeur triste" already prepares the reader for a paradigm of nation-states, mutual recognition and bilateral political relations, and instantly evokes the entire apparatus of imagined communities that remains, as Benedict Anderson has shown, at the foundation of nation-states. Yet, apart from the location of the ambassador's current posting, New Delhi, the only other pertinent geographical information available is that his origins are in a "pays nordique" ['a Nordic country'] (12). 
The story never evokes the usual markers of the nation-state apparatus like passports, languages, maps, flags and currencies. One never finds out what country he represents and where exactly he comes from. His country of citizenship remains for him, as well as for the reader, a "pays perdu" ['lost country'] (9).

A collection that starts with the unknown origins but the known current location, New Delhi, of an ambassador ends with another story, "Bleu Glace" ('Ice Blue'), about another unnamed man. This time though, both where the unnamed man comes from and where he is located remains unknown. In between the two extremes - of the precise locatedness of Rue la Poudrière and the unanchored man from "Bleu Glace" - lies the itinerary that Devi's work has followed to crystalize her notions about spatial divisions.

The collection starts with a story about a representative figure of the process undergirding nations - an ambassador - and a recognition of the existence of a country, namely India. The collection ends at an isolated seal-meat processing factory where the reader is introduced in great detail to how the product comes into existence, but one finds absolutely no identifying markers about this man, or, indeed about any of the other workers. Identifying markers apart from the factory floor do not exist, because they cannot exist, for such is the stifling spread of a product-based world, is the lesson I would like to take from these two extremes of identifying human location.

Between the two stands India. Or, rather, two spatial dynamics of the same bounded entity bearing the name India. One, heralded by the Hindu right of the country, remains as an example of a modernist state working in collusion with the growing capitalist network. The other is the decentered India that emerges from Devi's texts: an illustrative example that unravels through itself the workings of a larger paradigm of nation-states, to become eventually a processual, non-national space. Devi has always written against the reductive idea of nationhood, as is seen in the discussion above where, even when she represents the "Indo-Mauritian society" the objective is to expose "nationalist notions of identity as limiting" (Tyagi 2011, 106). Yet, by the time Devi's text has traversed oceans to reach India, it has both started reflecting on other manifestations of bounded nationhood as well as begun presenting multilayered ways of countering these manifestations. In order to see these transformations that take place in Devi's writing, it is important to see how her characters are navigating the roads of Mauritius. 


\section{Along a Local Road}

It is unthinkable to imagine Devi's literature without women's struggles against society. Similarly, it is becoming unthinkable, in seeing the transformations taking place in her oeuvre, to imagine her writing without a genuine engagement with the processes that shape space and shape us in relation to space. This is more than just a presentation of a passive landscape. It is about seeing everyday human activities as crystallizations of a geographical logic that attempts predeterminations of all: from the mundane to the extraordinary.

For example, Françoise Lionnet (1995) writes about the woman subject in Devi's novel Rue la Poudrière: a literary context within which, dating from nineteenth-century to contemporary literature, "from the noblest to the most perverse, the metaphysical to the sexual, cities have been read as both utopian and dystopian" (50). Focusing on Paule, who works as a prostitute, who has been rejected by her parents, and who inhabits what can only be described as the financial underbelly of the city, Lionnet elaborates on how the woman subject, and in particular the postcolonial woman writer, negotiates the dynamics of these urban images. After unwittingly sleeping with her drunk father, mistaking him to be a client, Paule drinks a poisonous potion and dies.

As Paule prepares the potion, she imagines her mother's presence. Her mother is the one she imagines offering her this poison. The act is described as the abortion that the mother always wanted: "Et finalement, finalement, c'est arrivé, ce qu'elle voulait finalement. Marie s'est avortée de Paule..." ['And, finally, finally it happened, what she had wanted finally happened. Marie aborted Paule...'] (Rue 188). A woman bearing the name of ultimate motherhood, Marie, ${ }^{14}$ makes no efforts to hide that Paule is an unwanted daughter, and then in the end assists in her suicide. Lionnet's ominous reading discovers Rue la Poudrière "conflating the female's and city's demise," where the "subject's attempts to disentangle herself from" oppression "leads to annihilation" (1995, 68). Cities are those postcolonial spaces in which the female subject is "tragically caught in a vise." I completely agree that not only in Rue la Poudrière but also in other of Devi's works urban spaces designate how "with global development come the ills of late capitalism" (Lionnet, 1995, 68).

Indeed, the urbanscape in this novel does function as the metaphoric equivalent of Paule. Here is what Paule's narrative voice contemplates, as she looks on to the city from her window: 
Vivre, comme Port-Louis, sans conscience et sans moralité, des états divergents d'amour et de haine [...] Vivre, comme Port-Louis [...] dans une terrible ritualité sans signification, sans question (191). [...] Mais si Port-Louis bouge, moi je suis immobile, parvenue à un point d'arrêt, au point de non-retour. [...] j'imagine les eaux du port se refermant autour de mon corps en dérive, le bruit de déglutition des eaux lourdes dans ma tête. (191) [...]

Dehors, le bruit s'amplifie, la chaleur augmente. Les cris deviennent plus perçants. L'enfer. Port-Louis brûle. Puis, un bruit plus fort tonitrue auprès de moi. Je suis secouée, arraché de ma contemplation. Ma fenêtre toute proche, blanche de soleil, me découvre ce côté bourbeux de Port-Louis, plein de tôle rouillée, de latrines découvertes, de réchauds à charbon fumants. Tout brûle, des vapeurs s'élèvent, transparentes, chaudes, odorantes. L'odeur de Port-Louis s'élève, vers le soleil-forge qui cogne sur les choses rougies à vif. Le soleil glaive qui fouille et s'enfonce dans votre tête, consumant l'esprit. La petite maison devient tout doucement un four. (192)

[To live, like Port-Louis, without conscience and without morality, conflicting states of love and hatred [...] To live, like Port-Louis [...] a wretched meaningless ritual, without questioning. [...]

But, if Port-Louis moves, I am immobile, at a standstill, point of no return. [...] I imagine the water of the ports closing in on my drifting body, the heavy swallowing of the water in my head. [...]

Outside, the noise is amplifying and the heat going up. Cries become increasingly piercing. Hell. Port-Louis is burning. Then, an even louder noise booms near me. I am shaken, ripped from my contemplation. My window, right next to me, sun-bleached, reveals to me Port-Louis' grimy side, brimming with rusting corrugated iron sheets, open latrines, and smoking coal stoves. Everything is ablaze, fumes rise up - transparent, hot, stinking. Smells of Port-Louis rise up, toward the forge-Sun that smashes into red-hot things. The sword-Sun that forages through and digs deep into your head, ravaging your brains. The small place slowly turns into an oven.]

In this literal equivalence between the woman and the city, it is easy to see how, according to Véronique Bragard, ${ }^{15}$ Paule's life "epitomizes in several ways the city of Port-Louis itself." Both "have been bought, fragmented, imprisoned and are 
falling to pieces" (119). Interestingly, "vivre" ['to live'] is an ironical expression used to equate Paule's existence with that of Port Louis. For it is soon afterwards that Paule is to die. At the same time, the comparison is not completely ironical, because the point here is that the modernist machinery and the productive human body are interchangeable. While the body might die, the city does "live" in its personification of perpetual decay.

This literal overlapping of the woman and the city unfolds the gendered creases of spaces. Home is a site of terror as much as the city constantly domesticates discontent. Space can no longer be understood in terms of the urban and the rural, the home and the outside; neither do any of the associated connotations of safety or threat hold true. The novel's reading of the simultaneous colonization of the body and the city displays how both work and sexuality are constituted by a newly emerging paradigm of urban spatiality, where women have to be relegated to the spatial and economic margins. The modernist urban spaces of commodification accept only conforming bodies; bodies invested in its mission. Within this dynamic, all human relations have to dissolve. Urban productive processes alienate the human body from itself. Paule's personal bewilderment at having her father as a client also becomes a discontent directed at the urban productive processes within which her labor of a prostitute is prefigured. In this urban paradigm, a discontent Paule is doomed to be erased. Paule imagines her mother furnishing the poison, putting a definitive end to any vestiges of affective relations as the defining feature of human contact.

Instead, these relations and their value are now predicated on the extent to which they are invested in a relationship between productive elements. At least that is how I would like to see the slow movement of the description, which moves from inside the room to the outside, and rises along with vapors and the smells of the city to the sun to return to the room. As the noise and heat are rising, so are the smells and sights of open latrines and coal stoves ("latrines découvertes, de réchauds à charbon fumants" ['open latrines, and smoking coal stoves']). All human senses are under attack. The description moves from the ground and along with the rising vapors reaches a red-hot sun that takes on the qualities of a forge ("soleil-forge" ['forge-Sun']) to end inside the head, where it muddles up the brain. As the room where Paule sits in this circular trajectory is converted into a "four" ['oven'], the rendering of the city and the body as sites of manufacturing and production is complete. 
This is a scene of rejection. While the modernist aesthetics would have us focus on the shiny object, the final consumable entity and its exchange value, this description focuses on the refuse that machinery creates. It is not what lies in between the two, but the open latrines on the ground and the vapor floating on top that one focuses on; both are the ungainly byproducts of means of production that here challenge the senses and yet never figure as part of the exchange value that the scenic, touristy Mauritius is often depicted to be. Similarly, Paule's unworthiness in relation to the productive process has predetermined her rejection from the system. Paule's father had sold her into prostitution to Malacre. The "terrible rituatlité" ['wretched meaningless ritual'] - both for Paule and for the city - then is to be understood as the repetition and the constant reiteration that creates meaning. Both are quite literally "sans signification" ['meaningless'], without importance as well as without signification. Or rather, both the urbanscape and the bodyscape have been emptied of meaning and what one sees here is their reinscription in a dynamics of machines and decrepitude.

The intermingling of the city, the commodified body, natural elements and all human sensations signals the ultimate rationalization of the human experience as well as the spatial limits within which Devi places her earlier work. Just as Paule imagines "les eaux du port se refermant autour de mon corps en dérive" ['water of the ports closing in on [...] [her] drifting body'], so does this narrative delimit its treatment of all that remains within the waters of the Indian Ocean, that is on the island of Mauritius. One would have to wait for Devi's later works to see the city, and other delimited geographies of human experience such as nations and nationalisms, figure as part of a global dynamics.

As her work looks outward into the horizon beyond Mauritius through the spatial equations it contemplates within the frame of human relations, Devi's writing has continued foregrounding the imbrication of gender in the urban expanse. It also displays an increasing awareness of how the nation and its accompanying nationalism collaborate with a financial apparatus to scale out their expansion, always and necessarily in collusion with cities. Indeed, in her recent works, the material logic of urban growth in India makes manifest how the workings of an international capital lead to the creation of physically and socially constructed inequalities. The financial apparatus of Indian urban landscape thus articulated is part of a global whole whose authority percolates through geographical units of nations and cities that it has aggregated into itself. 


\section{Dislocating Location}

Throughout Devi's work, there lies a refusal to define location. The evolution of this purposeful placelessness, a lack of stable meaning, can be read alongside the juxtaposition of Glissant and Baudrillard, both of whom contemplate locations within a frame of constantly escaping meaning, though from completely different vantage positions. For Glissant this absence of meaning exhorts a constant struggle with identity and offers a productive opportunity for remaining engaged with the process of defining one's location. Baudrillard, on the other hand, in the dystopian Disneyland parallel in the epigraph above, sees capitalism emptying American society - and by extension the entire postglobalized society - of meaning. While at an explicit level Devi has staunchly refused to define location, and her work remains closer to Glissantian articulation, a deeper reading of her recent works reveals an awareness of the kind of dystopian world Baudrillard talks about.

"Incontournable," from Glissant's well known refrain "le lieu est incontournable," has multiple possible translations ('place cannot be ignored' or 'place cannot be avoided' or 'place is uncircumventable'). For J. M. Dash this expression means that "place can neither be gotten rid of nor can its contours even become fully known." ${ }^{16}$ It is this dual bind of realizing that location exists and yet cannot ever be fully known or be ignored that provides a productive impetus to the constant quest for meaning that forms the basis of Glissant's understanding of a world that exists in relation. ${ }^{17}$ Verne's world that is mediated through a grammar of measures, quantification, and colonial apparatuses has to be necessarily circumventable. Glissant's, on the other hand, is always already uncircumventable. Indeed, he demonstrates performatively through the semantic ambiguity of this spatial metaphor incontournable, which could both refer to an uncircumventable location as well as an unapprehendable meaning, how it is important to search for meaning despite knowing it to be inaccessible.

When responding to a question, Glissant retorts with astonishment at entertaining the possibility of decoupling identity from location:

Qu'est-ce que ça [lieu] à voir avec l'identité ? [...] l'identité ne peut pas se passer du lieu. $(37)^{18}$

[What does it [location] have to do with identity? [...] identity cannot exist without a location.] 
One understands how and why the physical spatial location is important to Glissant's work. The constant causal links that he draws between human subjectivity and location is why Glissant makes frequent reappearances in this book: "si nous sommes dans le monde, c'est par le biais d'un lieu" ['if we are in this world it is because of a location'] (36).

I am only looking at the locational inflections of this adjective, "incontournable," which Glissant privileges in his insistence above. Others, like Mary Gallagher, ${ }^{19}$ scouring through different aspects of Glissant's work have found in this "cleaving to place" an evidence of "place and memory being inextricably intertwined" (Gallagher xix). It is also in this location that Geneviève Belugue ${ }^{20}$ finds in Glissant's treatment an infinite entity, 'an aesthetics of the Diverse' where all is 'interlinked and interdependent. ${ }^{21}$ The point here of course being how this and other spatial analogies in Glissant's work very self-consciously draw attention to their mode of representation of the world. Glissant's constantly evolving signifier resists any elisions, nationalistic or otherwise, and sets up his spatial metaphors, and his literature in general, to absorb the mutating complexities of the postcolonial identitarian text.

The textual interceptions that Glissant's texts carry out result from a signifier purposefully let loose to wander about. Baudrillard's America too belongs to what Gilbert Germain calls a "new significatory space" where "signs are free to commute unbounded by strictures of any sort"22 (Germain, 42). However, these are elements reintegrated into a capitalist system determined by consumption. In the earlier stages of capitalism, the value of a commodity "was determined largely by its use and exchange value" (Germain 40). In present times with the technical hurdles to production "such as cost and accessibility" overcome, and the focus being on consumption, we have reached a new principle of social organization, wherein what matters is the image of the product as it is "self-consciously crafted by manufacturers and advertisers" (Germain 41). This is an image that is created in anticipation of (and to encourage) its eventual consumption. It is thus that in our age the value of a product is no longer attached to its real world signifieds. It is because they remain disconnected from their referent that Germain concludes for Baudrillard: "Value becomes a floating signifier" (41). ${ }^{23}$

The dominance of capitalism has ensured that our current day world functions as a signifier independent of any signified, not answering to any definitional limits. In this sense Los Angeles and America, in relation to Disneyland, become hyperreal: a "realer than real" world (Germain 42). In this equation, it is in Disneyland that the postmodern subject lives out the fantasy of the American dream. Propelled by mechanization, cartoon characters and social situations, the subject is able to experience true American reality, as it could be, in what would 
seem like artificially created contexts. The hyperreal then is the America that surrounds Disneyland, where the consumption-driven signifier is overwhelming the reality. This is the product of a consumerist world where "the images representing them so overwhelm their referents that they break the bonds of representation entirely, thus becoming free to commingle indiscriminately" (Germain 42).

Where for Glissant the free-roaming spatial signifier functions as the precondition for a productive disruption of the domineering colonial text, the snapping of the bond between the signifier and the signified in Baudrillard's reading of the capitalist society is the fabrication of a new order where the definition of the world too exists as a "floating signifier." The two spatial referents then are the two kinds of undefinable spatial locations that complement each other in Devi's work, which the subject must capitalize on and manipulate to stake claims to a postcolonial space.

\section{Grounding Identity}

It is not as if Devi is consciously cognizant and engaged with these two distinct spatial paradigms. Neither is it as if Devi claims to juxtapose the two against each other. I juxtapose the two in order to highlight the transformations in a literary oeuvre that in its earlier days began on the streets of Mauritius and is now offering deliberate self-conscious insights into the human society as the creation of capitalism. When I say that for the purposes of Devi's oeuvre, at an explicit authorial level it is the Glissantian kind of a geographically unanchored narrative that is the enabling condition of a forever-evolving identity, I am doing what Odile Ferly does in her book, A Poetics of Relation: Caribbean Women Writing at the Millennium. ${ }^{24}$ Ferly's study "does not claim that Glissant's Relation directly inspired all the women writers [that Ferly has] discussed" (6). Ferly premises her arguments on Glissant's lack of engagement with gender and shows how women authors through their literary practices, which remain sensitive to the importance of gender, produce a "modified, more gender-aware version of Relation" (6). ${ }^{25}$ While acknowledging Glissant's contributions and influences in the Caribbean literary world, Ferly functions with the belief that "Glissant's 'gender blindness' can be corrected" (6). I too would argue that Devi's spatial engagements when read alongside Glissant produce a much richer and a more nuanced kind of relation.

This idea of an unanchored place that Devi has reiterated in several of her works, and that she advocates for more explicitly in nonfictional writings, makes 
itself available through poetic mechanisms in Devi's poetry collection Quand la nuit consent à me parler. ${ }^{26}$ This collection assumes a woman's voice to address the reader. In talking of the moment ("Quand" ['when']) of consent to "parler" ['speak'], the title of this collection presents speech and carries within it the absence of speech that preceded it. Devi, after all, is faced with writing about the impossibility of communicating the abject human exploitation, in the very language, French, that served to subjugate the colonized populations of Mauritius.

Appearing toward the end of the collection, the poem "Les mots meurent de mort lente" ['Words Die a Slow Death'], which displays how "les mots érigent des murs de mensonges" ['words erect walls of lies'] $(43 ; 65)$, might seem to be about such an impossibility of language. However, when this poem deploys language to underline its own limitations, it puts into action a process of harnessing poetry writing in order to bypass the inabilities of human language. Since it provides us a way out of a linguistic cul-de-sac by speaking of the simultaneity of speech and nonspeech present in the title - When the Night Agrees to Speak to $M e$ - one understands why poetry figures in this poem, and indeed all throughout this collection, as "notre veine porte" ['our vein a door'] $(43 ; 65)$.

In her insistence on "poétique" ['poetics'], Devi shares much with other well-known concepts in the Francophone literary tradition. Through allusions to similar articulations, such as Poétique de la Relation (Poetics of Relation) by Glissant, Devi enters into a dialogue to set up her own voice. Just as some renditions of Négritude unambiguously situate their origins in Africa, many writers belonging to the diaspora of slavery and indentured labor display yearnings to locate fixed geographical origins in their quest for an identity. In her poem "Poétique des îles" ('Poetics of Islands') Devi is retorting, no doubt, against such a geographically tied understanding of identity when she angrily states:

rien à faire rien à foutre des images désarrimées de nos terres ... images gravitationnelles [...] nous condamnent à rôder le nez au sol (49)

[to hell with all the disarrayed images of our homeland ...

gravitational images $[. .$.$] condemn us to keep our noses to the ground$ $(67-9)]$

This indictment of homeland and similar "images gravitationnelles" ['gravitational images'], is an acknowledgment of the reductive nature of such identity paradigms that "nous lestent de trop de nous-mêmes" ['weigh us down with too much self'] $(49 ; 69)$. In other words, these paradigms do not recognize the 
complex, multifaceted nature of identity construction that makes any anchoring unachievable. The rejection ("rien à faire rien à foutre" ['to hell with']) of the pull of these geographical locations is in direct proportion to the urgency of identitarian interrogation she responds to in her work. When writing her quasi-autobiographical poetic essay for the collection Je est un autre: Pour une identité-monde, ${ }^{27}$ which bears the self-explanatory title "Flou identitaire" ['identitarian haze'], in an imaginary conversation with "pourvoyeurs d'identité" ['purveyors of identity'] (179) Devi presents herself as suffering from the "maladie" ['illness'] of "démultiplication débridée d'appartenances" ['unbridled amplification of identities'] (179). The abundant irony of this "illness" counters the urge to sediment and limit the many facets of herself, as these "pourvoyeurs d'identité" would want her to. The idea here is not to repeatedly emphasize this nonfixity that Lionnet (among many others) already recognizes as a hallmark of Ananda Devi's writing. Lionnet evokes how in Rue la poudrière, the "narrator's, and the narrative's, double flight from meaning and reality, from fixed location and stable identity" needs to be read as a "desire to escape from circumcised existence" $(1995,60)$. The narratives, the locations and human interactions have all set up a productive ambivalence that challenges the power dynamics undergirding the context in which Devi's marginalized characters struggle.

Such moves that wrench multiple postcolonial subjects from metaphorical and literal 'purveyors of identity' and rearticulate them as the site of plural influences abound in Devi's work, whether it figures as literary texts, writings about herself, or about the larger postcolonial identity. The unbridled then in 'unbridled amplification of identities' exceeds, both the patriarchal and the traditional frameworks and becomes the fertile ground where differences are diffused and provide the means for communal resistance to dominant structures, nations and imposed identities.

When speaking of a colonial conception of a nation, I am referencing not only the modernity-inspired model of nation-states but all conceptions that tie down identities to specific borders. The colonial deterritorializations that resulted in slavery and forced migrations are in Ananda Devi's discourse translated into a nonbinary empowering form of spatiality. Devi is one of the women authors to have registered the impossibility of a nonmultiple space, reinscribing the colonial project instead within an open-ended spatial paradigm that is one of possibilities. Nation-states, or narrow nationalisms built on the belief of a single identity, working under the sign of modernity, could never satisfy this need for a dynamic interactive space that respects and recognizes the influences of a plurality of identities. 


\section{Patriarchal Homelands}

This diffracted, multifaceted, nonsedimented type of topography available in Francophone literature has taken a long time to take its contemporary form. Before Francophone authors harnessed spatiality's full productive potential, its definition remained subsumed within a reductive understanding of colonial-capitalist space. For example, by situating his movement's geographical origins in Africa, Léopold Sédar Senghor's version of Négritude only advanced the same old colonizing model of defining identity through a nation. In his haste to set up normalizing identities, Senghor is among those early writers who advanced simplistic definitions of history as well as geography that are based on exclusion. Senghor's is a twofold move that involves firstly establishing the African as different, unique, and then looking toward Frenchness or Francité as the defining force. Senghor speaks fervently of adopting a French way of thinking that would allow the African and the African diaspora to express itself with clarity that is inherent to French thought. ${ }^{28}$ It is no wonder then that Y. V. Mudimbe saw Négritude as a part of Western thought. Mudimbe calls Négritude "a product of a historical moment proper to Europe, more particularly to the French thought, which marked it." ${ }^{29}$

Even more startling is its clear misogynist outlook. Indeed, the name itself of Négritude has been criticized for its patriarchal leanings, as it takes the word nègre - the black male - as its starting point. What makes this enunciation on the space of Africa scandalous is that the mostly male writers of the Négritude movement, like Aimé Césaire, Léopold Sédar Senghor and Léon Damas, exploit female allegorizations of Africa in their search for self-vindication. ${ }^{30}$ Colonization raping the passive mother Africa and the continent as a beautiful woman who beckons are just some of the sexualized metaphors of the female body that have provoked Maryse Condé to describe Négritude as "a sexualized discourse of Black liberation." ${ }^{31}$ This was an urge to locate in space structures similar to those of the colonizer.

When it comes to recognizing gender as a formative element in the colonial experience, one points to Frantz Fanon as an example of a male theorist whose contribution remains notable. However, there are moments when ruptures in his text give access to ${ }^{32}$ what Anne McClintock calls "designated agency" (98) for women. ${ }^{33}$ While it is true that Fanon lived in a period where political movements and definition of power were all male-centric, Fanon's continuing intellectual influence demands a closer look into his presentation of the role of women. 
One has pointed to the much-discussed passage that follows as an example of Fanon's ambivalent acknowledgement of women's role in the Algerian struggle for independence. Belonging to Fanon's Sociologie d'une révolution (L'an $V$ de la révolution algérienne), ${ }^{34}$ the following quotation presents how the traditional Algerian Muslim woman takes off the veil to participate in Algeria's war against colonization, an act that allows her unhindered access to the European quarters. An ease of travel that the Algerian woman is then able to use toward the purposes of the revolution:

Le voile protège, rassure, isole. Il faut avoir entendu les confessions d'Algériennes ou analyser le matériel onirique de certaines dévoilées récentes, pour apprécier l'importance du voile dans le corps vécu de la femme. Impression de corps déchiqueté, lancé à la dérive; les membres semblent s'allonger indéfiniment. Le corps dévoilé paraît s'échapper, s'en aller en morceaux. Impression d'être mal habillée, voire d'être nue. Incomplétude ressentie avec une grande intensité. Un goût anxieux d'inachevé. Une sensation effroyable de se désintégrer. L'absence du voile altère le schéma corporel de l'Algérienne. Il faut inventer rapidement de nouvelles dimensions à son corps, de nouveaux moyens de contrôle musculaire. Il faut se créer une démarche de femme-dévoilée-dehors. Il faut briser toute timidité, toute gaucherie (car on doit passer pour une européenne) tout en évitant la surenchère, la trop grande coloration, ce qui retient l'attention. L'Algérienne qui entre toute nue dans la ville européenne réapprend son corps, le réinstalle de façon totalement révolutionnaire. Cette nouvelle dialectique du corps et du monde est capitale dans le cas de la femme.

Mais l'Algérienne n'est pas seulement en conflit avec son corps. Elle est maillon, essentiel quelquefois, de la machine révolutionnaire. Elle porte des armes, connaît des refuges importants. Et c'est en fonction des dangers concrets qu'elle affronte qu'il faut comprendre les victoires insurmontables qu'elle a dû remporter pour pouvoir dire à son responsable, à son retour : « mission accomplie »... RAS $(39-40)^{35}$

The quotation has been extracted from a chapter that is appropriately titled "L'Algérie se dévoile," ${ }^{6}$ in Sociologie d'une révolution. In the synonymy that the title of this chapter establishes between woman and Algeria lies the crux of the argument. One could easily read the verb "dévoiler" as referring to a woman taking off her veil, or to the unveiling of a new Algeria. Or even the other way round. 
It is not so much which of the two (woman or the nation) acts as a synecdoche for the other that needs to be ascertained. ${ }^{37}$ Chantal Kalisa rightly summarizes Fanon's understanding of the male colonizer when she asserts that, according to Fanon, for the male colonizer the "body of the colonized woman came to represent a national emblem and the land itself" (25). What one needs to point out is that in equating the country and the woman, this title, "L'Algérie se dévoile," is paradoxically carrying out much the same thing that Fanon aims to criticize in the white colonizer. The very first signs of the tension "between nationalism and feminism" (Kalisa, 25) in Fanon's work emerge right from the title of this chapter that purportedly talks about the contributions of women in the struggle for independence. Fanon, Kalisa points out, "repeats the same process of erasing the colonized woman in the decolonizing effort" (25).

Let me push this reading a little further. Fanon derives his authority to speak about Algerians from the insight he drew as a result of his work as a psychiatrist. Is it not possible to see the above presentation of the discussions that allowed Fanon access to the subconscious workings of Algerian women otherwise than what he claims it to be? What if this description - which starts with a veiled woman, goes to an inappropriately dressed woman ("mal-habillée"), then a naked woman ("nue"), and finally to a woman who walks stark naked, in full public view, through the European city ("toute nue dans la ville européenne") were to be seen as the condensation of the desire of a heterosexual male? Could it be that Fanon himself is no different from the subject of his analysis: the pathologically sick colonized black man who feels himself superior in sexually possessing a white woman? He is after all thinking of a woman bearing all the traits of a white European woman walking naked on the streets. He does assume the voice of a black man in his much-quoted Peau noire masques blancs, to speak of how in caressing the white woman's body the black male is able to appropriate "civilisation et la dignité blanches" ['white civilization and dignity']:

Dans ces seins blancs que mes mains ubiquitaires caressent, c'est la civilisation et la dignité blanches que je fais miennes (76). ${ }^{38}$

[When my restless hands caress those white breasts, they grasp white civilization and dignity and make them mine (45). $\left.{ }^{39}\right]$

One could of course retort that Fanon's could not be a selective vocabulary that privileges a certain kind of female sexuality, and is instead a scientifically arrived at conclusion of an objective professional. In addition, it could be that the "je" 
that is talking about holding the breasts of a white woman is no more than a rhetorical device aimed at heightening the textual effects. But, is it?

To ask another question: Is "l'homme" ['man'] as it appears in Fanon's text, an indicator of general mankind, as Bhabha claims, or is it a gender-loaded term, which as Kalisa points out "is primarily describing a male world" ${ }^{40}$

The answer would be an emphatic yes. Fanon's is most definitely a male world. At least that is the conclusion one draws on seeing this woman, who after encountering dangers, taking great risks, taking charge of her body, rebelling against the society, conquering the European quarters, reports back to: "son responsable" - "her male supervisor.' 41

Is it not paradoxical, how when speaking of the European city, Frantz Fanon underlines the "revolutionary" manner in which the woman participant deploys her body ("réinstalle" ['re-establishes']) against the European city only then, almost immediately, to classify this as a conflict with her body? If by relearning her body she is able to invade the European city, which the male revolutionary is unable to, would it not be logical to see the woman as the very catalyst that redefines and appropriates the European city toward a revolutionary end ${ }^{42}$

Several scholars (McClintock and Rashmi Varma, for instance) have pointed to the rather obvious contradictions in Fanon's enunciation regarding gender and nationalism. McClintock for example, shows how women militants in Fanon's writing can only be understood as "passive offspring of male agency and the structural agency of the war" (98).

In other words, for McClintock "theirs is a designated agency." No wonder, caught between the male revolutionary and the need for national identity, the woman revolutionary can only figure as repeatedly fractured, out of control body:
"corps déchiqueté" ['body torn apart']; "lancé à la dérive” ['set adrift']; "membres semblent s'allonger indéfiniment" ['the limbs seem to len- gthen indefinitely']; "corps dévoilé paraît s'échapper" ['unveiled body seems to escape']; "en morceaux" ['falling into pieces']; "Incomplétude" ['incompleteness'].

Lastly, and perhaps the most destructive, is the "sensation effroyable de se désintégrer" ['frightful sensation of disintegrating']. Through Fanon's text one can see how women ${ }^{43}$ "are typically constructed as the symbolic bearers of the nation but are denied any direct relation to national agency" (McClintock 90). Indeed, Condé's assessment of Négritude being "a sexualized discourse of Black 
liberation" neatly applies to Fanon's presentation about the war of Algerian independence. Women are progressively unclothed and deployed for the task of an Algerian homeland.

Spatial practice in Devi's literature, while remaining in conversation with the normative colonial narratives of space as available in Fanon's text, also presents colonized bodies in a manner aimed at unsettling patriarchal understandings of space. In Quand la nuit consent à me parler, Devi strongly counters all homelands and the associated reductive "images gravitationnelles." It should not be surprising to discover that Devi's poetry also uncovers the wounds that a woman's body bears.

This would explain why Devi constantly beckons, as she does in the ninth poem, to "Enlève ma peau. Dévêts-moi de moi./Regarde de plus près" ['Peel back my skin. Unclothe me of myself./Look closer'] (20;19), and then confronts the reader with instances that show the lack of identity, or rather an inarticulatable identity. In the twenty-eighth poem, "un roulis de saris verts" ['An unrolled swathe of green sari'] (40;59), ${ }^{44}$ the very garment that a woman covers herself with, exercises indifference toward her and indicates instead her erasure; here, one understand how any attempts at locating identity, in particular locating a woman's identity, can only mark a site of absence:

Un roulis de saris verts

Indifférents au sort

De la femme annulée

Masquée par ses bleus (40)

[An unrolled swathe of green sari

Indifferent to the lot

Of a woman erased

By her bruises (59)]

Even as stabilizing the complexities of identity remains an impossible task, this insistent invitation to attempt definitions of this opaque presence sets apart Devi's poetry and identity politics in the mostly male-centric, origin-fixated postcolonial Francophone canon. It is also because of this simultaneous invitation and refusal that I can state that in Devi's work this unidentifiable location is to be understood as "incontournable" in the Glissantien sense of the term.

Devi's fictional spaces allow us to decipher the gendered workings of geography and to understand them not just as passive entities but as active participants 
in the process that makes postcolonial identity. To use Varma's words, in reading texts like those of Fanon, I would like to see how through the act of walking "women register their place in the tumultuous Algerian society" and are able to alter space by drawing "different maps of the colonial city" (25). In other words, authors like Devi are able to interact with spatial concepts such as geographical nation-states like India to reinscribe them within a knowledge paradigm accommodating more varied struggles of identitarian assertions.

It is through such a theorization of impossible homelands that Devi's work delivers a distinctive geopolitical statement about the contemporary need to realign our understanding of nations and geographies alongside lived experiences. Impossible homelands signal the impossibility of abstractions of nationalism that would contain space within mathematical paradigms of maps and charts; this is so not only (and quite obviously) because their physical coordinates cannot be located in the aftermath of the colonial violence but also because of enunciations such as Devi's. In such enunciations one can understand how space, identity and language cannot exist as separate entities but will have to be understood forever as part of a multilayered, constantly evolving process in which all three are intertwined in a mutually influencing relationship.

\section{Tango with India}

Let us look a little deeper into the impossible homelands that mark Devi's writing. Devi posits herself as "culturally hybrid"45 and constantly disavows any attempts to anchor down her identity or her literary craft. Why this growing fascination with India? One sees that two of her recent works, the novel Indian Tango and the short story collection L'Ambassadeur triste, are set in India. Despite the candidness with which Devi accepts not knowing the "quotidien" ['everyday'] of India and wonders if it might be just a mythical India that inhabits her, she does not hesitate in crossing the Indian Ocean to place her recent writing in India, which she refers to as "contrée inconnue" ['unknown land']. ${ }^{46}$

One understands the reasons why the origins of the numerous foreigners in India in the short story collection must remain unknown, if they are to indeed become emblematic of a new all-welcoming citizenship. For example, in "L'Ambassadeur triste," the ambassador remains unidentified, as does the unnamed woman in "À l'aventure" who harbors a desire to be like one of those 
adventurous women she secretly admires. For her sixtieth birthday, she comes to India in search of an adventure.

With a bottle of Avian water in hand her adventure involves renting a car for the first time in her life and driving independently in one of India's cities, where all road rules and social conventions are unknown to her. One could easily find the chaos of this unnamed city with its unruly bumper-to-bumper traffic, hassled traffic police officers and street side beggars, in any number of nondescript Indian cities. One had told the protagonist that the people in this generic Indian city were more polite, and the city was located close to scenic places. She had also been informed (wrongly, she realizes) that the traffic was less chaotic (29). As she negotiates the traffic with great difficulty, the descriptions connote everyday urban Indian commonplace. The woman finds herself in a nowhere land:

Aucun panneau, aucun signe, aucune indication. Elle était dans un pays sans nom. (28)

[No signs, no markers, no directions. She was in a nameless country.]

The city becomes a microcosm of human identity, where the visibly materially comfortable woman of unknown origins forms a human bond with a street-side child beggar, whose peeling wounds and fever mean he will not survive long. ${ }^{47}$ One needs no language, no signs, no direction markers, for they would be the prerequisites of a knowledge model that seeks to stabilize meaning. This "pays son nom" ['nameless country'], through which this unnamed tourist drives, is emblematic of Devi's conception of belonging and human identity. Even as it frustrates the unidentifiable protagonist, this unidentifiable location also becomes the site for human affinities where, as the story closes, she has formed a bond with a child with whom she shares neither language nor culture, and definitely not her comfortable financial situation.

The very first story in this collection is about an ambassador placed in the city of Delhi. The very last story, "Bleu Glace," furnishes no toponyms. The unnamed man is from an unnamed place, working in another unnamed location. Placed between the two, the short narrative "À l'aventure" retains India as the only factual geographical coordinate. It is almost as if the collection is progressively dissolving all geographical markers that could serve as anchors for identity. One understands that if they are to remain "incontournable," these locales within the identitarian paradigm have to remain always already marked with the 
potential of human interactions, even as they move closer to vanishing point while furnishing the possibilities for reconciling human incongruencies. The quotation that follows, where Devi talks about why she placed her novel Indian Tango in India instead of Mauritius, prepares the groundwork for understanding how her work recalibrates spaces through its focus on bodies and dislodges the dominant spatial paradigm, which inscribes humans in maps, and charts, and numbers, as one sees in Verne's work:

I started with this idea of a transgression, a transsexual transgression. [...] I always need a strong sense of place [...] I was able to bring in the strangeness of the place that even I feel when I go to India, and at the same time to have one part which is really set in traditional India. (Hawkins 10)

In talking about India, what Devi achieves in her works is this seemingly incompatible "strong" sense of place, along with a strangeness linked to her Indian identity. The "gravitational images" that appear in her poem "The Poetics of Islands" and that I mentioned earlier do attract, but what one encounters in the end is a zone that exists in this space beyond boundaries.

When read alongside the "strangeness of place" that she experiences in a known India, the suffix "trans" - available for example in transgression and transsexual - is one I choose to read as belonging to a newly created spatial paradigm that evokes a spatiality beyond known definitions that harbor fixed identity. One that becomes the ideal staging ground for the layered complexities of identity.

Nevertheless, why India? If Devi is serious about denouncing how authors tend to get caged in by ideas of "restrictive" ${ }^{48}$ national belonging, why then, in an oeuvre that destabilizes the foundation of nationhood, does India have to figure as the constant narrative locus? Is one to understand this purposeful inclusion as a contradiction, or perhaps a change in ideological positioning? Is she locating in India a homeland, as did other Francophone writers who looked toward Africa as the place of their origins?

Notions of caste, religion, spirituality and community that she identifies with India played a major role in Devi's upbringing. These influences are abundantly available even in her earlier works. ${ }^{49}$ Think, for example, of the pandit in L'Arbre fouet, the protagonist Aeena's father, who has come from India and whose brahminical patriarchal ways have become the reason for Aeena's constant repudiation. Elsewhere, she evokes the sea as a constant reminder of the 
country of their ancestors. ${ }^{50}$ India's presence as a far-away country is here just one of the many identitarian vectors, albeit an important one, that both problematizes as well as provides the means to counter the hierarchical assumptions of a casteist and gendered society. In Devi's earlier work, India served to magnify the complexities of the Mauritian society.

To challenge successfully anchored homelands that one identifies as geographies of source, as happens with Senghor, Devi has to engage with India. The illusory India was distilled through the immigrant's vision and displayed as a set of spectacular and mythical traits to fill in the lost contours of the dispossessed's everyday life. Engaging with this India allowed Devi's text to unhinge her work from all fixed locations and to place them within a constantly evolving orbit of Glissant's “incontournable."

The point interestingly is not really about the unknown origins of these foreigners, or about the unnamed city. This is a paradigm of nation-states and ambassadors where India is the only named geographical entity, and other geographical coordinates like countries of citizenship and precise locations, both within and without, slowly dissolve. The India that emerges loses its limiting moorings to figure eventually outside the nation-based grammar that is central to the evocation of a parochial nationalism.

In order to locate the human story within a network of human solidarity and collective resistance, it is crucial for this India to be located outside the national frame. The human location exceeds all known geographies, and characters of different provenances have been transformed into a collective. No longer in search of some elusive definitions, they situate themselves in terms of a national geography, but a geography that sits on shifting identitarian sands and needs constant recalibration.

In other words, while for the colonial-capitalist project geography served the purpose of an exclusionary anchor, of an essentialist identification, for Devi's world these homelands come to be seen as the spatial residue of imperial times that the contemporary project needs to constantly reckon with. Further, and more importantly, what was hidden from the view of this make-believe India of reincarnations and sins was the often-ungainly site of real human labor and exploitation and the troubling social and economic relations that undergirded the postglobalized Indian nation-state. This change of location allows confronting the internal contradictions of both the very concept of a homeland within the postcolonial Francophone context and the shifting financial dynamics of the globe. 
To move within international borders creates the grounds for fracturing these borders from within. What one discovers within this urbanized India - in the form of contradictions between the restrictive homeland and its imaginary evocations, between the false promise of eternal salvation and the everyday grit and grime - prepares the grounds to unhinge the homeland. These homelands could be both the different illusory forms of homelands available within the Francophone canon, as well as the restrictive homeland that takes patriarchal forms in Devi's other works.

In the brief analysis that follows, India appears as an "imagined community," to use Benedict Anderson's phrase. Rather, India appears as a gendered imagined community. The representation of human collectivities increasingly accommodates the relation between bodies and geographies, between identity and belonging, between citizenship and the material conditions, and becomes more marked in its portrayal of everyday life.

It is this Janus-faced India, with its constrictions and possibilities that scaffolds Devi's identitarian preoccupations vis-à-vis the nation where the human body confronts economic repression and exploitation. The name of the novel, Indian Tango, already puts the Indian nation front and center and informs through "Tango" of the constant negotiation with space that one needs to carry out. This novel is the story of Subhadra, a Delhi woman living with her husband and mother-in-law. Before she meets and commits the subversive act of sleeping with another woman, the stasis of her everyday life is contrary to the movement that the title evokes.

Devi's presentation of India, and in particular of the aspirations and imaginations of its middle class, draws on a nationalistic tradition that sees all elements as constituting subsections of the nation of India. Subhadra's aging authoritative mother-in-law, referred to as Mataji ${ }^{51}$ in the novel, the carrier of the parochial and patriarchal workings of a modern nation-state, in her insistence on the need to maintain the purest form of a patriarchal Hindu country, is a quintessential example of the bigoted India that Devi implicitly deplores. The India that emerges through Mataji's character becomes a conduit for distilling a definition of a nation in the interests of an ideal nationhood. Within this cultural conservatism, any symbol of nonbelonging, regarded as bereft of tradition, exists beyond boundaries, and the nation thus created has to play out on its subjects' bodies.

Indian Tango opens some time right before the 2004 general elections in India, when the country was debating the possibility of the Italy-born Sonia Gandhi becoming the prime minster. This white woman, according to the wishes 
of Mataji's dismissive racism, has to be sent back to England. That Sonia Gandhi, as the informed reader would know, is actually of Italian origins remains a moot point. The color of her skin has destined her to an elsewhere, which is a place away from the ideal India.

It is Jugdish's (Subhadra's husband's) responsibility to read the daily paper to his mother. What the reader witnesses in one of these regular sessions is quite literally how a nationalistic India purges human bodies not conforming to the demands of an ideal nation. As Jugdish's reading progresses, the news items he highlights and those he omits, according to what he understands to be his mother's preference, reveal an India where dead bodies of murdered Muslims, of immolated villagers and those of brides burnt to death by their mothers-in-laws are run-of-the-mill affairs for Mataji. As the novel puts it, Jugdish reads only those news items that "ne choquera pas sa mère" ['would not shock his mother'] (36). Even if, hypothetically speaking, Jugdish had chosen to read the omitted portions, the reader is well aware that the matriarch would not have believed what such trashy newspapers ("feuilles de chou" ['rags']) said against the "grand pays non-violent" ['the great non-violent India'] (37). This is an India belonging to Gandhi's legacy that she has imagined for herself. ${ }^{52}$

In Indian Tango, there are numerous examples of women's bodies being called into the nationalistic agenda of the Indian nation-state. The two violent deaths of women in the novel are a perfect example of what McClintock says about privileging women's shamed bodies as indispensable to the creation of an idea of nationhood:

Quatre-vingts musulmans piétinés par la foule en colère. Dix hindous empalés sur des pieux par vengeance. Vingt enfants disparus. Cinquante femmes violées puis éventrées. (36)

Une enfant exposée, une virginité vendue aux enchères [...] trop du ventre de ce pays. (37)

[Eighty Muslims crushed by an angry crowd. Ten Hindus impaled on stakes in retaliation. Twenty children missing. Fifty women raped and disemboweled.

A naked child, her virginity auctioned to the highest bidder [...] too much of the country's underbelly.]

While both are news items published in the newspaper that Jugdish is reading out aloud for his mother, the first reports the death of people in communal riots 
and gains great approval from Mataji. The novel is set during the immediate years that follow the 2002 riots in Gujarat, a state in Western India, headed at that time by Chief Minister Narendra Modi. Mataji's vengeful endorsement of Hindus massacring Muslims aligns the mother-in-law alongside a right-wing nationalistic political ideology.

Ils vont tous nous massacrer. Se venger, oui, oui, c'est bien, c'est très bien. (36)

[They will slaughter us. We need revenge! This is good! Yes! This is very good!]

The irony is not lost on the reader. Mataji is presented as "[r] éfugiée derrière la parole de Gandhi" ['seeking refuge in Gandhi's words'] and yet consumed by a paranoid sectarian hatred. She finds it perfectly acceptable to endorse the killings of Muslims in order to protect "nous" ['us'].

While one identifies Hindus and Muslims according to their religion, women and children are identified as such. That these women are raped and then have their abdomens torn out ("éventrées") is already a powerfully violent imagery that speaks to the violence prefigured within a restrictive nationhood toward women's bodies. A woman's body, irrespective of its other identity markers, is always implicated with its reproductive sexuality toward nation building.

Mataji's conception of a right-wing nationalism does not flinch at the thought of the female body immolated in the cause of ethnic cleansing. The same ideology also very actively disapproves of any other kind of violence that might undermine the imaginary greatness of India. One needs to elide all disconcerting imagery regarding this reproductive body in order for it to continue scaffolding the national cause. The news story that revolves around the second quotation above is about a young girl from the slums. Her mother puts her virginity on sale to the highest bidder. Enraged men, whose offer the mother turns down, rape and mutilate the girl. The price was not good enough.

Since it would contradict Mataji's "illusion de la grande Inde philosophale" ['illusion of a great philosophical India'] (37), Jugdish does not read this news item to his mother. The idea of a for-sale young naked virgin girl gang raped would not sit well with her vision of a great philosophical India. The voice in the background of the novel explains that reading this news item would "révèle trop du ventre de ce pays" ['reveal too much of the country's (under)belly'] (37). 
The changing connotations of the French word "ventre" (meaning both womb and belly) testify to the arbitrary lines drawn across the human body that equate it with the nation. Is it the literal "ventre" the "ventre" of the raped woman's body? Or does this "ventre" function here as a metonymic device for the entire country: the underbelly of the nation? Or is it meant to be both? This ambiguity renders the nation's belly and the woman's belly indistinguishable. Much like in Fanon's title "L’Algérie se dévoile," this woman-nation ambiguity belongs to a prescriptive grammar that creates the nation as a gendered entity. Nationalism, to remain meaningful, feeds on the body for its own constitution: exposing one "ventre" would necessarily implicate shaming the other.

Mataji's Gandhian nonviolent India is not so much a descriptor of reality but is instead a paradoxical field of epistemic violence. A violence that first categorizes and then reduces these bodies to the demands of a nation. This violence shows how inhabiting a nation's boundaries is not equally available to all. Where for McClintock it was important to engender the nation as a mother, here the affirmation of a national identity is necessarily dependent on a very purposeful erasure and concealment of this gendered body's overt exploitation.

\section{Delhi's Underbelly}

The idea here is not to present the overpowering pervasiveness of these forces; instead, this figures as a revelatory argument. If this novel presents spaces wherein feminine sexuality becomes a function of national spatiality, there are also moments in Devi's writing that contrast this logic of expropriation. Her work becomes the staging ground where spatiality and identity are extricated from the clutches of nationhood to link them instead to a community created by the shared urban experience of everyday exploitation. This tension between the body and the determinative powers also becomes a means to counter these powers. This rejected body, in the fractures and derision it negotiates, produces a corporeality that is participatory, unlike the distinctly subservient kind that Mataji's India commands.

The quotation that follows is a description of the landscape of Delhi from the point of view of Subhadra's eventual lover. This unnamed woman breaks away from constant surveillance and control to discover a transformed landscape 
expressed in terms not of mythical borders but of the economic presence that underwrites bodies in the urban environment:

Le soleil qui entre par les impostes dès cinq heures du matin m'empêche de dormir. Mes draps sont embrumés de rêves chauds. Je sors tôt pour tromper la vigilance de la lumière.

Je n'ai plus peur de la rue ni des regards. Mais tout le monde fait comme moi et, bientôt la rue est encombrée de scooters et de marchands ambulants et de porteurs tenant en équilibre sur leur tête des balles de riz de cinquante kilos, ou, sur le vélo qu'ils poussent, des empilements de planches de plusieurs mètres de long, des armoires, des matelas. Ma promenade vers le petit parc non loin devient un parcours d'obstacles. Je m'y habitue. Je me faufile. Je contourne les enfants encore endormis sur le trottoir sans les réveiller, avec un regard de tendresse navrée pour leur petite bouille sage.

Je laisse, subrepticement, un fruit, un vêtement, un stylo, auprès d'eux. Mais je sais que, si je les réveille, le regard qu' ils ouvriront et poseront sur moi ne sera pas rempli des rêves de la nuit mais de l'immédiateté de la vie. C'est un gouffre que je n'ai pas envie d'affronter. (46)

[The sun that starts shining through the fanlight at five in the morning prevents me from sleeping. My sheets are all soaked up in clammy dreams. To evade the vigilance of light I set out early. I am no longer scared of the street or its people.

But everyone, like me, has come out early, and very soon the roads are choked with scooters and street hawkers, and porters with fifty kilo rice bags balanced on their heads, or, pulling their cycle rickshaws piled up high with planks that are several meters long, with almirahs or with mattresses. My walk to the little park, not very far from home, turns into an obstacle course. I figure my way out. I weave in and out. I go around the children still asleep on the footpath without waking them, looking with sad tenderness at their small calm faces.

I quietly place a fruit, or a piece of clothing or a pen next to them. But I know that if I wake them up, the eyes that open and with which they shall look at me shall not be brimming with the dreams of the night, but with the immediacy of life. It's an abyss I have no desire to confront.] 
It is almost as if one is reading the exact converse of the scene that describes Paule's dying moments. Not only in its descriptive itinerary but also in the way it registers economic activity, this is an antithesis of the culminating moments of the novel Rue la Poudrière. Paule, dejected and having given up on life, sits contemplating the crumbling city from which she has definitively retreated. The description moves from inside Paule's room to outside and after following the white-hot sun returns to a sun-heated furnace-like room, where one presumes the protagonist finally succumbs to the pressures of the city.

In Indian Tango, as if to mirror the beginning of everyday life that is to follow, the description begins with the rays of the early-morning sun entering the room to wake up the unnamed woman. The narrative then follows the woman, who unlike Paule, moves into the city in an act of defiance, even as she senses the societal pressures ("Je n'ai plus peur de la rue ni des regards" ['I am no longer scared of the street or its people']). Where Paule is recording a moment of unraveling of the city as the ungainly and often hidden byproduct of the urban processes, here the description adds up the city with the bustle of the mundane minutiae of everyday microlevel economic activities, the totality of which aggregates into lives of ordinary urban populations all across the world.

The scene begins in the bedroom of Subhadra's lover and ends on the footpath where homeless children are sleeping, that is to say the scene ends in their bedroom. The reversed map of financial movement, from the bedroom of a well-to-do woman through the vendors of things for everyday use, finally ends with the financially frozen children lying on the footpath. Through this reversed map, as the novel spatializes the narrative by charting objects in her room, on the street, on the footpath as well as in her own consciousness, it paves the way for understanding the materiality of lives in terms of everyday iterations. Multiple levels of interweaving emerge through the trope of charting through bodies. When the novel moves through the woman's body, then through the hawkers and vendors, and in the end quite literally over and around children sleeping on the roadside, it presses for rethinking the idea of community and communal space solely in terms of a nation.

The novel follows the mobile narrator to elaborate on the plethora of possible relationships between citizenship, everyday life and marginalized subjectivities. Instead of focusing on the moral and physical imperatives of a nation's imposed law this trajectory, which traces through the lines created by bodies spread across communal spaces, juxtaposes private and public not as separate entities but as components integral to each other. Indeed, it asks us to interrogate, as the narrator implicitly does, the financial distance between the two sleeping places. 
Where for the sanitized version of the mother-in-law, the child's naked body left for sale in a public space needs to be negated and ignored, the same body multiplied many times over forms here an irrevocable itinerary marker through which this woman charts her path across the city.

In this telling, the social is unimaginable without understanding the investment of bodies within the communal. This novel reveals for us the concealment of the effects of the national discourse on bodies, in particular on gendered bodies, and the nation having male characteristics. If this novel reveals national spatiality as the privileged site through which one exercises control on bodies, it also unfolds for us the simultaneous dissolution of such spatial configurations. It is through such a communal spatial depiction that the novel challenges the limits of nationality even as it presents alternative configurations of imagining community beyond the hegemonic and abstracted spaces of nationhood.

Devi's focus on the commoners' everyday also prefigures the anxiety to counter the order of the Baudrillardian hyperreal. During the fast globalizing twenty-first century, Devi records how the inscrutable financescapes, whose proliferation propels Appadurai's writings and which I discussed in Verne's context, have alienated the most elemental of all spaces: the human body. The body in movement ("marchands ambulants" ['street hawkers']; "porteurs" ['porters']; "le vélo qu'ils poussent" ['pulling their cycle rickshaws']; "Ma promenade" ['My walk']; "Je me faufile. Je contourne" ['I weave in and out. I go around']) in the description above that is situated according to urban coordinates will, in the section that follows, lose all its moorings. Within the hyperreal, signified-less consumerism co-opts these bodies and alienates them from their contextual anchors as well as from their subjectivity.

\section{Antipodal Itineraries}

As already discussed, the collection L'Ambassadeur triste is bookended by two very-loosely connected vignettes about two lonesome men who relocate internationally for financial persuasions. The first, the title story's "L'Ambassadeur triste" ("The Sad Ambassador") is the unnamed ambassador of a Nordic country posted in Delhi to boost his country's economic ties with India. Surrounded by all possible comforts and a retinue of servants normally afforded to the rich in India, the perpetually sad ambassador lives a miserable life constantly pining 
for his home country. Abandoned by his wife three months into his stay, he awaits, for the last ten years, the day when he would be able to leave this "terre de damnés" ['godforsaken land'] (10). As if to prepare the argument about the antipodal relationship between the two men, "Bleu Glace" ('Ice Blue') is the last story, placed at the other textual extreme of the collection. "Bleu glace" is about another unnamed male located at the opposite end of the social and financial spectrum. Unlike the ambassador, this financially nondescript man lacks empathy and is "rarement triste" ['rarely ever sad'] (178). Without any "diplômes, sans aptitudes particulières" ['particular qualification or aptitudes'] (176), in search for money, he has traveled to one of those "lieux si inhospitaliers que personne ne veut y travailler" ['places that are so inhospitable that no one wants to work there'] (176-7). Where exactly might this place be? No one knows. However, there are enough indicators to suggest that the ambassador and this man might have interchanged geographical locations.

The ambassador "rêvait de fjords et de lave figée" ['dreamed of fjords and frozen lava'] (9) and is from a place where it is only occasionally that "lumière fendait les nuages d'un scalpel" ['light is able to slit through the clouds with a scalpel'] (9). That he is from a "pays nordique" ['Nordic country'] (12) is the only geographical information available about him, apart from the location of his current posting - New Delhi. The unnamed man in the other story works in an extremely cold place where ice breaks under one's feet like glass, and frozen liquids in air make crackling sounds - all climactic condition one would identify with a Nordic country (175-6). It is one of those places, the narrative voice tells us, like northern Alaska, Greenland, Iceland or the coasts of Newfoundland, where no one wants to work.

Their connection is never overtly stated. However, these two stories do talk of a meeting between two men, who resemble very closely the profile of these two unnamed characters. From the ambassador's point of view, one learns that he had advised a strange man looking for work in his country to seek employment instead in Alaska (16-7). In a mirroring narrative, "Bleu Glace" talks of the man approaching many ambassadors, one of whom, with "l'allure triste" ['sad looks'] (177), after trying to dissuade the unempathetic man from such an undertaking might have directed him to his current job, where he works now in a seal-meat processing factory. The narrative states:

Les seuls endroits où des gens comme lui - sans diplômes, sans aptitudes particulières - sont bien payés, c'est là où il y a la guerre ou dans des lieux si inhospitaliers que personne ne veut y travailler. Le nord de 
l'Alaska, le Groenland, l' Islande, les côtes de Terre-Neuve. Il a sollicité plusieurs ambassadeurs, dont l'un, à l'allure triste, a tout fait pour le décourager d'une telle démarche, avant d'être aiguillé sur cet emploi. $(176-7)$

[The only places where people like him - without any particular qualification or aptitudes - are well paid, is where there is a war or in places that are so inhospitable that no one wants to work there. Northern Alaska, Greenland, Iceland, the coasts of Newfoundland. He approached many ambassadors, of whom one, with sad looks, tried his best to discourage him from such an undertaking, before being directed toward this job.]

It could well be that the sad ambassador had directed the man toward this job. In addition, because of the way the place names have been included in the quotation above from "Bleu Glace," it is unclear whether they refer to one of the inhospitable places that are likely to hire an unqualified person like him, or if they refer to the embassies of these places that he might have visited to explore job opportunities. The point being that one cannot be certain if "cet emploi" ['this job'] in a seal-meat processing factory is placed in Alaska, where the ambassador might have directed him, or if he is in one of the other locales, such as Greenland and Iceland - one of the Nordic countries.

Nonetheless, what connects these two men, and brings them together in this argument, is not only that they have interchanged geographical locations with each other. Nor is it only that they stand at geographically, socially, emotionally and financially opposite ends. Despite their antipodal relationship to each other, they are both subservient to a system where the collusion of the modern nation-state and capitalism exercises control and resignifies their bodies, as well as their geographically dispersed locations, within an interconnected financial matrix that extends across the globe, across nation-states and encapsulates all classes and peoples alike. While Indian Tango and L'Ambassadeur triste both, right from the title itself, are inherently dependent on a matrix of nation-states, the narratives themselves prepare the grounds for understanding its confrontation with alternative articulations by displaying the collusion between these states and capital.

Without ever taking overt center stage, the presence of a network of global financial system is palpable and constantly available through the effects that it produces on peoples' lives and in particular on their bodies. In a story that gives 
you little inkling of the ambassador's origins, it nonetheless points out that it is the economic system, a system that is "des plus abscons" ['most complicated of all'], which is behind his existence in India and the intergovernmental connection between these two countries:

Il ne savait plus qui avait cru que le salut économique du pays était lié aux accords commerciaux avec les géants de l'est. Cela aurait eu un sens s'ils avaient eu quelque chose à exporter, mais toute leur économie était bâtie sur un système bancaire des plus abscons et [...] il avait été envoyé là-bas en fanfare et à grand renfort de promesses électorales de relance économique. Mais, une fois rendu, il s'était heurté à une fin de non-recevoir masquée par des manifestations volubiles d'amitié. (12)

[He had no idea who thought that the economic salvation of his country was dependent upon commercial agreements with giants of the East. It would have made sense if they had something to export, but all their economy was based upon the most complicated of all banking systems $[. .$.$] he had been sent there with great fanfare, backed with$ electoral promises of economic revival. But, once there, he collided with blunt refusals laced with voluble shows of friendship.]

The "most complicated of all systems" needs to be understood here as more than just a qualifier for the banking system of the ambassador's native country, and instead needs to be interpreted as an exemplar of the Baudrillardian space I have been evoking. When "economic salvation" and "economic revival" are the reasons for the ambassador's presence in India, this complicated system becomes the reason for the sadness of the main character of the title story and thus also the very raison d'être of this collection. Due to economic compulsions the powerful ambassador is forced to relocate toward India, and, in the last story, the unqualified worker is forced to relocate away from India. Not only does this forced relocation speak to the all-encompassing power of this system that circumscribes the globe - it also gives access to a seemingly far-flung vector of a system that is changing definitions of a fast liberalizing Indian setup. From a period when Vernian travelers, as active colonial incarnations traversed a colonial geography relying on colonial infrastructure, in Devi's work one comes to witness the dynamics of a system that abstracts laboring bodies across the globe. This system props up unseen capitalist pillars not only in the freezing cold of "Bleu Glace" but also in the hot Indian desert of Rajasthan that is found in "L'Ambassadeur 
triste." This all-encompassing global apparatus enfolds within itself moving parts like the lowly-educated unnamed man, and hegemonic tools like the ambassador, as well as all those nomads who have come to a standstill, unable to wander about the desert (in the Baudrillardian sense that I discuss below) because of production processes being played out elsewhere.

\section{Desert Safari}

We are speaking of the time when the ambassador travels through the deserts of Rajasthan where he thought the heat would kill him (23). Despite catching a dreadful diarrhea that forced his guide to stop every ten minutes to "évacuer mes intestins" ['evacuate my intestines'] (23), the ambassador does return alive. He brings back stories of space-constricted nomads, unable to move, as if frozen in place due to a hyperreal that is spreading in from the cold seal-meat factory of "Bleu Glace." This was a mission to go and locate a rich businessman who, interested in unique experiences in the most inhospitable places (21), had decided to travel to Indian deserts. The businessman never returned and his wife, concerned about his well-being, contacted the embassy. The ambassador, convinced that on completing the mission his government would let him return to his home country (24), charges for the desert. He finds a dead body. Or, rather, he finds what remained of a human body after the sun, the wind and the vultures had done their job (24). One learns that the nomads accompanying the businessman, panicked on discovering that the foreigner in their charge had died. Apprehensive of the harassment they would face at the hands of the police if they were to report the death of this man, they fled the spot.

This desert holds no promises. Or, rather, because of the advancing hyperreal, it cannot hold any promises. It leads to death, and for the ambassador, to ultimate disillusionment when he finally realizes, after this two-day trip, that India loathes him and wants to expel him like a virus:

Mais après deux jours dans ce désert aux couleurs effarantes, [...] j'ai compris une vérité qui m'avait jusqu'ici échappé : ce pays me détestait... non, me honnissait, éprouvait envers moi une haine opiniâtre, comme si j'étais un virus dont il devait se défaire. (24) 
[But after two days in this desert of frightful colors [...] I finally understood a fact that had until then escaped me: this country hated me ... no, it despised me, displayed an unyielding loathing toward me, as if I were a virus that it had to rid itself of.]

This desert of frightful colors, which does not give the sad ambassador a passage home, is quite unlike Baudrillard's desert, which, as James Walters points out, offers both the hyperreal stripped of "meaningful interaction and social dynamism"53 (120-1) and the possibility of redemption. For example, in Simulacra and Simulation, Baudrillard's Las Vegas figures as "the absolute advertising city," which rises "whole from the desert in the radiance of advertising at dusk, and return [s] to the desert when dawn breaks." This is a Las Vegas where "advertising is not what brightens or decorates the walls, it is what effaces the walls"; where surface reabsorbs "whatever signs circulate there" and plunges us "into this stupefied, hyperreal euphoria" (Simulacra 91-2). This desert is, to borrow from Lefebvre, ${ }^{54}$ where "space appears solely in its reduced form. Volume leaves the field to surface." The walls and the human activities that they enclose no longer give the desert its meaning. The contourless surface of the desert becomes the flat backdrop on which can be projected a new value, a new semiotic process that owes its allegiance to bright neon lights, advertising screens and mechanization.

This process also owes its allegiance to all the "tableaux Excel" ['excel spreadsheets'] and "outils de communication de dernière génération" ['cutting-edge tools of communication'] (21) that had helped the rich businessman plan everything in the most precise manner and that he subesquently introduces into the landscape of Rajasthan. His death needs to be understood as martyrdom in the cause of reinforcing this new mechanism of generating meaning, in a place that is as isolated as the seal-meat processing factory and as infernally hot as the unnamed man's current location is cold.

In an earlier work like L'Arbre Fouet, almost all evocations of India involved a mythical entity of inscrutable laws and faraway religion. Even in the novel Indian Tango India remains a magical land where "bonheur n'a pas de traduction" ['happiness has no meaning'] and "veillesse est grande" ['old-age is venerated'] (19). By the time one comes to L'Ambassadeur triste to speak of the unskilled man who has exchanged locations with the ambassador, who himself is busy chasing after the rich businessman, the matrix of signification has completely changed. The undefinability in Devi's work that followed Glissant's "lieu est incontournable" is now replaced by the signified-less signifier of Baudrillard's hyperreal global spaces. 
The cold of the seal factory is as implicated in the process of value creation as the extreme heat of Rajasthan, where nomads, apart from being guides, now work in hotels:

Il faut dire qu'ils étaient désormais des êtres assiégés, leur territoire diminuant jusqu'à ce qu'il ne leur reste plus, pour leur transhumance, qu'un espace délimité de toutes parts par la sédentarité agressive des autres peuples. Leur bétail n'était plus aussi prisé qu'avant, ayant été remplacé par des produits congelés venant de Nouvelle-Zélande. Leur artisanat aussi avait été détrôné par des objets en tout point semblables venus de Chine. Ils vivaient grâce aux touristes fascinés par leur étrangeté, leurs yeux clairs, leur peau burinée par les vents et le soleil, et aux hôtels qui faisaient appel à eux pour chanter, danser, cuisiner des plats traditionnels et s'exhiber comme des ours savants. Leur regard avait la couleur de l'horizon, car le voyage était inscrit dans leurs gènes. $(21-22)$

[It needs to be pointed out that they were becoming increasingly besieged beings. Their lands were shrinking till all they had left for transhumance was an area bounded from all sides by the aggressive sedentariness of other peoples. Having been replaced by frozen products from New Zealand, their cattle wasn't as sought after as before. Their handicrafts too had been ousted by products made in China, that were comparable in all respects. They were making a living thanks to tourists fascinated by their strangeness, their pale eyes, their skin etched by the wind and the sun, and also thanks to the hotels that called them to sing, dance, and prepare traditional dishes, and perform like trained bears. Their eyes had the color of the horizon, because traveling was written in their genes.]

This is quite literally a scene of the advancing hyperreal and a change in the meaning of space through changing definitions of movement. Tourists, those current-day cousins of Phileas Fogg, have transmuted into nonambulatory entities because travels (if one can call it that) involve staying in hotels. Ironically, it is this new paradigm of touristic displacement across hotels, a part of "sédentarité agressive" ['aggressive sedentariness'], which is constantly shrinking desert spaces $^{55}$ belonging to these nomads, whose nomadic movement and transhumance are the very reason these tourists are here. 
It is not that the nomads are not moving (after all, "le voyage était inscrit dans leurs gènes" ['traveling was written in their genes']). Their movements now involve traveling along prefixed pathways that lead to hotels where they recreate an authentic cultural experience for the traveling tourists: "chanter, danser, cuisiner des plats traditionnels et s'exhiber comme des ours savants" ['to sing, dance, and prepare traditional dishes, and perform like trained bears']. This made-forthe-tourist value-based system, where it is in the hotels that these nomads recreate the desert and its culture for the rich, exists no more than as a simulation of the real. So much so, that even what one sells as traditional arts and crafts are nothing but impostor imitations mass-produced in China.

What completes the saturation of this desert by the new capitalist order of value is that these nomads of Rajasthan now consume "produits congelés venant de Nouvelle-Zélande" ['frozen products from New Zealand'] because of which their own cattle have lost their place of pride. Where "Bleu Glace" presents the process of packaging meat in a faraway land (a process in which an uneducated man of potential Indian origin is implicated), "L'Ambassadeur triste" shows the changing definitions of the lives of the people of Rajasthan due to similar packaged products that originate from a different hemisphere.

The forced movement of the likes of the uneducated man contributes to the forced stasis of the nomads. In this tourist-infested, imitation-product-flooded land of nomads who consume packaged products, it is no longer possible to disengage from the "illusion of value" (Simulacra 153). Where Las Vegas is a desert of advertisement and neon lights, in Devi's narrative it is the make-believe life of these nomads that hides the real. Their economic activity of creating a hotel-based signifier of pretend practices offers no hope, either for the ambassador or for the nomads. For Baudrillard, though, it is still possible to be nomads of the desert of hypereality "disengaged from the mechanical illusion of value" (Simulacra 153).

It is following from Borges' story of a map that eventually crumbles into the desert that Baudrillard found his opening parable for his famous Simulacra and Simulation to speak of the hyperreal that surrounds us. Borges, in his short one-paragraph story "Exactitude in Science," ${ }^{\text {6 }}$ talks of the "Art of Cartography" that reached such perfection that the Cartographers Guild "struck a Map of the empire" of such exactitude that its size conformed to the size of the empire. The map "coincided point to point with it" (325). Eventually, with later generations, who, it turns out, were not interested in cartography, the map is left to rot in the desert. Baudrillard reverses this map-territory parable to speak of the present day hyperreal that I have been referencing above. ${ }^{57}$ "The territory," Baudrillard 
explains, "no longer precedes the map." Instead, it is "the map that precedes the territory" (Simulacra 1). The hyperreal of the consumerist society is just that. It follows the map imposed by a designed-for-the-consumer culture.

In Borges' narrative this map lies in tatters "in the Deserts of the West, still today," and there is "no other Relic of the Disciplines of Geography" in the "Land" ("Exactitude"). However, in the multiple usages of the desert in Baudrillard's writing one can still see hope against a simulacra that ensnares unnamed workers in the cold of snow and among unfriendly machinery.

James Walter states that if this desert makes multiple appearances in Baudrillard's work, it is, for sure, to connote the decrepitude associated with the desert in the fable above, such that "the desert is a metaphor for late consumer capitalism, stripped of symbolic exchange, of meaningful interaction and social dynamism" (120-1). This desert "symbolizes the vacuous superficiality of the hyperreality" (Walter 120). More importantly, this desert is also "the desert of Mount Sinai where desolation makes possible revelation" (Walter 121). That is why one can hope to discover a path in this desert that shall take us back to the order of the symbolic exchange. The "superficiality of the hyperreality" and the potential of "revelation" both are simultaneously available in Baudrillard's enunciation below:

[O]nly the phantom of value still floats over the desert of the classical structures of capital, just as the phantom of religion floats over a world now long desacralized, just as the phantom of knowledge floats over the university. It is up to us to again become the nomads of this desert, but disengaged from the mechanical illusion of value. (Simulacra 153)

Desert as a metaphor here operates like the depthlessnes of the capitalist city; "The desert of the real itself" (Simulacra 1). Baudrillard will soon go on to write, "because the desert of cities is equal to the desert of sand" (Simulacra 153). If the capitalist city is the desert, it is still possible to "again become nomads of this desert," to be "disengaged" from this all-pervasive "illusion of value." The shift toward the desert where it is possible to be disengaged from "illusion of value" is what the following section displays. It lays out how Devi's work, in the way that it delineates the lives of ordinary global citizens, is markedly political and is geared toward an active engagement with the collusion that contemporary society is witnessing between capitalism and nationalism.

Exploited bodies are invested in a machinery of capital generation that shows up, despite its absence as an overtly overbearing entity. This is the 
dominant hierarchy, working in the background that reconfigures human bodies according to the demands of an abstracted system of transactions. Devi's narratives stage these bodies to assert their presence within capitalistic dynamics, all at the same time revealing its workings to open up the possibility of undoing India as a modernist nation that figures as one of the vectors in the global system of capitalism. It is through negotiations of simultaneous revealing and undoing of a global economy that Devi's oeuvre begins to chart out alternatives to standardized understandings of nations with boundaries and representative economies.

\section{Producing Dissent}

Returning, then, to the cold of the seal-meat processing factory where the workers, both locals and outsiders, are negotiating their everyday lives and bodily associations within a system that regulates and regiments everything to maximize production. With very little interaction between them, already the division between the local workers and those from outside is rigid. Further, the employers have proscribed any interaction between outsiders and the local women. This is to prevent a repeat of incidents like the rape of a local woman by a foreigner, as had apparently happened in the past. There is, however, one day of exception. On Christmas, outside workers get to bid against each other in an open auction to buy the privilege of sleeping with a local woman. This one-night arrangement with the local population, while being extremely expensive for the workers, makes locals more money in one night than they would earn in an entire year (187).

Could one call it prostitution then? I would resist the urge to hasten with a judgement. We do not know the actual cultural moorings of this geographical context to qualify this as a stigmatized practice, and Devi's text offers no explanation. While these alone are good reasons to stay away from labels, I choose indifference toward a definition because I would like to read this as the ultimate affect-less dystopian market dynamics of financial abstraction, where things derive their definitions by their association with the larger monetary network. While Paule from Rue la Poudrière is a prostitute in Mauritius and inhabits spaces, both geographical as well as moral, that connote the stigma associated with the profession in the local context, the women from "Bleu Glace" are participating in the creation of a hyperreal institution generated by the consumerist dynamics of satisfying sexual needs. 
This arrangement almost literally plays out David Havey's assertion about how "capital continuously strives to shape bodies to its own requirements, while at the same time internalizing within its modus operandi effects of shifting and endlessly open bodily desires, wants, needs, and social relations." ${ }^{58}$ As a signified-less signifier this arrangement cannot have a name, because its contours depend on the changing dynamics of this production mechanism, which in itself is built-to-demand for eventual consumers. This system is designed to absorb the perpetually "shifting and endlessly open" bodily needs and desires of workers that it imposes upon them, thereby ensuring smooth and nimble operations of constantly evolving financial equations that result from a global matrix.

With factory workers themselves acting as consumers, the auction figures as the mediating mechanism that modulates demand and supply of local sexual availability, in these dynamics of international proportions. If the ambassador is part of a system that aims to increase economic ties within nations, then it is not without the exploitation of people like this unnamed man, whose international movement in turn is both facilitated by and is dependent upon ambassadors and nations. While it is the worker's body that bears the ultimate abstraction within a system of value, they both remain as interdependent cogs of a much larger whole.

In the culminating moment of "Bleu Glace" the uneducated man through his sole annual act of purchased lovemaking displays the complete enmeshment of the worker's body within the capitalist system. The first thing that the worker notices on his arrival is the strong smell in the seal-processing factory: "Ce qui le frappe [...] C'est l'odeur." ['What strikes him [...] It's the smell.'] (183). The last thing that the reader gets to know is that on the only night of annual sex the man "fait l'amour à l'odeur des phoques" ['made love to the smell of seals'] (192). Between the two moments lies the gradual process of conformation of the human body to capitalist contours. Both the man's and the woman's subjugation to the product that they serve is thematized in the transition that one sees between the seal-worker relationship. This conversion suggests ways of understanding meaning under the new economic grammar and the altered bodily conventions under the new dispensation.

The first of the two descriptions below presents this man's maiden encounter with the dead seals in the factory. The second is a description of the woman the unnamed man is having sex with. It delineates the woman's body from his point of view and uses a vocabulary that is startlingly similar to the one used in the first description, where the unnamed man stands watching a coworker sitting astride over a dead seal, processing its body for eventual packaging and sale: 
...dans une position trop humaine. La tête est beaucoup trop petite pour ce corps massif. Les yeux sont fermés, [...] les nageoires sont réunies, presque dans une position de communiant. [...] sa couleur bleunoir, la glissade de la masse lorsqu'elle heurte le sol. [...] L'homme se place au-dessus du cadavre, une jambe de chaque côté, trouve une prise avec ses doigts et déchire la peau, écartant largement les lèvres de la fente ... (184-185)

[... in a pose that was too human. The head was too small for this massive body. The eyes are closed, [...] the flippers are together, almost as if they were receiving communion. [...] it's blue-black color, the slipperyness of the mass as it hits the floor. [...] The man climbs atop the carcass, one leg on each side, finds a hold with his fingers and tears the flesh, spreading wide the lips of her slit...]

The graphic description of the worker violently tearing the seal's body, and spreading wide the lips of its sexual organ, establishes the power dynamics between the worker and the product. Until this point, the product and the worker exist as separate entities, both implicated no doubt in the production process, but in a way where the seal exists as the raw material being rendered into exchange value. It prepares the grounds for understanding the change in this dynamic that one discovers in the scene of the two workers having sex. The man, completely drunk, sees the woman sitting astride over him as bearing the characteristics of a seal. At the same time, his resistance-less body is being carved like that of the seal:

Dans le noir, il voit ses yeux fixés sur lui, parfaitement immobiles. Sa tête est un peu petite, par rapport à la masse du corps qui se fond à l'obscurité. Elle a les mains jointes - une pose de communiante. Elle se lève à demi et se glisse sur lui. [...] Sa bouche glisse sur lui. Elle va et vient, le longe et le dévore.

Elle s'assied à califourchon sur lui en lui tournant le dos. Sa chevelure, très longue, lui recouvre entièrement le dos. C'est comme un pelage bleu-noir qui cache le teint pâle de la peau au-dessous. Cela lui rappelle quelque chose, mais il ne sait pas quoi. Il est engourdi par le sommeil et l'alcool. Il ferme les yeux, commence à se livrer à elle, mais ensuite, ses narines frémissent. (191-2) 
[In the dark, he sees eyes fixed on him, perfectly immobile. Her head is a little small, in relation to the mass of her body which dissolves into the darkness. Folded hands - a communicant's pose. She half rises and slides on top of him. [...] Her mouth slides over him. She goes back and forth, goes lengthwise and devours him.

She sits astride over him with her back toward him. Her hair, very long hair, covers her entire back. It's like a blue-black fur that hides the pale complexion of the skin below. It reminds him of something, but he can't say what. He is numb with sleep and alcohol. He shuts his eyes, and starts to give in to her, but, then his nostrils quiver.]

The earlier quotation personified the dead seal: its eyes closed shut, in a "position trop humaine" ['pose that was too human']. Now, it is the woman, her eyes fixed on the man, who assumes the physical traits of the seal. While the text provides multiple examples of how the woman replicates the seal's appearances, here are a few that interest me: "tête est un peu petite" ['head is a little small']; "yeux fixés" ['eyes fixed']; "mains jointes" ['folded hands']; "pose de communiante" ['communicant's pose']; "pelage bleu-noir" ['blue-black fur']. All of them transpose on to the woman the seal's traits using a language that is an almost literal reproduction of the language used to describe the seal in the earlier quotation:

"tête est beaucoup trop petite" ['head was too small']; "yeux sont fermés" ['The eyes are closed']; "nageoires sont réunies" ['Alippers are together']; "position de communiant" ['receiving communion']; "sa couleur bleu-noir" ['its blue-black color']

At the same time, through various stages of coitus, the woman's actions, as she "se glisse sur lui" ['sits astride over him'], replicate the worker's lengthwise carving of the seal's body: "Elle va et vient" ['goes back and forth']; "le longe" ['goes lengthwise']. In the end, she "le dévore" ['devours him']. If she physically resembles a seal and acts simultaneously like a factory worker, the man could also very easily be understood, in his passive surrender, as replicating the passivity of the earlier presented dead seal. It is difficult to say if this scene of sexual intercourse needs to be understood as a reversal of the worker-seal equation, such that it is the seal that now sits astride the worker, or if it is a continuation of the earlier dynamics where it is now another factory worker, the woman, who carves out the flaccid and senseless unnamed man, no different from the dead seal. The story 
ends with a declarative sentence, simply stating that for his "unique nuit de sexe de l'année, il fait l'amour à l'odeur des phoques" ['only night of sex of the year, he made love to the smell of seals'] (192).

For the rest of my argument it is irrelevant which of the two serves as the metaphoric reminder of the seal. In fact, in functioning simultaneously as the workers and the seal, and remaining enmeshed in each other, the two humans replicate in this scene the process of value creation from the factory floor and put on display the extent to which they are imbued with the meaning of the product that their labor produces. This mutual interchangeability between the labor power and the seal gives us an insight into the complicated relationship between capital, labor and raw material. Both the man and the woman are simultaneously human as well as animal, labor as well as raw material. The coming together of these bodies, clearly identified as originating from different locations and yet condensed as one with the raw material, also displays the concurrence of two spatiotemporal scales wherein, at the global scale, "globalization' and all its associated meanings" intersect "with bodies that function at a much more localized scale" (Hope 109). In other words, "the long historical geography of capital accumulation" (Hope 109), as would be necessary in setting up this local factory as well as the entire global apparatus that it metonymically represents, manifests here in the night-long annual ritual, which can only be understood as the sexual by-product of a system of accumulation.

Harvey contends that accumulation "accelerates turnover time" and that even "while [it] simultaneously" annihilates "space through time," it does nonetheless retain "certain territorialities (of the factory and the nation-state) as domains of surveillance and social control" (Hope 109). One cannot help but wonder if Devi might have purposefully followed Harvey to set up her literary narrative, in which the nation-state and its apparatuses of ambassadors serve as conduits for the international movement of labor to this factory in order to process local raw material. In addition to bounded territories, nation-states and factories also serve as binding entities: situating identities and creating a new matrix along which to situate the globe.

Lest we completely capitulate and concede the world to the hyperreal, let us pause for a moment to ask ourselves the following question: Is it not interesting to note that for an author like Devi, who has repeatedly made her work the site for exposing and also speaking against women's exploitation, this story offers little if any explicit commentary on the annual ritual of bidding on women for the privilege of spending the night with them? Neither does it in any evident way speak about the phallic structure of the society we live in. Contrary to 
the purposeful insistence, for example, on the vengeful parricide by a wronged daughter that challenges the misogynist society of L'Arbre fouet, the short narrative "Bleu Glace" seems to gloss over the gender-related power dynamics. The woman climbing astride, taking charge over the man's body, her back turned toward him, is this simplistic reversal the only challenge to the male-centric society that one can read in the work of an author who has always written about women?

In fact, in one fell swoop this moment of heterosexual intercourse dismantles the entire sign-based system that defines our consumerist culture and the gender-based society we live in. It is not without reason that this sexual scene figures here as part of an economic system, whose components aggregate into a much larger whole that is greater than the sum of all its components, based on capitalist exchange value. William Pawlett ${ }^{59}$ points out how, in Baudrillard's writings, sexuality "like economy, is separated out from total social relations, from ritual meanings. It is abstracted, individualised and modelled on economic metaphors" (101). Much like the products in the capitalist society that follow the order of the consumer, the human body, gender and sexuality too are all within the hyperreal, now situated according to the "market of signs." ${ }^{60}$ Women "are given 'woman' as sign, as simulation" (Pawlett 95), in the same way as sexuality "is not a fact or a thing, it is the product of signifying practices that are uniquely modern and Western" (Pawlett 96). What one sees in this scene of purchased lovemaking is a commentary on the human body, sexuality and capitalism, all three intertwined and interlinked by "signifying practices" of modernity and yet creating conditions for overwhelming this system of values to return to a system of "symbolic exchange." 11

The culminating moment of the woman atop the man belies the mental image he held of these women, and which betrayed his adherence to the phallic order. He had imagined them as docile women ("se plieront" ['give in'], "un bon élève" ['a good student'] (189)), possessed by local men: "attendent d'être prises" ['waiting to be taken']. However, once inside the tiny room, he is surprised when the woman first looks him straight in the eye with "une sorte d'effronterie" ['a sort of effrontery'] (191), and then takes the lead in undressing him. She sits on his lap and kisses him with such greedy passion that he is taken aback (191).

The establishment of symbolic exchange does not happen with the woman eventually attaining the sexual position atop him. It is in his mixture of bewilderment, of alcohol and sleep-induced incomprehension that the first instance of exchange takes place outside the tyranny of the modernist sign. He drifts between sleep and semi-wakefulness, "Les yeux à demi fermés, quasi révulsés" ['eyes half shut, almost revolted'] by what he sees on top of him. It vaguely "lui 
rappelle quelque chose, mais il ne sait pas quoi" ['reminds him of something, but he cannot say what'] (192). He will not be able to either, because the woman is replicating Baudrillard's seduction ${ }^{62}$ and creating a unique event of deriving pleasure in a scene that can only perplex him. She:

s'étale vers lui [...] le lape, le noie, l'engloutit

[reaches out toward him [...] laps him up, drowns him, swallows him up.]

The man can only watch the scene pass by him. The linguistic sign stands inadequate to this event and he can only resort to a vocabulary of his quotidian. It is no wonder then that the culminating sentence uses a vocabulary related to seals and the production process to state that he "fait l'amour à l'odeur des phoques" ['made love to the smell of seals'] (192).

Striptease, as Pawlett develops Baudrillard to point out, "is ambivalent because it involves 'a woman's auto-erotic celebration of her own body' [...] that both evokes and revokes the other, the male onlooker." ${ }^{63}$ Similarly, this unnamed man, whose presence in this cold place has been facilitated by an order of values, is responsible for the woman's pleasure, and yet he lies confused, not understanding what transpires around him. As he makes love to the only coordinate that the system of signs allows him, the smell of seals, the woman progressively derives pleasure in and through his presence: "Sa bouche l'absorbe. Elle va et vient, le longe et le dévore" ['Her mouth absorbs him. She goes back and forth, goes lengthwise and devours him'] (192). Striptease involves a male onlooker, who cannot actively participate, who is both "summoned and excluded" (Pawlett 98); here, the man unwittingly participates in a process of exchange about which he remains unaware. He remains implicated in a different erogenous experience from the one that the woman goes through. Present for the purposes of the woman, yet absent from any symbolic exchange.

In the first story of this collection, "L'Ambassadeur triste," the nomads run away from the dead body of the rich businessman. Because such a flight from the carrier of the latest technology and tools of abstraction only amounts to validating them, in abandoning this dead body the nomads have strengthened the order of abstracted values. In "Bleu Glace" there is no need for overt resistance to the male order, or for a political statement against this man's obvious phallocentric worldview, because "seduction in its symbolic order is not exchanged" (Pawlett 99). Any resistance to this world of signs would imply its recognition and indeed a transaction with its static meanings. In Baudrillard's work, as we 
know, seduction "in its symbolic form occurs beyond the conscious volition of subjects" (Pawlett 103). The woman just exists.

In "L'Ambassadeur triste," the ambassador's wife, seeing him disheartened and inconsolably discouraged in Delhi, would reassure him that this was only a stepping-stone, and that they would be at the Metropolitan Opera in New York before long (10). Within three months the wife left "lui et l'Inde" ['him, and India'] (10) forever. Indeed, she leaves him alone to the revolting olfactory experience of the vapors and odors of India:

Une poussière et une terre qui lui entraient par les narines et ressortaient par les pores, [...] il se résorbait dans les vapeurs chimiques de diesel et de soufre qu'un air nocif diffusait dans la pureté de sa chair. $(9-10)$

[A dust and soil that was entering through his nostrils and exiting out through his pores, $[\ldots]$ he was getting dissolved in the chemical vapors of diesel and sulfur that noxious fumes were dispersing into the purity of his body.]

The unnamed man makes love to the smell of seals, and the ambassador's every pore is diffused with the sign of nations. It is in abandoning the ambassador that his wife walks away from the machinations of a nation-based grammar. For this woman in the factory, it is in possessing this man that she renounces him, as well as the rationalized spatiality of the world composed of these factories and nation-states like India, which facilitate the presence of those like him among the seals. The factory floor then becomes the place to produce dissent. A process that commences with the dust and vapors of Delhi ends in a nowhere-land where this man is left whiffing seal smells, thereby ensuring that Mataji's stable and imagined India has forever been dislocated from the grammar of nation-states.

\section{Rediscovering India}

I will take a detour now to connect Devi's still unfolding oeuvre about India with the country's current political situation. If it is important for Devi to write about India, it is also equally important for her to evoke as well as to divest this 
bounded geography of bigoted and exploitative qualities that one is imposing upon it. This concluding segment helps understand the contours of contemporary India that Devi focuses on.

Remember the Gujarat riots and Mataji's communal paranoia that takes a vengeful form against Muslims in the Indian state of Gujarat? The riots took place in 2002. In 2014, news reports began flooding the media about how twelve-year-old school children in Gujarat were learning that current-day scientific discoveries have their roots in ancient India. They were learning that "the first aeroplane was invented during the mythical Dvapara Yuga, when the Hindu God Ram flew from Sri Lanka to Ayodhya in India with his wife Sita and brother Laxman in a Pushpaka Vimana - a swan-shaped chariot of flowers." ${ }^{34}$ This blind valorization, which values above all the imagined purity and greatness of Hindu religion, would very soon start spreading its tentacles across the entire country. Narendra Modi, who was the chief minister of Gujarat during the now infamous 2002 riots, is currently heading the national government as the country's prime minister. Modi led his right-wing party, the Bharatiya Janata Party (BJP), to victory in 2014 and then again in 2019 . His government has progressively led a conscious effort "to reflect its own specific brand of 'cultural nationalism' in these institutions [bodies that deal with education and culture] by engineering long-term changes in their programmes and priorities." ${ }^{65}$ Examples abound of the sure march toward a saffronization of India's educational and cultural institutions ${ }^{66} \mathrm{~A}$ march that will eventually change the very character of the country.

As there has been a growing crackdown on universities and thought-lead$\mathrm{ers}^{67}$ that disagree with the government and its ideologies, concerns have been raised about this systematic quelling of all dissent. ${ }^{68}$ In 2014 Bidwai warned that if things continued unabated, "our educational and cultural institutions will be totally saffronised and irreparably damaged." ${ }^{69}$ Indeed, as the current scenario of the year 2020 reveals, more than just being ideological, the aggression toward universities in India has become overtly violent. One sees acts of violence on universities as a direct result of Modi's bigoted policies. ${ }^{70}$

In addition to promising a corruption-free government, Modi had primarily come to power on the mantra of development, specifically a model of development he borrowed from his own home state. ${ }^{71}$ This "Gujarat model is based on nothing remotely resembling a development strategy, only a fawning subservience to corporations amounting to a more or less complete handover of control over the pace and pattern of development to private capital" (Desai 55).

All of this to show that Devi's literary work is responding to a contemporary India that is simultaneously moving into two opposing directions: toward 
the past in search for pure cultural roots and also along the path of "development" paved with rosy pictures of GDP, growth figures, and foreign direct investment in Indian markets. Ordinary people, already enduring exploitation by the hegemonically advantaged within India, are now being thrown at the mercy of markets operating across international borders.

In fact, these national boundaries are softening in another sense as well. Being Indian is no longer about having Indian citizenship. A citizenship now involves a globally scattered ethnic diaspora that has to belong to the "motherland" for the nation to appear stronger, and for nationalism to thrive. Mahesh Gavaskar $^{72}$ describes how Modi woos the ethnic diaspora during his international prime-ministerial travels, noting how imagining "a homogeneous 'people of Indian origin' on foreign shores" elides the "troublesome reality back home" of a "fractured society" and therefore appears "more hospitable to nationalist utopias" (9). It is thus with the diaspora that "the nationalist in Modi lives his dream on such occasions" (Gavaskar 9).

One needs to understand Devi's diasporic writings and their spatial engagements with India as a response to this citizenship that contemporary forms of power are imposing upon her, and those like her, to limit them to postcolonial statist and capitalist logic. While studying Verne's work I looked at the colonial project's tyranny on the world. In this chapter the focus shifted to postcolonial nationalism and its understanding of human spaces. To display the exploitative energies of the nation-state this chapter traced how this spatial division reinforces itself at the cost of identities and human bodies.

It is almost as if there is a finite container of identitarian energies within the human microcosm. For these spatial divisions to find relevance, they have to feed off human bodies. The better these spaces become at containing (both meanings intended) humans, the less pronounced is the presence of human subjectivity. It is true that this mutual exchange between humans and spatial divisions, natural as well as artificial, has already been the subject of several postcolonial authors' works. Yet, when read alongside questions of homelands and belonging, the spatial arrangements in Devi's work remind us that it is imperative for us to create alternatives both to earlier Senghor-like spatial narratives that mimic colonial nationalisms and to Fanon-like reckless masculine articulations of national identities. They also remind us that it is becoming even more urgent to reckon with the ever-mutating forms of transnational markets that create value out of human bodies. Spatial arrangements in Devi's work reject the sign-based hegemony that both global capitalism and a religion-based right-wing ideology are attempting to achieve over the image of India. 


\section{CHAPTER 4 \\ MARTINIQUE: \\ SPACE, LANGUAGE, GENDER}

Je compris soudain que Texaco n'était pas ce que les Occidentaux appellent un bidonville, mais une mangrove, une mangrove urbaine. La mangrove semble de prime abord hostile aux existences. Il est difficile d'admettre que, dans ses angoisses de racines, d'ombres moussues, d'eaux voilées, la mangrove puisse être un tel berceau de vie pour les crabes, les poissons, les langoustes, l'écosystème marin. Elle ne semble appartenir ni à la terre, ni à la mer un peu comme Texaco n'est ni de la ville ni de la campagne.

-Notes de l'urbaniste au Marqueur de paroles ${ }^{1}$ (289).

[I understood suddenly that Texaco was not what Westerners call a shantytown, but a mangrove swamp, an urban mangrove swamp. The swamp seems initially hostile to life. It's difficult to admit that this anxiety of roots, of mossy shades, of veiled waters, could be such a cradle of life for crabs, fish, crayfish, the marine ecosystem. It seems to belong to neither land nor sea, somewhat like Texaco is neither City nor country.

-From The Urban Planner's Notes To The WORd SCRATCHER ${ }^{2}$ (263).]

Through an analysis of Patrick Chamoiseau's work, this chapter looks at the interaction of the postcolonial subject with the island of Martinique. The previous chapter analyzed how the immigrant in Mauritius imagines India, the country it identifies as its source nation. This chapter reverses the island-mainland equation. 
It is the constantly evolving relationship with the landscape of Martinique that occasions an understanding of the island's relationship with its mainland other - France. Participating in post-departmentalization Martinican literature marked by uncertain literary citizenship, the dominant presence of French borders, and the urgency to reckon with inequalities inherent in Martinican society - Patrick Chamoiseau's Texaco is a literary production that inverts the text-space relationship.

This literary text, forces us to probe further the role of space within the postcolonial context, through its spatial metaphorization of 1) the linguistic equation between French and Creole; 2) Martinique's political relationship with France; and 3) the gendered subject's equation with a patriarchal history. Through its literary structures, Texaco responds to these challenges and performatively enacts the rupture with French colonial borders.

How does space, in its interactions with language and the human body, counter the hovering presence of France and French colonialism over this island's literary production? This is the main question this chapter seeks to answer. The intermingling site where the text of Texaco and the hutment of Texaco are producing each other complicates our understanding of the inherent relationship between language and space. This postcolonial narrative is purposefully set within an appropriated linguistic frame, to produce a self-reflexive understanding of both space and language that is antagonistic toward modernity-inspired spatial fixity available in nations and urban centers.

One of the objectives of this chapter is to display how the gendered articulation of the human body fuses with the colonially marked geopolitical space of the island. This brings to the fore the necessity of understanding the human body as an essential vector of spatial analyses. Marie-Sophie's tactical survival techniques against both the fast-changing urban landscape and the colonial forces exerted on her body remind of the imperative to excavate the forgotten histories of colonized women.

Since Texaco is the centerpiece of this chapter, I begin with spatial readings to show how the novel opens up possibilities of seeing Marie-Sophie invested in the creation of the meaning of her hutment. The next section delineates how, within the Matinican context, Chamoiseau's work and its spatial preoccupations are part of a literary engagement with metropolitan France's political borders. The spatial and linguistic implications of Créolité, and Texaco as a literary rendition of Créolité, become the subject of the third section. I end this chapter by discussing how Marie-Sophie's personal history, formed as it is by a colonial spatiality, gets transported onto the hutment of Texaco. 


\section{Section 1. Contextualizing Texaco}

\section{Texaco and its Significations}

Texaco, Patrick Chamoiseau's third novel, hit the Parisian literary scene in 1992 and earned him the prestigious Prix Goncourt, thereby ensuring him a permanent place in the annals of literature. Texaco is a story that spans over four hundred pages and recounts the loves, lives and travails of the protagonist MarieSophie Laborieux and her father. The protagonist spends the last leg of her life setting up and saving her hutment - Texaco. Texaco, the title of the novel, is a signifier at the intersection of several signifieds. It is the name of the oil company that has its oil depots on the island of Martinique. On discovering the site, Marie-Sophie becomes enamored by its 'magical'3 qualities, decides to make it home and sets up her hutment there. The French-speaking white man who owns these oil depots and the land on which they are placed is determined to have Marie-Sophie evicted. Her relentless efforts to come back ensure her victory over the 'oil-béké's and force him to sell his land to the town council. The inhabitants of the hutment succeed in appropriating Texaco's land.

The company goes but the name remains - the hutment is called Texaco. With Texaco as the name for both the oil depot and the hutment, the title of the novel becomes the signifier of their struggle. By using Texaco as their name, the residents are able to extend their topographical victory to the toponym. From their hutment being passively designated by the company's name, they snatch it to use as their own. Instead of the name naming the topography, the residents' struggle and their ensuing victory gets projected on to the name.

The process of appropriation within the Creole ${ }^{5}$ reality of the name of an American company described in the plot of the novel is analogous to its writing process. Throughout the novel, the reader faces a mixture of both French and Martinican Creole. Marie-José N'Zengou-Tayo and Elizabeth Wilson point out that

one of the major effects of the novel is the way in which he [Chamoiseau] plays with/on languages. The text is replete with puns, word-play, a variety of linguistic registers, code-switching, blurring the distinctions and complicating the relationship between French and Martinican Creole, creating what Milan Kundera in an earlier review of Chamoiseau's work called 'Chamoisified French.' (90-1) 
The name of a big multinational company is staked as a signifier to designate the placement of a hutment. Correspondingly, in Texaco, Chamoiseau uses French to speak of Creoleness. The name of the novel then represents not a nominal category but a process - that of a reversal of appropriation. The process encompasses within it the struggle of how a hutment wrests naming power from a far more powerful entity. The real victory in the novel comes not with the occupation of the land, but through a subversion of the signifier that defines it.

\section{A Spatial Metaphor}

In addressing a French language 'marked by the trace of the mute one' Jacques Coursil is clearly giving another definition for the adjective 'chamoisified" ${ }^{77}$ proposed by Milan Kundera. More importantly when Coursil signals the existence of this spatial war as a metaphor for a linguistic conflict, he conveys that the relationship shared by Creole and French could be better understood by taking into consideration the location of the hutment of Texaco vis-à-vis the city of Fort de France. One notices that "the Town Hall [is] located at the heart of power in the affluent 'centre-ville' while Texaco sprawls miserably around the periphery of the town" in the mangrove swamp on the fringes: "nos cases échassières dans la mangrove visqueuse" ['our stilted houses in the slimy mangrove swamp'] (28; 18). One establishes a clear correspondence between Texaco's spatial orientation in relation to l'En-Ville and the linguistic association between Creole and French. The periphery/center arrangement metaphorically denotes the marginal relationship of Creole to French. This spatial representation of the linguistic connection is made explicit by one of the notes written by the Urban Planner to the Marqueur de Paroles:

Au centre, une logique urbaine occidentale, alignée, ordonnée, forte comme la langue française. De l'autre, le foisonnement ouvert de la langue créole dans la logique de Texaco. Mêlant ces deux langues, rêvant de toutes les langues, la ville créole parle en secret un langage neuf et ne craint plus Babel. (242-3)

[In the center, an occidental urban logic, all lined up, ordered, strong like the French language. On the other side, Creole's open profusion according to Texaco's logic. Mingling these two tongues, dreaming of all tongues, the Creole city speaks a new language in secret and no longer fears Babel. (220)] 
A spatial replication of the center-periphery relationship between the two languages is abundantly obvious in the above quotation, where l'En-Ville with its penchant to organize and its yearning for order represents the French culture, whereas Texaco is marked by the excessive abundance of Creole. ${ }^{9}$ One of TiCirique's notes to the Marqueur de Paroles, while establishing that the hutment signifies Creole, further nuances this spatial equation. In desiring to use 'a French more French than that of the French,' this self-described "Universal" character presents the French language as a representative of the "Universal":

A écrire [...] l'on m'eût vu Universel [...] exaltant d'un français plus français que celui des Français, les profondeurs du pourquoi de l'homme [...] mais nullement comme tu le fais, encossé dans les nègreries de ta Créolité ou dans le fibrociment décrépi des murs de Texaco (19).

[At the task of writing [...] many might have seen me Universal Man [...] exalting the depths of man's raison d'être [...] in a French more French than that of the French [...] but not at all like you do it, you small pea lost in the pod of the monkeying of your Creolity or in Texaco's decrepit asbestos wall (9).]

It is with the acceptance of the peripheral spatial entity of the hutment into l'En-Ville that the novel meets its objective. A relationship based on hierarchy is eliminated, and as Lorna Milne (2000) points out, the hutment will be "different from - but equal to - the metropolitan Center" (167). The novel shows how in many ways the periphery is able to assert its equality with the center. Milne's conclusion about the spatiality of the novel also stands for the linguistic binary proposed by it - Creole, which comes from the margins, is recognized as an equal and is to be reconciled with the center - French. Texaco makes the margin the center of our agenda and shows it to us by making the topographical space represent metaphorically the relationship between the two idioms at stake.

\section{Literary Margins: City and Language}

Apart from the question of nationalism, space and gender, one of the arguments I intend to advance below is that Texaco is both a meta-commentary on the Martinican linguistic actuality and itself a performative product of the kind of linguistic rupture the novel advocates. If one is to agree with Richard Watt that it is in "the margins of the text that the intense mediation of the Francophone 
texts gender, racial, political, aesthetic, and, in the broadest terms cultural specificity takes place,"10(4) then quite clearly Texaco's literary margins are laying out the broad themes that make the core of this chapter. As if in a performative moment, the literary space of the novel Texaco too replicates this relationship of the periphery to the center. The broad agenda of the story of the novel - the struggle being fought for the margins of the city of Fort de France - can be found in the novel's margins.

In addition to the dedication and epigraph (which I discuss below), the main narrative is bookended by two sections. The first (13-15) presents the "repères chronolgiques" ['chronological markers'] important for Texaco. The second is a more traditional table of contents (431-3) that lays out the section-by-section division of the novel. ${ }^{11}$ The subdivisions, both for the chronological markers as well as table of contents, bear headings that speak of construction material: "Temps de cabaret et d'ajoupas" ['The Age of Longhouses and Ajoupas']; "Temps de paille" ['The Age of Straw']; "Temps de bois-casse" ['The Age of Crate Wood']; “Temps de fibrociment” ['The Age of Asbestos']; “Temps béton" ['The Age of Concrete'] (431-3; 3-6).

Pitted against a colonial history, the margins of this text are presented as a form of indistinguishable enmeshment between temporality, language and spatiality. Just as these elements from the margins contaminate the stabilizing locus of modernity through the interactions they produce between the text, space and history, similarly the quotations by Edouard Glissant and Hector Bianciotti placed in the epigraph draw attention to the interplay between language, space and gender:

Que rappellera ici le scribe qui ne rappelle à travers elle le sévère destin de toutes ces femmes condamnées aux maternités perpétuelles, expertes à déchiffrer les prophéties du vent, des crépuscules ou du halo brumeux qui parfois semble émaner de la lune, pour prévoir le temps de chaque jour et les travaux à entreprendre ; ces femmes qui, luttant à l'égal des hommes pour leur subsistance, firent ce qu'on appelle une patrie et que les calendriers réduisent à quelques dates bruyantes, à certaines vanités dont souvent les rues portent le nom?

Hector Bianciotti

La ville était le sanctuaire de la parole, du geste, du combat. Gibier...tu n'es qu'un nèg-bouk: c'est de là qu'il faut parler!...

Edouard Glissant (11) 
[What will the scribe recall, who through herself already tells of the stern destiny of all these women forever condemned to pregnancies, who, in order to foresee the day's weather and figure out what labors to take on, are expert at deciphering the prophecies of the wind, of dusk, or of the misty halo which sometimes seems to ooze out of the moon; these women who, while fighting - as much as men - to survive, made what is known as a fatherland, and whom calendars reduce to a few noisy holidays, to a vainglory after which streets are named?

-Hector Bianciotti

The city was the sanctuary of the word, of the gesture and the geste, of struggle.

You, game ... are nothing but a city-blackman: that's where you have to speak from! ...

-Édouard Glissant (5)]

Of the three quotations, the last two belong to Glissant and alert to the strong affinity that Chamoiseau shares with the former. In fact, in addition to Véra Kundera, the novel is dedicated to Glissant. As is often true of Chamoiseau's other works, the major framework of Texaco is based on Glissant's thoughts (Burton 193). ${ }^{12}$ One also points out that apart from being quoted in the epigraph, Glissant's presence in Chamoiseau's work manifests itself in many other ways. ${ }^{13}$ Serving as homage to Glissant, these two quotations not only present the novel's preoccupations with space and language but also in themselves are examples of how the work inscribes these preoccupations within its structures.

Divided into two parts, the first of these quotations defines "ville" ['city'] in relation to "parole," "geste" and "combat." The second part of the quotation ("de la parole, du geste et du combat") enunciates the link between "parole" and "combat" and places the idea of their relation literally at its center - on the word "geste." Apart from meaning a physical gesture, ${ }^{14}$ geste alludes to an oral tradition whose primary preoccupation was to recount the gallant actions of an epic hero. "Geste," by referring to the orality of the chanson de geste, helps choose from among the number of definitions that "parole" could conjure up: parole is speech - orality associated with the heroic gesture. The idea of combat, evoking the existence of an adversary, is closely related to the first part of the quotation ("La ville était le sanctuaire"). The city offers a safe haven, a sanctuary, a chance at the resolution of conflicts. "[C]ombat" is syntactically placed at the sentence-final position, at the opposite end from "ville." "[C]ombat" is connected 
to the first part of the quotation ("La ville") by the "sanctuaire de la parole," the sanctuary provided by oral speech.

In addition to pointing to urban space as the site for a combat through the spoken word and ensuing action, this quotation opens up the question of the interrelationship between language and space. An interrelationship that I have already discussed in the context of the novel's title, which simultaneously evokes the physical site as well as the literary work and is most abundantly available in Marie-Sophie's project, as she uses the force of her words to seek reconciliation of Texaco with the urban center:

avec pour seule arme la persuasion de ma parole, qui devrais mener seule - à mon âge - la décisive bataille pour la survie de Texaco. (38)

[with my word for my only weapon, who had to wage - at my age - the decisive battle for Texaco's survival. (27)]

Needless to say, she is the epic hero, defined by her grand actions. Her conquest of l'En-ville comes about through her words: "notre conquête de l'En-ville [...] contant ma vie" ['our conquest of City [...] telling my life'] $(38 ; 27)$. How exactly this arm needs to be deployed, and the definition and contours of this speech, get further defined by Glissant's second quotation:

Gibier...tu n'es qu'un nèg-bouk: c'est de là qu'il faut parler!... (11)

This quotation, in which Glissant refers to Chamoiseau as "Gibier"15 and suggests faimiliarity through the use of the second person informal pronoun "tu," needs to be understood as part of an intertextual dialogue being conducted on the margins of literature ${ }^{16}$ about topographical and linguistic margins. The Creole word "nèg-bouk" (city-blackman) in a sentence written in French is followed by an instruction: "il faut" ['one must'] "parler" ['speak'] from the position of "nèg-bouk." 17 The "là" then becomes doubly endowed. Chamoiseau must speak from the position of a "nèg-bouk," a city-blackman defined by the idiom Creole. Secondly, the "là" specifically shows how by speaking he can reflect his subjectivity of a "nèg-bouk" - exactly as it has been done in this quotation - by creolizing his French. Moreover, the inclusion of the quotation above as an apostrophe acts as an injunction and puts the reader in a dialogue with the novel. It informs us, as it instructs Chamoiseau, about both the language and the subjectivity that the word "nèg-bouk" presents. 
With an instruction to speak as a city-blackman, the "lä" reiterates the importance of this urban space for subjectivity formation. Richard Burton notes that while Chamoiseau seems to characterize the city as a true zone of resistance, Glissant is anti-city, seeing in it a factor that causes assimilation with France (801). Texaco's is a literary geography that reflects the movements of an idiom. From being a physically abstract space, the quotations suggest the invocation of city as both a product and a metaphoric designator. More specifically, they highlight the performative nature of space that registers the force of language - space is influenced and becomes at the same time an influencing factor in the novel. These two quotations only verify the stakes the title "Texaco" has demonstrated for us - the novel is the site of both linguistic and spatial manifestation.

\section{Marie-Sophie as Texaco}

The large corpus of research devoted to illuminating the importance of space and language in Texaco has rightly recognized this dual implication of the title. ${ }^{18}$ This latter also stands as the signifier for yet another entity - Marie-Sophie. On discovering for the first time the oil company's property, the protagonist decides to make it her home and gives herself a secret name: "Je me nommai un nom secret" ['I named myself a secret name'] $(326 ; 296)$, which is revealed only at the end of the novel to be that of the oil company Texaco:

que jamais en aucun temps, dans les siècles et les siècles, on n'enlève à ce lieu son nom de TEXACO [...] mon nom secret qui - je te l'avoue enfin - n'est autre que celui-là. (417-8)

[let no one, across the centuries and centuries, ever remove the name of this place, TEXACO [...] my secret name which - you may know now - is none other than that one there. (382)]

This self-christening adds another dimension to the meaning of the already multilayered title of the novel. Beyond language and space, "Texaco" also becomes the signifier that cradles Marie-Sophie's presence as yet another signified within it.

For Lorna Milne, the name Texaco being projected back onto the place after having been appropriated by Marie-Sophie articulates the importance of history in subjectivity formation. "In the course of this metaphorical detour via MarieSophie's purposes, however, the word 'Texaco' has been transformed, for it now, 'irradiates' an extra layer of meaning forged out of the personal and collective history associated with it" (Milne 2000; 173). I would argue that this reverse 
naming endows the site with the history of the woman subject, who by transposing the appellation of Texaco back onto the site necessitates an engagement with her personal narrative in any assessment of this topographical location. While Glissant's quotations points in the direction of language and space, Bianciotti allows perceiving a gendered topography linked to the history of women.

Oiseau de Cham (also referred to in the novel as Marqueur de Parole) serves as Marie-Sophie's scribe in Texaco. Through a rather transparent anagram, Chamoiseau (Oiseau-de-Cham) has inserted himself in the text and taken it upon himself to compose the narrative that Marie-Sophie recounts from her collective memory. The scribe becomes a medium vehicle between the speaker of the novel and the reader - he is where the orality becomes the written word (Coursil 162).

Chamoiseau opens with a quotation from Bianciotti that presents the inability of a scribe to speak about a woman who through herself reminds of the harsh destinies of other women. By contrast, this inadequacy of the scribe highlights the injustice meted out to this woman, thus presenting the difficulty of rendering into text her lived experience. I could hypothesize the choice of this epigraph as an attempt at personal humility on Chamoiseau's part, perhaps an homage of sorts to the matadora Martinican woman, whose unrecognized struggles he can never claim to translate into words but which he wishes to acknowledge in his work. At a literal level, however, this recognition of his inability to write about women holds a stark resemblance to Chamoiseau's engagement with questions of women and gender.

\section{Chamoiseau and Feminism}

What needs to be underscored, before continuing with Marie-Sophie's struggle in this novel both against the patriarchal as well as the colonial forces, is the rather bizarre relationship that Chamoiseau has with feminism and development of female characters in his work, for which he has been chastised multiple times. As he lambasts what he characterizes as "Western masculinist critique" ("Créolité Bites" 154$)^{19}$ of his work, calling it "inept and inapt," Chamoiseau insists that his novels are about "Creole women, matadoras - women who come from matrifocal families and have always had to fight, to develop strategies of survival and resistance" ("Créolité Bites" 154). Even if one is to accept, for a moment, that his presentation of women as "virile and masculine," "maternal" and "distinctive heroines" is his way of "bearing witness to the Antillean imaginary" ("Créolité Bites" 154) and thus paying them homage, there is plenty in his personal and ideological stance that gives pause regarding his claims about human equality. 
Shock is the only word I can use to describe my feelings when I discovered the transparently misogynist statement he delivers when retorting against Annie Le Brun's criticism of Chamoiseau et al.'s reading of Césaire. ${ }^{20} \mathrm{He}$ labels her as "névrotique" ['neurotic'] and driven by the "frémissement de ses ovaires" ['quivering of her ovaries']. ${ }^{21}$ No wonder then, that because of this exchange Chamoiseau has been compared to an "Iranian Ayatollah" (19) and a "hired bouncer at the door" of a private club. ${ }^{22}$

Yet, Chamoiseau's work also furnishes a woman character whose body bears the marks not only of colonialism's expansionist agenda but also of a patriarchal society, both of which she successfully counters. So, how does one justify my feminist reading of Texaco's spatiality vis-à-vis Chamoiseau's own vexed association with questions of gender? Let us go back to Bianciotti.

Going by the other two quotations by Glissant, this epigraph indicates both what the author wants and what is to ensue in the narrative that follows. ${ }^{23}$ The one particular woman, who through her presence reminds of the plight of other women, neatly references Marie-Sophie's presence within the novel. It bemoans the spatial injustice meted out to women, who despite having struggled equally alongside ("luttant à l'égal" ['fighting - as much as men']) men only see the establishment of what one calls fatherland ("firent ... ce qu'on appelle une patrie" ['made what is known as a fatherland']). This politicogeographic spatial reference ("patrie" ['fatherland']), invested in the patriarchal system, allows women the vainglory of a few roads named after them ("les rues portent le nom" ['streets are named']) and a few deceptive moments ("dates bruyantes" ['few noisy holidays']) as recompense.

The verb "rappeler" means to recall. In its two occurrences, once for the scribe in the future tense and for the woman in the present tense, the verb conjures up forgotten history and serves to draw a comparison between the two. It is this woman, who despite her travails and struggles, excels at speaking for other women - an act she already performs better than the scribe possibly could: "Que rappellera ici le scribe" ['What will the scribe recall'].

There seem to be genuine engagements with the gendered geography that follows from colonial revolt. Nonetheless, several references hark back to a long-rejected biological essentialism that speaks of an instinctive harmony between women and nature. For instance, women are evoked as "expertes" ['experts'] at "déchiffrer" ['deciphering'] nature, using their expertise to "prévoir" ['foresee'] beforehand the workings of the wind and the moon. These references make one wonder if the "sévère destin" ['stern destiny'] in the above quotation should be read as a comment on the hardships imposed on women, or should destiny here be read as women who are predestined by an essential gender? The 
'empowered' (if one could use the word) woman here shares a symbiotic relationship with nature, which she uses to ascertain "les travaux à entreprendre" ['what labors to take on'].

There is a tension that Milne recognizes in the way Chamoiseau's novels treat male and female characters, a tension that is available in the two apparently contradictory presentations of women in Chamoiseau's epigraph. ${ }^{24}$ According to Milne, it might seem that "Chamoiseau redefines men and women in less conventional terms $[. .$.$] privileging strong, sexually and socially autonomous women$ characters, yet, at "a less conscious level" his work remains irrevocably limited to "patterns of masculinity laid down by colonial power structures" (Milne 2001; 72). As discussed in the context of Anne François' work, Milne also recognizes a "masculinist hegemony regarding the right to write" (Milne 2001; 72) within the postcolonial Francophone context. When one adds to Milne's thoughts Chamoiseau's rather egregiously sexist comportment toward Le Brun, it is not difficult to conclude that this author is unproblematically exploiting a historically created privilege and remains unaware of the limits of the power paradigm he operates within.

Yet, Texaco is "arguably créolité's most ambitious and most complete literary articulation" (106), ${ }^{25}$ and thus, its literary and spatial constructs demand much closer scrutiny. There is also the fact that when considered alongside the spatial interactions of her body, one cannot help but be mesmerized by the myriad ways in which Marie-Sophie shatters conventional definitions. Despite the possibility of reading Marie-Sophie as part of a "masculinist aesthetics" (Milne 72), there is also the fact that she takes these colonial spatial paradigms head on and creates new meanings of terms like citizenship and subjectivity. I would tend to read this valorization of the heroine as literature "bearing witness" (to subvert Chamoiseau's words against his purposes) to the changing literary landscape. Despite his egregiously sexist vocabulary, Chamoiseau's work betrays the influence of feminist authors and theorists who have been adamantly restructuring these very same paradigms to articulate race, class and gender differences.

If indeed it is the case, as Milne reminds that the "Antillean male unconscious" (2001; 72) perpetuates these structures, would it not be fair to account for the work of feminist authors and critics, whose work too forms a part of Antillean life, and has undoubtedly yielded immense influence on the contemporary Antillean literary landscape and unconscious? At least that is the hope this chapter holds out when it reads the complex enmeshment of national, local, global and urban spaces with Martinique's colonial history and contemporary association with France. 


\section{Reinventing the City}

And this is also a hope that the epigraph kindles when it shows that space can be "firent" ['made'] a homeland. In emphasizing the 'making,' the production of this land, I am implying that "organization, use, and meaning of space is a product of social translation, transformation and experience." ${ }^{26}$ In other words, I am addressing a space that reflects society and its evolutions, a space that is produced according to the forces applied to it. If, through their joint struggle the man and the woman can wrest this space and make it their own, and if this space can then subsequently conform to patriarchal norms as 'fatherland', then this spatial malleability surely also holds the possibility of further transformation. It shows land as a changeable entity - it is not fixed. It "indicates the sociality of this spatial change, a change that registers space as performative, shifting the grammar of land from passive noun (as object) to active verb (as doing); space is processual, it changes" (Brady 5) according to influences acting on it. In reading the spatial reorganization via Marie-Sophie, as such, I would like to direct the analysis toward those moments when Marie-Sophie imbricates her own presence of a postcolonial woman subject into spaces whose meaning she redefines.

In one of the notes of the urbanist, who from his initial inimical objective of razing Texaco moves to taking a supportive stand, I see the desire to reconceive space to better appreciate the contours of the marginal spatial entity of Texaco:

L'urbaniste occidental voit dans Texaco une tumeur à l'ordre urbain [...] Non, il nous faut congédier l'Occident et réapprendre à lire: réapprendre à inventer la ville. (296)

[The Western urban planner sees Texaco as a tumor on the urban order $[\ldots]$ No, we must dismiss the West and re-learn to read: learn to reinvent the city. (269)]

To invent ("inventer") the city echoes well with the making of land that the epigraph proposes. As the spatial aspect of the epigraph gets mirrored in the novel, the question to ask is: does Texaco also replicate the powerful women presented in the epigraph? If it does, what is then the kind of interaction that the space in the novel shares with "ces femmes" ['these women']? Interestingly in presenting 'these women,' Bianciotti's epigraph lays emphasis on one of their traits - forced perpetual maternity - by specially spelling it out. Be it Marie-Sophie's neighbor from l'En-Ville-Sylphénise, ${ }^{27}$ or be it a habitant from Texaco, Labautière, ${ }^{28}$ 
women in the novel have a generous retinue of children around them. So much so that one could describe the women of the hutment of Texaco as:

créatures ne vivant que pour être enceintes et exposer des bouquets d'enfants à chaque creux de leurs coudes, jeunes filles ridées au regards sombres. (n 2 p33)

[creatures living only for pregnancies and children peeking out of every sleeve, wrinkled damsels with somber looks. (n 2 p22)]

The question, though is how the one woman who "à travers elle" ['through herself'] represents the other woman with whom she shares the state of multiple pregnancies negotiates her tryst with l'En-Ville? If one is to see her rape as a reminder of the dominated bodies of slave women, then does her decision to self-terminate the resulting pregnancy operate as a reminder of the slave women rebelling with those very same bodies to ensure that no further slaves are born? Given that it is after this rape that Marie-Sophie decides to leave l'En-ville to set up Texaco, might it be right to surmise a direct relationship between her body, the city and the topographical margins. In addition, what inferences could one draw about Chamoiseau's oeuvre, the Créolité movement and of course about Glissant's work that functioned as the central motor of Créolité? As one answers these and other related questions to discover the workings of l'En-Ville, one better understands the changes taking place in the colonial meaning of space that redefine the island's relationship with France.

Before I understand how this meaning is redefined, one needs to look at the brief political and literary history of Glissant in Martinique post the Second World War. This juxtaposition of Glissant's work against French borders helps better understand the different articulations of Martinique's relationship with France that jostle with each other. It is a brief literary history whose analysis is central in understanding how spatiality within Martinican literature denotes predominantly national boundaries. Identitarian formulations have invariably had to contend with, and sometimes respond to, overt pressures exerted on Martinican literature by France and French borders. Indeed, even when the Martinican text has been set against an intellectual dialogue framed in terms of the space of national boundaries and is read through the lens of the MartiniqueFrance relationship, it is possible to read for ways in which peoples' everyday lives are interacting with colonially generated spatial divides. Reading outside the frame of linguistically charged nationalistic criticism helps better explore 
how literary contestations of space, and indeed literary contestations over the meaning of literature, have structured the discourse in order to bring forth the workings of a gendered space within the Martinican context.

\section{Section 2. Martinique's Literary Identity and French Borders}

\section{Martinique: Colonial History, Postcolonial Literature}

Slavery provoked mass deterritorialization and radically changed the meaning of the most primeval of spatial terms: the world and the homeland. As different peoples churned together in plantations and other similar projects of a nascent market economy across the world, what emerged along with the knowledge of the existence of divergent lands and cultures was the simultaneous forever loss of homeland for these displaced populations.

Martinique, which is an official part of the French Republic, is inhabited mostly by descendants of those who were uprooted as a direct result of colonization. The societal and economic structures from centuries ago that accompanied the acquisition of the island within the French empire persist to date. Even today, neocolonial structures determine the economic setup and societal "stratification along race and class lines [that] remain deeply entrenched long after the formal abolition of slavery." ${ }^{29}$ The island's "economy of food and other consumer goods remains in the control of békés and their commercial-political allies in metropolitan France" (Wong and Gomes), and while being thousands of miles away from Mainland Europe, Martinique still remains a part of the European Union. In addition, this spectral presence of mainland France in its everyday life, the constant negotiation of its identity vis-à-vis the French borders, has given rise to a peculiar situation in which notions of margins, center, local, global, nation and its Other, are both problematized and rendered insufficient for understanding of Martinique's literary engagement with space.

As I shall show below in a discussion of Glissant's work, literary production in the Martinican literary tradition has largely recognized and placed at the center the despair of the colonized subjects against the workings of the metropolitan financial hegemony. To continue with a discussion from the introduction of this book - Glissant's larger work borrows from space and spatiality to present its worldview and to speak of the opacity of cultures. However, it stops 
short of explicitly treating, at a literary level, the changes in the understanding of global interconnections that Martinique's multifaceted spatial existence produces. Elizabeth Hoving ${ }^{30}$ reads Glissant's space to find that it "offers a highly abstract conceptualization of space." (128) So, instead of reading "Glissant's spatial discourse as if he were a Caribbean Deleuze," part of "an aesthetics which is distanced from the materiality of the world" (129), what Hoving proposes is an interesting juxtaposition of Glissant and Jamaica Kincaid. Hoving shows how in their work "the cross-cultural world is represented not as real or imagined postcolonial space but as a lived transnational space, highly concrete and at the same time highly abstract" (135).

Hoving's basic argument lies in theorizing a "situated awareness of global space" (135). This article derives its argumentative impetus from the space of the home, which Hoving describes as: "home is a constant battle against the transnational forces that invade one's home and family" (137). The main idea is to move away from the often-repeated thematics of travel, migration and movement that have marked postcolonial identitarain contestations, and to speak instead of situatedness. Instead of pushing for new concepts, Hoving identifies a call for "lingering in the midst of concepts" (125). Knowledge is not only created by constant conceptual travel but also by remaining where one is.

It is quite clear from the above discussion that Glissant's thinking depends greatly on space and spatiality. What also becomes clearer is that this is a space that demands a purposeful engagement to understand its contours. Much like the opacity these spatial concepts describe, they remain resistant to attempts at understanding them. The treatment of Glissant's usage of space remains also largely true for Francophone literary production as well.

The extract below, from Aimé Césaire's famous poem, "Cahier d'un retour au pays natal," speaks about the city of Fort-de-France on the island of Martinique and seems to describe the city from the sea. Unlike the metaphorical spatiality that prefigures Glissant's concepts attempting to understand the world, this extract presents the production of a particular site: the island of Martinique. While Hoving tries to understand the situatedness of the Caribbean from a concept like Tout-Monde, what I do below is to draw out conclusions about Césaire's spatiality from this poem's treatment of the location of Martinique. This description lays out how the hungry and diseased Antilles ("dynamitées d'alcool" ['dynamited with alcohol']) remain shipwrecked at the doorstep of Fort-de-France. Indeed the city itself exists under the burden of the geometric cross that Fara Lee Rabenarivo ${ }^{31}$ interprets as a reminder of the Christian cross and the logical thinking of Western reasoning and that quite clearly has taken 
over from the "le suc de cette terre" ['juice of this earth'] as the determining function according to which the city grows:

Au bout du petit matin bourgeonnant d'anses frêles les Antilles qui ont faim, les Antilles grêlées de petite vérole, les Antilles dynamitées d'alcool, échouées dans la boue de cette baie, dans la poussière de cette ville sinistrement échouées [...] cette ville plate - étalée, trébuchée de son bon sens, inerte, essoufflée sous son fardeau géométrique de croix éternellement recommençante, indocile à son sort, muette, contrariée de toutes façons, incapable de croître selon le suc de cette terre... ${ }^{32}$

[At the end of first light burgeoning with frail coves the hungry Antilles, the Antilles pitted with smallpox, the Antilles dynamited by alcohol, stranded in the mud of this bay, in the dust of this town sinisterly stranded $[\ldots]$ this town sprawled - flat, toppled from its common sense, inert, winded under its geometric weight of an eternally renewed cross, indocile to its fate, mute, vexed no matter what, incapable of growing according to the juice of this earth... ${ }^{33}$ ]

These images of stark decrepitude and decay do, as Rabenarivo points out, "play havoc with the expectation" (57-8) of the informed reader of the early twentieth century. Though Rabenarivo does not specify what these expectations were, this remark undoubtedly refers to the expectations formed by the descriptions of tame and welcoming landscape of the "doudou" poets. For the latter, the island was an exotic locale. The island was, as Maeve McCusker reminds us, a "celebration of the paradisiacal elements of the environment" (48). ${ }^{34}$ The point here, of course, being that Césaire's iconoclastic imagery and rendition of the colonized landscape rightly breaks from the mold of what was understood as traditional Caribbean poetry, whose play on exoticism fulfilled the desire of the metropolitan reader to discover and tame the savage landscape of the Other. However, Césaire's writing, in so far as it addresses the spatial changes Martinique's association with France brings about, stops right there - with an acknowledgement of the effects of colonialism on the region represented in the presence of the modernity-evoking cross on this island, in a region pockmarked with colonial misery. But, then again, this poetry collection with its unique imagery was written within the backdrop of homelands forever lost, which can only be recuperated in poetry. For Césaire, "Cahier" is about an "imagined return to his homeland, a process which entails acceptance of the past, both its positives and its negatives," (27) 35 and did not ever 
claim the task of situating the detailed dynamics of how these Antillean islands were "dynamited with alcohol," or an in-depth analysis of how it changed these islands. Most creative production in Martinique attests to the changes in the dynamics that signify meaning, recognizing the presence of France as creating tension in a place defined by an already unstable identitarian locus. Postcolonial spatiality emerges as the perceptible backdrop, a container wherein citizenship, home and subjectivity are presented as lived experiences, and not as produced by this spatial reorganization. These narratives frame the challenges and struggles of its inhabitants against the everyday hegemony of dominant colonial forces within an island spatiality, without making explicit the presence of this spatiality as another enabling element of its totalitarian dynamics.

The urgent need to reconcile the subjects' standing and life alongside the visually constant border, the "actual physical borderland" that Gloria Anzaldua speaks about in her fascinating work Borderlands: the New Mestiza = La Frontera (about "the Texas-U.S. Southwest/Mexican border") ${ }^{36}$ and that, for example, the India-Pakistan border has conjured up in the famous short narrative Toba Tek Singh, is clearly not experienced with the same urgency within the Caribbean context. Yet, all the associated psychological, economic and political violence these borders provoke is readily perceptible in the Martinican text. The "repressed" associated spatial anxiety, to borrow from psychoanalysis, gets "displaced" onto other spatial manifestations.

When Chamoiseau talks about reclaiming the urban landscape as a function of the Creole language, he presents a candid insight into this psychological association:

La récupération de la ville que j'ai faite à partir de Chronique de[s] sept miséres a été, pour moi, importante. Et ça s'est fait toujours par la langue créole. Par le problème de l'oralité. Donc du coup je suis allé chercher ce que je connais de plus intime, et ce qui en moi était considéré comme inutile, vulgaire, insignifiant, sans intérêt. Et qu'est-ce que j'ai trouvé ? J'ai trouvé la ville. Parce que j'ai toujours inconsciemment nié, dans ma réalité, ma dimension urbaine, je suis parti à sa conquête. Par conséquent, la ville aussi, c'est une de mes grandes thématiques. Mais ce n'est pas une thématique intellectuelle, c'est une thématique personnelle. Je récupère mon espace urbain (21). ${ }^{37}$

[Rediscovering the city as I did through Chronique de[s] sept misères was important for me. And, this always happened through the Creole 
language. Through the problem of orality. So, I went in search of what I know the most intimately, what on the inside I considered useless, crude, insignificant, without any interest. And, what did I find? I found the city. Since I have always unconsciously denied, the urban dimension for my reality, I went to conquer it. As a result, the city also is one of my important thematics. But it is not an intellectual thematic, it is a personal thematic. I am rediscovering my urban space.]

Earlier in this chapter, I have already discussed the direct association between the idiom and the urban landscape. For an author whose work expresses the linguistic struggles of an idiom under distress, this statement should best be read as the displacement of a painful repression of his literary struggles onto the urban form. In talking about the city in his works, Chamoiseau presents its unconscious denial and then follows it up by presenting his urban reality as a subjective enunciation, " $a$ personal thematic" dissociated from any intellectual preoccupations. This psychoanalytical analogy allows me to show how I read the evolving literary Martinican landscape as a site that condenses the political and the identitarian struggles of the Martinican subject over the spatial form. It is this constant multidirectional exchange between a subjective authorial engagement, the colonial reality, multiple linguistic influences and local and regional conceptions of nationhood that produces for this study the contested and repressed site of Martinican spatiality bearing the marks of spectral French borders; a site that needs to be excavated.

Before I see how engagements with the ante-national kind of spatiality that emerges have remained subsumed within a debate on Martinican nationalism, let us have a quick look at the synecdochic relationship between the Antilles, Martinique and the city of Fort de France in Césaire's poem above. The verses of the 1939 poem move from the larger defining archipelago of Antilles to the shore of island ("mud of this bay") of Martinique and eventually to the city of Fort de France ("this town"), all three locations standing united in their colonial-capitalist misery. The movement in Césaire's poem speaks about the spatial energies that defined the three entities as interlinked with each other. Before the 1946 declaration, Fort de France and Martinique were both anchored as part of the archipelago. Martinique's departmentalization disrupted the regional narrative and created a schism in the discursive links by introducing French borders into the chain. Henceforth, after the 1946 departmentalization, Glissant in his works would constantly keep taking recourse to terms anchored in the Caribbean like antillianité and créolisation, in order to resituate Martinique according to local coordinates, unceasingly attempting to break away from France. While 
Glissant's legacy is still unfolding and it is too early to testify to the extent that his work has successfully dissociated Martinique and the Antilles from France, we at least now have ways to dismantle Europe from its early nineteenth-century modernist anchors. We can now look at its evolving map and describe it using an Antillean vocabulary, as Glissant does, when he sees Europe "splitting into regions" and asserts "Europe is being 'archipelagoized." 38

\section{French Borders, Martinican Text}

1946, the year when the French National Assembly would vote to include Martinique as a part of France's political and administrative borders, is a year of irony that marks Martinique's political as well as literary identity. The 1946 vote in the assembly, the first step toward making Martinique a full-fledged département (a French administrative unit), was not only celebrated but also initiated by literary leaders of the time, like Aimé Césaire. Martinican literature has not stopped struggling with the ensuing identitarian conflict. Since the middle of the twentieth century, almost all literary accounts of value in Martinique have reckoned with the economic and the political fallout of the departmentalization of Martinique. Recording representations of the Antillean region in general, and of Martinique in particular, from earlier periods of colonization, these literary narratives have registered the transformations from its earliest colonial status of a controlled plantation economy to the more contemporary economy that survives due to metropolitan patronage.

Even as Chamoiseau and his contemporaries have recognized the great contributions of Aimé Césaire in giving the Martinican people a sense of identity and belonging, and in setting up important intellectual and literary precedents, they have also held Césaire responsible for Martinique's economic and political dependence on France. "Within the space of a generation," partisans of the Créolité movement say, "Martinicans were transformed from self-sufficient producers into welfare-dependant consumers" ("Créolité Bites," 128-9). Glissant, a contemporary of Césaire, had started registering the declining sense of self in the years following the departmentalization as early as the 1950s, through his first novel La Lézarde (1958). J. Michael Dash in his book on Glissant explains how the drying up of the "watercourse of the river [Lézarde] that represented the freed spirit of the people" is likened to losing "a collective sense of purpose" (92) among the Martinican people. ${ }^{39}$ This pessimistic literary view includes commentary on the dependent economy among the other effects of Martinique's departmentalization. ${ }^{40}$ Dash expounds also about Glissant's farce, Parabole d'un 
moulin de la Martinique, which "satirizes the dismaying changes taking place in departmentalised Martinique" (92). If one looks at Glissant's four-decade engagement (marked by the publication of two works, La Lézarde in 1958 and Parabole in 2000), we come to understand more than just his representation of the internal strife in Martinique. In all his political and literary activities, France remained as the constant locus that marked Martinique's status, both locally, within the Caribbean region, and in the outside world.

The best parable for the France-Martinique literary equation may be found in the overtly antagonistic relation that Glissant had with France. Increasingly disenchanted and wanting a complete decolonization from France, Glissant would set up the 'Front-Antillo-Guyanais pour l'Autonomie, ${ }^{31}$ whose demand was a complete break for French departments, Martinique among them, and their eventual reestablishment within the Caribbean region. Charles de Gaulle the French president at that time "declared the organization a threat against the nation" ${ }^{\prime 2}$ and ordered its dissolution in 1961.

The fallout would be Glissant's arrest in Gaudeloupe in September of 1961. Ironically, for his demands for separation from the French mainland, the authorities would hold him under house arrest in metropolitan France and bar him from traveling to the Antilles. Only in 1965 would he again go back to Martinique. From a literary point of view this desire to define itself without France and without French borders, and indeed without the effect of the French language has always necessarily meant working within the French boundaries and working with French language. For all Martinican authors French borders operate rather conspicuously within their literary articulations. Yet, for Glissant, as well as for other authors, this increased presence of France has also always entailed moving toward the Caribbean in search of a literary and a philosophical counter-response. Antillanité (based on the understanding of the Caribbean as region of contact) and créolisation (based on the Creole idiom) are both regional metaphors deployed to understand the workings of a constantly evolving world.

Glissant's Le discours antillais, according to $\mathrm{H}$. Adlai Murdoch presents a Caribbean "self assertion" that becomes the basis of a "philosophical stance" that insists "on recognizing the latent value of historical patterns of discontinuity and pluralism across the Caribbean" (11). ${ }^{43}$ In Le discours antillais, and elsewhere, the Caribbean serves as a carefully articulated template that negates any essentialist impulse that may have formed the basis of Western Europe's "secularization of human existence in the context of its own global expansion. ${ }^{.44}$ Glissant deploys the "region's constant creative flux and its insistent patterns of transformation and exchange to inscribe a globalized network of relational being" (Murdoch 11). The 
Caribbean, or the Antillean, in Glissant's discourse serves as a microcosm for understanding global movements and exchanges of peoples; or, as Murdoch rightly points out, for understanding the "globalized network of relational being" (11).

Créolisation is another one of those Caribbean concepts that Glissant adapts from Martinican reality and deploys to explain how the world operates as a changing reality. Glissant has taken the trouble to point out how créolisation is distinct from Chamoiseau et al.s Créolité, ${ }^{45}$ which he finds to be a restrictive definition of the human being. While Créolité attempts to define a distinct Creole way of being, to understand "ce qu'est l'Antillais" 46 ['what an Antillian means'], for Glissant, créolisation encapsulates a distinct global vision. Créolisation, which finds its intellectual energies locally, is a 'process that plays out in the Antilles, and plays out also in the entire world. The entire world is creolizing, all the cultures are creolizing this very moment in their contact with each other. ${ }^{2} 7$

In Glissant's depiction, the geographical realities of the world and the Caribbean, while interrelated and playing upon the energies of each other, remain firmly ensconced in a nonbinary world order that eventually leads to a new understanding of the space of the world as interrelated. This new understanding stays very firmly clear of identitarian boundaries, of which national boundaries operate as the dominant identitarian vector. It would almost seem as if the growing influence of France also meant an even firmer anchoring in the Caribbean in search for an answer. Glissant relentlessly questioned France's place within the Caribbean as well as presented the idea of the nation as an antithesis to the kind of rbizomatic interconnected world he envisaged. With increasing run-ins with the French Republic, Glissant experienced both the loss of his world in relation as well as the specificity of the Caribbean. Further dismayed by the eroding sense of the self within Martinique (which Dash calls "the personal loss of this youthful idyll"), Glissant established in 1967 the "Institut Martiniquais d'Etudes in order to oppose the drift toward cultural oblivion" (Dash 93). The idea, of course, was to create an 'autonomy for scientific discourse of the modern Antilles, ${ }^{38}$ and for the institute to serve as a storehouse of information available on the French Antilles in general and on Martinique in particular. This institute would bring together researchers who together would make the 'first institutional embryo of a truly Antillian research group. ${ }^{39}$ Glissant thus sought to achieve at least on the institutional level the independence he was unable to achieve on the political plane. Choosing to remain silent on overtly political issues, including the burning issue of Martinique's official status (for which Glissant attracted criticism ${ }^{50}$ ), Glissant wanted IME to be above all the place that would allow Martinique to have its own space for 'discourse and scientific language. ${ }^{\text {.51 }}$ 
More importantly, this French presence within the Martinican literary context has been far more palpable than just literary and conceptual metaphors that attempt at reconciling with the Other's presence. A further and related effect of the economic fallout was a change in the way Martinican literature was read and taught, as it now necessarily had to be taught alongside, and in certain ways even as an offshoot of, Metropolitan French literature. Unlike in the neighboring island nation-state of Haiti, ${ }^{52}$ which gained its independence in 1804, formal literary teaching in Martinique (as well as Guadeloupe, which is also a French department) is not just influenced by France but "is almost entirely similar to the situation in the Hexagon" (Jonaissant 59)..$^{53}$ Jean Jonaissant accounts for the differences in the Haitian literary pedagogical corpus vis-à-vis Martinique and Guadeloupe to speak of how "French and Haitian literatures are two distinct corpuses, despite the influence of French metropolitan literature on Haitian writers" (59). Indeed, it was no doubt in response to this crisis of literature, as Glissant points out in the first issue of the journal Acoma, that IME sought to display and facilitate for the Martinican teacher a teaching methodology valid for the local situation, adapting academics to the specific context (Fonkoua 105). More than the literary text as an outside element lamenting the changing postcolonial equations, the definition of literature itself became a site of contention. The important question for Martinican literature, unlike for Haitian literature, became one of how to speak in the French language about carving outside the French canon a space for one's self while at the same time participating in the French institutional power structures. Colonial association with France has thus produced precarious literary relationships. French borders and French nationalism have remained as the overbearing spatial markers in literary production, even when it seeks to engage with issues like gender, text and urban space.

\section{Section 3. Text, Texaco and Landscape}

\section{Texaco: Space and Language}

The issue of language and various manifestations of space and their combined and complex relationship with human beings has been the subject of numerous disciplines. The objective has always been to see how these actual, real world physical spaces deal with the creation and evolution of human language. Texaco 
disturbs conventionally held understandings of how language relates to space. While it certainly shows how literature, as a working linguistic sample, offers the possibility of creating novel sites that challenge conventionally held notions, what remains of particular interest for this novel is its unique representation of an artificially created idiom (what Kundera calls "Chamoisified French"), which evokes spatial metaphors to speak of a political equation.

In his earlier novels, Chronique des Sept Misères and Solibo Magnifique, ${ }^{54}$ Chamoiseau raises issues associated with the Creole language and culture. In both these novels - written in French - he explores Creole's relationship with French. He crystallizes his position in Eloge de la Créolité(In Praise of Creoleness), an essay that Chamoiseau coauthored with Jean Bernabé and Raphaël Confiant. N'zengou-Tayo and Wilson point out how this essay later became the basis for Texaco: "Chamoiseau is faithful to the aims set out in their manifesto [Eloge]" (91). To recall, Glissant criticizes Chamoisau et al.'s use of Créolité as a reductive paradigm. This is so even though, in their particular appropriation of the term Creole, the Créolistes claim to destabilize the urge to define identity through race or origin; furthermore, by according the signifying power to a local idiom, they hope to create a palimpsest of Créolités upon which to reinscribe the world. What Chamoiseau sees in the Creole language is "a cultural emergence," a "complex alchemical and anthropological process" (McCusker 76). ${ }^{55}$

As much as he claims to have developed upon the energies of this "cultural emergence," Chamoiseau has attracted criticism for moments when he asserts that the "creolization process didn't produce uniformities; it produced singular emergences, or events" (McCusker 76). Chamoiseau is insistent on his claims that "we are dealing with créolités in the plural: a Martinican créolité, a Cuban créolité, a créolité of the Southern United States, and so on" (McCusker 76-7). As a result, Glissant and others have disowned Créolité, calling it a misinterpretation of créolisation and seeing in this insistent plurality an attempt at the stabilization of human identities. Despite criticisms that questioned the novelty of this manifesto ("a delusive rupture," ${ }^{\text {6 }}$ Michel Giraud calls it), or derided it as being 'false revolution, ${ }^{, 57}$ one has to acknowledge that Eloge "did in fact constitute an epistemological irruption on the French as well as Francophone and Caribbean literary scenes" (Moudileno 19). Eloge might have generated false expectations that "something even bigger was going to happen in the following decades," but finally, "Éloge did not keep all of its promises" (Moudileno 23). For me this "epistemological irruption" (Moudileno 19), which finds its basis in a neologism of the Creole idiom, is of particular importance because of the epistemological shift it provides in articulating identity in terms of space and language. 
The very usage of the word "Creole" to speak of "Créolité" in Eloge stands as an example of how appropriation is carried out in Texaco. The noun Creole refers to both a particular idiom and a subject. H. Adlai Murdoch, ${ }^{58}$ relying on the definition given by the Oxford English Dictionary, proffers a Creole subject defined in its racial ambivalence:

'In the West Indies and other parts of America, Mauritius, etc.: orig. a person born and naturalized in the country, but of European (usually Spanish or French) or of African Negro race: the name having no connotation of colour, and in its reference to origin being distinguished on the one hand from born in Europe (or Africa), and on the other hand from aboriginal.' In this way a creole person can be either white or black, colonizer or colonized, articulating an essential ambiguity. (4)

A consultation of Le Trésor de la Langue Française furnishes a different definition of 'Creole':

(Personne) qui est de race blanche, d'ascendance européenne, originaire des plus anciennes colonies d'outre-mer. [...] P. ext. Nègre, noir créole. Né dans les colonies (et non en Afrique)."

[(Person) who is of the white race, of European ascendance, originally from former overseas colonies. [...] by ext. Negro, black creole. (Born in the colonies and not in Africa.)]

Both definitions jointly validate Murdoch's claim of a Creole subject marked by "essential ambiguity." OED's definition projects an ambiguity with reference to race by positing an equality between all those it designates, be it "white or black, colonizer or colonized." In recognizing both "race blanche" and "noire," Le Trésor de la Langue Française too addresses a racially ambivalent Creole subject. But this latter definition also embodies a race hierarchy - it gives primacy to the white subject and defines a black Creole as its extension. One should not pass off this difference between two dictionaries, one French and one English, as the result of dissimilar worldviews. On the one hand, it justifies Coursil's advice for prudence. ${ }^{60} \mathrm{On}$ the other, it also serves to strengthen Murdoch's conclusion, showing how the ambiguity of a Creole subject can assume different forms.

Racial ambivalence, though, was not always what defined the usage of "creole." According to Confiant, up until the appearance of Eloge, this word had clear 
racial connotations. In its adjectival form, it covered all aspects of Martinican life; as a noun, Creole spoke only of a white subject. Before Eloge:

...the word Creole was booby-trapped. French dictionaries defined Creole as 'a white person of pure race born in the Antilles'; the Bekes - white Martinicans - had monopolized the term, so for most Martinicans, Creole meant 'white.' They didn't see any contradiction in refusing to call themselves Creole although they called their cuisine, their songs, even their language Creole. So we had to explain to them. 'Everything you do is Creole; the proof is that you speak Creole; you call your jewelry Creole, you call your clothes Creole; it's not Bekes who do that, it's you!' (“Créolité Bites” 133)

The notion of Creole presented a contradiction. It spoke only partially of the Martinican ground reality, ${ }^{61}$ and thus, became a site that manifested racial imbalance. More importantly, it spoke of an identitarian fragility. An identity that is vulnerable to a subjective interpretation, and constantly under the threat of a monopolization by White Martinicans. It is an apprehension of loss, and a desire for what can only be described as an authentic, non-White Creole subject that leads Chamoiseau et al., the authors of Eloge, to subvert this word from its contemporary usage to divest it of all racial connotations and make it the basis of their regional linguistic identity. The opening sentence of Eloge reflects the implications of this shift:

Ni Européens, ni Africains, ni Asiatiques, nous nous proclamons Créoles. (13)

[Neither Europeans, nor Africans, nor Asians, we proclaim ourselves Creoles.]

According to the authors of Créolité, "Creoles" in this proclamation stands apparently outside designators of race and origin, but it is nonetheless participating in a circuit of power that hinges identity to specifics of location and language. Their particular rendition of local Créolité, the "Martinican créolité" that is one among many others like "Cuban créolité, a créolité of the Southern United States, and so on" ("Créolité Bites" 76-7), proclaims the "la langue créole comme noyau" ['créole language as its core'] (Eloge 34). The network of identity, language and location that this proclamation unfurls speaks to, firstly, the need 
and the desire to articulate the colonized subject's relationship with language and space, and secondly to the inadequacy of the current paradigms to express the generalized identitarian anxiety about language and location of the colonized subject.

The appropriation and subversion of Creole from its traditional usage that the opening of Eloge displays signals Texaco's linguistic strategy. The first sentence of Eloge, though talking about the authors distancing themselves and placing Creole at the heart of their identity, is itself written in French. It is reminiscent of the way the name of the novel, Texaco, operates. The name of a big multinational company is staked as a signifier to designate the placement of a hutment, anchoring thus within the academic world a spatial conundrum that is difficult to define.

Correspondingly, in Texaco, Chamoiseau uses French to speak of creoleness. The novel abounds in Creole phrases and a syntactical structure meant to perplex its reader. In an interview ${ }^{62}$ conducted with one of the English translators of Texaco, Chamoiseau talks of how Creole in the novel communicates the opacity of Martinican Creole identity for others:

...speaking of Texaco, many people say: 'I don't understand,' 'some of the things are beyond my reach,'... and so on. People don't accept the fact that a narration may have opaque, unintelligible, untranslatable zones which are maybe true for me and do correspond to realities which mean nothing to them, which are opaque to them. And so I had to impose certain things. In that spirit, I don't put glossaries in my books, ... I include the Creole words as they are. I don't translate them, etc. (347)

Coursil would describe Chamoiseau's approach in Texaco as symptomatic of Antillean literature, where "la littérature antillaise est bilingue (français, créole). C'est une langue double dont l'une est muette: elle s'écrit en français, le créole jouant le rôle de la muette." ['Antillean literature is bilingual (French, Creole). It is a double language one of which is mute: it is written in French, Creole playing the role of the mute one.'].

Texaco takes the project Chamoiseau demarcated in Eloge to its logical conclusion by making French sing the praises of its silent partner, Creole. Similarly, the title of the novel stands as a testament to how the hutment of Texaco silences the company Texaco by subverting its name. 
Working in the context of Jamaica, Susan Dray shows how local meanings and practices of space have inserted themselves into linguistic designators of space: local signage. As Dray analyzes the interaction between place and language, the author finds plenty of proof belying the general perception that one "would not be able to find any signs written in Creole"63 (103). In myriad ways, and most importantly unbeknownst to the speaker, without ever taking the form of a distinct script, Creole has inserted itself into the largely English signage of Jamaica. The valid necessity Dray points to, of "recognizing local reappropriations of linguistic forms" (104), could not be truer. While Dray advocates a semantic excavation of signage as a linguistic sample in which the speaker functions as an unaware passive participant, Texaco is a metadiscursive commentary that, in addition to carrying out the kind of analyses mentioned above, functions in full awareness of the linguistic paradigm it participates in. Despite the dissatisfaction that one might express regarding its ideological stance, Texaco testifies to the simultaneous creation of a new idiom and a new space, as well as a new processual interaction between the two.

Within the context of the Caribbean, where colonially displaced populations were forced to reapprehend new landscapes using linguistic categories of origin, and where linguistic idioms assert their competing worldviews, Texaco presents the colonial reality not just as a backdrop, which the speaker passively testifies to or accepts as an irrevocable given. This novel's complicated, multilayered readings of Martinican society critique colonial analyses that forgo an active engagement with physical space and language, or that treat space and language as immutable entities, or that do not engage with the discomfort of colonially displaced populations that possess only linguistic approximations of a hitherto unknown reality.

It is not that there is a complete lack of cognizance regarding linguistic usages that re-signify the meaning of place within the colonial context. Sabina Sestigiani's monograph, Writing Colonisation: Violence, Landscape, and the Act of Naming in Modern Italian and Australian Literature, ${ }^{64}$ attempts an analysis of the Italian and Australian literatures' association with a colonial understanding of space. There are numerous interesting readings. For instance, when discussing Patrick White's Voss, Sestigiani speaks of how the eponymous character, in bypassing the act of naming manifests a "process of anthropomorphism," and shows how Voss "aspires to the role of God." This is because God, "in the biblical tradition, did not name the world: he created it in utterance" (41). Writing Colonisation discusses "human attempts to conceptualise spaces at the periphery of human-built Western empires or 'civilisation.' [...] themes pertain to 
colonialism" (3). The book makes a valid point that the act of naming "retains the violence of an interpretation which is a projection of the subject's desires" (3). However, it focuses almost uniquely on the colonizer creating a colonized space, whereas Spatial Boundaries, Abounding Spaces lays emphasis also on reading literature as a spatial response to colonization. Writing Colonisation does discuss the spatial implications of theorists like Maurice Blanchot, Walter Benjamin, and Gilles Deleuze and Félix Guattarri. The book however stops well short of taking the debate into the realm of scholars working on theoretical questions of spatiality, as does, for example this current chapter in dealing with the linkages between space and language.

Let me take another example from a book that analyzes "buildings and analysis of texts about them" (36). Thomas A. Markus and Deborah Cameron ${ }^{65}$ in The Words Between the Spaces: Buildings and Language work with the premise that all "kinds of texts about buildings contain some 'prescriptive' element" (36) and that textual representations architects and designers work with "are products of linguistic choices which construct reality in particular ways" (14). Markus and Cameron uncover the "non-obvious or 'hidden' meanings" (3) of these texts and the resultant "materialization of textually embedded propositions in actual buildings" (35). Following from Foucault, to take an example, in speaking about prisons and schools the authors seek to understand how architectural texts translate the underlying social power structures and workings of the society about children and crime into actual buildings that surround us (62). Very briefly they bear upon the postcolonial situation via Indonesia's instance on displaying how the buildings, monuments and urban environment, all an important part of the postcolonial identity, were "initiated, promoted, designed and built, and then managed, by texts" (128). Language in the above example takes the form of codified texts and written forms particular to architecture, and the definition of space that follows is largely associated with purposefully created structures that emerge from such writings: both existing in a state of stasis and definability. That is, both architectural texts and topographical spaces that they designate follow closely the dictionary meanings of these terms: charts and plans, buildings and monuments, etc. This stasis, and the modernity evoking definitional stability that it references, are not the only contrasts that this study holds out when compared with Texaco's self-reflection, which is a story not only about the margins of a city but also about the marginalized of this city. Marcus and Cameron base their understanding on political speeches and architectural debates surrounding the meanings of "cultural identity" and "tradition" (131), and how to translate them into the build environment of a postcolonial 
Indonesia. Texaco, on the other hand, follows the unplanned struggles of ordinary citizens who do not construct their habitat according to a predestined meaning. Meaning is located in the habitat that results from the bricolage by these habitants. Texaco shows that kings, presidents and architects, and their speeches and plans - which Marcus and Cameron exclusively focus on - to organize parks, houses, traditional villages, are not the only ones to hold power over space. Space and its meaning also emerge from people's everyday negotiations with them. The idea of discussing this analysis and others that follow is to exemplify the stakes that are grounded around questions of space and language, in order to point eventually to the difficulty of the task involved in reading space in postcolonial Francophone literature.

Indeed, in reckoning with postcolonial creative production that has been primarily formed as a function of colonial understanding of nations and their boundaries, how does one understand the spatial metaphor of the slum-city conflict that mirrors the French-Creole relationship, a linguistic relationship that in turn bears back upon the tumultuous equation that Martinique has shared with French borders? I am not claiming that any of these analyses of space will help us understand a fictional representation of fictional characters and their association with space and its many manifestations within the literary structures. It would be too simplistic to say that these analytical models cannot be applied to literature. It is true, though, that one cannot help but acknowledge that through their lives, struggles and aspirations related to changing definitions of space these literary works are opening up newer questions and displaying uncharted academic terrains. Apart from these fictionalized characters, which could be dismissed as not belonging to the real world, Texaco the novel exists as a live linguistic example that purposefully questions and destabilizes all parameters associated with any kind of space-language equation.

Barbara Johnstone's essay, which calls for revisiting "terms such as region, rurality, local, and place" and in general resituating "the meanings of these and others of the concepts we use in generating hypotheses" (78) within the discipline of sociolinguistics, draws out another relationship between language and space. ${ }^{66}$ Following from humanist geographers, Johnstone's essay talks about going beyond "physical space and large-scale regional politics" (75) to supplement these understandings "with studies of "local knowledge" (75). Johnstone is absolutely right in acknowledging that physical "place is claimed to be less significant as a source of individuals' identities than it used to be" (74) and that terms like local and regional speech need to be reassessed when looking at research methodology in sociolinguistics. Place and language, as they appear in 
Johnstone's comments on "discourse analysis," are both greatly dependent on the speakers' self-description. Johnstone's work unhinges these two terms from disciplinary fixity to take them closer to a subjective understanding. It nonetheless does not furnish the tools to understand the kind of space-language relationship that Texaco is unfurling.

Within its fictional bounds, Texaco is clearly invested in making apparent how texts are formative of spatial divisions in the way that Marcus and Cameron enunciate, as it does for example in the image of the urban planner who walks into the hutment of Texaco with the idea of making the landscape conform to the city's plan. It also brings forth a clash between two linguistic communities and two different perceptions over how land use needs to be understood. It is not simply about two neighboring communities' disparate linguistic logic. It is rather about a purposefully formed linguistic idiom that forcefully wrests its rights and asserts that not only do terms like local and regional need to be reassigned according to a more dynamic logic, but even terms like speaker and native informant, as bearers of a passive linguistic logic, fall short of explaining this anti-colonial linguistic insurgence.

The fictional world of Texaco already acknowledges and verifies the hypotheses of studies by Johnstone, Markus and Cameron, discussed above. More crucially, this novel in itself stands as an exemplar of a linguistic rendition of Martinique's relationship with France and the French language and functions as a metacritic of the space-language equation. The internal, incomprehensible bricolage logic of Texaco, and the analogous Creole idiom - both constantly being formed and reformed according to the needs of the fluid populations of the slum quarters - are redefining the meaning of language and region. In this constant evolution of all terms, one should, of course, see the postmodernist influence under whose sign Chamoiseau is crafting his work, but at the same time there is also the understanding of space and language as processual, as an ongoing product that changes according to the historical conditions it exists within. In doing so, it reminds us that terms such as nation and text are after all irrevocably connected to the complex material history of politics, race and language.

\section{Rewriting l'En-ville}

The hutment of Texaco deploys the syncretic energies of the Creole language. The city center, l'En-Ville too, which initially wants to destroy the hutment, reveals itself as a processual space. This Creole expression is not to be confused as an exact translation of the French signifier Ville. It means "Literally, the 'In-city" 
(Texaco. trans., Translators' note, 3). It should mostly be understood as a part of the urban space - the center around which exist, as in the case of this novel, the various slum quarters. Marqueur de Paroles, the putative author inscribed in the narrative of the novel, explains the significance of "En-ville" in a footnote belonging to a postscript of sorts placed at the end of the novel, titled "Résurrection."

In order to understand the meaning of l'En-ville, one begins at the bottom of the page right at the end of the novel, and then re-traverses the rest of the text to supplement the meaning of a term that has been central to this text, and whose contours are being developed through much of the novel. As if to replicate the processual nature, through the constant back and forth movement that produces space and its meaning, the text already simulates for the reader through this textual movement the process that constantly produces meaning. A process that involves constant reiteration, revisitation and re-situation of meaning. Here is how Marqueur de Paroles explains the significance of "En-ville" in a footnote:

La langue créole ne dit pas 'la ville', elle dit 'l'En-ville': Man ka désann an-vil, I ka rété an-vil, Misté sé jan an-vil, An-vil Fodfwans... ${ }^{67} \mathrm{~L}$ 'Enville désigne ainsi non pas une géographie urbaine bien repérable, mais essentiellement un contenu, donc, une sorte de projet. Et ce projet, ici, était d'exister. (422)

[The Creole language does not say la ville ['the city'], but rather, l'Enville ['The In-city']: Man ka désann an-vil, I ka rété an-vil, Misié sé anvil, An-vil Fodfwans... [I am going down to city, He lives in city. This fellow is from City, from Fort-de-France]. City thus designates, not a clearly defined urban geography, but essentially a content and therefore a kind of enterprise. And here that enterprise was about living. (386)]

The quotation above tells us that l'En-Ville has to be understood as the spatial rendition of an affective aspiration. It is not a place but an idea and a project. Coursil suggests that the signifier l'En-Ville communicates Creole's yearning to take over both the city and the French language in the same move:

Un simple trait de nasalité différencie la sémantique des deux langues: 'lavil' (français, aspect affectum) est un lieu, 'lãvil' (créole, aspect effectum), une conquête, un désir. Dans cette guerre de quartier, métaphore du conflit des langues, le français sort marqué par la trace de la muette. 
[A simple nasal trait differentiates the semantics of the two languages: 'lavil' (French, affectum aspect) is a place, 'lãvil' (Creole, effectum aspect), a conquest, a desire. in this war over a locality, metaphor for the linguistic conflict, French ends up marked by the trace of the mute one.]

L'En-Ville represents a triumph over "ville" and thus over the French idiom. In a novel devoted to spatial conflict, this usage makes us aware of the desire to replicate this linguistic victory over the topographical space that the word "ville" designates. What is more important is that it shows how space and language are inherently interconnected. Whereas the French expression "la ville" stands equated to a "géographie urbaine bien repérable" ['locatable urban geography], it is the Creole rendition "l'En-ville" that holds meaning ("contenu"). The exact meaning of this space, then, depends not so much on the physical contours but on the constant open-ended evolution that the "projet ... d'exister" ['enterprise ... about living'] of the colonial subject communicates.

This no doubt destabilizes the nation-state, considered the "hegemonic political form" 68 (33), as the sole container of linguistic identity, and establishes spatiality within "less familiar patterns" (33) of defining "links between linguistic forms and political space" (33). Texaco imbricates questions of living and quotidian existence, something that can only be done in Creole, into landscape, such that the subject, landscape and language are seen as mutually interlinked and constitutive of each other. Working in a more contemporary context on "the transnational migrants" and "the local and global media," (51) Marco Jacquemet ${ }^{69}$ presents the case for understanding "transnational spaces" that result from the ease of travel across national boundaries and access to communication technologies that today's hyperconnected populations have. Interestingly, "transidiomatic practices, ${ }^{70}$ to be understood as linguistic innovations necessitated by the need and desire to "operate in multiple, co-present and overlapping communicative frames" (63), were already available in the Martinican, and indeed Caribbean, slave plantations. Except, of course, that while contemporary practices result from the luxury of technology and the ability of willing travelers to traverse spaces and disperse across the globe, the transidiomatic practices of the plantation evolved as a survival technique of eviscerated populations spatially corralled together on these islands. ${ }^{71}$ It is perhaps in response to this linguistically imposed microcosm that Créolité inverts the space-language equation. This time it is the subverted dynamics of this imposed idiom that extend outwards in an attempt to redefine the world according to its energies. ${ }^{72}$ Its immediate 
goals notwithstanding, Créolitês biggest contribution has been to reframe the questions of global displacement and belonging in terms often overlooked when discussing colonialism. It is thus that Texaco dissolves the differences between private and public, between the metropolis and the colony, and most certainly between the text of Texaco and the landscape of Texaco, to focus instead on what produces a spatiality more compatible with a postcolonial citizenship.

\section{Section 4. France, Martinique and Marie-Sophie's Body}

\section{Marie-Sophie and Texaco}

Je compris soudain que Texaco n'était pas ce que les Occidentaux appellent un bidonville, mais une mangrove, une mangrove urbaine. La mangrove semble de prime abord hostile aux existences. Il est difficile d'admettre que, dans ses angoisses de racines, d'ombres moussues, d'eaux voilées, la mangrove puisse être un tel berceau de vie pour les crabes, les poissons, les langoustes, l'écosystème marin. Elle ne semble appartenir ni à la terre, ni à la mer un peu comme Texaco n'est ni de la ville ni de la campagne.

-Notes de l'urbaniste au Marqueur de paroles (289)

[I understood suddenly that Texaco was not what Westerners call a shantytown, but a mangrove swamp, an urban mangrove swamp. The swamp seems initially hostile to life. It's difficult to admit that this anxiety of roots, of mossy shades, of veiled waters, could be such a cradle of life for crabs, fish, crayfish, the marine ecosystem. It seems to belong to neither land nor sea, somewhat like Texaco is neither City nor country.

-From The Urban Planner's Notes To The Word

SCRATChER (263)]

"Umwelt, the terrain and water worlds we inhabit and exploit" (ix) ${ }^{73}$ is the subject of the exploratory logic that drives Ethnophysiography, "a nascent discipline: 
one which draws on at least a half dozen existing disciplines" (101) and looks to understand the relationship between language and landscape. ${ }^{74}$ It may also be thought of as seeking to understand what David M. Mark et al. call "landscape vocabulary" (7)..$^{75}$ Texaco is placed on the edge of a city, along a mangrove swamp that anchors, however tentatively, both the identitarian metaphor for Chamoiseau and, on the literal level, the forever-shaky foundation of the slum quarters. ${ }^{76}$ This in-between space, placed between land and seawater, functions, no doubt, like Bhabha's third space, allowing for multiple existences, but it also provides plenty of new insights regarding our relationship with this Umwelt. By no means do David M. Mark et al. claim to present an exhaustive overview of this nascent discipline, which has only started taking shape in the last few years. Their volume, published in 2011, is only an exploratory exercise that hopes to come to a better understanding of "knowledge systems, beliefs, and customs of a people concerning landforms and landscapes." ${ }^{77}$ As the discipline of ethnophysiography evolves in its quest to understand the "relationship between physical attributes of land and the meanings attributed to it by those who dwell in that place"78 (3), I am sure it will also soon reckon with colonialism and literature as two important vectors that have influenced the meaning of landscape.

Texaco furnishes multiple occasions to see the contrast in topophilias. Andrew G. Turk points out ${ }^{79}$ the contrasts between his own personal experience, that of the non-Indigenous Australians who have farmed their land for six generations, and that of the Indigenous Australians who have occupied the land in "excess of 2000 generations" (58-9). Turk rightly implies that his own personal experience, and that of non-Indigenous Australians' association with land, cannot compare with that of Indigenous Australians, whose "knowledge of, and attachment to, their own place is of an immeasurably greater magnitude" (59). Texaco, it must be remembered, is a novel placed on the fringes of the city; a novel that also furnishes numerous examples of competing worldviews regarding the meaning of inside and outside, center and periphery, and local and global. Worldviews that vary depending upon not only the linguistic background but also political leanings, physical location, class and most certainly, in MarieSophie's case, according to the material context of the postcolonial subject defined by gender.

There is one element (conspicuous by its absence in David et al.s discussion of ethnophysiography) that interacts the most with space and is central in giving it meaning: the human body. ${ }^{80}$ Texaco, the hutment, is embued with the seemingly contradictory qualities ("hostile" ['hostile']; "berceau de vie" ['cradle of life']) of the mangrove. Texaco the novel abundantly places on record firstly 
the perception of the mangrove and secondly how that perception becomes the anchor point to situate entities with never before seen coordinates, which is what Texaco the hutment is meant to be. The mangrove site provides multiple examples of how its inhabitants change the meaning of the land, imbuing it for example with meanings learned historically across generations from the Hills of Noutéka, which are the "ancestor of Texaco" ${ }^{81}$ (duRivage 36). Similarly, when Marie-Sophie comes to this swamp, her understanding of this in-between place is influenced by the perceptions of her body. More importantly, it is through this gendered and racially marked human body that she negotiates new meanings for this landscape.

The question here is not simply about reading gendered phenomenological associations. It is rather about how Marie-Sophie's experiences in the cityscape are formative of this new definition of space. It is most certain that she too is seen to elaborate "new forms of political identity and to disarticulate the city as the site of masculinist and colonial publics" (Varma 2). Marie-Sophie also reminds that the modernist cities only allow for certain economic activities and thus expose those gendered bodies to the kinds of sexual violence Marie-Sophie endures within a domestic space reigned over by a mulatto man and a follower of the French idea of assimilation. This gendered body speaks of a markedly different perception of l'En-ville when it is forced out of it. Not only are spaces inscribed in the way one perceives them, this perception then folds back upon its inhabitants to maintain the hegemonic spatial status quo. The human subject too bears back onto landscapes to give it new meaning that derives from personal material histories.

Of course, Texaco is reinscribing space within a matrix where bodily associations are changing and Marie-Sophie is certainly representative of those women of color who at a "range of spatial scales, from the most local in the home to the global scale [...] have challenged conventional assumptions about the relationships between identity, both individual and group, and location" $\$ 2$ (38). For she is indeed in her struggle challenging the conventionally held power structures, ranging from the local to the global. Moreover, as a result of a hutment born out of a gender and racially marked body, this is no more a contrarian space, but one that follows the flows of the body: metaphorically formed of the travails that a gendered body endures and also literally following the necessities of the body. Unlike the geometric logic of l'En-ville, Texaco's is a logic in which the body is firmly placed within the frame of colonially inflected spaces and perceptions thereof. Marie-Sophie shows how the body exists as an interactive container of spatial practices. 
The section that follows provides a detailed textual reading of MarieSophie's gendered experiences in l'En-ville that directly lead to the formation of Texaco. Following from the implications of the epigraph to better understand the entity of Texaco and the spatial changes carried out in the novel, we need to look at the way in which women, or rather one woman - Marie-Sophie - has been defined. She is the one who is primarily responsible for bringing about the change in the landscape: Marie-Sophie converts the "urbaniste" from being a threat to an ardent supporter of the hutment. She is both the agent and instrument of this change. Following the parameters of the epigraph, it is this "dame" and her experiences as a woman that should shed light on the spatial organization in Texaco. In the quest for realignment of this space it is her presence and her maternal experiences as one of "ces femmes" that tell us about the exact interaction between space and women.

One of the examples through which this interaction gets highlighted is the way pregnancies, and most certainly Marie-Sophie's pregnancies, relate to space. Being one of "ces femmes," she is "condamnées aux maternités perpétuelles" ['forever condemned to pregnancies'], but with one difference - she chooses to remain childless. Ultimately, she has to face sterility due to self-executed abortions. Later on, despite her strong desire for a child she cannot have one. Her state of childlessness stands in stark contrast to her name, Marie, which symbolizes ultimate motherhood (Burton 191). In "Mémoire d'Afrique, mémoire biblique," Joseph Nnadi ${ }^{83}$ talks about Texaco's anti-Christian stance. One could read this contrast as another instance where Texaco caricatures some basic notions of Christianity (Nnadi 83).

Marie-Sophie's refusal of maternity could possibly be explained as a rebellion, where Maryse Condé would call it 'one of the most frequently seen forms of protest in the works of antillean women novelists [...] as the project of an eventual 'gender clash." ${ }^{44}$ To continue in the same vein, François duRivage explains Marie-Sophie's childlessness as "perhaps symbolic of the low birth rate at the time of slavery, as the slaves used abortion and infanticide to spare their children from life in captivity" (42). While both Cilas Kemedjio and duRivage present women who use their ability to procreate as a tool against oppression, they do not take into account the interaction between gender and space. Another element one needs to take stock of is Marie-Sophie's presence as one of 'these women.' She cannot be alone in protesting by not giving birth. She speaks for 'these women' by being like them. We need to explain how Marie-Sophie can remain childless while remaining a part of "these women" defined in their procreative abundance. 
One possible way of reconciling these considerations would be by postulating that Marie-Sophie's "biological infertility is in fact a blessing," because it allows her to "both write and create the community of Texaco" (duRivage 42). I would go further to say that one needs to read this as a counter to the fetishistic nationalism that advances preconstructed social categories. For instance, McClintock speaks about the "Afrikaner womanhood" that is presented as "suffering, stoic, and self-sacrificing" 85 (105).

This latter explanation allows us to show how Marie-Sophie's experience with pregnancy bears direct spatial implications. The birth of the settlement of Texaco materializes through the choice exercised by Marie Sophie - the same power of choice that kept her childless. Moreover, while it retains her in solidarity with other women, it radically challenges the essentialist nature of Chamoiseau's epigraph, wherein women living in perpetual state of motherhood have an intrinsic association with nature. In a single gesture, she reclaims the right to her body and a space of her own. The very space, the woman's body, that has thus far been deployed against her to create a fatherland ("patrie") participates in the redefinition of a landscape that exists outside a paradigm in which women "are typically constructed as the symbolic bearers of the nation but are denied any direct relation to national agency" (McClintock 90). It is from Marie-Sophie's body that the hutment is born and it is through the understanding of her body that one can understand the landscape of Texaco. All of Marie-Sophie's troubles associated with her state of being a woman - namely, unwanted pregnancies, self-executed abortions, attempted rape and eventually a rape - are those that she faces during her stay in l'En-ville.

A perfect example of the way the space of l'En-ville plays an important role in her life are the circumstances under which she is forced to leave her father's hut to be a part of the city. A man named Lonyon had rented to them the hut, located in a quarter called Quartier des Misérables, around the city of Fort de France. After the death of Idoménée - Marie-Sophie's mother - there being no one to earn their livelihood, Marie-Sophie and her father cannot pay the rent. Lonyon has them beaten up for their noncompliance, which contributes to her father's death. In the meantime, Bec-d'Argent, the local strongman who had helped Marie-Sophie and her father earlier against Lonyon's attempts to evict them, again helps out Marie-Sophie by avenging her against Lonyon's men - he cuts their ears off. The tamed Lonyon then is also supposed to help Marie-Sophie move into the city. Lonyon's solution: "travailler chez lui, comme personne de maison" ['work in his house, like a house girl'] $(225 ; 204)$. The incident described above - Marie-Sophie moving away from her quarter 
to the city - once again shows the spatial dynamics in the broad spectrum of the story.

Marie-Sophie's interaction with Lonyon is emblematic of the effect the city has on her body and her sexuality. After dispossessing Marie-Sophie from the Quartier des Misérable, he offers her shelter. Seizing her dependence on him as an advantage, Lonyon deals the first blow during Marie-Sophie's stay in the city - he attempts to rape her. In losing her own space, she is likewise losing control over her body. As a corollary, Lonyon's brute power over Marie-Sophie emanates from his control over her shelter.

Her entry via Lonyon's home is a prelude to her spatially triggered sexual travails. An attempted rape marks her first stop in the city, and her last refuge at Alcibiade's house culminates in him raping her. The two attacks mark the beginning and the end of the challenge to Marie-Sophie's sexuality. They contain a spectrum that demonstrates the escalation of hostilities upon her. Apart from the attempted and the eventual rape, she faces unwanted pregnancies, agonizing self-executed abortions and resultant sterility. Coinciding with the various challenges that she confronts in regard to her sexuality is the fact that, all the while, she is resident in a space that is not her own. By losing space on the fringes of l'En-Ville and finding shelter in the city, Marie-Sophie also loses the right to her own body. Her sexuality becomes a site to be claimed.

Burton (192) points out how Texaco presents a set of binaries, where the hutment is "feminine" and the city "masculine." Marie-Sophie's stay in the city is a perfect example of how the city takes on a masculine aspect. Men as masculine avatars of the city challenge her body several times. These assaults continue right until the moment she quits the bounds of l'En-Ville. To guard the sanctity of her body and maintain her control over it, it becomes imperative for Marie-Sophie to move out of the one space that challenges her existence - l'En-ville. With the setting up of the hutment of Texaco, she is also finally able to assure herself not only of spatial but also sexual security.

A reading of the quotation that follows helps elucidate the exact nature of the relationship between the "masculine" space of l'En-ville and Marie-Sophie. It explains the circumstances under which Alcibiade rapes her. One notices that Alcibiade is able to rape her not because he presents himself as a more formidable aggressor, but rather because by the time the rape takes place, Marie-Sophie is progressively weakened by the effect of the city. It is as if she gives in to the rape. Marie-Sophie's body literally comes under the control of both the city and the man. Moreover, one learns that her body, which becomes a site to be controlled in many ways by the city, is also the very space from which the decision 
to rebel against all power - signified by the city - emanates. Her body becomes center stage for the various politicospatial debates proposed by the novel; it is a site that is challenged and the genesis of the hutment of Texaco:

Même à présent quand j’y repense, je ne comprends pas ce phénomène qui fit que je ne réagis pas quand il me recouvrit, me déshabilla, et me creva d'un rein sauvage. Son corps invincible me fracassait à grands ahan, m'écartelait, me désossait, me transperçait. Il grognait d'une joie revancharde. Moi qui revenais de l'étreinte de Nelta, je basculai dans une ravine où s'embrouillaient le plaisir, la honte, la douleur, l'envie de mourir, l'envie de tuer et d'être tuée, le sentiment de l'injustice, de ne pas exister, d'être une chienne méprisée, la haine de cet En-ville où je me tournaillais seule, livrée aux sept malheurs sans choisir le chemin. D'avoir été comme ça durant presque deux heures, le jouet flaccide de ce sieur Alcibiade, dut être ce qui m'amena à ne plus jamais me laisser commander par personne, à décider à tout moment, en toute autorité, toute seule, de ce qui était bon pour moi et de ce qu'il fallait faire. (279-80)

[Even now, when I think of it again, I don't understand the phenomenon that made me fail to react when he got on top of me, undressed me, and ruptured me with one savage thrust. His invincible body shattered me with much striving, quartered me, boned me, ran me through. He grunted with vengeful joy. I, who was just back from Nelta's arms, toppled into a ditch full of mingled pleasure, shame, pain, the desire to die, to kill and be killed, the feeling of injustice, of not existing, of being a scorned dog, the hatred of this City where I swirled about all by myself, faced seven dangers alone without ever choosing my path. Serving as Monsieur Alcibiade's flaccid toy for almost two hours - that must have been what would bring me to never let anyone order me around, to decide all by myself what was good for me and what had to be done. (254)]

The above quotation describes Alcibiade's "revancharde" ['vengeful'] rape of Marie-Sophie. It presents Alcibiade's actions as being opposed to Marie-Sophie's passive silence. It also shows how this event transforms Marie-Sophie from being a passive victim to a person of resolve whose strength allows her to face numerous onslaughts in her quest to save Texaco. 
One can describe the change of tone in the two verbs used by Marie-Sophie, found at the two extremes of this quotation. She moves from her passive state ("je ne réagis pas" ['fail to react']) to being a decision maker ("à décider" ['to decide']). During the rape her passivity is represented by the following verbs or actions performed by Alcibiade on her body: "il me recouvrit, me déshabilla, et me creva d'un rein sauvage" ['he got on top of me, undressed me, and ruptured me with one savage thrust']; "me fracassait" ['shattered me']; "m'écartelait, me désossait, me transperçait" ['quartered me, boned me, ran me through'].

She allows his acts of aggression with little realization of her submission. This complete disconnection from the self is communicated by her failure to comprehend her own actions: "Même à présent [...] je ne comprends pas ce phénomène" ['Even now [...] I don't understand the phenomenon']. MarieSophie's passivity is communicated by the choice of the verbs describing Alcibiade's aggression - to undress, to quarter, to bone, to rupture - increasing in domination. His actions range from covering her body to the point where he pierces her. These acts of domination progressively move inward from the exterior of her body, thereby bringing all aspects of Marie-Sophie's body completely under Alcibiade's command.

The gradual intensity of Alcibiade's acts corresponds to the increasing degree of surrender on Marie-Sophie's part. By covering her body with his own, Alcibiade acts with his own body. Next, he undresses her and quarters her. These actions display a progression. He has moved on to manipulating her body with his own. The violence reaches its pinnacle when she feels him piercing her. $\mathrm{He}$ conquers her body by piercing and completely shattering it, thus completing the cycle of control. Her passivity is contrasted by and stands against the backdrop of the strength of his body ("son corps") communicated by the adjective "invincible" - a contrast that gets starker due to the violence felt in the savage sexual thrust.

Of all the verbs described in this sequence, "grognait" ['grunted'] is the last one and the only verb that is unrelated to the violence performed on MarieSophie's body. Seemingly the least potent one, it is actually the most so. It accentuates the aggression defined by the series of verbs ending with "transperçer" ['ran me through']. Recounting a rape that goes on for about two hours, the above quotation juxtaposes Alcibiade's actions and Marie-Sophie's thoughts. While various verbs delineate fierce movement, there is only one sound - Alcibiade's grunting that contrasts with Marie-Sophie's passive contemplation. It is as if, in this overtly silent scene of violence, the domination takes a singular verbal form representing communication between the aggressor and the agressed. All it takes to overpower 
Marie-Sophie's silence is this incoherent grunting. It is through the vocalization of this expression that Alcibiade's vengeful joy is complete. "Grognait" echoes Marie-Sophie's muteness and becomes the most telling of all verbs.

An analysis of the French language verbal sequence "il me recouvrit" (translated as 'got on top of me') will show that Marie-Sophie is visually - by virtue of the first-person direct pronoun "me" - the object covered and defined by "il" and his action "recouvrit." "Me" falls between the third person pronoun "il" and the verb "recouvrir." The first-person direct object pronoun "me" communicates and shows its dependence on the verb. Alcibiaade's actions determine the "me" that designates Marie-Sophie. The multiple appearance of "me" in the following verbal sequences adds to Marie-Sophie's passivity, compounded by the numerous acts performed on her body.

Marie-Sophie's passivity in relation to Alcibiade is replicated in her connection with l'En-ville. She expresses her present misery as a part of her general state of being in the city. This state of being is not a choice; it is the expression of the rudderless existence that the "haine de cet En-Ville" ['the hatred of this City'] imposes upon her. The scene of bodily rape is intimately related to the machinations of the city against her and the fact that she cannot choose among its many paths ("sans choisir le chemin" ['without ever choosing my path']). L'En-Ville, by making her feel isolated and anchorless, spatially mirrors the disorienting rape that is finally committed on her body. She is delivered to the misfortunes of the city. All her current problems are caused by the space of the city - L'EnVille - that makes her its passive victim. It is her fight with the city that causes Marie-Sophie to drift and wander about ("tournaillais" ['swirled']) - "seule" ['all by myself']).

This word, "seule," which appears twice in the above quotation, is the one that communicates the changeover from the negative passivity of Marie-Sophie to her active self. In the first appearance of "seule" ['all by myself'], she is forced to live alone by the city; and by living in it, she is caused to be disoriented by it. The second "seule" ['all by myself'] is present at the other end of the spectrum and is marked by all positive qualities. In its second appearance "seule" ['all by myself'] is appropriated by Marie-Sophie and not imposed upon her. Able to make a decision at this point, she chooses to remain "seule" ['all by myself'] From not being able to choose a path, she decides her own destiny. No one will command her. "Seule" ['all by myself'] the second time, is not imposed but is chosen as a result of the rape.

To better understand this scene, it must be noted that right before this rape, Marie-Sophie had met Félicité Nelta and had made love to him. She moves from 
the hold of one man ("revenais de l'étreinte de Nelta" ['just back from Nelta's arms']) to another's ("il me recouvrit"). She makes pleasurable love and faces sexual violation on the same day. Her varied and opposing emotions - ranging from "plaisir" ['pleasure'], to "honte" ['shame'] and ending with "douleur" ['pain'] can be explained as a result of the two opposing sets of sexual encounters. The two contrasting experiences lead her to face questions of existence - from wanting 'to die,' wanting 'to kill', and wanting to 'be killed' ('l'envie de mourir, l'envie de tuer et d'être tuée”).

\section{Marie-Sophie's body and Martinique}

It would also serve well to remind at this point of the political overtones of this vengeful act. Marie-Sophie is raped for openly displaying her political support for Aimé Césaire - the Martinican intellectual and one of the founders of the Négritude movement. He appears in Texaco as a character holding the post of the mayor of the city of Fort-de-France, the same post he held in real life. In Texaco Césaire wins his first elections (1945), voted for by people from the hutments sprawled around the city. Alcibiade, Marie-Sophie's employer, does not hide his disdain for Césaire's politics:

\section{Un nègre se disant de l'Afrique, allait administrer la Ville...et commu- niste en plus!... (277) \\ [A blackman declaring himself African was going to administer the city ... and a communist no less!... (252)]}

Marie-Sophie votes to elect Aimé Césaire and dares thereafter to join a victory procession without her employer's permission. The brutal rape of Marie-Sophie highlights the text's focus on the body as a space that becomes the site where political differences are manifested. Caught between opposite forces, MarieSophie's control over her body is compromised in more than one way - not only is she raped but her body is also rendered a mere tool used to contest political differences. In receiving sexual retribution for a political act, the body literally becomes an archive of political history. One is shown how 'the [Antillean] woman can be considered as the site where history can conserve itself, can perpetuate itself. Women symbolize a possible memory. ${ }^{86}$ To better understand the above-mentioned travesty and the text's sociopolitical moorings, one would need to excavate further this archeology of recorded memories in the space defined by Marie-Sophie's body. 
Significantly, Alcibiade rapes Marie-Sophie after the celebration for Césaire's 1945 victory, a victory that was the first step toward the island of Martinique becoming a French department. Within this backdrop MarieSophie's rape also points to her body as a space where Chamoiseau's objections to Césaire's politics solidify. In Texaco, although Alcibiade is opposed to Césaire, there is one similarity between the two that puts them at odds with the author of Texaco - both have been shown seeking assimilation with France.

Alcibiade, who believes in the greatness of colonialism, enthusiastically preaches a politics of assimilation, albeit with moderation (273; 248). Assimilation, he says, would allow the colonies to grow along with the mother country. While Alcibiade only lauds the idea, it is Césaire who converts it into a reality. In showing Césaire's work as a continuation of Alcibiade's, a political similarity is established between the two. Chamoiseau, though extremely respectful of Césaire's achievements, still chooses to distance himself from the latter's politics. He blames Césaire for Martinique's departmentalization, which he says made its people dependent on France. Lucien Taylor describes the objections that the Creolistes (including Patrick Chamoiseau) have to Césaire's outlook:

The Creolistes' central problem with Cesaire is his politics. In 1945, Cesaire ran for office [...] He won, becoming mayor of Fort-de-France [...] he led the legislative battle to make Martinique an official French departement [...] In the Creolistes' eyes, things have gone downhill ever since. [...] Within the space of a generation, Martinicans were transformed from self-sufficient producers into welfare-dependant consumers. ("Créolité Bites" 129)

Given Chamoiseau's views in the above quotation, it would not be wrong to say that he would equally disapprove of both Césaire and Alcibiade as two different agents of assimilation. At this point, we may examine Nelta's role in Texaco - that of a political worker supporting and actively participating to ensure Césaire's victory. Marie-Sophie meets and makes love to Nelta during celebrations that follow Césaire's first election victory of 1945 . The following quotation describes Marie-Sophie's sexual pleasure enmeshed with the joy of the political victory:

...je poursuivis mon vidé, emportée par un mécanisme sans-manmanni-papa, qui d'ailleurs me jeta dans les bras de Nelta Félicité, un nègre docker versé en politique, qui ne me lâcha plus, et dans les bras duquel 
je vautrai, après vidé, [...] secouée de folie polissonne, de plaisirs et de cœur agoulou. (278-9)

[...I went on with my vidé, carried by a mechanism without mother or father, which, besides, threw me in the arms of Félicité Nelta, a black longshoreman learned in politics who wouldn't let go of me and in whose arms I wallowed after the vidé, [...] shaking with mischievous madness... (253)]

The first thing that stands out here is Marie-Sophie's passivity. She once again finds herself regulated by forces other than her own volition. She is "emportée" ['carried'] by the celebrations that "me jeta" ['threw'] her in the arms of Nelta, who in turn takes control of her by not letting her go: "qui ne me lâcha plus" ['who wouldn't let go of me']. Moreover, when she identifies her lovemaking as a continuation ("après vidé" ['after the vidé']) to the election victory, one sees a clear connection between the two moments of rejoicing - one sexual, the other political. This connection gets further credence when one realizes that the backdrop of their meeting is a political demonstration.

If one is to go by Chamoiseau's opinion about the departmentalization of Martinique in 1946, then according to the author of Texaco the Martinicans are celebrating their eventual downfall. When Marie-Sophie says 'I went on with my vidé, she follows the movement of this "vidé" in more than one way - apart from accompanying the celebration she fuses her fortune with that of the victorious parade. Her pleasure of lovemaking, which parallels the political pleasure, ironically becomes a way of celebrating the reasons for her imminent ill fortune. Alcibiade rapes Marie Sophie for daring to participate in this celebration of assimilation. It is as if Marie-Sophie's sexual travesty foretells the reader of the political destiny of the habitants of the island. Her body becomes one with the fate of the people of Martinique.

As Marie-Sophie mirrors the joy of the people of the island, her passivity while she enjoys her lovemaking as well as when Alcibade rapes her reminds of the passivity of the islanders. She has gladly given herself to someone who wants assimilation, Nelta, Césaire's follower, after which Alcibiade, who wants to be a part of "Mère-Patrie," rapes her. While being raped, Marie-Sophie, just like the people of the island of Martinique, remains perplexed, not knowing why she does not react to events that affect her body ("je ne comprends pas [...] que je ne réagis pas" ['I don't understand [...] fail to react']). Her body represents the relationship that the Martinican subject has with its Other - France. In Chamoiseau's 
postulation, this subject is conquered at the same time as Martinique lays the foundation stone of assimilation with France. Marie-Sophie's mixed emotions also reflect the passage from pleasure to pain that the islanders have had to traverse. Through the emotional turmoil of her body she speaks of not only her own sentiment of inexistence ("le sentiment de l'injustice, de ne pas exister" ['feeling of injustice, of not existing']) but also that of the Martinicans. They remain from this point subsumed under the larger identity of the French. Marie-Sophie's rape, retribution for her political stance, then makes her body the determinant for Martinique's relationship with France as it reflects the spatiopolitical tensions. It is the point at which France's domination of Martinique gets crystallized.

If one is to consider the effects of sterility on Marie-Sophie's life, the influence of France's domination on her body gains even more credence. Because of this rape, Marie-Sophie once again becomes pregnant and decides to self-terminate this unwanted conception. Her repeated abortions leave her unable to bear a child:

J'avais tant saigné, je m'étais tant abîmée avec cette herbe grasse [...] que mon ventre avait perdu l'accès au grand mystère. (297)

[I had bled so much, I had hurt myself so much with that watergrass [...] my belly no longer had access to the great mystery. (270)]

This rape-induced pregnancy becomes the direct cause of her sterility. Later on, when she does not want Nelta to leave her and go to France and knows that she "aurais pu retenir Nelta avec un petit Négrillon" ['could have kept Nelta with a child'] (297; 270), Marie-Sophie finds that, despite her repeated attempts, she cannot conceive anymore.

The domination by France is doubly manifest on her body. First, the desire of assimilation with France leads to her rape and contributes to her infertility, after which her lover abandons her. Infertility, as regarded by Marie-Sophie, is the cause of her failure to prevent her lover from going to his dream place, France:

Mais le rêve de Nelta c'était de baille-partir. Partir, c'était son mot français. [...] D'abord, vers la France qui (comme pour nous tous) lui habitait la tête. (295)

[But Nelta's dream was to get up and leave. Partir that was his French word [...] First to France which filled his head (like all of ours). (268)] 
France overpowers her, leaving her lover-less and childless in one stroke, weakening her, ravishing her, rendering her, as I have said: "seule" ['all by myself'].

Her sexuality is the space within which this spatial conflict plays out, and with the rape as the crescendo, the battle goes France's way. Our current understanding of her body - denoting the space of the island of Martinique - also influences our understanding of the two appearances of the word "seule" ['all by myself'] in the rape scene. I have discussed how, in its first appearance, "seule" ['all by myself'] presents Marie Sophie's state of confusion. This word is charged with the injustice committed by the space of l'En-ville unto her. Apart from being an expression of Marie-Sophie's regret at not having determined her path in the space of the city, "seule" ['all by myself'], carries within itself the result of France's influence. It is indicative of the turmoil caused due to Martinique's interaction with France. To recapitulate a part of the rape scene:

la haine de cet En-ville où je me tournaillais seule, livrée aux sept malheurs sans choisir le chemin [...] à décider à tout moment, en toute autorité, toute seule, de ce qui était bon pour moi et de ce qu'il fallait faire. $(279-80)$

[the hatred of this City where I swirled about all by myself, faced seven dangers alone without ever choosing my path [...] to decide all by myself what was good for me and what had to be done. (254)]

The second "seule" ['all by myself'] acts as a counterforce to the first "seule," and helps Marie-Sophie separate herself from l'En-Ville and as a result, from France. Injustice committed on her body by the spatial entities of France and l'En-Ville is to be fought by spatial measures. It is from this rape that her decision to set up Texaco takes shape. She adopts a resolve that holds her in good stead when she establishes her hutment of Texaco against perpetual assaults. From not being able to choose her path in the city, she decides to go outside of it and establishes a force to counter the city's injustice. The second "seule" ['all by myself'], then, not only helps her tear away from l'En-Ville but also acts as a fitting answer to France's symbolic rape on the space of her body.

Both the city and the men attack Marie-Sophie, robbing her of the power of controlling her body and space. Her rape, while enfeebling her, acts as a catalyst for the creation of the hutment. Texaco, born out of her physical trauma, reminds of how 'the body of the [Martinican] woman will become the site for the formulation of resistance to the structures of oppression. ${ }^{37}$ More importantly, 
the rape literally recalls what is stored in the collective psyche of women who had to endure a past dominated by slavery. That was a time when 'the African woman underwent the ultimate of aggressions, which was the daily and repeated rape by a crew of sailors rendered insane as a result of exercising their vocation.' 88 Marie-Sophie's ordeal encapsulates flashpoints in memory - of sexual exploitation and subjugation - that the slave women retained.

Struggles against colonialism have often taken spatial forms in Antillian and in particular Martinican literature. The more France and the French metropolitan borders have asserted their presence within Antilles, the more urgent has become the reliance on regional spatial configurations. Texaco is one of those novels implicated, both explicitly and implicitly, within this spatial dynamics. Just as different textual spaces within the novel interact with each other, so also the hutment of Texaco and its relationship to the center figure as spatial metaphors for a linguistic debate within the text. Within this equation MarieSophie's place as a gendered colonized subject is central to the unfolding of the argument about space finding meaning as a result of its interaction with the human body. France's borders and their history of conflictual relationship with Martinique play out on the spatial division on the city of Fort de France in the shape of the spatial binary that Texaco and the Inner city produce. These borders also impose the burden of France's colonial history on Marie Sophie's sexuality.

To go back to an earlier discussion based on Milne's conclusion, one sees that when the protagonist assumes the name Texaco as her own, "the word 'Texaco' [...] [is] transformed, for it now 'irradiates' an extra layer of meaning” (173). This "extra layer" is composed of the personal accounts of Marie-Sophie - her experiences of a woman. Marie-Sophie's body - the storehouse of memories - becomes an inextricable part of Texaco. She enmeshes her experience into the topography and ensures that nobody forgets the enslaved past that targeted these women's bodies and molded their psyche. Furthermore, she guarantees the perpetuation of this memory when, at the end of the novel, she reveals her secret name to be Texaco, and requests of the Urban Planner that it be never removed from the hutment:

Je lui demandai une faveur $[. .$.$] que jamais [. .$.$] on n'enlève à ce lieu son$ nom de TEXACO [...] mon nom secret. (417-8)

[I asked him a favor [...] let no one, across the centuries and centuries, ever remove the name of this place, TEXACO $[\ldots]$ my secret name. (382)] 
With this request, Marie-Sophie's past is fused forever with the destiny of the hutment. She converts her memories into a tool with which to confront the future and leaves an indelible mark on it - the hutment of Texaco will perpetually evoke Marie-Sophie's struggles.

One also needs to point out that just as Marie-Sophie simultaneously completes her story as well as the story of the hutment, the novel Texaco also reaches its conclusion. What one has in the confluence of these three entities, all three bearing the name Texaco, is the imperative to keep the question of the enmeshment between space, gender and language alive. Indeed, they need to be understood as historically placed entities co-locating each other.

Humans inhabit space, and space finds its meaning through humans. A clear-cut division to understand them as discreet entities is not possible. These three Texacos - the novel, Marie-Sophie and the hutment - remind us that there is still the need for a continued and rigorous analysis of the myriad ways in which spatial ramifications of colonial as well as anti-colonial nationalisms are still playing out on everyday lives and more specifically on the bodies of subjects. These Texacos together are also telling us that the spatial answers to such spatial riddles could be found in the kind of simultaneous unraveling of the three as interconnected, as this chapter has tried to delineate. 



\section{CHAPTER 5 \\ OUT OF PLACE: FRENCH FAMILY AT (ALGERIAN) WAR}

The historian knows how vulnerable is the whole texture of facts in which we spend our daily life; it is always in danger of being perforated by single lies or torn to shreds by the organized lying of groups, nations, or classes, or denied and distorted, often carefully covered up by reams of falsehoods or simply allowed to fall into oblivion. Facts need testimony to be remembered and trustworthy witnesses to be established in order to find a secure dwelling place in the domain of human affairs. ${ }^{1}$

- Hannah Arendt, Lying in Politics

With this chapter, we are back in France, Jules Verne's home country. In this French story, I look at the ground of difference that separates as well as links the two colonial products Georges Laurent (Daniel Auteuil) and Majid (Maurice Bénichou) in Michael Haneke's award-winning 2005 film, Caché (Hidden). ${ }^{2}$ This space of difference lays bare any claims to a definitive ontological space of Otherness, whose apparent stability in Le Tour du monde en quatre-vingts jours, anchored a picture of security for the colonizer. The film revolves around the Laurents, who have been receiving anonymous video recordings of the mundane comings and goings of the couple and what appear to be childlike hand drawings. Despite the active involvement of the authorities, the author of these images, their motive, and even when and from where they recorded the images remains unclear to both the viewer and the couple throughout the film. 


\section{Immaterial Differences}

This last chapter is an amplification and at the same time an extension of the material space that has thus far occupied my attention. In the previous chapters, colonial subjectivity is actualized as a result of its interactions with the physical geography it inhabits. As Le Tour du monde en quatre-vingts jours structures an uncomplicated subjectivity that emanates from, and indeed is dependent upon, colonial structures (both meanings intended), Chamoiseau and Devi's texts, through a process of restructuring an anchored geography, accentuate the complexities of postcolonial spatial assertions. The two authors problematize the very notion of the passivity of topographical space to portray a physical presence - not only as a register of social change but also as one of the instigators of this change. As I have pointed out before, this topographical space is not an isolated element, instead, anytime evoked it activates an entire matrix of interconnections where, owing to mutual reflexivity, the effects of each change are felt through the entire matrix.

Even as the unfurling of this mutually inflected relationship remains at the center of this chapter, the spatiality it delineates is definitely less tangible. This spatiality will likely cause further consternation among scholars like Chris Philo. Philo is among those who, while commenting on the cultural turn of human geography, bemoan that "we have ended up being less attentive to the more 'thingy,' bump-into-able, stubbornly there-in-the-world kinds of matter (the material) with which earlier geographers tended to be more familiar." Joanne Sharp cites Philo's concerns as an example of "many geographers' fear of the overly abstract nature of much geography in the wake of the cultural turn which emphasized texts and representations" (74). If the fast-paced changes and the ever-expanding disciplinary reach of this turn has provoked fear among geographers, it is not without generating simultaneously a whole plethora of opportunities for other disciplines to reorganize themselves geographically. For instance, one need only look at Kevin Hetherington's Expressions of Identity: Space, Performance, Politics ${ }^{5}$ to understand how a corollary of this un-thingy-fication of geography is also a productive spatialization of the cultural landscape. When Hetherington speaks of identity using expressions like "theoretical decentering"; "layering"; "locality"; "outside"; "mapped out"; "position"; and indeed goes on to state that "everywhere can be both a centre and a margin" (23-4), we see how important the inflection of geographical categories has become toward understanding each other and the cultural landscape one inhabits. 


\section{Locating Caché}

It would not be wrong to state for Haneke's entire work what Monica Filimon and Fatima Naqvi ${ }^{6}$ say about his television production, Variation. The director relies "on physical spaces in his film to make larger claims about human interactions" (244). In varied ways the already complex spatial question in Haneke's cinema $^{7}$ is even more pointed for Caché. After all, this Paris-based film displays how the bloodshed related to the Algerian war of independence, fought elsewhere and in another time, continues to rend everyday life right here and right now in the very heart of the French republic. Several studies have attempted to understand the violence inherent to the relationship between Georges and Majid as a function of their geographical locations. Their lives are intertwined along national, urban, racial and colonial divisions. For instance, Kate Ince's essay ${ }^{8}$ in the edited volume The Cinema of Michael Haneke: Europe Utopia (edited by McCann and Sorfa) analyzes Caché to show how Haneke’s "use and realisation of existential or lived space" is "crucial to the atmosphere of anxiety and tension generated throughout" Haneke's cinema (86).

The private (or domestic) space and the colonial violence it produces within a racially charged society have attracted much attention in spatial analyses of Caché. Brianne Gallagher,' for instance, has analyzed the violence embedded in the division of the "private space of the home" and "the public space of the media" (19). Caché is "transmorphing the home space into a site of contention connected to colonialist histories" (Gallagher; 25). Michael Cowan ${ }^{10}$ also notes that "in the era of immigration" where "private space is treated as a defensive shell against the outside world and the public space of encounters," Caché brings the "two acts of violence" - state violence and the violence of the domestic family space - "into congiguous relation by the film's plot" (118). Similarly, while discussing the "unjust spatial-affective economy" of Paris, Joy Schaefer shows ${ }^{11}$ how Caché brings attention to "the systematic dumping of negative social emotions, such as fear and disgust, onto bodies and spaces that are marked as 'bad"' (52). In other words, the city center designates the good space and the French banlieue (the racially marked suburbs) becomes bad. Cachés experiments with cameras and editing, through which it "re-maps off-screen space in newly disconcerting ways" and "constructs a multiplicity of invisible spaces" have opened up newer ways of conceiving cinematic spatiality (7). Indeed, Peter Eisenman, who also analyzes this "probing of filmic conventions," concludes that Caché offers the possibility of redefining our association with space. Eisenmann shows 
how Caché changes the very meaning of human sense of vision to open up "perhaps more than any other visual medium, new possibilities for architecture" (129)..$^{13}$

These studies show how topographical space in Haeneke's work is far from passive. Spatial divisions are not only registers of social change - they are also instigators of this change. This chapter extends the meaning of this thingy-fied space that the above studies focus on to understand its implication for the human identity. ${ }^{14}$ For the purposes of this current study, Cachés cinematic technique displays how the violence of the Algerian war is embedded in the architecture of the larger space of colonial identity that one inhabits along with the colonial Other.

It is just this kind of spatiality, where the human subject locates itself and its identity in relation to others, that Elizabeth Grosz explores in her essay "Space, Time, and Bodies." ${ }^{15}$ Grosz follows feminists like Julia Kristeva and Luce Irigaray in order to understand how "the sex [by extension race and class] is assigned to the body" and how "bodies are assigned a single sex" (84). To show how human subjectivity is able to locate itself in the space that its body occupies, Grosz borrows from Roger Caillois' sociological and entomological spatial analyses. It is crucial to remember that for the insect world "mimicry is a consequence of the representation of space" (89), and that mimicry, which involves imitating "either other insects or their natural environment" (88), takes place because of the way the insect perceives space around it. The insect mimics and adapts itself based on the way it perceives the existence of this space.

As a corollary to the mimicry in the insect world, Grosz shows that for the human subject to "take up a position as a subject, he [subject] must be able to locate himself as being located in the space occupied by his body" (89). To elaborate just exactly what this interrelation between subjectivity and space might be Grosz turns to Caillois' example of a psychotic individual who experiences a dissociation between the self and space, and who is "unable to locate where he should be" (89) and instead "he may look at himself from outside himself, as another might" (89-90). Grosz quotes Caillois:

I know where I am, but I do not feel as if I'm at the spot where I find my-
self $[$... the body separates itself from thought, the individual breaks
the boundary of his skin and occupies the other side of his senses.
(Caillois $1984 ; 30)^{16}$ 
Psychosis, then, is "what Caillois describes as the 'depersonalization by assimilation to space"' (Grosz 90). Such an individual loses its positionality, and ceases "as it were, to occupy a perspectival point" (Grosz 90), to merge with its perceived space. This psychotic does not belong any more to its body as a unique point in space; a belonging in space that is the "condition under which the subject has a perspective on the world" (89). This subject instead, abandons itself

to being spatially located by/as others. The primacy of one's own perspective is replaced by the gaze of another for whom the subject is merely a point in space and not the focal point around which space is organized. (90)

It is to be understood that it is thus that the "gaze of another" imposes sex, class and race. The subject conforms to its space in the manner that it perceives this space to exist. So, when talking about being "spatially located by/as others," the spatiality that Grosz evokes is the kind of space that this chapter premises its arguments on as it looks at the two contemporaneous products of Majid and Georges, who are spatially located "by/as" each other. When talking of a psychotic individual who loses itself in the backdrop, becoming just $a$ point in this space and not the point having its own perspective, the important thing to understand is the definition that emerges of the subject and its relationship to the kind of space it represents:

The representation of space is thus a correlate of one's ability to locate oneself as the point of origin or reference of space: the space represented is a complement of the kind of subject who occupies it. (Grosz 90)

The colonial subject, in the way that it locates itself as well as others (racially, sexually or otherwise), is a function of the way it perceives the identitarian space that surrounds it.

Frantz Fanon's work, notably Peau noire, masques blancs (Black Skin, White Masks), lays out how both the colonizer and the colonized exist as the psychological detritus of colonialism. For instance, as Jock McCulloch ${ }^{17}$ points out: in "[Black Skin, White] Masks Fanon's basic thesis is that the colonised Antillean and his white master live within the grip of a psychoexistential complex" (64). In Grosz's elaboration of Caillois' work the psychotic individual appears as an example to demonstrate how human subjectivity is actually an embodied 
subjectivity existing in relation to space. The psychotic is not the principle preoccupation of Grosz's text.

This example nonetheless furnishes a fortuitous similarity at a literal level. Georges is a colonial "psychotic" individual existing "within the grip of a psychoexistential complex" that McCulloch uncovers in Fanon's work. Metonymically representing the French nation, Georges can only locate himself and others according to the identitarian space of colonialism that surrounds him. Georges, then, functions as the mimicking psychotic who conforms to the identitarian space of colonialism, as he perceives it to exist. In this space, he defines his place of comfort and stability, in relation to, and at the expense of, the colonized Majid, who has to exist as the sanitized Other, its validity determined by the extent to which it can continue to uphold the mirage of the French republican family.

This chapter is an amplification of the material space because it follows just the kind of spatialized understanding that Philo is apprehensive about, to analyze the space of difference that the two colonial subjects, Georges and Majid, occupy. One should not see this chapter as a simple juxtaposition of two separate entities of geopolitical space and another space of ontology. Instead, what it furnishes is further proof of the intertwining coexistence of the human subject and physical space. Humans occupy space. Humans occupy space in relation to each other. Humans understand each other as a function of their spatial knowledge. The "space" in the "synchronic space of difference" that I analyze is not just a metaphoric placeholder for an ambiguous entity. This is a purposefully deployed "space," because it displays how our relationship to others is inflected with our knowledge acquired through our relationship to the physical world.

It was in anticipation of the arguments I present in this chapter that I had initiated the discussion in the section titled "Postmodern Spaces - Material Histories" of my introductory chapter. I will not restate the debate about the inimical relationship between material readings of space and the kind of linguistic vocabulary of difference that I deploy in my readings here. In this book, which claims to read space in the wake of colonialism, it would be unthinkable to concentrate uniquely on the "thingy"-fied geography and not see how spatiality has pervaded our understanding of the world and of each other.

As synchronic elements, both the colonizer and the colonized form a mutually influencing equation of colonial malaise that is no more than a symptom (albeit an important one) of a conditioning process whose coordinates extend over time. The extent to which the two colonial entities are implicated in each other's formation, and how exactly, can only be understood diachronically; as such the thrust also remains on understanding Caché as an intersection where 
the space of the human subject interacts with human history. In other words, following Foucault, this insistence on analyzing the synchronic space is not a "rejection of the proven powers of the historical imagination, nor is it a substitution of a spatialism for historicism." In a way, this chapter follows Foucault's plea "for opening up the historical and tightly interwoven sociological imaginations to a deeper appreciation for the human life." ${ }^{18}$ With "interwoven" as the key term, I would call this chapter an attempt to read the human subject as both spatialized and historicized - as the result of a process that is formed over history and in relation to other subjectivities, all of whose aggregates form the contemporary moment. In this process all are connected to each other in a movement of perpetual change, each space defining as well as being defined by others. Implicit in this process of countercolonialism is the impossibility of the definition of a subject. Or, rather, the assertion that all definitions are subjective. One cannot ever find the meaning of these images when it is lies and subterfuge that define the familial metaphor that is Caché.

\section{White Lies}

Georges suspects Majid, a long-forgotten childhood association of Algerian origin, of sending the images that have been terrorizing his family, and goes to confront him in his apartment in an underprivileged French neighborhood. After a heated exchange where he threatens Majid with serious consequences if the recordings do not stop, Georges calls up Anne (Juliette Binoche), his wife, from outside the apartment building, and lies to her by saying that the apartment was uninhabited.

What the spectator witnesses (knowing that Georges has indeed met Majid in the same apartment a short while ago) is only one of the many familial deceptions. For the Laurents, who have been leading a bourgeois-bohème life of relative material ease in a house full of books in a well-off part of Paris, this lie and its eventual discovery by Anne that provokes an argument between the two, is a particularly important moment effectively displaying the widening fissures in the household. Familial fissures that are central to the film as well as to this chapter.

One finally learns of the colonial and the familial connection between Majid and Georges. When they were both children, Majid's parents used to work for Georges' parents. As a result of the violence unleashed on 17 October 1961 by the Parisian police on demonstrators who were protesting the French 
government's war in Algeria, hundreds of people of Algerian descent disappeared. Among them were Majid's parents. What followed the massacre was the French government's denial of this crime for many decades afterwards. While later I shall discuss how it was only after an extended contestation in 1997 that the French government finally did open up its archives, that too only selectively, suffice it to say for the moment that this covering up of a colonial crime is the kind of political lie that provoked Haneke to make Caché.

In the meantime, Georges' parents adopted the orphaned Majid. Resentful of his parents' decision and envious of the attention given Majid, the boy Georges through his lies ensures that his parents send the orphan to the charge of the authorities. As Caché opens, Georges Laurent has attained fame as a successful literary talk-show host. He leads his bourgeois-bohème life in a Paris townhouse with his wife Anne and son Pierrot (Lester Makedonsky). Majid, it would be found out later, has been leading a humble life in one of the low-cost, high rise apartments located on the periphery of Paris and of French society.

Both the childhood lie to get rid of Majid, the adopted Algerian "brother," and the national and colonial lie that obscures the reality of 17 October 1961 are the kind of lies that Hannah Arendt writes about. In Lying in Politics, Arendt provides an explanation that can be adapted to understand Caché. This film depicts "single lies," the kind that Georges advances, and "the organized lying" of a nation, working together to deny the colonial reality of violence related to the Algerian war, perpetrated in Paris, the very heart of the French republic. In this 1972 essay, while discussing lying in general in political history, Arendt presents the example of the Vietnam War and the obfuscation of reality by American administrators. ${ }^{19} \mathrm{~A}$ war, which one must remember, the United States eventually lost. American bureaucrats enacted "pseudoscientific theories" (Young-Bruehl9) and denied facts that contradicted their "scientific-sounding assertions," all with the hope that "reality would conform seamlessly to their lies" (Young-Bruehl 9) and they would be able to win the Vietnam War. In deploying this "novel variety of lying" (Young-Bruehl 9), the American bureaucrats were replicating the kind of national lies that France perpetrated regarding their own colonial reality.

Caché, then, is a film that revolves around the lies that deny Majid his place in both the Laurent family and the French republican family. Just as Georges lies to his parents to have the Algerian kin removed from his household, so does the French government purge the memory of the colonial violence related to the Algerian war that took place in Paris. One of the questions this chapter attempts to answer is: How does Cachés cinematic technique engage with this travesty of colonial history, elaborated to support the fiction of a French nation? This intangible space of 
difference, where one articulates the formation of a postcolonial subjectivity without falling prey to the temptation of definitively defining the colonial sign, helps mark Majid's presence as a hidden member of the family and serves as a reminder that despite all attempts to erase him, traces of Majid's exclusion surround us.

It is thus that I would like to read the clandestine recordings of the Laurents' everyday life: just as attempts at finding out the colonial truth, suppressed and mangled, can only end in a cul-de-sac so must the riddle of who sends the tapes remain unresolved. Yet, the presence of these tapes furnishes proof of an ignored historical reality of colonialism. This proof that a colonial past did exist also becomes the first piece of the puzzle that holds the potential to reconstitute meaning. A meaning that, given the individual and the state lies that Arendt talks about, stands forever disfigured. Nonetheless implicit also in the film is a demand to attempt a reading of this disfigured meaning, as subjective as it might be.

\section{Hidden Agenda}

Although Georges is convinced of Majid's involvement in these drawings and recordings, there is no proof to substantiate Georges' accusations. Even after Majid's suicide, the cinematic technique of Caché leaves one with the impression that the clandestine recordings of the Laurents' lives have continued. Toward the end, an apparent calm has been restored as Georges is shown taking some pills and going off to sleep. Apparent, because the culminating scene that follows not only forecloses any possibility of a precise solution but also adds another layer to the intrigue. In this last scene for the very first time in the film one sees Georges' son, Pierrot, and Majid's son (Walid Afkir), talking to each other in front of Pierrot's school. If the dialogues had been audible one could have researched the possibility of them having colluded with each other, but Haneke refuses to fulfill a responsibility that the director believes lies with the spectator:

J'ai écrivé (sic) un vrai dialogue entre les deux [fils] mais je ne vais pas le dire. ... Qu'est-ce qu'ils parlent ça doit rester une question pour le spectateur. ${ }^{20}$

[I wrote a real dialogue between the two [sons] but I won't reveal it.... What they are talking about is a question for the viewer.] 
Distinctly called into the film's intrigue, the viewer of the film unmistakably understands through Haneke's explication of this last scene what has been obvious throughout the rest of the film. The film titled Caché (Hidden) might not have disclosed the author of the tapes, but through Haneke's invitation to scrutinize the secret dialogue, it implicates the viewer into their authorship. As if in a way replicating the identitarian space between Majid and Georges, the space between the viewer and the film now performatively plays out our relationship with the watched subject of the cinematic screen, reminding us that we shall forever remain implicated in the subject of our gaze.

Before I hasten to embrace the director's refusal to elaborate on this secret as the dominant model through which I could read the refusal to acknowledge other such hidden secrets of the film, perhaps the question one should ask here should be about its title - the overtly hidden element of the film. This title, Ranjana Khanna rightly points out, "asks us to investigate that which is hidden" $(242) \cdot{ }^{21}$

In Haneke's refusal to elaborate on the last sequence between the two sons, there is an indication that "crucial plot information was apparently hidden within the background activity of the image" (223). ${ }^{22}$ While the last sequence forces us to read that which has been purposefully secreted, the slow unraveling of Georges' guilt and its connection to a historical event both demand to be read as hiddens - in the sense of being obscure, of not being obvious. In the film's fictional world, the secret has taken the place of prominence, and we may well try to divine the links to a historical event behind the guilt Georges has been hiding; but following Haneke's refusal we are never to know for sure that which has been purposefully hidden.

Apart from its adjectival value, Caché as the past participle of the French verb "to hide" further resists any attempts at reconstituting the meaning of the title. One sees neither the subject of hiding - the object that was hidden - nor the subject of the sentence to which this past particle belongs. Who hid what, in other words, is the dominant question. Caught in a bind between the past participle and the adjective, the hidden then appears as a perpetual process that bridges the past to the present and obscures the boundaries between the subject and the object such that one doing the hiding (who, as the unknown subject of the sentence is already hidden) could also be its unknown object. Paradoxically, with what was hidden remaining unknown, whether in the past or the present, only the certainty of something being hidden dominates our understanding of the title. Further reading of Caché will continuously evoke this ambiguity of the secret but without giving any means to conclude if it is hidden or secreted, nor 
to say if this hidden does exist but is not meant to be found, like the dialogue between the two sons. In other words, one engages in full awareness that all enunciations of this hidden past are necessarily subjective. One cannot ever recreate it and can only furnish tentative responses. Such complications are not very far from the central intrigue of the film, in which the hidden is present at almost all turns.

The film's many instances of uncovering (Anne soon learns that Georges lied about meeting Majid) are largely overshadowed by the number of unresolved hiddens. The most obvious among them is the authorship of the clandestine recordings. The second could very well relate to Majid's role. Is there a link between Anne's potential infidelity and the guiding intrigue of the film? The forever-secret answers to many such questions then mark the film, making the subject-less act of hiding even more ambiguous. Knowing that the hidden exists instantly makes evident the necessity of questioning, but the answers are nowhere to be found.

The accumulation of questions only leads the viewer into an ever-widening blind spot where the number of hidden elements makes it difficult to define even the very nature of hiddenness. Hence, the film as an accruing puzzle only singles out Caché, that is to say hid/hidden, as the one known fact. It is not the whodunit in this thriller-like film that one needs to worry about, but what exactly happened or rather the purposeful hiding of that which has happened. This is perhaps what makes the film resist "attempts to read it as a puzzle to be decoded."23

Jennifer Szalai expresses justifiable indignation at the number of critics who respond with unequivocal solutions to questions that Haneke poses and allows to "linger without providing many answers." ${ }^{24}$ At the same time, given that the film's "silences are just as informative as its utterances," it should not be a surprise that "it elicits a wide range of responses from so many different perspectives" (74). ${ }^{25}$ The viewer then experiences the hidden as an all-pervasive element Cachés only reality. The manifest invitation in the title to fill in both the subject and the object position of the verb "cacher" is what allows me to read the different "hiddens" in my own manner.

Apart from the film's links to the October 1961 Paris Massacre and the purposeful omissions as starting points dictated by the director, there are other "hiddens" and their answers in the film. My attempts at calling the viewer into the equation or trying to focus on the cinematic images as an allegory of history may or may not uncover something. However, connecting the film to debates current in the postcolonial world will validate at the very least the relevance of 
attempts at answering such questions. Placing myself in the position of the reading subject and of choosing among the many "hiddens" allows me to bring out the connections with the all too present subject of colonialism in a film released in the twenty-first century. Additionally, this reading also reveals me through my choices in the same degree as it will investigate the hidden.

\section{Colonial Family; National Lies}

Writing about the "colonial family romance" Françoise Vergès has pointed out how the "rhetoric of the French revolutionary community of brothers paradoxically justified the subjugation of peoples in the name of fraternité, liberté, égalité." ${ }^{26}$ Vergès is writing about, of course, how one deploys familial metaphors from the French Revolution to promote colonialism in order to uplift the apparently disadvantaged brethren in the colonies. In elucidating this paradox of colonialism as "the invention of men constructing France as the parents of the colonized" (5); a France which then leads to their destructive subjugation, Vergès might as well have been thinking of the dysfunctional (colonial as well as conjugal) family romance in Caché. This colonization, which for Vergès "was the expansion of republican brotherhood" (4), is very literally reflected in the childhood relationship of Majid and Georges who, entwined in the brotherhood of colonialism, nearly became brothers. If the colonial fiction was establishing an unequal family for France, what Caché reveals through cinematic fiction in its fragmentation of human relations is that this family existed as nothing but a racial construct, whose presence was available in the very heart of Paris.

As the war in Algeria raged on, on 17 October 1961 people of Algerian origin demonstrated against the French government's colonial policy in Paris. Maurice Papon, the then head of Parisian police, ordered a violent reprisal against the demonstrators. Indeed, that the exact number of casualties until date remains unknown speaks volumes about the uncertainty surrounding this colonial moment, which became the key to Caché. We know, as Georges reminds us, that "Il semble que les parents de Majid étaient de ceux-là" ['Majid's parents were apparently among those who disappeared'].

The definitive blow dealt on 17 October 1961 was undoubtedly the most shocking moment, and abundantly displayed how the "fraternal bond dreamed by metropolitan brothers was affected by colonialism and its logic of racism" 
(Vergès 5). However, administrative actions and communications aimed solely at controlling the movement of French Muslims were already generating the hate that culminated in these killings.

What happened on 17 October 1961 was not only that "tens of thousands of Algerian demonstrators marching in disciplined rank through the heart of the capital in protest against police repression" ${ }^{27}$ were the target of state reprisal. In addition to the fact that this was, as Jim House and Neil MacMaster assert, "the bloodiest act of state repression of street protest in Western Europe in modern history" (Paris 1), this massacre also brought forth a deep-seated administrative racism. Desirous of containing the activities of "Algerian terrorists" who had been increasingly challenging the French police, Maurice Papon proclaimed a communiqué limiting the movement of Muslims:

En vue de mettre un terme sans délai aux agissements criminels des terroristes algériens, des mesures nouvelles viennent d'être décidées par la préfecture de police [...] il est conseillé de la façon la plus pressante aux travailleurs musulmans algériens de s'abstenir de circuler la nuit dans les rues de Paris et de la banlieue parisienne, et plus particulièrement de 20 h 30 à 5 h 30 du matin. ${ }^{28}$

[With the objective of putting an end to the criminal actions of Algerian terrorists, new measures have been initiated by the police headquarters [...] Algerian Muslim workers are urged to refrain from moving about during night-time in the streets of Paris and in the Parisian suburbs, in particular from 8:30 p.m. to 5:30 a.m.]

This initial proclamation is a cautionary warning of what is in store for "Muslims," who are clubbed together with "Algerian terrorists," all of whom when being selectively asked to observe a curfew are at an obvious and a significant remove from the rest of the French family. Furthermore, this collective punishment meted out to a group of people officially recognized as French could only be exercised by following a principle of physical segregation:

Cette mesure est fondée sur la responsabilité collective d'une catégorie de citoyens considérés officiellement comme Français [...] pour distinguer un Français musulman d'Algérie d'un Français dit de souche, les policiers se fient à l'apparence physique, au faciès. Le couvre-feu, fondé sur la ségrégation, institue donc le racisme. (Einaudi 86) 
[This measure is based on the principle of collective responsibility of a category of citizens officially considered as French [...] to differentiate a French Muslim from Algeria from a so-called native French person, police rely on physical appearance and profiling. The curfew, based on segregation, then institutionalizes racism.]

Papon's attempt at asserting his position presumably against only "Algerian terrorists" in effect reveals French Muslims as nothing more than a categorization distinct from the non-Algerian French. For French police, the French Muslims from Algeria were very clearly (and perhaps had always been) under suspicion. Should it be a surprise then that soon thereafter the Parisian police killed (or perhaps committed a fratricide against) hundreds of Algerians protesting against the government? In taking the twentieth-century "gradual erosion" in Karen Jacobs' account of "vision's key role in the unfolding narrative of modernity" 29 at a literal level, one does have reason to be surprised by the contradictorily dominant role vision played in this colonial exercise at the start of the sixties. This authority of the visual sets the tone for Caché to question its validity - not in the way that would attempt a retelling of this story, but instead a questioning of the very paradigm that determines the operation of the visual. Haneke's personal investment in the manipulative powers of the image ${ }^{30}$ already tells us that Caché too, much like his other films, ${ }^{31}$ is going to explore the role of the image as much as it portrays the aftermath of the dismantling of the colonial family, which (re) orphans Majid.

I hesitate to call Majid's exit from the care of Georges' family that follows his parents' disappearance his "second orphaning." The simultaneous collapse of the colonial familial delusion actually signals his third orphaning. One should read Majid as symptomatic and representative of the many hundreds who were treated to Maurice Papon's segregationist techniques: expatriated to France and then cut off from belonging to the French national family.

In the context of France trying to sort out a tumultuous relationship with Algeria, and widespread violence in the early nineteen-sixties punctuating debates about the colony's future vis-à-vis France, Georges' childhood rejection of his adoptive brother stands as a metaphoric reminder of the failure of a dysfunctional "family romance" of the French Republic. Confronted with the possibility of admitting a sibling to the household, Georges' inability to share ("Il fallait que je partage tout" ['I had to share everything']) signals a definitive end to the fictional tale of fraternité. A child's lie thus perpetuates and colludes with the national lie. 
At this moment, Majid's destiny becomes one with the Algerians. Implicated in an imagined relationship, with Georges' metaphoric refusal their erasure from the colonial family, following Papon's rejection, is complete. Georges' hidden guilt has given us an individual element of a larger discursive pattern that one needs to read and understand through him. This in no way promises a definitive solution, rather a possibility of speaking about the myth of the larger "family romance" through one localized lie.

For decades after the massacre, successive French governments not only refused to acknowledge it but also actively denied the massacre ever took place. One treated any departure from the acceptable narrative of a happy French republican family as a dirty family secret. Although Papon's actions did later receive widespread condemnation after a public trial against him, the official denial has been a part of the memory of 17 October 1961 massacre. It is this silence surrounding an unaddressed guilt about the rejection of Algerians in Paris that propelled Haneke to address the colonial angle of Georges Laurent's lie about his adoptive brother.

This lie, which later evolves into Georges' many willful distortions ("petits mensonges" ['small lies'], Serge Toubiana calls them in his interview with Haneke), falls on a continuum of exclusionary identarian thinking based on the purposeful selective exclusion of the past. This denial of history defines the operational dynamics of the French colonial household and is pivotal to Caché. In 2005, the year Caché was released, 17 October 1961 was already over forty years old, and there had been only a sketchy reference in France to what Martine Beugnet calls this "blind spot" ${ }^{2}$ (228) in the history of the violent repression that forms the essential backdrop for the film. The initial reluctance to recognize and the subsequent exposure of the culpability of the French authorities are two moments that testify to a change - from denial to acknowledgement - of which Caché is an example. That Haneke can release this film in 2005 recognizes the relative willingness to discuss this topic, but that has not always been the case. ${ }^{33}$ To a certain extent, despite Haneke's contemporary efforts, even today, as Catherine Wheatley rightly points out, "the subject remains taboo" (34).

The role of the French government in promulgating various laws and regulations to hamper the unraveling of facts that could shed light on the extent of the French police's involvement in the massacre illustrates the mechanism underpinning Cachês association with the past. House and MacMaster describe in detail how the French government refused to divulge many pieces of information pertinent to understanding 17 October 1961. Toward the end of 1997,34 under growing pressure from the French media, the initial restrictions placed by 
the French law on archives were lifted; however, the French government soon resumed curtailing access to historical facts. The "Socialist led government was backtracking or acting in a secretive manner [...] Historians were still not allowed to check [...] through direct access to the original documents, except for three hand-picked historians" (Paris 8-9). Although many incriminating details regarding this massacre did emerge during the trial against Papon for the crimes he committed against humanity during World War II, amnesty "laws concerning the Algerian war would protect him from any conviction relating to his propagation of and participation in violence at that time" (Khanna 240).

Just as the simple search for a resolution to the crimes committed in the past is negated, so does the question of what happened in Georges' past remain elusive in the movie. Haneke's film does not provide a resolution but opens the door to an alternate ending than the one this story has been mired in. The film allows us to explore pathways that acknowledge the purposeful ignorance of the very subject so palpably present in the film. It also allows us to bring forth the hidden guilt associated with a colonial past.

Haneke's treatment is very clearly in conversation with the "historical amnesia" and the "blind spot" (228) that Beugnet comments upon while describing France's treatment of 17 October 1961. "J'étais super choqué" ['I was super shocked'], Haneke comments in his interview with Toubiana, "comment on peut avoir...deux cent morts qui sont dans la Seine et personne parle de ça pendant des années ?" ['How can we have ... two hundred dead people in the Seine and no one talks about it for years?'].

The search that Haneke is alerting to is not for the reasons why these people were floating dead in the Seine, nor is it for the source of the conflict. Neither does his utter disbelief at the massacre translate into activist strategies to counter history-altering efforts like the (eventually unsuccessful) 2005 French law that required schools to show the positive side of French colonialism. Nor is it about counterbalancing the preceding silence by providing elucidation on the facts of the event. ${ }^{35}$ Rather, it is to bring to the fore a story of guilt. As Haneke told Christopher Sharrett during an interview (Cineaste; summer 2003), the film is "about the French occupation of Algeria on a broad level, but more personally is a story of guilt and the denial of guilt" (quoted in Wheatley 34).

The guilt and its denial are historical in nature, of which I would say 1961 is only an important punctuation mark that destabilized the foundations of the colonial household. Even today, the French government's desire to control and dominate its colonial past attests to Maurice Halbwachs' claim that "the past is constructed not objectively but as myth, in the sense not of fiction, but of a 
past constructed collectively by a community in such a way as to serve the political claims of that community." ${ }^{36}$ Georges' unraveling, while only a single event, is singularly important because it gives us access to the dynamics of historical hiding (and the hiding of history) as represented in Caché. Here, when talking about its dissolution, I can discuss the unfolding of this past and its fundamentally irreconcilable relationship with the present.

\section{Colonial Past; Cinematic Present}

The more I revisit Caché, the more I am intrigued by Haneke's choice of not making an explicit connection with the Algerian War. Haneke answers all too simply a question Toubiana asks about about why only a few words in the film connect it to the Algerian war: "Je voulais pas appuyer sur ce point-lä" ['I did not wish to highlight that point']. It must be remembered that the Algerian war was perhaps one of the most violent battles for independence in modern history - French or otherwise. More importantly, why despite its centrality to Georges-Majid relationship, does Haneke purposefully occlude any reference to the war or the 1961 massacre? What is one to make of this authorial omission and the film's relationship to the colonial past? Caché figures as an acknowledgement of occlusion, which also becomes the first proof of the existence of that which remains hidden.

In a Derridian move, the Caché in the title finds its relevance in signaling an absence, thereby also making it possible to accept and to approach the buried and the hidden from the past. Michel Laronde organizes "postcolonial literatures according to the nature of their ties with the French nation, with its literature and with the French language. ${ }^{37}$ I cannot find among the three categories of "the new national literatures, the literatures of 'contact,' and the literatures of immigration" one that would accommodate Caché. This is not to fault Laronde, whose article looks at the "Literature(s) of Immigration in France" (181-2); instead it is to point to a new space of articulation that revels in a (con)fusion of boundaries - both temporal as well as spatial - producing a multiplicity of discourses. Caché, a film about an unknown and unknowable past, is then a case that escapes textbook definitions.

It is because of this insistent simultaneous absence and presence of borders that Caché hides and constantly beckons us to uncover the many answers possible to Khanna's question: "what, exactly is cache" (237)? This sort of performative 
presence in engaging both the temporal and the spatial axes stands not only as an example of a (atypical) postcolonial work but also as a reflection back that constantly seeks to change the meaning of the ever-evolving terms colonial and postcolonial. Caché, a film about an unknowable past, questions the postcolonial while participating in it and thus, I would argue, postulates an unlimited world determined by limitless boundaries.

The relevance of the unease caused by the video cassettes sent to Georges, which nullify the semblance of calm and stability in Georges' bourgeois-bohème lifestyle, extends much beyond his household. No more can such fixed definitions as those of the colonizer and the colonized be taken for granted in a new world defined by an unstable sign - this is the fundamental transformation that I read in the film and see as evident from the opening sequence itself. The sequence I discuss below is the very first montage of the film, which from a temporal perspective shows how Caché straddles over two spaces. It has become impossible to dissociate the past from the present. The past appears as a constant of the everyday - not as something that precedes it and is over and done with, but as the all-pervasive element that marks much of the film.

The first sequence serves as an allegory of this film's presentation of the relationship between the past and the present. A scene where Georges watches himself being watched dissolves the colonial binary. Answers to the colonial question are not found in the further reductive definitions of the Other. Instead, the focus shifts to a destabilized self that anchors itself on to the Other. As if already to prepare the background for the familial metaphor that I have been drawing upon, the very first sequence - which recounts the destabilization of Georges' life - centers on his townhouse, the supposed locus of his familial stability and security. This townhouse instead has been securing them inside, making them thus "prisoners of their own making, or at least of their own circumstances." That these characters are imprisoned "literally behind bars, and bars" is apparent in the presentation of their townhouse: "the composition of shots of its exterior puts its vertical barred windows center frame; horizontal bars cut across shots; the iron gate clangs (216)."38

Ezra and Sillars have rightly pointed out that the first long establishing shot "disrupts our expectations" by not following "cinematic conventions through the length of take, the static camera and the increasingly ambient noise" (Ezra and Sillars, Hidden 218). The film opens with a well-lit static shot of a townhouse (Fig. 1), with sparse passing traffic and the chattering of birds making for some ambient noise. There is a jump cut, with the same house being filmed toward the evening with reduced lighting from a different perspective and with reduced ambient noise (Fig. 2). In this second shot, Daniel Auteuil walks out of 
the house. A profile wide pan shot follows him across the street and back into the house, where after following his wife in, he locks up the door. The sequence cuts back to the well-lit frontal static camera of the townhouse.

It is only when the moving images of this static shot stop and are being forwarded that the viewer has the first inkling of watching a recording within a film. All this while two voices - Auteuil's and Binoche's - continue having a conversation both off and on camera. With the next cut, when the cinematic camera moves inside the Laurents' living room (Fig. 3), the viewer finally realizes that the opening shot of the film was the work of a hidden camera and it is only the
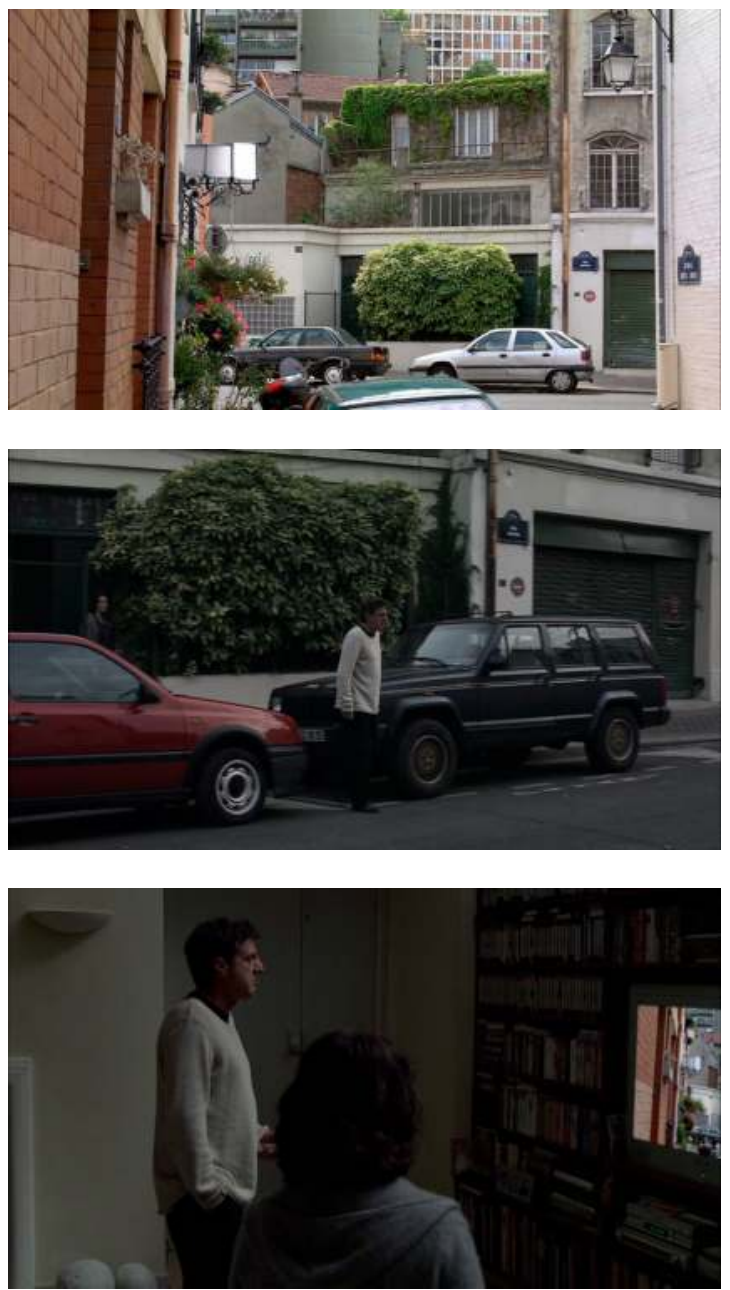

Figure 1: Cachês opening shot. Laurents' townhouse. Still from Michael Haneke's Caché, 2006, 00:02:30. DVD.

Figure 2: Georges Laurent (Daniel Auteuil) walking out of his house as Anne (Juliette Binoche) watches. Still from Michael Haneke's Caché, 2006, 00:03:07. DVD.

Figure 3: Georges and Anne watching the clandestine video. Still from Michael Haneke's Caché, 2006, 00:05:01. DVD. 
second dimly-lit pan shot that followed Georges, which was the first non-clandestine visual of the film. One also needs to bookmark this opening sequence as representative of many other similar moments where it is only retrospectively that the viewer is able to state definitively if the visuals on the screen belong to the linear cinematic camera or are the product of some previously recorded video.

I could have hastened to point out from the very beginning what the viewer establishes soon afterwards: that these shots belonging to two different moments of the day (the well-lit shot belongs to clandestine recording from a few hours ago; dimly-lit shots belong to the current narrative) form a mise en abyme of a couple watching a video recording of themselves, but that would have restricted the sequence to only one reading.

The clandestine images overlap onto the narrative flow in such a way that these images seem, despite the editorial jump cut, at least initially to be very much a part of a linear narrative and to form together a coherent filmic sequence. It is only once the mise en abyme becomes clear that one can see that there are two distinct shots of the same house at two different times of the day, and also that the opening shot of the film is in fact a recording from the past being replayed in the Laurents' living room. It lays bare a perceptible lack of temporal continuity between them.

What we have then is the emergence of two distinct narratives, not necessarily oppositional but distinct nonetheless in a way that raises questions about temporal unity and the relationship between the past and the present. This confusion about the two narratives needs to exist, neither explained nor emphasized, but just to be there for the viewer to realize that the "video image does not so much 'puncture' through [...] but rather weaves itself" into the narrative. For why else would Haneke shoot "the entire feature in High Definition format" (Beugnet 230), erasing the lines between the clandestine and the narrative video? Using the same format creates the possibility of reading the two as both a single sequence as well as two distinct sequences. They could form a single continuous narrative and two discrete narratives at the same time. "This questioning of the status of the image - both its temporality and its truth value - is repeated throughout Cache" (Ezra and Sillars, Hidden 218). In other words, the destabilization of temporal unity that remains the deciding motif throughout the film emerges from the very first sequence. ${ }^{39}$ Georges is made to reckon with a past that remanifests itself at the least expected moment. This dynamic establishes the inseparability of the past from the present, and simultaneously allows an insight into the opposition that Georges' present faces from the violence of the colonial past.

When the first of the video cassettes (also the very first sequence of the film) of these very bars that form the exterior of the house finds its way in, one 
has introduced the virus that will undo this semblance of security. Breaking through, it not only conveys the outside to the sheltered inside but also brings the past into the present. If, according to Beugnet, one needs to read the gaze of the video image in Caché as the "objectifying, mechanical yet voyeuristic stare of the surveillance camera" (228), then the (colonial) household is shaken for good. As a sequence that provides the beginning of the disturbance caused by the clandestine recordings of Georges' life, these shots also establish the lack of temporal unity and the constant question mark about the authorship of visuals that remain recurrent tropes throughout the film.

Georges watching himself as someone watched him earlier in the day is a forceful re-inscription into the present of Georges' memory; a memory that has been unwittingly colluding with the history of colonialism. This forced autosurveillance is a reminder that, in this continuum of time, one can never disentangle from oneself. It also speaks of a psychological stranglehold of the ever-present gaze of self-introspection that dispenses with Georges' convenient selective amnesia. Forgetting Majid might seem like the completion of the colonial task but what remains ignored is the role of the person forgetting, who even in this elision of the Other still remains the link between the present and the forgotten. Georges is the witness, if not of the memory then at least of its forgetting. The comprehension not only of the colonial subject at hand but all that composed it over time can only be achieved by a process of contemporaneous unraveling that would explain the dynamics of one's interaction with the Other within the identitarian space. This is why Caché can only begin with this three-shot sequence, where Georges' past and the present seem to cohabit in shots from different times of the day.

The pan follows Georges from his house (the subject of the clandestine videos) to the position where one would have placed the camera (Fig. 4). After trying unsuccessfully to locate the camera Georges returns. Georges has, then, perused the perspective that captured his past from earlier in the day to reassume the state

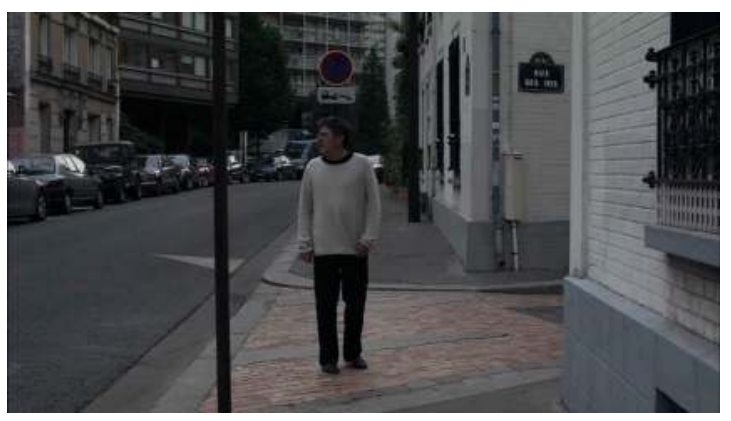

Figure 4: Georges tries to locate the placement of the hidden camera. Still from Michael Haneke's Caché, 2006, 00:03:21. DVD. 
of the recorded subject, bringing to light in a succinct manner the far more complicated process of introspection that recalibrates the present via the past, today's self through an earlier self, and an imagined self through an Other self.

By putting himself where the camera could have been, Georges reveals what is soon to become evident to the viewer about the construction of the space of identity: that this space that defines us is a function of our own gaze and that the observer is the observed itself from a different perspective. Indeed, the name of the road in the background toward the top right-hand corner of the frame, "RUE DES IRIS," evokes the iris of our eyes. Placed conveniently over Georges' head, as he tries to locate the person who recorded him, this sign, whose ironical presence Georges remains inattentive to, functions as the reminder of what this chapter has been insisting on: we remain oblivious of the truth of a colonial past that stares at us everywhere.

If Grosz's psychotic merges itself into space according to what it perceives this space to be, then the kind of past that Georges evokes gives us an insight into his, and France's, contemporary image of themselves. To access the past is to animate the dysfunctional present self that ascertains the past based on our perception of the present. Indeed, it also diffuses the dynamics of opposition between the two supposedly distinct entities of the past and the present. It transforms them from two subsequent elements on the continuum of time into a simultaneous spatial equation where the two are interlinked as mutually influencing juxtapositions.

In addition, it is not the video cassettes themselves but Georges' flummoxed reactions to them that occupy the film's attention, in a way suggesting that one needs to find the answers to the colonial trouble in his psychosis and the evasive desire it engenders to disclaim what these cassettes represent. What this film about forgetting the colonized Other does in suspending any allusions to an author of these clandestine videos and yet maintaining Georges as the viewer is to remind us of his inability to escape the colonial subject and the subject of colonialism: both being alive in Georges and indeed due to him. Georges' isolation is complete, not in a way that would sequester him, although that too is happening, as I shall discuss later, but leaving him isolated as a symptom of the space of colonial identity.

In a way, this reading allows for the obliteration of the Other. Not the other of Majid. It is the conceptual Other, whose inferiority became the basis of colonialism, that gets obliterated. The existence of these videos is solely the function of Georges' presence. They are not only of him or about him, but also by him, and in being so they point also to his centrality as a link between a forgotten past and the present. 
The integrity of a linear history is no more a reality. One cannot forget the colonized Majid, into an unrelated extinct colonial history. The temporal simultaneity that I claim becomes evident in the recording that juxtaposes events alongside each other instead of manifesting them in linear succession to create a history of progression. One is to read Georges simultaneously as the passive subject of surveillance as well as the active pursuer of an answer about the past. If answers are to be sought in (and about) this film mired in questions of history, it is not through a search of origins, be they historical or geographical, but rather through a strategy of subjective articulation. On receiving the first tape, as "Georges and Anne become fixated on discovering where the tape has been shot from - in other words, its geographical point of origin" (Ezra and Sillars, Hidden 218), so does Georges follow the videocassette back to the potential point of filming. It is a similar strategy of locating the "point of origin" that occupies my reading of Cachés relocation of history. The caveat being that such an origin is never to be found and remains in flux, with the knowledge that it exists and needs to be articulated.

Such a looking into the past does not work to recreate history but does work like the "propétie du passé" 40 ['prophetic vision of the past'] that Glissant talks about in his Caribbean Discourse. This vision is an exploration "related neither to a schematic chronology nor to a nostalgic lament. It leads to the identification of a painful notion of time and its full projection forward into the future [...] That is what I call a prophetic vision of the past. ${ }^{\prime 41}$ Glissant presents this paradoxical 'prophetic vision of the past' as a way of problematizing a domain that existed before this unitary world came into being with its unitary linear history in the sixteenth century. ${ }^{42}$ For my reading of Caché, this offers the opportunity of presenting a subjective "prophesy" of a forgotten past associated with 17 October 1961.

Such a practice enjoins us to push the historical narrative to a purposefully indeterminate space, uncertain, unverifiable and constructed; it necessitates the deployment of a vocabulary that allows the discursive space to be forever open. Such temporal destabilization, as this reading of an uncertain memory proposes, goes well against those critics who, in postulating the postcolonial, rely on its modernity-inspired variant that goes in search of a fixed past and essentializes the postcolonial.

In other words, this postcolonial that I see in Caché is not a flat contourless present, in which any attempt at understanding history is seen with the same suspicion that has been reserved for the colonial project and its temporal linearity. To succumb to such a flat linearity would mean renouncing all attempts 
at understanding the effect of the past in our present and our present understanding of history. By extension, it would leave us with unexplained hiddens whose continued haunting of our present would prolong the very guilt that assails Georges and much of the postcolonial world.

\section{Escaping Images}

I now turn to the cinematic techniques deployed in Caché as an invitation to the viewer to find a larger collective solution. Nowhere is this involvement with the viewer more visible in the film than in the confusing opening shot. When one understands that Cachês very first frame is a clandestine recording of Georges that he happens to be watching, the distinction between the viewer and the viewed suddenly becomes more nuanced, and the binary split between the two enforced by the cinematic screen is diffused. This is the moment when, as the viewers realize they are watching on the screen Georges who is watching himself on another screen, Cachês viewers move from simply viewing a subject to becoming directly implicated in a similar equation. ${ }^{43}$

One needs to understand this retrospective understanding of the visuals, which severes the temporal unity of the narrative, as an apostrophe to the viewer who can never take these visuals for granted, as their authorship remains forever in question. Are these images part of the film time, or the work of the clandestine recorder, or perhaps even a part of Georges' profession of a TV show host? The viewer of Caché is never sure of who is watching whom and thus remains implicated in this game of situating one's perspective.

One scene that explains these dynamics of the viewer's presence and involvement in the watching comes in the second half of the film, as Georges is editing his show. Pierrot goes missing for a night, only to return the following morning. Having decided to spend the night at a friend's place, he neglected to call his parents, provoking a minicrisis of sorts. The reason I bring up the apparently innocuous conversation between the father and the son (Georges' fatherly concern for example: "Pierrot, ça va bien toi?" ['Are you okay Pierrot?']) is because of the animated talk show scene that it cuts to. What appears, as soon as the son exits the bathroom, is a shot over Georges' right shoulder of two guests in a talk show setting discussing the nineteenth-century French poet Rimbaud. Of the four guests, these two dominate most of the incoherent conversation and the 
other two are able to squeeze in a few brief comments. Despite being the host, Georges is silent and appears in two over-the-shoulder shots and one cut away in which he is nodding understandingly with his hand to his mouth. What follows does not belie any expectations about Caché. With Georges' injunction of "Bon bon, stop" ['Ok, ok, stop'], the screen freezes (literally on the word "stop"). One continues hearing Georges' voice at the same time as the footage from his show is either being forwarded or reversed. The viewer soon realizes that Georges is on the editing table. Once again, it is only retrospectively that the viewer realizes that the talk-show sequence, unlike the father-son conversation, was in fact part of Georges' professional life. From the conversation with the son, the scene had cut not to the recording floor of Georges' live TV program but instead to the scenes of a previously recorded program that Georges was watching on the editing table.

As Georges edits out the unwanted portions, he complicates a tension about the control over images that has by now become a constant in the film. Contrasting his silence during the interview with the imperative to his editor to stop also problematizes his association with a silent history. These images, which reflect the views of the participants Georges was interacting with but which nonetheless are under Georges' control, allow him to - literally in this case recreate by selectively modifying his recollection of the past. As in this case, he edits by instructing the editor:

Ça devient trop théorique là. Coupe à 'on est d'accord sur ça' et va plus loin quand Teulé parle d'homosexualité.

[It's becoming too theoretical here. Cut at 'we agree on this' and go forward to when Teulé is speaking about homosexuality.]

This sort of altering and obliterating displacement could be commonplace on an editing table. However, in the light of the combination of Georges' association of denial with his past and his present plagued by clandestine unedited moments of his life, this episode in the editing room is to be understood as an accurate presentation of his preference for selective history. A moment that allows his speech to prevail momentarily over other narratives.

Presenting this editing scene as an example of how "reality is manipulated by TV to be more attractive to viewers," Haneke provocatively - and perhaps rightly - portrays this as the "terrorism of the mass media today." ${ }^{44}$ In a moment that responds to the very "dumbing down of our societies" that Haneke dreads, 
this particular scene, in forcing the viewer to readjust to a shift in temporal narrative, has already called for a participatory involvement that creates as well as reinterprets the sign of history. One is familiar with the fact that a sign is formed both diachronically (over time) and synchronically (through mutual acceptance by members of the community). If this animated debate over the meaning of Rimbaud is a concrete example of how a sign gains universal acceptability then it would not be too far-fetched to see in Georges' selective editing a disproportionate investment of his own self into this process. Reading this moment as one of Georges' victory would only be succumbing to the overly powerful pattern of convenient forgetfulness of colonial history that Haneke is challenging. Including the viewer and dissolving this bipartite equation of Georges watching (and editing) Georges (thus also altering the past) to a tripartite one where the viewer watches Georges watching Georges instantly liberates the sign of history from a one-sided stranglehold and provides the necessary outlet of a third perspective on the situation. With the viewer into the game, the hidden act of manipulation is not so hidden anymore.

If Georges is revealed through these images, what does the cinematic screen of Caché speak of my relationship with it? A shared collective guilt would be Michael Haneke's answer (Porton 50-1). And in a French language film based and produced in France it is not just related to France's past but to a larger question of "dark stains" that are part of collective human unconscious. To repeat Haneke:

I don't want my film to be seen as specifically about a French problem. It seems to me that, in every country, there are dark corners - dark stains where questions of collective guilt become important. I'm sure in the United States there are other parallel examples of dark stains on the collective unconscious. ${ }^{45}$

Georges represents an individual manifestation of the many different guilts that confluence together to realize the global "collective unconscious" that Haneke evokes in the creation of this movie. This collective should rather be read as an imperative to the viewer from Haneke that involves the relationship between Georges the viewer and Georges the viewed subject. Both as an expression of caution and an act of indictment, Haneke's formulation is best read as a stipulation to undertake a similar excavation of the self to isolate the personal contribution to this collective guilt that would reveal within each of us a zone of images from the past, markers that Haneke calls "dark stains." The resolution of Georges' unspoken complicity with a history of guilt is exemplified in this 
moment of Georges watching Georges. Moreover, in this equation when one evokes a collective, does it not make sense to presume that the viewer too is implicated in a similar relationship with the screen as Georges is with his? Much like Georges, Cachés viewer is both present and watched in the film, and in including the viewer Caché has developed a strategy that diffuses all binary divides by dissolving the difference-creating cinematic screen.

The screen refuses to become complicit in Georges' acts of omission. There are indications that this pattern of control and prevarication (familial as well as historical) start to unravel nearly mid-way into the film. Georges and Anne receive another videocassette, this one shot from a moving car, leading up a road into a Parisian banlieue (Romainville - to the northeast of Paris) and onto a blue front door of an apartment with the number "047" written on it. By this time Anne has started becoming suspicious and starts asking questions about an earlier videocassette that featured the house of Georges' mother ("Qui connaît la maison où t’as passé ton enfance?" ['Who knows the house where you spent your childhood?']). Georges firstly starts by lying ("Je sais pas" ['I don't know']). Further on, he does confess to having an inkling about the sender but also simultaneously refuses to divulge who it is. Following an argument where a tearful Anne walks out, Georges visits the apartment in Romainville and after a stormy meeting with Majid (where he threatens Majid: "Tu vas regretter, je te jure." ['You will regret it, I swear.']) he performs yet another act of commission - he lies by telling Anne he found it empty and even convincingly adds a story about how further inquiries revealed the apartment to be a store of some sort.

But - and here is the uncooperating screen that this discussion is leading up to, as a forewarning of how these images are no longer going to be his refuge Anne discovers Georges' lie. Another clandestine recording of the conversation between Georges and Majid reveals to Anne not only that Georges had lied but also the exact content of their meeting, forestalling and revealing Georges' pattern of control and denial of the past, which falsifies testimonies and relies on misrepresentations.

Georges might try to explain his lie as being motivated by concern for Anne, but the ubiquitous presence of these stratagems of self-denial adds layers to an already overpowering guilt. All of them together alert us to the underlying motivation of these isolated acts. Georges' omission of Majid produces a revisionist strategy concerned with recreating a convenient recognition of the past and a complete erasure of the Other. Despite repeated demands from Anne, Georges refuses to elucidate on the possible reasons for Majid's anger against him: "Je ne m'en souviens plus' ['I don't remember'], he retorts back. 
That with these recordings the process of reconciliation with the past is taking hold, not allowing any escape route and thus leading Georges to an explosive personal cul-de-sac, is what Caché tacitly communicates. Georges' world controlled by images, his job as a talk show host and the all-powerful editing table eloquently direct our attention to a process where, despite his silence, he is the one who holds the power to manipulate images.

To reiterate an earlier contention, this system, however, is not as static and passive as this one-way reading might have us believe. The (almost always) long unedited cuts from the clandestine videos counter the editing table to calibrate temporality. These unedited shots confront Georges with moments he desires to escape. They serve as a reminder that he is trapped in a constant mode of overcoming and will forever remain the one constant of the past that he desires to negate. In a game of catching up, just as these videotapes expose the lies Georges has been telling Anne, these images also slowly escape his control. Even the scene on the editing table, when read retrospectively, abounds already in the disruption of manipulation that the videocassette has carried out for Anne.

\section{Deadly Images}

As Georges edits his TV show in the editing bay, he receives a phone call, presumably from Majid, who wishes to meet. Georges goes back to apartment no. 47, is received by Majid, who leads him to the same room where the first meeting between the two had taken place. A visibly irritated Georges refuses the invitation to sit down and reacts angrily to Majid's declaration of not having anything to do with the cassettes ("Je n'étais pas du tout au courant pour les cassettes." ['I knew nothing about the cassettes.']). What follows is Majid's suicide. It is the most graphic scene of Caché, and Ipek A. Celik signals it as an example of Haneke's "terrible realism." ${ }^{46}$

The initial moment of Majid taking out the knife startles Georges. When Majid cuts his own throat splattering the wall with blood, more than Georges' complete shock what is noteworthy is the resemblance the blood pattern on the wall bears to the smear of red ink on the anonymous childlike drawings the Laurents have been receiving along with the cassettes (Fig. 5 \& 6). Majid's body blocking the door of the room, with blood still gushing from his neck against the backdrop of a blood pattern that makes a single canvas of the wall and the 
door, functions as a continuation of the childlike drawings (Fig. 7). By blocking Georges' only exit, this blood pattern metaphorically traps Georges - both spatially and temporally - between unwanted and uneditable images.

Georges' bitter confession soon thereafter to his wife, as he returns home dazed, makes a more explicit connection between the suicide and the drawings (“Tu te rappelles les dessins ? C'était sans doute pour annoncer cette saloperie à l'avance ou bien quoi ?" ['You remember the drawings? Who knows, maybe it was to announce this filth?']). On Anne's insistence Georges describes his childhood lies that were responsible for having Majid kicked out of the house. First, it
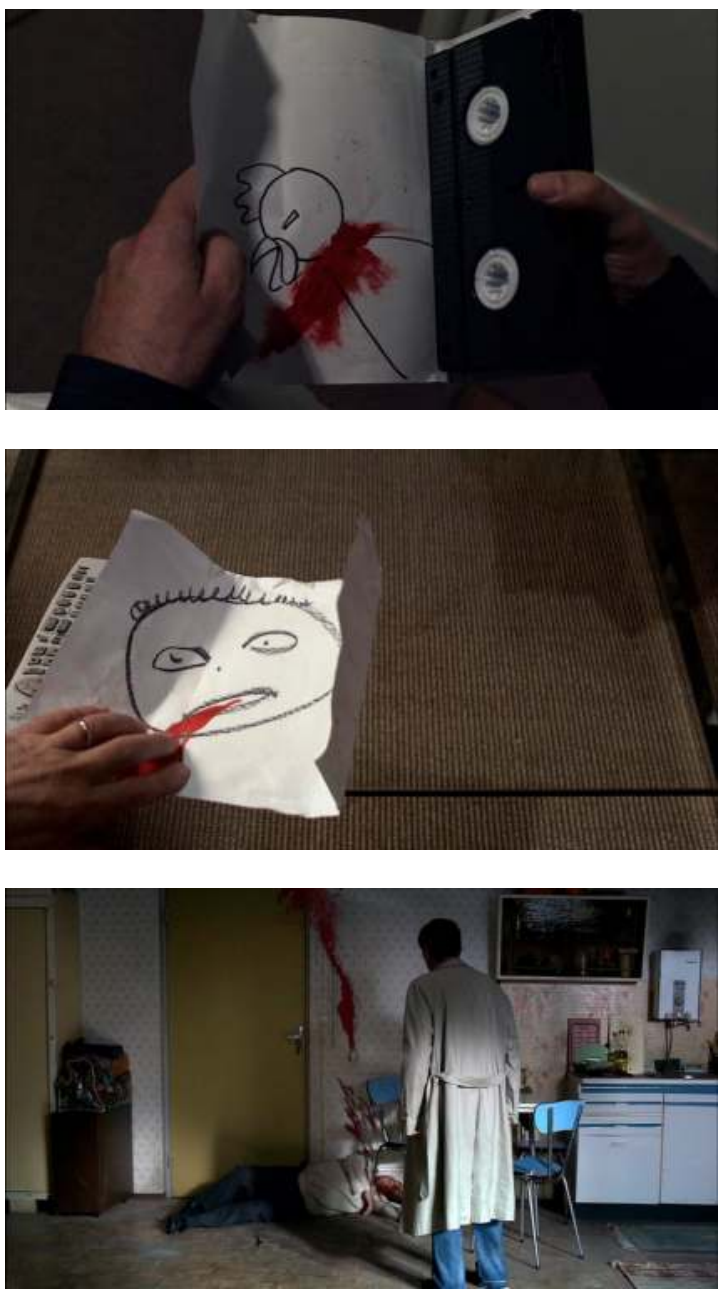

Figure 5: Drawing - Red smear across the neck of a cock. Still from Michael Haneke's Caché, 2006, 00:26:20. DVD.

Figure 6: Drawing - Red smears coming out of a mouth. Still from Michael Haneke's Caché, 2006, 00:13:40. DVD.

Figure 7: Majid lying dead, blocking the door. Still from Michael Haneke's Caché, 2006, 01:25:15. DVD. 
was a lie about Majid coughing up blood (“J'ai raconté à maman qu'il crachait du sang" ['I told mom that he was spitting blood']), which a doctor's examination disproved. Then Georges convinced Majid that his father wanted him to kill an aggressive cock ("Après, je lui dit que papa voulait qu'il tue le coq." ['Then, I told him that papa wanted him to kill a cock.']). A child Majid covered with blood and the beheaded $\operatorname{cock}^{47}$ gave Georges the opportunity for the final lie, which had the young Majid abandoned: "Et j'ai raconté qu'il avait fait ça pour me faire peur." ['And I said that he did it to scare me.'].

It is not without reason that this chapter has been equating a child's lie with a national lie. Children imitate what surrounds them, and their imitation "is an act of enormous intellectual complexity" (Grosz 90). To explain better the human subject as a function of the space it occupies, Grosz also turns to the example of a child, for whom imitation of others around it is "a central activity in its acquisition of a social and sexual identity" (Grosz 90). A child's identity is formed as it fashions itself, through its imitation of others. When the child assumes that "it is like others [its imitation] [...] is conditioned by the child's acquisition of an image of itself, of an other, and a categorical assimilation of both to a similar general type" (Grosz 90). In other words, Georges' childhood lies function in Caché as an imitation that conforms to the national lie of exclusion. Papon's written directives, the ensuing massacre and a decades-long cover up were meant to erase the Algerian from the streets of Paris, from French memory, as well as from the French national family. These national lies were laying out the identitarian spatial template whose imitation became the basis for Georges' lies. This child's lie then folds back neatly on to the national lies, and it is the rejection of Majid, common to both lies, that serves as the "general type." This child's lie is not only a replication but also a strengthening of this new spatiality of erasure, which complements the fabric of the larger colonial project. It is within the interstices of such a self-reinforcing spatiality that Caché, then, takes it upon itself to show the hiding of the truth from the past. Via Georges it also reveals the French republican family for what it is: a myth.

Majid's suicide as the ultimate text of the past forces an alternative to a space that has always had Georges and the nation as its foci. Undoubtedly, there is the possibility that this self-immolation "could be interpreted as Haneke's collusion with the comforting idea that the colonial native can be made to disappear in an instant through the auto-combustive agency of their own violence" 48 (234). Instead of a self-erasure, one needs to read this as the ultimate isolation of a destabilized Georges. Within a colonial spatiality, it is not Majid who gets 
eliminated, but Majid the colonial Other that has stopped playing along as fodder. The focus instead shifts to Georges' guilt.

The killing of Algerians on 17 October 1961 in Paris replicated, within the very heart of the French empire, the colonial violence that was taking place in colonies overseas. These brutal unacknowledged murders by the French police reproduced within the metropolis the workings of the power structures and the colonial dynamics responsible for much of the colonial violence. The dead man slumped on the floor in the presence of Georges condenses the violence from colonial Algeria as well as from Paris within the confines of this room. The difference being that Georges, who denies his role in Majid's marginalization and indeed blames the Algerian for his current miseries, is now confronted with this violence.

The blood-splattered enclosure completely sequesters Georges and surrounds him with blood-soaked images from the past, which have already been catching up with him in the form of drawings that accompany the videocassettes. The childlike line drawings depict two images: a mouth with a red streak coming out of it, and a cock with a red smear across its neck (Fig. $5 \& 6$ ). Majid, by cutting his own neck recalls the bloodletting, blood from the mouth and the blood-covered child that is central to their shared childhood as well as these drawings.

The focus is not the Other; nor can such strategies as turning to the comfort of his editing table allow him to escape the images of his guilt. What had started with Anne discovering Georges' lie and the contents of his conversation with Majid through clandestine video recordings leads, for the last time, to the same flat no. 47, where circumstances eventually force Georges to reveal to his wife the implications of all that he had been denying.

Following the suicide, and right before Georges returns home to confess to his wife, the spectator sees him exit a cinema hall. The posters adorning the façade of this cinema hall "seem to spell out the various domestic and allegorical configurations in which Georges is implicated, as well as the various narrative and generic routes down which Caché as a film could have gone" (Ezra and Sillars, Hidden 217). In fact, two film posters - Les choristes (based in an orphanage for boys) and La grande séduction (about a doctor being wooed by a small village in French-speaking Canada) - apart from the four that Ezra and Sillars comment upon - Deux frères, Ma mère, Mariages and La mauvaise éducation - do give occasion to bring out the many themes associated with this colonial household that I have been drawing out. Additionally, as generic examples, when looked at together they add up as a collectivity of cinema - to which Caché too belongs.

But more importantly, coming out of a suicide scene filmed in the single long cut, which resembles (and could be from) a clandestine video, when 
Georges is seen exiting the cinema he has joined the viewer, once again in doing what the viewer is doing just at that very moment: watching a film. It could be that, as Beugnet signals, going to the cinema after the gruesome self-immolation is a commentary on (the limitations of) cinema. Cinema "is not merely a play on representation but an actual process of thought: contemporary realities are thus thought through the operations of film itself, and refracted through the prism of a specific aesthetic vision" (Beugnet 231).

Coming out of the security of the editing room, having witnessed Majid's suicide in the long (possibly clandestine) shot, it could also be that "he instinctively disappears into the darkened space of the cinema, presumably to allow the flickering images to efface harsh realities" ${ }^{\prime 49}$ (247). While these possibilities explain why Georges might have gone to the cinema, a simpler and unanswered question is perhaps more pertinent for the viewer of Caché: what did he watch there? In saying that one needs to find the answer in cinema (both the artistic genre and the cinema hall that Georges has visited), I wish to show agreement with Beugnet's just quoted explanation of cinema as "a process of thought."

What film did he watch? becomes yet another apostrophe to the viewer to reckon with about yet another cinematic screen. A question that has no answers. Caché, a film about clandestine moving images, takes the viewer through multiple mise en abymes, always projecting the false hope of an answer. In a way, it prepares an unending quest for a stable sign without ever fulfilling it. Just as the conversation between Majid and Georges' sons is never revealed, the sender(s) of these cassettes remain unknown, and thus remains unanswered (among others questions) the question of the relationship between Georges and cinema. And it is with a demand to discover this hidden, unstable sign that a movie like Caché addresses us, questions us, and leaves us aware and yet uncertain of our individual understanding of the past in relationship to the present.

Reading the colonial equation via this non-thingy-fied space as I have done above helps understand the staging of these characters and their histories in equations of make-believe hierarchies. Their perception of their location in this space and the creation of this space itself are both fictional constructs; the products of a colonial psychotic's imagination. Georges as a colonial psychotic, part of the French colonial family, can only imagine the world and his place in it according to identitarian coordinates that are tethered onto Majid. The more Georges tries to negate Majid's presence the more there are constant reminders of a spatialized identity where Georges locates himself according to Majid.

Within this identitarian dynamics, reflections that emerge in Caché on cinema and moving images constantly disrupt all attempts at situating one's self as 
distinct from these tethers. Georges' lie and the national lie are intertwined. The title of the film, Caché, functions as the past participle of the French transitive verb "cacher" and tells us that someone hid something in the past. Intermingling cinematic narratives and the presence of these clandestine images from elsewhere and from another time insistently remind us that what one hid there and then continues to be embedded in the here and now.

If the above paradigm is subjective, where is the true location? Any attempt at a definitive answer is destined for failure. It is not colonization, understood as a fixed sign that one needs to excavate from the past. Rather, one needs to concede that such a sign exists. This acceptance opens up the interesting reality of unanswerable questions that within themselves carry the paradox of something that happened which can be neither discerned nor recreated but yet needs to be understood. The answer in the film lies neither in determining the author of the tapes nor in their contents (these tapes only replicate what Georges, and the viewer, already know about Georges' life), but instead in accepting the ensuing criminal guilt - that unspoken and unrecognized residue from the colonial past - that they reference.

The imprecise nature of the sign has ramifications for the definition of the Other, as well as the very perception of our world. In an interview, Haneke refuses to define Majid as a vulnerable figure. In fact, the director avoids any clear-cut definitions for the characters central to Caché. Firstly, he equates both characters in his assertion that we "don't know if Georges is telling the truth and we don't know if Majid is telling the truth," and then goes on to add that we "don't really know which one of the characters is lying - just as we don't know in real life" (my emphases; Porton 50-1). What Haneke reveals is that notwithstanding the film's (and Haneke's own) sympathies with the cause of the colonial underdog, the world it represents cannot be read from any position of subjective authority that would reproduce fixed notions of colonial identity couched in the comfort of compartmentalized definitions of victim and aggressor.

One should distinguish this lack of a clear picture from a lack of engagement on Haneke's part - for this confusion is in itself the answer. At least, that is how I would read the director's comment that postulates the film as "a lie that can reveal the truth" (Porton 50-1). In this off-handed comment, which draws a relationship of synonymy between these two opposing terms of truth and lie, I infer a similar relationship in Caché, where the confusion over the images is what leads to an answer. More specifically, it is not a simple quest for the existence of the truth/lie binary. The focus instead is on the (thrice) repeated affirmation, "we don't know," or, rather, as I have been stating - we can't know. 



\section{EPILOGUE:}

\section{INTERJECTING PASSAGES}

In 2005, as banlieues all over France burned, the world press attempted to explain the crisis. Ranging from governmental apathy, a partisan police force, to the deep-seated racism of French society, the press advanced many explanations for the fiery and riotous aftermath of the death of two minority teenage boys, Zyed Benna and Bouna Traoré, electrocuted in an alleged attempt to escape the police. In this journalistic profusion of analyses and commentary, an article in the New York Times Magazine caught my attention. ${ }^{1}$ It zeroed in on city planning as the culprit.

The famous Swiss architect Le Corbusier, the article stated, had designed the banlieues to keep the poor working-class clustered around the city in huge high rises. Placed on the periphery, these soaring "apartments, he thought, would finally give sunlight and fresh air to city laborers, who had been trapped in narrow and fetid back streets since the dawn of urbanization" (Caldwell). Unfortunately, Le Corbusier's noble intentions notwithstanding, the spatial distribution became a trigger for social discord and laid the groundwork for the eventual ghettoization of urban France. Poverty, unemployment and disgruntled youth made for a dangerous cocktail, resulting in the fiery petrol bombs that lit up the French suburbs.

What the article does not elaborate is that the line dividing the banlieue from the city stands not only as a rendition of the economic difference between two classes but also, very clearly, as a racial divide. The majority of the underprivileged banlieue dwellers are nonwhite immigrants from the former Frenchoccupied territories and their French offspring. The simple spatial appellation of a French banlieue - no longer a passively demarcated space - is the indicator of a constellation of colonial influences. The unrest that started in the banlieues 
spread from the margins to the center, highlighting the changing signification of spatial domains. It has forced the French to reassess their colonial history.

This colonially marked border taking on a life of its own and exacting revenge could have been a statement of exaggeration had it not been for Marseille going unscathed during the riots. Unlike most French cities, Marseille "is turned inside out, so that 'inner city' and 'suburbia' retain their American connotations" (Caldwell). In the case of Marseille, much like in the American context, it is the inner city that is marked by poverty, and the suburbs connote relative affluence. Despite "one of the heaviest concentrations of immigrants" children in France" (Caldwell), this port city of Marseille, owing to the absence of a historically generated colonial periphery, was spared the violence that besieged most of urban France. No banlieue meant no violence. With no banlieue to act as a carrier of colonial history, Marseille was spared the social conflict.

The global vision that undergirded this ideological project of colonial space remains pertinent even today. If capitalism and brute force were central to the French colonial project, it was not without space management techniques playing an equally important role in exercising a racial and ethnic superiority over the native populations. ${ }^{2}$ Once Algeria won its independence in 1962, all the administrative techniques employed to manage the colonies - techniques of spatial abstraction also on display in Verne's work - were brought back home. This led to the perpetuation of "a form of interior colonialism" (7) that contributed to neo-racism in France. ${ }^{3}$ Even more importantly, this interior colonialism serves to explain France's continued contemporary colonial engagement. Those spatial practices that kept the colonies at a disadvantage were now implemented within France, with not very dissimilar results - and the periodic unrests in the French banlieues are only a testament to this continued presence of colonialism.

The literary works and film analyzed in Spatial Boundaries, Abounding Spaces: Colonial Borders in French and Francophone Literature and Film have demonstrated the setting up and continuation of various aspects and manifestations of colonial spaces at different moments. The spatial results of the process of intensive colonization - to which Jules Verne's novel Le Tour du monde en quatre-vingts jours testifies, are still unfolding. Colonization has not ended with the liberation of colonies and the formation of new nation-states. For this book it has been important to show that colonization of space that is found in today's Paris - as it is found in London, where Phileas Fogg the protagonist of Verne's novel starts his journey - is also found in other works that make up the corpus of this book. The spatial obliteration that colonization carried out "there" in the realm of the Other at another time is present now and here - and indeed 
everywhere. Verne details the exploits of an English gentleman, testifying to the setting up of this global colonial space, as much as he also prepares the ground for the return of the repressed that is to take place in the twenty-first century film Caché, where it is colonial guilt that assails the characters.

These works are deeply expressive of the realities of communities dealing with contestations that arise from spatial transitions. That these are spatially charged intrigues and one needs to read them as such is evident from their own focus on different manifestations of space. Moments of changing spatial divisions and newer usage of space within the colonial context are the explicit backdrop for creative works that Spatial Boundaries, Abounding Spaces analyzes. Verne's literature records European contact with hitherto unknown locations as well as the setting up of a technologically defined spatiality. The relationship that Devi's characters have with India, Indian nationalism, global capitalism and the territorial definition it imposes upon the world are the focus of analyses of Devi's works. At the heart of the novel Texaco is the fight over the ownership and meaning of the hutment that bears the name of Texaco. In Caché Majid inhabits the geographical and colonial location of the banlieue that was responsible for the electrocution of Zyed Benna and Bouna Traoré. More importantly, it is his place in the margins of the French nation that shows how we are all marked by spatial colonization in relation to each other.

In addition to bringing out the obvious centrality of spatial divisions, this book has analyzed the larger spatial paradigms and spatial networks that these works reference. When read through the prism of postcolonial theoretical concerns, the evidence of spatial paradigms shows creative spatiality assuming forms that develop on complex relationship between space and creative production. Such a reading also shows how in multiple ways spatiality has anchored itself in various facets of our lives, thus also displaying the necessity of a deeper examination of the enduring effect of these colonially initiated spatial interconnections.

Literature for Brosseau is "a subject that becomes a geographer in its own right" (Brosseau, "City" 92). The spatial evidence from these works, when placed against postcolonial theoretical concerns, reveals spatial networks. Disparate locations mutually interact with each other to create novel geographies and to give the world a new geographical meaning. For instance, an examination of the route taken by the adventures in Le Tour du monde en quatre-vingts jours reveals an opium economy that mathematically rationalizes different parts of the colonial empire to ensure the smooth transport of opium across the world. Understanding the surreptitious operations of the opium network that redefines global spaces also shows why human subjectivity too can only appear as 
a by-product of this mathematical thinking. Analyzed against the debate about geographies of origin, different locations in Devi's work together speak against the idea of a stable national identity. When these locations together highlight the collusion between the nation-state and an exploitative capitalism, they show how a creative work can become a "geographer in its own right" (Brosseau, “City" 92).

Throughout this book, I have attempted to understand and make sense of these spatial paradigms by seeing the world they construct and the myriad and complex relationships they bring out within their various components. Placed within their own local context, as much as they belong to a worldview, each of these creative works also defines the world and its relationship to the world differently. Whether it is in terms of nascent trade routes, a linguistic colonization, an advancing globalization, or in terms of national boundaries, these local narratives evoke their place, explicitly or implicitly, within a larger global spatial network.

During the infamous Berlin conference of 1884-5, the colonizing powers of the time - Belgium, France, Germany, Great Britain, Portugal and Spain - got together in Europe and divided the African continent among themselves. They carved the map of Africa in straight lines, ignoring local customs, languages and history. Colonization was after all a project of spatial expansion. They first divided lands on charts and maps and then transposed that colonial understanding onto the African continent. This division of the continent on pieces of paper, which predetermined the European contact with local populations, serves as the perfect example of the kind of spatial interaction that Verne prepares with the elsewhere in his literary corpus. It was important to show how Verne follows a geography of colonial expansion in order to display why the colonized subjectivity, even before any contact, is already rationalized. Diktats of straight line on colonial maps would henceforth define a colonized subject.

The first chapter of this book laid out the theoretical parameters necessary to understand the concerns highlighted here. It outlined the backdrop necessary to understand how analyses of literary spatiality show the human subject is engaged in a process of mutual exchange with colonial spaces. The second chapter recorded a moment of shift in the spatial stakes involved in defining a colonial subject. Verne's literature displays colonial expansion rationalizing world spaces in terms of capitalism and colonizing nationalisms. Territorial expansion and acquisition of newer markets during colonialism could not have been achieved 
without reconfiguring the human subjectivity along axes of capitalism and nationalism. The definitions of human beings that accompanied the colonial reassessment of space followed the same mathematical logic that was defining territories.

The third, fourth and the fifth chapters engaged with particular spatial questions that have resulted from the colonial project. Each chapter figured contemporary responses to a vision of the world constituted by a vocabulary of expansion, discovery and conquest. In addition, these questions of spatiality also furnished the occasion to discover and discuss how and to what extent issues important to the postcolonial world are intertwined with questions of spatiality.

More specifically, the third chapter placed Devi's narratives of colonial displacement against discussions of geographies of colonial origins and location to understand how her work responds to identities that reductive postcolonial nationalisms impose. Different manifestations of Devi's India anchor debates about nation-based identities in the postcolonial world, and have also helped understand the evolution in Devi's own literary relationship with India. Spatial analyses revealed how Devi's earlier resistance against the general idea of a fixed identity has taken the shape of a more focused resistance against the impositions of a religion-based nationalism. Her work also highlights the combined workings of the nation-state and global capitalism, responsible for global displacements and clustering of populations.

The fourth chapter placed Chamoiseau's work within the larger historical context of Martinique's colonial relationship with France to understand the interaction between space, gender and language within the Francophone literary tradition. The struggle led by Marie-Sophie for the ownership of Texaco becomes a metaphor for the conflict that Chamoiseau sees between Creole and French. Marie-Sophie enmeshing her memories with the hutment of Texaco serves as an imperative to define a location in relation to the personal memories of its inhabitants.

It is not just about the claims of two communities - the Creole-speaking hutment and the French-wielding city authorities - over a piece of land. Rather, when analyzing the colonial connections between France and Martinique alongside the strained relationship between French and Creole, it is about the inability of the French language to communicate the Creole community's relationship to the place it inhabits. More broadly speaking, this chapter shows how humans live in a situation of constant exchange with the spaces they inhabit. Human perceptions determine the meaning of space as much as spaces define human beings. Simply put, one needs to understand the two in relation to each other. 
A book that claims to participate in the 'spatial turn' of the last few decades cannot be complete without seeing how colonial space and spatiality have influenced our understanding and articulation of the world. The very last chapter moved to the space of difference between two colonial products negotiating their relationship with colonial history. The human subject anchors itself in relation to its own perceptions of all that surrounds it. In Haneke's film Caché representative of the French nation Georges Laurent can only locate himself and his colonial Other Majid using colonial coordinates that surround him. Humans give meaning to spaces and a spatial understanding becomes the basis for humans defining each other. These readings show how our knowledge of Others and of ourselves is influenced by our interaction with the physical world we inhabit.

In Postmodernism or the Cultural Logic of Late Capitalism, Jameson discusses how it has become impossible to locate ourselves either physically or theoretically in the space of postmodernism. An architectural analysis of Hotel Bonaventura shows how the "postmodern hyperspace" has transcended the human body's ability "to map its position in a mappable external world." This absence of spatial coordinates serves to point to the lack of critical distance at a theoretical level. Even forms of cultural resistance are "disarmed and reabsorbed by a system of which they themselves might well be considered a part, since they can achieve no distance from it" (44).

If the human subject inhabits a social and political reality whose coordinates it cannot locate and that is undefinable, how then does one establish a model of political change? To answer this question and to regain the "capacity to act and struggle" (Postmodernism 54), and also to elaborate a cultural model such that the individual subject might place itself in the larger global system, Jameson extends Kevin Lynch's spatial understanding of "cognitive mapping" (51) onto the political realm. In the "alienated city" (51), such as the contemporary grid of Jersey City, people are unable to locate "either their own positions or the urban totality in which they find themselves" (51). Cognitive mapping involves a "practical reconquest of a sense of place" (51). It permits an understanding of one's own place as well as of the larger spatial whole. When projected "outwards onto some of the larger national and global spaces," cognitive mapping that Lynch presents in the context of gridlike cities offers the potential for the kind of political change Jameson desires (51).

Jameson elaborates "cognitive mapping" (51) in order to find bearings in "the world space of multinational capital" (54). Given the analyses undertaken above that display the central presence of transnational capital, one could easily see how Devi's literature figures as a cognitive map of a "world space of 
multinational capital." Not only do Devi's works define the immediate context of their characters, they also present a vision of a postcolonial world in which capitalism and nationalism are defining the everyday lives of ordinary peoples. However, the cognitive maps that the chapters of Spatial Boundaries, Abounding Spaces elaborate should be understood as responding to a colonially redefined world. Against the backdrop of a global spatiality (that continues to be) brutalized by colonialism, the creative spaces of these works are attempts at understanding the world and their place within it from their own vantage position.

For these works, creative spatialities are sites where postcolonial assertions confront colonial spatial paradigms and register the formation of new subjectivities even as mutating forms of subjugation continue challenging ideas of belonging and community. These analyses trace some of the colonial and postcolonial struggles to define one's relationship with geography. The itinerary charted out through these analyses is intended to provide access to ways in which questions of language, gender, nationalism and race are intertwined with our understanding of space in the contemporary world. These analyses and the creative works analyzed therein function as attempts to triangulate their presence within the world via theoretical coordinates important for the postcolonial world. Jameson points to how the invention of the compass and other instruments for naval navigation allow for the charting of one's presence as a coordinate of "unlived, abstract conceptions of the geographic totality" (52). These creative works triangulate their presence in the world at different locations: both geographical and theoretical. From each of them emerges a perspective on the world that provides a theoretical anchor that shows not only how spatiality is an important vector in the formation of human subjectivity but also how our perception of space in itself is the result of interaction with all that effects human identity. In particular, the last chapter on Haneke's cinema has been a gesture to show the constant ongoing exchange between our understanding of space and human identity. If humans have been responsible for shaping spatial contours, then our understanding of space too has influenced our understanding of human interactions.

In Spatial Boundaries, Abounding Spaces I have analyzed the presence of (sometimes abstract) notions of space in critical as well as creative French language works to show how they present colonial spatiality as a necessary vector in the formation of a colonial subject. These works offer sometimes poignant, at other times stark, at times even menacing, but never disinterested accounts of 
association with French colonial history, Metropolitan French borders and French conceptualizations of space. This task has been far from easy and has carried the risk of oversimplification, in particular when analyzing creative production in the contemporary world made up of overlapping networks, circuits and ever-changing notions of communal as well as individual spaces.

Indeed, to write a conclusion, to impose a limit on a book bearing Abounding Spaces in its title, will run contrary to its grain, hence the title "Interjecting Passages" for the concluding segment. In the various connotations that they together evoke, "Interjecting" and "Passages" sum up in many ways the objectives this book has tried to achieve. "Interjecting Passages," firstly because colonization is not a fait accompli and the passages and pathways (financial as well as logistical) that colonization created during the period of overt exploitation continue to expand and interject into our daily lives, as Devi's work shows, assuming ever-changing newer forms. Devi's work also displays how the creative response - her literary passages - continues to derail and interject these colonial-capitalist passageways and their nefarious collusion with power structures that impose sexual, racial, casteist and gendered imperatives, among others, on human bodies.

"Interjecting Passages" also because the passages in this book have hopefully productively interjected in the vibrant debate around postcolonial spatiality to show how spatial boundaries are constituted by, and at the same time are a constitutive vector of, the colonial subject. Multiple notions of space have crisscrossed with each other, interjected each other, to reveal in myriad ways how spatial boundaries have transformed the colonial subject. And, how these spatial boundaries in themselves are products of specific knowledge paradigms in which the subject participates.

It is thus, because the book takes its spatial cues from these literary works and engages with disparate spatial analyses, that it also bears Abounding Spaces in its title. Abounding, firstly because at times this book has espoused the unending, limitless space that was the mainstay of the last chapter's argument, and more importantly also because of the myriad spatial constellations it evokes. Multiple and varied assertions of spatial belongings and spatial rejections have produced a colonial subject, difficult to contain within any one spatial discourse.

Be it imposed spaces, subjugating spaces, spaces of contention, spaces of rebellion, or, dissenting, defiant and revolting spaces, these spaces in their various assertions are producing intersections of subjectivity and spatiality that testify to the influences on them of colonial expansion, modernist reassertions of nation-states, as well as creative postmodern engagements. 
It should not then be surprising that Spatial Boundaries, Abounding Spaces has simultaneously deployed material, historical, linguistic and postmodern readings of creative works to understand the overarching principles that guide the creative engagement with spatial oppression and the new paradigms of colonial citizenship that these French language works produce. It is in this spirit that I present the following reading, not as the conclusive limit of this much larger discussion, but as a punctuation mark that illustrates some aspects of the analyses this book has espoused.

As I mentioned earlier, through his avowed move to connect Caché to the "dark stains" on the collective unconscious of "every country," the Austrian director Haneke has already taken this Paris-based French-language film away from its national confines. Georges Laurent living in contemporary Paris is understood as a product of the colonization in Algeria as well as of the "blind spot" of history associated with 17 October 1961, when hundreds of people of Algerian origin were drowned in the river Seine without any consequences for the perpetrators.

As I have concentrated on zones of contact to question the containment - identitarian as well as spatial - of human beings, the idea has been to show that in order to understand the here and now, one needs to start with there and then. The first chapter of this book began with the work of a French author writing about an Englishman's colonial exploits that demonstrated how a uniform colonial space was created across Earth.The last chapter was about an Austrian director making a French film about French colonialism. In the same spirit of working with authors writing about locations of national nonbelonging, I end this book with a poem by the Polish-American Nobel Laureate, Czesław Miłosz, writing about Paris.

This gesture of reading an English translation of a non-Francophone author writing about the interconnections between the heart of French colonial empire, the capital city of Paris, and the "cloudy provinces" is an attempt at underlining the all-pervasive presence of French spatial structures; a presence that exceeds the linguistic divisions that one imposes upon creative works. "Bypassing Rue Descartes" is a poem that speaks about the arrival in Paris of those belonging to the "cloudy provinces." The poem nuances the interlinkages between Paris and the impoverished immigrants:

\section{Bypassing rue Descartes}

Bypassing rue Descartes

I descended toward the Seine, shy, a traveler, A young barbarian just come to the capital of the world. 
We were many, from Jassy and Koloshvar, Wilno and Bucharest,

Saigon and Marrakesh,

Ashamed to remember the customs of our homes,

About which nobody here should ever be told:

The clapping for servants, barefooted girls hurry in,

Dividing food with incantations,

Choral prayers recited by master and household together.

I had left the cloudy provinces behind,

I entered the universal, dazzled and desiring.

Soon enough, many from Jassy and Koloshvar, or Saigon or Marrakesh

Would be killed because they wanted to abolish the customs of their homes.

Soon enough, their peers were seizing power

In order to kill in the name of the universal, beautiful ideas.

Meanwhile the city behaved in accordance with its nature,

Rustling with throaty laughter in the dark,

Baking long breads and pouring wine into clay pitchers, Buying fish, lemons, and garlic at street markets,

Indifferent as it was to honor and shame and greatness and glory, Because that had been done already and had transformed itself Into monuments representing nobody knows whom, Into arias hardly audible and into turns of speech.

Again I lean on the rough granite of the embankment, As if I had returned from travels through the underworlds And suddenly saw in the light the reeling wheel of the seasons Where empires have fallen and those once living are now dead.

There is no capital of the world, neither here nor anywhere else, And the abolished customs are restored to their small fame, And now I know that the time of human generations is not like the time of the earth.

As to my heavy sins, I remember one most vividly:

How, one day, walking on a forest path along a stream, I pushed a rock down onto a water snake coiled in the grass.

And what I have met with in life was the just punishment Which reaches, sooner or later, the breaker of a taboo. 
The poem begins with two proper names, Seine and Descartes: the river where Cachês colonial subject Majid loses his parents and a road name that evokes René Descartes, the most well-known of all French philosophers, and here the emblem for France. Let me read this poem in light of the analyses from Spatial Boundaries, Abounding Spaces. It is through a necessary analysis of the passage (both meanings intended - pathway as well as the poem) leading from the road ("rue Descartes") to the river that one can hope to discover a world that radically redefines the way locations relate to each other; and a movement away from a world of hierarchical oppositions.

This poem can be divided into two distinctly temporal evocations. From "Bypassing" to "turns of speech," the poem remains in the past. The poem starts with a narrator who "descended toward the Seine." In the second segment (from "Again" to "taboo"), the narrator assumes the first person "I" and speaks in the present tense of an inclusive geography where history becomes central to our understanding of space.

In opposition to the plural place names ("Jassy and Koloshvar, Wilno and Bucharest, Saigon and Marrakesh") of these "cloudy provinces," Paris, "the capital of the world," exists in the singular. Unlike these provinces that follow the plurality of "customs of our homes" that need to be censored ("About which nobody here should ever be told"), Paris, associated with the one and only "universal," can behave in only one particular predictable manner: "in accordance with its nature."

There is consumption of food in both locales. In the cloudy provinces human beings exist in a hierarchy of "masters" and "servants [...] girls," that live in "homes" (in plural) and indulge in communal activities of "choral prayers." These inhabitants are "dividing food." That is, they exist as a community. The capital, on the other hand, is personified. The city laughs, bakes, buys fish and even pours wine, all for itself, and all following its predictable "nature."

This logocentric universal presentation of the city in contrast against the provinces should not be understood as a valorization of the old-world hierarchy of human beings with predestined social positions in "cloudy provinces." Within this opposition (universal versus hierarchical) lies the kind of reductive thinking that was at the heart of: a) Phileas Fogg's journey that presented the colonial world as a function of Europe; b) the crux of postcolonial identitarian assertions that sought to return to the original glory of cultures lost. Masters and servant girls, while both remind of humans existing in assigned hierarchies, are also gender specific, and speak to the kind of Senghorian Négritude that advanced its male-centric postcolonial identity at the cost of the woman subject. Just as the 
"master" is able to command ("clapping") servant girls to do his bidding, so did Négritude deploy the woman in its careless idolization of a sexualized Africa.

It is the incommensurability then of these two worldviews with any subjective assertions that leads to the violence that pervades the poem. Many from these provinces "[w] ould be killed" to maintain the customs, just as "universal, beautiful ideas" would coax others "to kill." These worldviews erase that which does not conform to the ideal.

It is the second half of the poem (from "Again" to "taboo") that articulates a geography where history becomes central to our understanding of spaces. For the very first time in the poem, there is a physical coming together of the narrator and the built city: "I lean on the rough granite of the embankment." This "barbarian" with customs from elsewhere comes to the Seine and leans upon the granite, which has its own history that has rendered it "rough." What one has in this interconnection is a new way of understanding the relationship between the city and the subject. If this present moment forces us to probe the circumstances that led the narrator to traverse geographies, and to be physically present against the embankment, it is not without wondering about the events that rendered the granite rough.

Miłosz's poem prepares the ground for a space of engagement where the iteration of human space and identity is not shackled by predetermined definitions of history or of other human beings. It should be no surprise, then, that what accompanies this implicit understanding of human and spatial identities within their diachronic and synchronic context is the collapse of a globe existing in hierarchies: "There is no capital of the world."

Humans and their histories lean on spaces as much as spaces and their various histories lean back upon humans: just as those who were "once living" then "are now dead," so is it important to point out that neither "bere," nor "anywhere else" is there anymore a "capital of the world." I italicize the temporal and the spatial designators to stress upon what I have already stated: in order to reckon with the here and now, one needs to start with the there and then. Only then can one hope to look beyond the smoke screen and surpass the debilitating compartmentalization that Phileas Fogg imposed upon the world; a compartmentalization inherently linked to the assertion of superiority over the colonized Other.

"Bypassing Rue Descartes" articulates the importance of spatial understanding to the creation of identity and then presents a time and space relationship that pervades inequality and rejects any watertight definitions - be they of human beings or of chunks of landmasses on which have been scaled nation-states. It is this counteractive challenge to borders that I have attempted 
to work toward in Spatial Boundaries, Abounding Spaces: Colonial Borders in French and Francophone Literature and Film. In their struggle to redefine spatiality, Chamoiseau, Devi and Haneke reassert the need for a more inclusive spatial paradigm, the kind that is present in Miłosz's poem.

Four geographically dispersed creative constructs belonging to four different creative traditions, different genres and different moments of colonial history speak together of the centrality of the ever-present colonial borders, just as they also attest to the inherent entwinement of these spatial divides with human identity. To explore this space is to recognize its inherent openness, to accept the anxiety of constantly changing coordinates of human identity. To explore this space would also imply being aware that one inhabits an ever-changing relationship with the Other; it is to know that colonization is found both in India and France as well as in the fictional hutment of Texaco. In order to understand this intertwined world of "foggy provinces" of Texaco, India and Martinique, one should not be bypassing Rue Descartes in Paris, is what I have hoped to communicate. 



\section{NOTES}

\section{Chapter 1 - Introduction: Charting Course}

1 All quotations in French from Le Tour du monde en quatre-vingts jours belong to the following edition: Verne, Jules. Le Tour du monde en quatre-vingts jours. Paris: Librairie Générale Française, 2001. Unless otherwise stated, all English translations of Le Tour belong to: Verne, Jules. Around the World in Eighty Days. Trans. William Butcher. New York: Oxford University Press, 1999. The first number within the parentheses indicates the page number of the French original and the second its translation.

2 "Une véritable mécanique!" ['genuine piece of machinery'] $(18 ; 15)$.

3 He uses "tous les moyens de transport, paquebots, railways, voitures, yachts, bâtiments de commerce, traîneaux, éléphant” ['every means of transport: steamship, train, carriage, yacht, cargo vessel, sled, and elephant'] (300-1; 202).

4 "On le voyait rarement sur le pont. Il s'inquiétait peu d'observer cette mer Rouge, si féconde en souvenirs" ['Rarely was he seen on deck. He made little effort to observe this Red Sea, so redolent in memories'] $(55 ; 39)$. Then, even after getting off the boat in Bombay, the abundant use of negation for potential places of interest and an insistence on his clock-like gait exemplify the indifference of this mechanical personality:

"de son pas régulier qui battait la seconde comme le pendule d'une horloge astronomique, il se dirigea vers le bureau des passeports.

Ainsi donc, des merveilles de Bombay, il ne songeait à rien voir, ni l'hôtel de ville, ni la magnifique bibliothèque, ni les forts [...]

Non! rien" (63).

['Then, with his regular pace marking the seconds like the pendulum of an astronomic clock, he headed for the Passport Office.

He did not think of visiting any of Bombay's wonders: not the Town Hall, the magnificent library, the forts $[\ldots]$

No! nothing' (44-5).]

The remaining 1,000 pounds he divides with his servant Passepartout and his nemesis Inspector Fix. Interestingly, right before his journey, Fogg gives away 20 guineas to a beggar woman. This was the 20 guineas he had won a short while ago in the card game that provoked the bet $(30 ; 23)$. 
6 Schivelbusch, Wolfgang. The Railway Journey: The Industrialization of Time and Space in the 19th Century. Berkeley: University of California Press, 1986.

$7 \quad$ Senghor, Léopold Sédar. "Vues sur l'Afrique Noire, ou Assimiler, non être assimiles." La Communauté impériale Francaise, edited by Robert Lamaignon et al. Paris: Editions Alsatia, 1945, pp 57-98. 93. Quoted in: Diawara, Manthia, "Reading Africa through Foucault: V. Y. Mudimbe's Reaffirmation of the Subject." Dangerous Liaisons: Gender, Nation, and Postcolonial Perspectives, edited by Anne McClintock, Aamir Mufti and Ella Shohat, Social Text Collective. Minneapolis: University of Minnesota Press, 1997, pp. 456-67.

8 Senghor speaks fervently of adopting a French way of thinking that would allow the African and the African diaspora to express itself appropriately with the clarity inherent to French thought. It is no wonder that Y. V. Mudimbe saw Négritude as a part of Western thought. Mudimbe calls Négritude "a product of a historical moment proper to Europe, more particularly to the French thought, which marked it." Quoted in Diawara (458). Aimé Césaire, another proponent of Négritude, writes in 1939 in Cabier du retour au pays natal about his inability to locate a homeland. Despite differences between his renditions of Négritude vis-à-vis Senghor's, Césaire does nonetheless participate in a debate that relates to geographical locations. For a distinction between Césaire and Senghor's usage of Négritude read James Clifford's discussion of René Ménil. In Ménil's analysis, according to Clifford, "the negritude of Léopold Senghor and that of Césaire are clearly distinguished. The former elaborates a 'backward-looking idealism, a falsely naturalized, consistent African mentality that tends to reinscribe the categories of a romantic, sometimes racialist European ethnography. Césaire's Caribbean negritude, by contrast, rejects all essentialist evocations" (178). Clifford, James. The Predicament of Culture Twentieth-Century Ethnography, Literature, and Art. Cambridge, Mass.: Harvard University Press, 1988.

François, Anne M. Rewriting the Return to Africa: Voices of Francophone Caribbean Women Writers. Lanham, Md.: Lexington Books, 2011.

Diémé, Joseph. De la plantation coloniale aux Banlieues: La Négritude dans le discours postcolonial francophone. Paris: L'Harmattan, 2012.

11 Chandna, Mohit. "Writing Colonial Spaces." Journal of Commonwealth and Postcolonial Studies, vol. 1, no. 2, 2013, pp. 87-95.

12 Glissant, Edouard. Poétique de la relation. Paris: Gallimard, 1990, p. 71.

13 Glissant, Edouard. Poetics of Relation. Trans. Betsy Wing. Ann Arbor: University of Michigan Press, 1990, p. 58. Translator's parentheses.

14 "Propriété fondamentale des corps d'être situés dans l'espace et d'en occuper une certaine partie." ['Fundamental property of bodies to be situated in space and to occupy a part of it.'] "Etendue." Trésor de la Langue Française. Le Trésor de la Langue Française Informatisé. http://atilf.atilf.fr/tlf.htm.

15 Coursil, Jacques. "La Catégorie de la relation dans les essais d'Edouard Glissant: Philosophie d'une politique." Poétiques d'Edouard Glissant: Actes du colloque international "Poétiques d'Edouard Glissant," complied by Jacques Chevrier. Paris: Paris-Sorbonne, 1113 March 1998. Paris: Presses de l'Université de Paris-Sorbonne, 1999, pp. 85-112. Henry, Freeman G. Geo/graphies: Mapping the Imagination in French and Francophone Literature and Film. Amsterdam: Rodopi, 2003.

Prieto, Eric. Literature, Geography, and the Postmodern Poetics of Place. New York: Palgrave Macmillan, 2013.

18 Prieto, Eric. "Phenomenology, Place, and the Spatial Turn." The Routledge Handbook of Literature and Space, edited by Robert T. Tally. Basingstoke: Taylor \& Francis, 2017, pp. 60-69. 
Later I take up Shiela Hones' criticism of Prieto.

Soja, Edward W. Thirdspace. Massachusetts: Blackwell, 1996.

Massey, Doreen. For Space. London: Sage, 2005.

Massey, Doreen. Space, Place, and Gender. Minneapolis: University of Minnesota Press, 1994. Foucault, Michel. Power/Knowledge: Selected Interviews and Other Writings 1972-77. Trans. Colin Gordon et al. New York: Pantheon Books, 1980, pp. 149-50.

For representative writings in critical geography over the last two centuries, see Bauder, Harald, and Salvatore Engle-Di Mauro, editors. Critical Geographies: A Collection of Readings. Praxis (e) Press, 2008. http://www.praxis-epress.org/CGR/contents.html. Wayback Machine, https://tinyurl.com/m7d4mf27.

Warf, Barney, and Santa Arias. "Introduction: The Reinsertion of Space into the Social Sciences and Humanities." The Spatial Turn: Interdisciplinary Perspectives, edited by Barney Warf and Santa Arias. London; Routledge, 2009, pp. 1-10. It is not for nothing that "The Spatial Turn" is the title. As this collection presents representative writings across disciplines that have contributed to the field of human geography, the book testifies to the field gaining in prominence over the last two decades.

For more on the theoretical ramifications of this "spatial turn" read the introduction of: Upstone, Sara. Spatial Politics in the Postcolonial Novel. Farnham: Ashgate, 2009.

Goonewardena, Kahisnka, et al. "On the Production of Henri Lefebvre." Space, Difference, Everyday Life: Reading Henri Lefebure, edited by Kahisnka Goonewardena et al. New York: Routledge, 2008, pp. 1-24.

Shields, Rob. Lefebure, Love, and Struggle: Spatial Dialectics. New York: Routledge, 2009. Cresswell, Tim. Place: A Short Introduction. Malden, Mass.: Blackwell, 2004.

"The fact is that place is a contested concept and what it is that 'place' means is very much the subject of decades of debate in human geography as well as philosophy, planning, architecture and any number of other disciplines. To some in planning, place refers to the built environment. To ecologists, a place is rooted in a distinctive ecology - as a bioregion. To a philosopher, place is a way of being-in-the-world. The rest of this book is an extended investigation of what place means and how the concept has been and might be used by geographers and others" (Cresswell 12).

"Confusingly for geographers de Certeau uses space and place in a way that stands the normal distinction on its head. To de Certeau place is the empty grid over which practice occurs while space is what is created by practice" (Cresswell 38-9).

"It has to be noted that the notions of space and spatiality can acquire different interpretations and meanings depending on which critic uses them, something that contributes to the elusiveness and ambiguity of the notion of space. Doreen Massey uses the terms of space and spatiality sometimes interchangeably, and sometimes she makes a distinction between the two; although her understanding of space is socio-political (and therefore synonymous with spatiality), she does also use a broader definition of space. Edward Soja makes a clearer distinction between the two terms when using them (space can be abstract, physical and social, while as spatiality refers only to social space). In Hubbard's and Kitchin's encyclopedia on Key Thinkers on Space and Place, the term 'space' does not figure at all in the dictionary; only 'spatiality' is listed” (12). Bolfek-Radovani, Jasmina. Space, Place and Spatial Loss in North African and Canadian Writing in French. 2012. University of Westminster, $\mathrm{PhD}$ dissertation. WestminsterResearch, http://westminsterresearch.wmin.ac.uk/13283/1/ Jasmina_BOLFEK-RADOVANI.pdf. 
Lefebvre, Henri. La Production de l'espace. Paris: Éditions Anthropos, 1981. Lefebvre, Henri. The Production of Space. Trans. Donald Nicholson-Smith. Oxford: Blackwell, 1991.

Milgrom, Richard. "Lucien Kroll: Design, Difference, Everyday Life." Space, Difference, Everyday Life: Reading Henri Lefebure, edited by Kahisnka Goonewardena et al. New York: Routledge, 2008, pp 264-81. 270. To understand further these "three processes" see Brady, Mary Pat. Extinct Lands, Temporal Geographies: Chicana Literature and the Urgency of Space. Durham, N.C.: Duke University Press, 2002, n. 18, pp. 208-9.

Read: Lefebvre, La Production de l'espace, pp. 46-57.

Also quoted in Shields, p. 163.

Poetics of Relation. Trans. Wing, p. 58. Translator's parentheses.

Sharp, Joanne P. “Towards a Critical Analysis of Fictive Geographies." Area, vol. 32, no. 3, 2000, pp. 327-34.

Brosseau, Marc. "In, Of, Out, With, and Through: New Perspectives in Literary Geography." The Routledge Handbook of Literature and Space, edited by Robert T. Tally Jr. Basingstoke: Taylor \& Francis, 2017, pp. 9-27.

Brosseau, Marc. "Geography's Literature." Progress in Human Geography, vol. 18, no. 3, 1994, pp. 333-53.

Tally, Robert T., Jr. "Introduction: The Reassertion of Space in Literary Studies." The Routledge Handbook of Literature and Space, edited by Robert T. Tally Jr. Basingstoke: Taylor \& Francis, 2017, pp. 1-6. This list is far from exhaustive. For example, one could also add "imaginative geography, literary cartography, [... and] geohumanities" to the list above (5). Alexander, Neal. "On Literary Geography." Literary Geographies, vol. 1, no. 1, 2015, pp. 3-6. https://www.literarygeographies.net/index.php/LitGeogs.

Tavares, David, and Marc Brosseau, "The Spatial Politics of Informal Urban Citizenship: Reading the Literary Geographies of Toronto in Dionne Brand's What We All Long For." Zeitschrift für Kanada-Studien, vol. 33, no. 1, 2013, pp. 9-33.

Brosseau often prefaces his literary analyses with historical accounts of the field. I would particularly recommend the journal article "Geography's Literature" (1994); the monograph, Des Romans-Géographes (1996); and the encyclopedia entry "Literature" (2009).

Brosseau, Marc. Des Romans-Geographes: Essai. Paris: L'Harmattan, 1996.

Brosseau, Marc. "Literature." International Encyclopedia of Human Geography, edited by Rob Kitchin and Nigel Thrift. Vol 6. Amsterdam: Elsevier, 2011. Internet resource, pp. 21219.

Tally, Robert T., Jr. Spatiality. London: Routledge, 2013.

Tally, Robert T., Jr. Literary Cartographies: Spatiality, Representation, and Narrative. New York: Palgrave Macmillan, 2015.

Tally, Robert T., Jr. The Geocritical Legacies of Edward W. Said: Spatiality, Critical Humanism, and Comparative Literature. New York: Palgrave Macmillan, 2015.

"Introduction." Routledge Handbook 3.

Brosseau's 2017 article lists a "vast range of ambitions questions." These questions show the numerous ways in which literature and geography can be, and have been, brought together (“In" 22).

Ogborn, Miles, and Charles W. J. Withers. "Introduction: Book Geography, Book History." Geographies of the Book, edited by Miles Ogborn and Charles W. J. Withers. Farnham: Ashgate, 2010, pp. 1-28. 
Hones, Sheila. Literary Geographies: Narrative Space in Let the Great World Spin. New York: Palgrave Macmillan, 2014.

Hones, Sheila. "Text as It Happens: Literary Geography." Geography Compass, vol. 2, 2008, pp. 1301-17.

Hones, Sheila. "Literary Geography and the Short Story: Setting and Narrative Style." Cultural Geographies, vol. 17, no. 4, 2010, pp. 473-85.

Brosseau, Marc. "The Traps: Bukowski as Interpreter of Cornered Lives." Anglia - Zeitschrift für englische Philologie, vol. 126, no. 2, 2008, pp. 380-96. For more on "alternative geographic epistemologies," read also other writings by Brosseau: 2009; 2013; and 2017.

Brosseau, Marc. "The City in Textual Form: 'Manhattan Transfer's' New York." Ecumene, vol. 2, no. 1, 1995, pp. 89-114.

Ross, Kristin. "Rimbaud and the Transformation of Social Space." 50 Years of Yale French Studies: A Commemorative Anthology. Part 2: 1980-1998, spec. issue of Yale French Studies, vol. 97, 2000, pp. 36-54.

Parry, Benita. "Beginnings, Affiliations, Disavowals." Postcolonial Studies: A Materialist Critique. London and New York: Routledge, 2004, pp. 3-12.

Mohanty, Chandra Talpade. "'Under Western Eyes' Revisited: Feminist Solidarity through Anticapitalist Struggles." Signs: Journal of Women in Culture and Society, vol. 28, no. 2, 2002, pp. 499-535. I am of course, adapting Mohanty's model of anticapitalist struggle because of its emphasis on contextual links, which provides the reasoning for reading together the works of this book.

By "setting up a paradigm of historically and culturally specific 'common differences' as the basis for analysis and solidarity," Mohanty's preferred model of feminist pedagogy aims at overcoming the "stereotypical terms" and "us and them' attitude" endemic to the other two prevalent models in the US academic scenario: "feminist-as-explorer" and "feminist-as-tourist." How the first model is "the pedagogical counterpart of the orientalizing and colonizing Western feminist scholarship of the past decades" (519) and the second "is an inadequate way of building a feminist cross-cultural knowledge base" is discussed in greater detail in Mohanty (516-24).

59 In my quest for finding an archetype that makes it possible to study literature comparatively without tying it down to the insulating confines of a historical period or a geographical area I have turned toward Mohanty's feminist assertions. But I am not the only one. Ross too, discovered in "women's studies" the closest model for setting up the World Literature program at the University of California, Santa Cruz: "for like women's studies we wanted to project an interdisciplinary coherence that was neither that of the historical period nor of the area study" (671). This book too hopes to contribute to a "relational way of thinking about literature and culture" where "Europe or America" cannot be thought of "in isolation of the rest of the world" (670) and have to be inherently studied through their mutually influencing interconnections with other parts of the globe. Ross, Kristin. "The World Literature and Cultural Studies Program.” Critical Inquiry, vol. 19, no. 4 (Summer 1993), pp. 666-76.

"This curricular strategy is based on the premise that the local and the global are not defined in terms of physical geography or territory but exist simultaneously and constitute each other. It is then the links, the relationships, between the local and the global that are foregrounded, and these links are conceptual, material, temporal, contextual, and so on" (Mohanty 521). 
In Internationalism Revisited, a materialist like Parry criticizes privileging the "diaspora" within postcolonial studies, a move belonging to "those infatuated by the liberatory effects of dispersion." Instead she desires one to "address the material and existential conditions of the relocated communities." The assertion that "the focus on diaspora leaves in obscurity the vast and vastly impoverished populations who cannot and might not choose to migrate" brings out more clearly the opposition of my own privileged position against that of my grandparents who were forced to migrate. Parry, Benita. "Internationalism Revisited or in Praise of Internationalism." Interventions: The International Journal of Postcolonial Studies, vol. 5, no. 2 (July 2003), pp. 291-314.

\section{Chapter 2 - Around the World in Eighty (One) Days}

1 Harvey, David. The Condition of Postmodernity: An Enquiry into the Origins of Cultural Change. Oxford: Blackwell, 1989, p. 294.

It might be clear from the usage of terms like "abstracted" spaces that I am borrowing from the lexicon of Henri Lefebvre to speak about how geography was organized and narrated under the influence of capitalism. In the matrix of "social space" that Lefebvre delineates, Fogg's eighty-one-day victory provides an excellent example of "representations of space" that refers to the space conceived by the organizers of a society, its planners, its architects and its technocrats, and which then becomes its dominant space (1991, 31-6). Unwin, Timothy A. Jules Verne, Le tour du monde en quatre-vingts jours. Glasgow: University of Glasgow, 1992, p. 42.

In Le tour (4-5), Unwin discusses the influence of Poe's story on Le Tour du monde en quatre-vingts jours.

"A modern stoic like Mr. Fogg knows that the surest way to discipline passion is to discipline time [...] and passion will give you no trouble" (141). Auden, W. H. The Dyer's Hand, and Other Essays. New York: Random House, 1962. Fogg's uncharacteristic emotional display falls on a continuum of the inverse relationship that Auden draws above between human emotions and discipline. The moment of realization that time can't be controlled is also the moment of Fogg's emotional unravelling.

"En effet, messieurs, ajouta John Sullivan, quatre-vingts jours, depuis que la section entre Rothal et Allahabad a été ouverte sur le 'Great-Indian peninsular railway', et voici le calcul établi par le Morning Chronicle:

De Londres à Suez par le Mont-Cenis et Brindisi,

railways et paquebots

$[\ldots]$

De New York à Londres, paquebot et railway 9 jours Total

7 jours

80 jours" (23).

['Yes indeed, good sirs,' confirmed Sullivan. 'Eighty days, now they've opened the section of the Great Indian Peninsular Railway from Rothal to Allahabad. This is the calculation done by the Morning Chronicle:

London to Suez via the Mont Cenis Tunnel and Brindisi,

by railway and steamship

7 days

$[\ldots]$

New York to London, by steamship and railway 9 days

Total

80 days (19).] 
In Michel Strogoff, Bongie sees a similar "biological foundation for the perpetuation of a political order" in the marriage of Michel Strogoff, the hero of Verne's novel, and his faithful assistant Nadia. Through the symbolic exchange of vows, the hero and the heroine perpetuate the imperial order that they helped restore (60). Bongie, Chris. Exotic Memories: Literature, Colonialism, and the fin de Siècle. Stanford, Calif.: Stanford University Press, 1991. Chambers, Ross. Loiterature. Lincoln: University of Nebraska Press, 1999, p. 28.

The following exchange takes place before the marriage proposal. Aouda says: "On dit cependant quà deux la misère elle-même est supportable encore!" ['When there are two of you, they say, even lack of money is bearable!']. To which Fogg replies: "On le dit madame" ['So they say'] (290; 195).

Hanson gives an account of transportation services "along lines of geographical scale" since the 1950s (470). Hanson focuses on the regional, national and metropolitan scales. Hanson, Susan. "Transportation: Hooked on Speed, Eyeing Sustainability." A Companion to Economic Geography, edited by Eric Sheppard and Trevor J. Barnes. Oxford: Blackwell, 2003, pp. 468-83.

For more on how Le Tour du monde en quatre-vingts jours "represents a complex and subtle response to the increasingly complicated relationships of people with time in the Victorian period" (91), read: Carroll, Jane Suzanne. "'You Are Too Slow': Jules Verne's Around the world in 80 days." Victorian Time: Technologies, Standardizations, Catastrophes, edited by Trish Ferguson. Basingstoke: Palgrave Macmillan, 2013, pp. 77-94.

While reading Frederic Moreau, the hero of Flaubert's L'Education sentimentale, Harvey concludes: "special is the way that he [Moreau] glides in and out of the differentiated spaces of the city, with the same sort of ease that money and commodities change hands" (Condition 263). Emphases added to highlight Harvey's literary reading.

Jameson, Fredric. Postmodernism, Or, the Cultural Logic of Late Capitalism. Durham, N.C.: Duke University Press, 1991.

Appadurai, Arjun. Modernity at Large: Cultural Dimensions of Globalization. Minneapolis: University of Minnesota Press, 1996.

One of the express pedagogical objectives of the Voyages Extraordinaires was to instruct adolescents about what lay "beyond the frontiers of the homeland" (5). Unwin, Timothy. "Jules Verne: Negotiating Change in the Nineteenth Century." Science Fiction Studies, vol. 32, no. 1, 2005, pp. 5-17.

Unwin, Timothy A. Jules Verne: Journeys in Writing. Liverpool: Liverpool University Press, 2005.

Unwin discusses Julien Gracq's account of the various spaces, of Earth and beyond, that Verne's voyages cover (Journeys 27-9).

Unwin Journeys (1). I discuss later Unwin's argument about Verne as a "writer and stylist" (4). The introduction of Journeys highlights how analyses focusing on endless clichés and generalisations, both positive and negative, overlook Verne's literary skills. Read "Introduction" also for a presentation of Verne's critical reception.

Read Boia (37-40) to understand how in recent times, with increasing attention to Verne's literary qualities, as the "l'étoile de l'écrivain monte, son étoile de prophète pâlit" ['star of the writer is rising as the star of the prophet is on the decline'] (38). Verne himself vociferously protested against attempts to credit him with predicting scientific discoveries. Boia, Lucian. Jules Verne: Les Paradoxes d'un mythe. Paris: Belles lettres, 2005. 
"[I]l fut longtemps l'auteur le plus traduit au monde....après Lénine et la Bible.” ['[F]or a long time he remained the most translated author in the world ... after Lenin and the Bible'] (8). Avrane, Patrick. "Prologue." Jules Verne. Paris: Editions Stock, 1997.

"Des dizaines de livres, des piles d'études universitaires, des milliers d'articles en français, en anglais, en russe, en espagnol, en italien, en arabe, en japonais, en chinois, en suédois, en allemand, en polonais et même [...] en kinyarwanda et en swahili." ['Tens of book, piles of university studies, thousands of articles in French, in English, in Russian, in Spanish, in Italian, in Arabic, in Japanese, in Chinese, in Swedish, in German, in Polish and even [...] in Kinyarwanda and in Swahili.'] (15). Maudhuy, Roger. Jules Verne: La face cachée. Paris: Editions France-Empire, 2005.

"Le grand regret de ma vie est que je n'ai jamais compté dans la littérature française" (Sherard 83; quoted in Boia 11). Sherard, Robert, "Jules Verne, sa vie et son travail racontés par luimême." Entretiens avec Jules Verne, 1873-1905, compiled by Daniel Compère, Jean-Michel Margot and Sylvie Malbrancq. Genève: Slatkine, 1998.

Also, Read Boia (11-15) for a detailed understanding of how Verne was elbowed out of canonical French literature. For a very long time Verne's literary popularity remained relatively stable "au niveau le plus bas" ['at the lowest level'] (13).

Platten, David. "A Hitchhiker's Guide to Paris: Paris au XXe siècle." Jules Verne: Narratives of Modernity, edited by Edmund Smyth, Liverpool: Liverpool University Press, 2000, pp. 78-93. 78.

24 "sans aucune importance dans le mouvement littéraire contemporain." Zola, Emile. "Jules Verne." Le Figaro littéraire, 22 Dec. 1878. Quoted in Evans (14). Evans, Arthur B., "Jules Verne and the French Literary Canon." Narratives of Modernity, edited by Edmund Smyth. Liverpool: Liverpool University Press, 2000, pp. 11-39.

Read Unwin (Journeys 16-19) for an overview of how by "the late twentieth century Verne's literary interest, in France at least, was no longer in question." By this time Verne "is firmly established as a 'respectable' literary figure" (18.)

26 All throughout Journeys, Unwin draws analogies between Verne's writing style and the exploration of unknown territories that are the subject of Extraordinary Voyages. While Unwin's response to Barthes ("travel is text, that text is travel"), which I quote above, serves perhaps as a signature example of Unwin's comparison, there are several similar instances. In the first chapter Unwin counters, for example, attempts to pigeonhole Verne as a writer of science fiction. Verne's novel approach of foregrounding science and technology and his reliance on "massive scientific and technological discourses" (13) makes for literary material that cannot be explained by prevalent understanding of literary criticism. Labelling Verne as a writer of science fiction only amounts to imposing prefabricated definitions on a writer who was exploring newer literary territories. It is this "concerted exploration of literature and its boundaries," Unwin points out, that "is mirrored by, and mirrors, the central theme of the Voyages extraordinaires, namely, the exploration of the geographical 'margins' of nineteenth-century civilisation" (16). There are several other moments when Unwin equates Verne's writing to the discoveries depicted in his novels, but I shall stop with this last one: "Words are everywhere; text is ubiquitous. Nature herself is a vast dictionary full of wondrous and exotic terminologies" (52).

27 Unwin laments that for an English language critic analysing Verne's original French text there is limited "scholarship in English devoted to close textual analysis and to critical readings of him as a writer and a stylist" (Journeys 3-4). 
Journeys p. 2; my emphasis.

In Journeys Unwin points out that "the text itself is an intertext made up of, and leading back to, infinitely many other texts"(32); "Verne works from text, through text, and back into text" (53).

Youngs, Tim. Beastly Journeys: Travel and Transformation at the Fin de Siecle. Liverpool: Liverpool University Press, 2014.

Youngs, Tim. Travellers in Africa: British Travelogues, 1850-1900. Manchester: Manchester University Press, 1994. Tim Youngs is commenting on British travelogues about Africa in the second half of the nineteenth century. The underlying premise can also be extended to other European writers exploring other parts of the colonial world. Here is the full quotation for context: "These authors wrote about Africa in the way they did because of their growing, if sometimes subliminal, unease with changes in the Britain they thought they knew so well" (1).

I rely on Bongie's explanation of exoticism in Exotic Memories.

Refer discussion about Fogg at the beginning of the first chapter.

Hetzel would edit out "tout ce qui semblait légèrement controversé, qu'il soit d'ordre politique, violent ou sexuel." ['all that seemed even slightly controversial, be it of political, violent or sexual order.'] Butcher, W. "Un Espace vierge: Les manuscrits du 'Tour du monde." Studi Francesi, vol. 48, no. 142, 2004, pp. 108-17.

Hetzel altered Verne's manuscripts to make them more marketable and acceptable to the readership. For instance Hetzel had "his eye on Verne's growing Russian market, and before releasing Michel Strogoff, he consulted both the novelist Ivan Turgenev and the Russian embassy in Paris to make sure it would not cause offence to tsarist readers" (59).

Lyons, Martyn. Reading Culture and Writing Practices in Nineteenth-Century France. Toronto: University of Toronto Press, 2008.

London Times Literary Supplement $(1972,1391)$ cited on p. 131 of Phillips, Richard. Mapping Men and Empire: A Geography of Adventure. London: Routledge, 1997.

In attempting to understand why Verne has been simplified as a writer, Philips makes a similar argument: "Thus, the dominant reading of Verne is supported by the biographical construction of the author as a man who loved excitement and faraway places, and was uninterested in politics" (131).

"Jules Verne a eu deux passions dans sa vie: le théâtre [...] Deuxième passion: la géographie [...] les voyages [...] voyager sur la carte, voyager par les livres, voyager en écrivant. [...] Tout Jules Verne est là. Tout chez lui est prétexte pour la géographie et pour une intrigue combinant des destins individuels, et beaucoup moins ou pas du tout des problèmes d'ordre social ou national." (26-29; 96)

"point fort de Jules Veme n'est pas l'étude de la société" (16).

Bastié, Jean. "Jules Verne et la Société de Géographie." Jules Verne, voyageur extraordinaire: A la découverte des mondes connus et inconnus by Jean-Yves Paumier. Grenoble: Glénat, 2005, p. 5.

Bastié points out how In Twenty Thousand Leagues under the Sea, Verne even tipped his literary hat at the Society for Geography: as part of Captain Nemo's library is also found the collection of Bulletins of the Society for Geography. The Bulletin has been in publication at regular intervals since 1822. It published Verne's writing and also served as a source for his literary works. 
Thompson, Ian B. “Jules Verne, Geography and Nineteenth Century Scotland." Zvi Har'El's Jules Verne Collection, 23 Dec. 2007. julesverne.ca/jv.gilead.org.il/ithompson/geography. html. French version of the article published in: La Géographie: Acta Géographica, Dec. 2003, pp. 48-71.

43 Berdoulay is referring to: Verne, Jules. Géographie illustrée de la France et de ses colonies... précédée d'une étude sur la géographie générale de la France par Théophile Lavallée. Paris: J. Hetzel, 1900.

Berdoulay, Vincent R.H. "Geography in France: Context, Practice and Text." Geography: Discipline, Profession, and Subject since 1870: An International Survey, edited by Gary S. Dunbar. Dordrecht: Springer, 2001, pp. 45-78.

Humeau, D. “Les dimensions géographique dans l'œuvre de Jules Verne." Géographie et Cultures, vol. 15, 1995, pp. 21-44.

45 Barthes, Roland. "The Nautilus and the Drunken Boat." Mythologies. Trans. Annette Lavers. New York: Noonday Press, 2007, p. 65.

46 Dupuy, Lionel. Jules Verne, l'homme et la terre: La mystérieuse géographie des voyages extraordinaires. Dole: Clef d'argent, 2006.

47 Reclus, Elisée. L'homme et la terre. Paris: Libr. universelle, 1905.

48 Dupuy's original: "dépeindre la terre dans sa globalité" (19).

49 Dupuy's original: "une forme d'écologie humaine avant l'heure" (16).

50 While the title of Dupuy's monograph, Jules Verne, l'homme et la terre, pays homage to Reclus, the introduction pays close attention to the coincidences that brought Verne and Reclus together. For instance, Dupuy remarks that both Verne and Reclus died in 1905 (15), and also that the two shared a mutual interest in Esperanto (21). Dupuy's intention is not to show a methodological affinity but to bring forth coincidental similarities between Verne and Reclus.

51 Dupuy mentions briefly the political difference between Verne and Reclus: "Jules Verne et Élisée Reclus se sont rencontrés et étaient amis, même si à l'époque de la Commune ils ont eu des positions opposées." ['Jules Verne and Elisée Reclus met each other and were friends, even though during the Commune, they held opposing positions.'] (20).

52 For more on Reclus' participation in the Commune read pp. 60-61 of: Ross, Kristin. "Rimbaud and Spatial History." New Formations, no. 5 (Summer 1988), pp. 53-68.

53 Verne not only sourced his information but also copied language from Reclus' work. Dupuy discusses Verne's plagiarism of Reclus' work in "L'imaginaire géographique au cœur d'un voyage extraordinaire: Le Superbe Orénoque de Jules Verne." Géographie et cultures, 2010, pp. 175-188. https://doi.org/10.4000/gc.1654.

John Breyer and William Butcher also comment on how Verne borrows for Journey to the Centre of the Earth (in a "widespread and blatant" manner) from the work of the technical and scientific writer Louis Figuier.

Breyer, John, and William Butcher. "Nothing New Under the Earth." Earth Sciences History, vol. 22, no. 1, 2003, pp. 36-54. https://www.jstor.org/stable/24136985.

54 For a difference between the two geographers and their participation in the early years of the development of the discipline read Ross, "Rimbaud."

55 Mercier, Guy. "Vidal de la Blache." International Encyclopedia of Human Geography, edited by Rob Kitchin and Nigel Thrift, vol. 12, 2009, pp. 147-50. Hosted on ScienceDirect.com. https://www.sciencedirect.com/science?_ob=RefWorkIndexURL\&_idxType=GI\&_ci$\mathrm{d}=278622 \& \mathrm{md} 5=32517 \mathrm{e} 01 \mathrm{fbc} 4 \mathrm{a} 53788 \mathrm{~cd} 2 \mathrm{e} 200373 \mathrm{f} 986$. 
Carr, Helen. "Modernism and Travel (1880-1940)." The Cambridge Companion to Travel Writing, edited by Peter Hulme and Tim Youngs. Cambridge, U.K.: Cambridge University Press, 2002, pp. 70-86.

Thompson very briefly touches upon how Verne's "personal travels were to make settings for several novels [...] but the vast majority of his books were set in [geographical] areas outside his experience."

Terry Harpold gives a very brief account of Verne's travels. Harpold wants to "dispense with the tiresome canard that Jules Verne never traveled far from his homes in Nantes, Paris, Crotoy, and Amiens" (18). It was only in the late 1880s that age forced Verne to restrict his travels. Harpold, Terry. "Verne’s Cartographies." Science Fiction Studies, vol. 32, no. 1, 2005, pp. 18-42. "ouvreur de routes et de révélateur de mondes" (Gracq 38; quoted in Chauvin). Butcher, William, and Sarah Crozier "Verne's Underground City: The Lost Chapters from Les Indes noires." www.ibiblio.org/julesverne/articles/undergroundcity.doc. Date of access - 1 December, 2019.

Butcher, in a section titled "Man and Less-Than-Man" (48-54), discuses Verne's attitudes toward other peoples: "the different [racial] groups are presented as varying in their degrees of modernity. Because they seem to embody stages of the past, the way might be open for exploring a significant ailleurs" (48).

Butcher, William. Verne's Journey to the Centre of the Self: Space and Time in the Voyages Extraordinaires. New York: St. Martin's Press, 1991.

Evans, Arthur. “Jules Verne’s America." Extrapolation, vol. 48 no. 1, 2007, pp. 35-43. (53).

Landy, Frédéric. "L'Inde de Jules Verne: Une lecture de La maison à vapeur." Géographie et cultures, no. 15, Autumn 1995, pp. 45-67.

McLaughlan, Robert. Re-Imagining the "Dark Continent" in Fin de Siècle Literature. Edinburgh: Edinburgh University Press, 2012.

Unwin points to the "familiar danger" of isolating Verne from his own work and cultural context. This would give "the unmistakable message that the writer cannot be dissociated from the activities of a nationally identifiable group of admirers" (Unwin Journeys; 5). Nonetheless, attempts have been made to analyze Verne's reception within specific geographical boundaries.

Costello, Peter. Jules Verne, Inventor of Science Fiction. New York: Scribner, 1978. Cited on p. 133 of: Phillips, Richard. Mapping Men and Empire: A Geography of Adventure. London: Routledge, 1997.

In the first of a three article series, Gehu comments on how Verne "a contemplé, en dedans de lui, les mornes solitudes de l'hyperborée; écouté la voix des banquises; médité la nuit polaire. [...] Il eut l'âme de tous les pionniers du désert blanc [...] Il a mis cette âme dans son récit" (182). Géhu. Edmond-P. "La Géographie polaire dans l'œuvre de Jules Verne: Aventures du capitaine Hatteras." Bulletin de la Société Jules Verne, vol. 9 (December 1937), pp. 181-98.

67 Ruins are "l'expression d'une véritable poétique de l'espace qui révèle un imaginaire géographique où l'homme éprouve la vulnérabilité de sa vie et de son œuvre face au temps" (50). Dupuy, Lionel. "Poétique de la ruine et imaginaire géographique dans les Voyages extraordinaires de Jules Verne." Sociétés, vol. 120, no. 2, 2013, pp. 49-59.

68 The desire to "occuper l'étendue immense de l'espace physique ou conceptuel." Butcher, William. "Etranges voyages de la Ligne: Fleuves, logos et logiques dans les Voyages extraor- 
dinaires." Zvi Har'El's Jules Verne Collection, http://www.ibiblio.org/julesverne/articles/ etranges.pdf. Originally published in: Jules Verne et la modernité, edited by Jean Bessière. Université de Picardie with Presses Universitaires de France, 1988, pp. 123-38.

Dupuy, Lionel, "L'imaginaire géographique au cœur d'un Voyage Extraordinaire: Le Superbe Orénoque de Jules Verne.” Géographie et cultures, vol.75, 2010, pp. 175-88. gc.revues.org/1654. For examples read: Dupuy "Superbe Orénoque de Jules Verne."

Yet another important set of studies concentrate on the scientific sources that Verne used in order to add layers to his spatial adventures. We now know, for example, that in Journey to the Centre of the Earth, "a large part of the scientific information in Verne's novel was taken directly from the 1863 work [Louis Figuier's La Terre avant le déluge]. This includes both the specific scientific details incorporated in the novel and the general worldviews espoused by the protagonists" (Breyer and Butcher, "Nothing New Under the Earth").

72 "le regard d’un géographe" (17).

73 For more, read: Dupuy En Relisant, pp. 29-46.

74 For example, in reading Le Tour du monde en quatre-vingts jours, Dupuy shows how this journey is not only a "voyage contre le temps" ['journey against time'] but also a "voyage dans le temps" ['journey in time'] (En relisant 57). By a voyage against time, Dupuy refers to Fogg's race against the clock, or, if we look at the eighty day journey, it is a race against the calendar. By voyage in time, Dupuy refers to the protagonists' journey across countries and various geographical spaces. These locales, through their historical, economical and social state, point to the stages of human evolution across time.

75 "magnifique métaphore écologique" (En relisant 102).

76 "une nouvelle Géographie Sociale" (Humeau 39).

77 "un espace géographique cohérent en osmose avec la nature" (Humeau 41).

78 "certaines des dimensions géographiques qui dominent l'œuvre de Jules Verne“ (22).

79 "ait mis en relief les oppositions subtiles entre possibilisme et déterminisme" (27).

80 "sa maîtrise progressive des forces naturelles" (Landy 51).

81 "les sociétés sont capables de dominer les milieux naturels les plus extrêmes" (Landy 52).

82 I summarize Humeau's discussion of Five Weeks in a Balloon (23-24).

83 Unwin also sees a similar parallel between Verne and Fergusson: "Like Verne with his index-cards, he [Fergusson] works from text and back into text” (Journeys 63).

Verne was fascinated with maps and cartography. Dozens of his works contain maps, which Verne either prepared himself or which were drafted under his supervision (Harpold 19-20). Maps do not just serve as secondary devices that one follows to understand the written text. Harpold argues that there are "textual passages that read like maps" (19). In an engaging reading, Harpold argues that Verne's "maps are always ambiguous and semiotically unstable objects" (19). Several others have analyzed the "rôle poétique" ['poetic role'] (Compère 69) of these maps, and their role in the "diffusion de savoirs géographiques" ['communicating geographical knowledge'] (Fontanabona). Among others, Butcher (1980) and Terrasse (1988) also discuss maps and cartography in Verne's work.

Compère, D. "Poétique de la carte." Bulletin de la Société de Jules Verne, vol. 13, no. 50, 1979, pp. 69-74.

Fontanabona, J. “La géographie de Jules Verne et ses cartes dans L'île Mystérieuse." M@ ppemonde, no. 97, 2010. http://mappemonde.mgm.fr/num25/articles/art10101.html.

Butcher, C.W. “Graphes et graphie: Circuits et Voyages extraordinaires dans l'œuvre de Jules Verne.” http://www.ibiblio.org/julesverne/articles/Graphes.pdf. Published in print as: 
"Graphes et graphie." Regards sur la théorie des graphes (Actes du Colloque de Cerisy, 1218 juin 1980). Lausanne: Presses polytechniques romandes, 1980, pp. 177-82.

Terrasse, Pierre. "Le Jeu de cartes de Jules Verne." Bulletin de la Société de Jules Verne (Nouvelle Série), vol. 22, no. 87, 1988, pp. 29-33.

Unwin comments extensively on Verne's relationship to his writing process. For instance, by "stepping outside of the diegetic process and showing it up for the artifice it is, Verne deliberately draws attention to the literary framework" (Journeys 10).

Phillips reads Verne not only against critical readings that dismiss the political relevance of Verne's work, but also against Verne's own personal political engagement, to show that the "geography of Verne's literature can be read as a site of resistance, including resistance to British imperialism" (137). Mukhopadhyay discovers a subversion of "narratorial authority of British imperial discourse," whereby, "these French novels [including Verne's] create an international, comparative, and interdisciplinary competition between literature and history, and between colonizing power and colonized territory" (Mukhopadhyay 120).

Mukhopadhyay, Indra. “Alexandre Dumas's and Jules Verne's India: The French Republic of Letters Discusses Imperial Historiography." France's Lost Empires: Fragmentation, Nostalgia, and La Fracture Coloniale, edited by Kate Marsh and Nicola Frith. Lanham, Md.: Lexington Books, 2011, pp. 111-23.

Chesneaux points out that the titles of Verne's novels "représentent un corpus original et riche, à la mesure de cette œuvre elle-même" ['represent an original and a rich corpus, at par with his body of work'] (25). Chesneaux, Jean. "Les Titres des romans verniens: Variantes, résonances et occurrences." Actes du colloque de Cerisy, Jules Verne: Cent ans après, edited by Jean-Pierre Picot and Christian Robin. Rennes: Terre de Brume, 2005, pp. 25-33.

"Circonférence d'un corps, d'un lieu plus ou moins circulaire; mesure de cette circonférence" ['Circumference of a body, of a place more or less circular; measurement of this circumference']. “Tour." Trésor de la Langue Française. Le Trésor de la Langue Française Informatisé. http://atilf.atilf.fr/tlf.htm.

"Mouvement, déplacement (à peu près) circulaire où l'on revient au point de départ" ['Movement, displacement (more or less) circular such that one returns to the point of departure']. “Tour." Trésor de la Langue Française. Le Trésor de la Langue Française Informatisé. http:// atilf.atilf.fr/tlf.htm.

One could make a similar argument about the title of Five Weeks in a Balloon that we have discussed above. We are reminded that both Verne as well as his travelers "somewhat naively reflect the racist and ethnocentric prejudices which at that time provided convenient justification for colonial expansion" (Chesneaux 112). This title combines units used for measurement of time, "five weeks," along with a means of travel, "balloon," that allows to judge locations without the need for contact. One could say that just as these three travelers are skimming over the surface of Africa, making scientific observations from afar, so does Verne remain engaged with the popular version of geography as a discipline.

91 When Passepartout is introduced in the novel as possessing multiple skills (among them a wandering singer and a trapeze artist), one expects him already to be Fogg's passport to success $(12 ; 10)$. Indeed, it is only through Passepartout's resourcefulness that Fogg is able to navigate his way around the world. Passepartout's skills also play a central role in Aouda's rescue in India, and also later in saving the life of his companions during an attack by the Sioux in America. And does the fact that it is Passepartout who literally drags his master 
across to the Reform Club at the very last minute, not say something about him being the master key to the Reform Club and a passport to Fogg's victory?

As Fogg is always engrossed in himself, if and what he's "thinking" no one knows, but Passepartout's many "doings" provide for several humorous interludes. His trouble with the law after he enters a temple wearing his footwear, in contravention of local custom, is only one of many examples.

Ray Bradbury sees the duo as two complements of "thinking and doing" (ix). Bradbury, Ray. "Introduction." Around the World in Eighty Days by Jules Verne. Los Angeles: Plantin Press, 1962, pp vii-xii.

If, as Lefebvre points out, Nietzsche found the visual to be "predominant in the metaphors and metonyms that constitute abstract thought: idea, vision, clarity, enlightenment and obscurity, the veil, perspective, the mind's eye, mental scrutiny, the 'sun of intelligibility', and so on" (139), then Verne's (Nietzsche's contemporary) description with its abundant insistence on the visual only broadens this discovery to include fiction as well.

The "global economy is a structure that is being created by the process of globalization. The structure invites compliance from states, corporations, and other organizations in the global economy; in turn, the actions that comprise that compliance enhance the process of globalization and so strengthen the structure of the global economy. The global economy, then, is a structure that is being produced by the actions of states, corporations, and other organizations; actions that are in response to existing conditions. In this interpretation, state actions and the global economy are causing one another" (510). Webber, Michael. "International Political Economy." A Companion to Economic Geography, edited by Eric Sheppard and Trevor J. Barnes. Oxford: Blackwell Publishers, 2003, pp 499-518. ebook. Read for further understanding of the relationship between nation-states and international economic structures.

Baudelaire, Charles. Les Fleurs du mal. Paris: Poulet-Malassis et de Broise, 1857, pp. 105-6. Since the discussion engages with the semantic field of the poem written by Baudelaire, I furnish above my own literal translation. Walter Martin translates the same stanza as following: And opium, can show how heavens move,

Distend infinity,

Intensify the hours, and let us see

The emptiness of love,

Then nauseate the soul with ecstasy.

Baudelaire, Charles. "Le Poison." Complete Poems. Trans. Walter Martin. New York: Routledge, 2002, pp. 128-9.

In a letter, his stepfather, General Aupick, shares his concerns with Charles Baudelaire's older brother: "It is urgent to remove him [Charles Baudelaire] from the slippery slope of Paris. People advise me to have him take a long sea voyage, to the Indies and India." (quoted in Culler, 79). Also, interestingly, despite the fact that he himself never "referred in print to his voyage afterwards or speak of it to his friends" (Culler 83), this voyage became the subject of many an interesting story. Théophile Gautier "even maintained amazingly, that Baudelaire had been born in India and that recurring thoughts often took him back there, to his youthful paradise" (Culler 84).

Culler, Jonathan. “'Trouver du nouveau ?': Baudelaire's Voyages." The Poetics and Politics of the Modern Journey, edited by John Zilcosky. Toronto: University of Toronto Press, 2008, pp. 79-97. 
For a brief account of Baudelaire disembarking at Mauritius and abandoning "Captain Seliz and his crew because he has the firm intention of catching the next ship back to France" (160), read: Lionnet, Françoise. "Reframing Baudelaire Literary History, Biography, Postcolonial Theory, and Vernacular Languages." French Cultural Studies: Criticism At the Crossroads, edited by Marie-Pierre Le Hir and Dana Strand. Albany: State University of New York Press, 2000, pp. 153-83.

Grasso, June, Jay Corrin, and Michael Kort. Modernization and Revolution in China: From the Opium Wars to World Power. New York: East Gate, 2004, p. 29.

The above quotation is my adaptation of Butcher's translation from Le tour (96-7). This adaptation reflects better the effect produced by the geographical nouns used by Jules Verne. In Lefebvrian terms, this domination of space through the increasing spread of technology exemplifies the introduction of "a new form into a pre-existing space - generally a rectilinear or rectangular form such as a meshwork or chequerwork" (Production 165).

"The Portuguese, the first European traders to arrive, were restricted by the Ming dynasty to Macao, a fortified port the Portuguese built near the Chinese city of Guangzhou." (Grasso et al. 28).

"Céleste," Le Trésor, http://atilf.atilf.fr/. "Qui appartient à Dieu, qui vient de Dieu, divin" ['That which belongs to God, which comes from God, divine']. Also "Celestial," Collins Dictionary Online, http://www.collinsdictionary.com/dictionary/english/celestial-empire. "Celestial Empire: an archaic or literary name for the Chinese Empire."

Today, as when Jules Verne wrote, Great Britain is the island that has England as one of its components. "Great Britain, also called Britain, island lying off the western coast of Europe and consisting of England, Scotland, and Wales. The term is often used as a synonym for the United Kingdom, which also includes Northern Ireland and a number of offshore islands." "Great Britain”. Encyclopedia Britannica Online. http://www.britannica.com/place/ Great-Britain-island-Europe.

The movement from Angleterre to Grande Bretagne plays an important role with the prefix "Grande" already making evident its increasing stature vis-à-vis Hong Kong. I italicize Grande or Great to highlight how the transition from Angleterre to Grande Bretagne plays an important role. "Grande" increases the colonizer's stature vis-à-vis Hong Kong. "England strictly refers to a single political division of Great Britain, but it is commonly substituted for (Great) Britain ..." "Britain," Fowler's Concise Dictionary of Modern English Usage, edited by Jeremy Butterfield. Oxford: Oxford University Press, 2015, p. 94. Foucault, Michel. "L’Arriere-fable." L'Arc 29, 1966, pp. 5-12. 7-8.

"The idea of a sociological organism moving calendrically, through homogenous, empty time is a precise analog of the empty time of the nation, which also is conceived as a solid community moving steadily down (or up) history." Anderson, Benedict. Imagined Communities. New York: Verso, 1991, p. 26.

Hong-Kong, Nanking, England, Great Britain, Victoria Harbour, Canton, Macao, Kent, Surrey, China, Celestial Empire, Bombay, Calcutta and Singapore.

small island, port, island, bank, city, docks, hospitals, cathedral, Government House, roads, etc.

110 Lomax, Elizabeth. "Uses and Abuses of Opiates in Nineteenth Century England." Bulletin of the History of Medicine, vol. 47, no. 2, 1973, pp. 167-76. 167.

111 Greenberg, Michael. British Trade and the Opening of China 1800-42. Cambridge, U.K.: Cambridge University Press, 1951, p. 110. 
Apart from Lomax, many others have researched on the effects of opium on nineteenth-century Britain. Louise Foxcroft, for example also speaks (80-82) about the unintended death of infants because of unregulated opium use. In addition to the legal changes that Lomax details, Foxcroft gives an account of the standing that opium had among medical professionals in Britain. Foxcroft, Louise. The Making of Addiction: The 'Use and Abuse' of Opium in Nineteenth-Century Britain. Aldershot: Ashgate, 2007.

Phipps, J. "Introduction." A Practical Treatise on the China and Eastern Trade. Calcutta: Baptist Mission Press, 1835. Quoted in Greenberg, p. 104.

"The British arrived in China in 1637 and were permitted to establish a trading post at the city of Guangzhou" (Grasso 28).

Owen, David Edward. British Opium Policy in China and India. Hamden, Conn.: Archon Books, 1968, p. 194.

Le Failler, Philippe. Monopole et prohibition de l'opium en Indochine: Le pilori des chimères. Paris: L'Harmattan, 2001.

Read Le Failler, in particular chapter 1, "La question de l'Opium en Extrême-Orient" for further discussions on the India - China opium link.

"la Chine devint déficitaire au profit de l'Inde" (Le Failler 34).

For more read: Marx, Karl. "Free Trade and Monopoly." New York Daily Tribune, 25 Sept. 1858. http://www.marxists.org/archive/marx/works/1858/09/25.htm. Marx, Karl. “Trade or Opium?” New York Daily Tribune, 25 Sept. 1858. http://www.marxists.org/archive/marx/works/1858/09/20.htm. (Also quoted in Failler, 34).

"La flotte de clippers faisant le trajet Calcutta - Singapour - Chine double entre 1842 et $1858[\ldots]$ intervalle qui s'étend entre les deux guerres de l'opium fut l'age d'or des grands marchands" (Le Failler 45).

"Il n'est pas excessif de considérer le trafic de l'opium comme le commerce fondateur de la colonie" (Le Failler 46).

When a war fought for the continuation of British trade in opium forces these scattered elements into a chain of uniformity, they all exemplify homogenization imposed by abstract space that "subsumes and unites scattered fragments or elements by force" (Lefebvre, Production 308). For there "is no need to subject modern towns, their outskirts and new buildings, to careful scrutiny in order to reach the conclusion that everything here resembles everything else" (Lefebvre, Production 75).

124 Read: Benjamin, Walter. "Work of Art in the Age of Mechanical Reproduction." Illuminations, edited with an introduction by Hannah Arendt. Trans. Harry Zohn. New York: Schocken Books, 1977.

25 Jennifer Hayward: "paralleling nineteenth-century capitalism in that both require an investment of time and money - along with the confidence that such expenditure will be rewarded in the long run - and both privilege abundance, even excess [...] both serial novels and capitalism institutionalize delayed gratification, while the serial re-creates fiction in capitalism's image by providing what is essentially a payment plan for narrative, thus simultaneously increasing audience and profits and lowering costs" (29). Hayward, Jennifer. Consuming Pleasures: Active Audiences and Serial Fictions from Dickens to Soap Opera. Lexington: University Press of Kentucky, 1997.

Marez, Curtis. Drug Wars: The Political Economy of Narcotics. Minneapolis: University of Minnesota Press, 2004, p. 46. Marez also mentions how this literature of opium den narratives "doesn't just ignore British responsibiliy for the opium trade but actively disavows it" (63). 
Hsu, Immanuel C. Y. The Rise of Modern China. New York: Oxford University Press, 1995. Quoted in Marez, 46.

Chesneaux, Jean. The Political and Social Ideas of Jules Verne. Trans. Thomas Wikeley. London: Thames and Hudson, 1972, p. 123.

Acting in the name of the queen, he would later arrest Phileas Fogg: "Au nom de la reine, je vous arrête!' ['In the Queen's name, I arrest you'] (279; 188).

When Butcher translates this sentence as "Fix pushed one into Passepartout's hand," he misses out on the connotation of surreptitiousness which the French verb 'glisser' communicates. I find the English verb 'to slip' more appropriate here.

But what exactly is she transformed from? While the text never explicitly states so, Phileas Fogg's remorseful regret for having brought Aouda to London explains India's position: we are reminded that India, for Aouda, had "devenue si dangereuse" ['become so dangerous'] (289; 194).

32 There is also some identity confusion at play in the novel. Predictably enough, Aouda (an almost European woman), even when identified with the indigenous people, belongs to the most elevated of all racial categories: "Elle était, en effet, de cette race qui tient le premier rang parmi les races indigènes" ['She did indeed belong to that race which ranks highest among the races of India'] $(118 ; 81)$. How Parsi, a religious category, might conform to the definition of a race is a question that necessarily begs discussion but this detour risks to take us away from the geographical analysis of opium. Suffice to say that in this hierarchy lies the facile racism that reduced the world into a hierarchy of species where Europe and European identities hold sway.

"By 'partial' I mean both 'incomplete' and 'virtual'. It is as if the very emergence of the 'colonial' is dependent for its representation upon some strategic limitation or prohibition within the authoritative discourse itself" (Bhabha 235-6). Historically speaking, Bhabha points to such an articulation of perceived exclusivity of the self as symptomatic of Verne's epoch. "The colonial discourse that articulates an interdictory 'otherness' is precisely the 'other scene' of this nineteenth-century European desire for an authentic historical consciousness" (Bhabha 240). Bhabha, Homi K. The Location of Culture. New York: Routledge, 1994.

Hong Kong as colonial mimicry thus is produced "at the site of interdiction" such that apart from "what is known and is permissible [...] [there is also] that which though known must be kept concealed" (Bhabha 239).

Appadurai, Arjun. "Grassroots Globalization and the Research Imagination." Globalization, edited by Arjun Appadurai. Durham, N.C.: Duke University Press, 2001, pp. 1-21. Also read Appadurai from 1996, when he presents how the "very system of nation-states is in jeopardy" (19). "The locality (both in the sense of the local factory or site of production and in the extended sense of the nation-state) becomes a fetish that disguises the globally dispersed forces that actually drive the production process" (42). Appadurai, Arjun. Modernity at Large: Cultural Dimensions of Globalization. Minneapolis: University of Minnesota Press, 1996.

Le tour, pp. 18-19; Around, p. 15.

According to P. Schulman the words "excentrique" and "excentricité" are used 12 times to describe Fogg (34). Schulman, P. "Autour de l'excentricité de Phileas Fogg et du Capitaine Nemo." Bulletin de la Société Jules Verne, vol. 123, 1997, pp. 33-6.

"des cercles dont les centres ne se rapportent pas" ['circles whose centers do not correspond'] (34). 
139

140

\section{Chapter 3 - Dislocating the Indian Nation: Ananda Devi's Homelands}

1

Devi, Ananda. Quand la nuit consent
lation by Kazim Ali (2021) p. 67.

2 Glissant, Edouard. Tout-monde. Paris: Gallimard, 1993, p. 29. Translation by Bongie (1999) p. 434 .

Baudrillard, Jean. Simulacra and Simulation. Trans. Sheila Faria Glaser. Ann Arbor: University of Michigan Press, 1994, pp. 12-13.

4 My translation of "processus de synthèse et de syncrétisme" that Devi speaks about in an interview: Sultan, Patrick. "Ruptures et héritages: Entretien avec Ananda Devi." 3 Aug. 2000. http://orees.concordia.ca. Quoted in Tyagi, Ritu. Ananda Devi: Feminism, Narration and Polyphony. Amsterdam: Rodopi, 2013, p. 15. Wayback Machine, https://tinyurl. $\mathrm{com} / \mathrm{pu} 6372 \mathrm{nb}$.

5 Devi, Ananda. Le Voile de Draupadi. Paris: Harmattan, 1993.

6 Devi, Ananda. L'arbre fouet: Roman. Paris: L'Harmattan, 1997.

7 Devi, Ananda. Indian Tango: Roman. Paris: Gallimard, 2007.

$8 \quad$ Devi, Ananda. L'Ambassadeur triste: Nouvelles. Paris: Gallimard, 2015.

$9 \quad$ Devi, Ananda. Rue la Poudrière. Abidjan: Nouvelles Editions Africaines, 1988.

10 Devi, Ananda. Les Jours Vivants: Roman. Paris: Gallimard, 2013.

11 It is Lionnet who attests to the real-life existence of a street named rue de la Poudrière "written with the 'de' that the local Creole colloquial speech eliminates [...] Until the 1950s the street was frequented by prostitutes" (56). Lionnet, Françoise. "Evading the Subject: Narration and the City in Ananda Devi's Rue la Poudrière." Postcolonial Representations: Women, Literature, edited by Françoise Lionnet. Ithaca: Cornell University Press, 1995, pp. 48-68. Tyagi, Ritu. "Rethinking Identity and Belonging: 'Mauritianness' in the work of Ananda Devi." Islanded Identities: Constructions of Postcolonial Cultural Insularity, edited by Maeve McCusker and Anthony Soares. Amsterdam: Rodopi, 2011, pp. 91-108.

"Born in a family of Indian origin, Devi is the first writer to bring the plight of Hindu women in Indo-Mauritian society to the fore" (Tyagi 2013; 18).

14 Elsewhere in this project I also discuss the signification of Marie-Sophie's name in the context of Texaco.

15 Bragard, Véronique. Transoceanic Dialogues: Coolitude In Caribbean and Indian Ocean Literatures. Brussels: P.I.E. Peter Lang, 2008.

16 Dash says: "Glissant never ceases to affirm, 'le lieu est incontournable' - meaning that place can neither be gotten rid of nor can its contours even become fully known" (113). Dash, J. M. "Rev. of Soundings in French Caribbean Writing since 1950, the Shock of Space and Time, by Mary Gallagher." International Fiction Review, vol. 32, nos. 1-2, 2005, pp. 112-14.

Bongie translates this as "sense of place is uncircumventable" (434). Bongie, Chris. Islands and Exiles: The Creole Identities of Post/colonial Literature. Stanford, Calif: Stanford University Press, 1998. 
See the introduction and the chapter on Texaco in this book for a better understanding of Glissant's use of the term "relation."

Glissant, Edouard. Une journée avec Édouard Glissant. Paris: Association lacanienne internationale, 2009.

Gallagher, Mary. “Introduction: Between 'Here' and 'There', or the Hyphen of the Unfinished Things." Ici-là: Place and Displacement in Caribbean Writing in French, edited by Mary Gallagher. Amsterdam: Rodopi, 2003, pp. xiii-xxix.

Belugue, Geneviève, "Du lieu incontournable à la relation." Poétiques d'Édouard Glissant. Actes du colloque international Paris-Sorbonne, 11-13 mars 1998, edited by Jacques Chevrier. Paris: Presses de l'Université de Paris-Sorbonne, 1999, pp. 43-54.

"une esthétique du Divers"; “où tout est lié et se répond” (Belugue 52).

Germain, Gilbert G. Spirits in the Material World: The Challenge of Technology. Lanham, Md.: Lexington Books, 2009. I rely on Germain's understanding of Baudrillard.

Germain elaborates further: "Baudrillard's account of the evolution of value in capitalist society stresses its progressive abstraction or spiritization. Whereas the value of produced goods used to be tied to 'real world' considerations such as utility and exchange, goods now are mere ciphers for their appended signs, signs which acquire meaning through their commutation with other equally disembodied, or referentless, signs" (43).

Ferly, Odile. A Poetics of Relation: Caribbean Women Writing at the Millennium. New York: Palgrave Macmillan, 2012.

For a more elaborate reading of Ferly's work in its context consult: Chandna, Mohit. "Re-Reading Postcolonial Women Authors." International Journal of Francophone Studies, vol. 18, no. 4, 2015, pp. 521-4.

All translations of Ananda Devi's 2uand la nuit consent à me parler belong to Kazim Ali's translation: Devi, Ananda, Quand la nuit consent à me parler. Trans. Kazim Ali. When the Night Agrees to Speak to Me. Noida: Harper Collins, 2021.

Devi, Ananda. "Flou identitaire." Je est un autre: Pour une identité-monde, edited by M Le Bris et al. Paris: Gallimard, 2010, pp. 179-86.

Diawara (whose reading I present) discusses how Senghor's "defense of assimilation rests on a view of the world centered around France" (459).

Mudimbe, V Y. L'Autre face du royaume: Une introduction à la critique des langages en folie. Lausanne: Éditions L’Age d'homme, 1973. Quoted in Diawara (458).

For a more detailed discussion read pp. 1-16. Fançois, Anne M. Rewriting the Return to Africa: Voices of Francophone Caribbean Women Writers. Lanham, Md: Lexington Books, 2011. Elsewhere, in a review of François' book, I contextualize Rewriting within the larger Francophone canon. Read: Chandna, Mohit. "Rev. of Rewriting the Return to Africa, by Anne M. François." International Journal of Francophone Studies, vol. 15, no. 2, 2012, pp. 324-26. Quoted in François, Rewriting 13.

For a summary of criticism on "Fanon's sexual politics within the colonial experience" (22) read Chantal Kalisa. Kalisa divides the critics into two groups. The first group uncovers "Fanon's patriarchal and sexist attitudes toward women in general." The second group, which includes Homi Bhabha, "apologizes for Fanon's blindness to women's position" (23). McClintock, Anne. "No Longer in a Future Heaven': Gender, Race and Nationalism.” Dangerous Liaisons: Gender, Nation, and Postcolonial Perspectives, edited by Anne McClintock, Aamir Mufti and Ella Shohat. Minneapolis: University of Minnesota Press, 1997, pp. 89112. 
Fanon, Frantz. Sociologie d'une révolution (L'an V de la révolution algérienne). Paris: François Maspero, 1972. Hosted at the University of Québec at Chicoutimi website. http://classiques.uqac.ca. Pagination follows the electronic version. English translation: Fanon, Frantz. A Dying Colonialism. Trans. Haakon Chevalier. New York: Grove Press, 1967. Wherever Chevalier's translation is incommensurate with my readings, I furnish my own. Otherwise, all translations from Fanon's Sociologie are by Chevalier.

'The veil protects, reassures, isolates. One must have heard the confessions of Algerian women or have analyzed the dream content of certain recently unveiled women to appreciate the importance of the veil for the body of the woman. Without the veil she has an impression of her body being cut up into bits, put adrift; the limbs seem to lengthen indefinitely. When the Algerian woman has to cross a street, for a long time she commits errors of judgment as to the exact distance to be negotiated. The unveiled body seems to escape, to dissolve. She has an impression of being improperly dressed, even of being naked. She experiences a sense of incompleteness with great intensity. She has the anxious feeling that something is unfinished, and along with this a frightful sensation of disintegrating. The absence of the veil distorts the Algerian woman's corporal pattern. She quickly has to invent new dimensions for her body, new means of muscular control. She has to create for herself an attitude of unveiled-woman-outside. She must overcome all timidity, all awkwardness (for she must pass for a European), and at the same time be careful not to overdo it, not to attract notice to herself. The Algerian woman who walks stark naked into the European city relearns her body, re-establishes it in a totally revolutionary fashion. This new dialectic of the body and of the world is primary in the case of one revolutionary woman. But the Algerian woman is not only in conflict with her body. She is a link, sometimes an essential one, in the revolutionary machine. She carries weapons, knows important points of refuge. And it is in terms of the concrete dangers that she faces that we must gauge the insurmountable victories that she has had to win in order to be able to say to her chief, on her return: "Mission accomplished ... R.A.S"' (59-60). Haakon Chevalier translates this title as "Algeria Unveiled" (35).

37 Chantal Kalisa also takes up the implications of this title in relation to the change in connotations that are brought about when the title is translated from French to English. "The title in French points to the fact that Algeria (or the woman) is the subject of the action of unveiling, whereas the English title points to the objectification of Algeria (or the woman)" (n. 5 p. 190). Kalisa, Chantal. Violence in Francophone African and Caribbean Women's Literature. Nebraska: University of Nebraska Press, 2009.

Fanon, Frantz, Peau noire, masques blancs. Paris: Les Éditions du Seuil, 1952. Hosted at the Université du Québec à Chicoutimi website. Pagination is of the electronic version. http:// classiques.uqac.ca/classiques/fanon_franz/peau_noire_masques_blancs/peau_noire_ masques_blancs.pdf.

Fanon, Frantz. Black Skin, White Masks. Trans. Charles Lam Markmann. London: Pluto Press, 1986.

This is Kalisa's understanding of Gwen Bergner reading Fanon in: Bergner, Gwen. "Who Is That Masked Woman? Or, the Role of Gender in Fanon's Black Skin, White Masks." PMLA, vol. 110, no. 1, 1995, pp. 75-88. For more on this debate read Kalisa, p. 27. Kalisa furnishes further arguments to show "Fanon's lack of regard for the role of colonized women in decolonization movements" (28). 
Chevalier translates "son responsable" as 'her chief.' I do not agree with the translation, as it clearly is not responding to the gender specific French possessive adjective, "son," which agrees with the noun and here shows that the presumed gender of the supervisor is masculine. Emphasis added in English translation. Varma elaborates this argument in her discussion on Fanon and the postcolonial city (8-14). Varma, Rashmi. The Postcolonial City and Its Subjects: London, Nairobi, Bombay. New York: Routledge, 2012.

A similar argument, about women as bearers of a national identity, also appears in relation to Marie-Sophie from Texaco.

This reference, in the twenty-eighth poem, of a green-colored sari - a South-Asian wraparound garment for women - clearly evokes Ananda Devi's prize-winning novel, Le sari vert. "Well, I think I'm culturally hybrid definitely. I use lots of different routes, lots of different food, nourishment in my writing and even the language" (11). Hawkins, Peter. "An Interview with Ananda Devi." Wasafiri, vol. 26, no. 2, 2011, pp. 8-13.

Devi, Ananda. Interview by www.indereunion.net: www.indereunion.net/actu/ananda/interAnanda.htm\#Site.

"cet enfant n'avait plus beaucoup de temps à vivre" ['this child was not going to live for long'] (42).

"We're hemmed in more and more by our national identities, which become restrictive" (Hawkins 11-12).

"my mother also used to tell us stories from Hindu mythology, so in a way that has also fed into ... that storytelling" (Hawkins 9). Also: "Themes common to Hindu mysticism recur: ...destiny, reincarnation, spirituality, the cosmos. [...] It is Karma, the belief that every action, every intention is inscribed in the destiny of all living beings, which constitutes the background of all of Devi's characters." Cooper, Danielle Chavy. "Ananda Devi et le poids des êtres." Ninth Annual International Conference on Foreign Literature, 1992, Wichita State University. Quoted in Lionnet, p. 58. Original ellipses.

"La mer [...] cet océan Indien qui nous reliait à l'Inde" ['The sea [...] this Indian Ocean that linked us to India'] (150).

Mataji is an honorific term for mother. In Hindi as well as in other Indian languages, it is often used to refer to elderly women.

"Réfugiée derrière la parole de Gandhi, Mataji refuserait tout ce qui pourrait contredire l'illusion de la grande Inde philosophale" ['Taking refuge in Gandhi's words, Mataji would have rejected all that could contradict for her the illusion of a great philosophical India'] (37).

Walters, James. Baudrillard and Theology. London: T. \& T. Clark International, 2012.

Lefebvre talks about how driving a car on roads, laid with the objectives of speed and functionality, means moving along predetermined paths and directions. In order to manoeuvre this space, one relies on visual cues and can move in only one direction. It is thus that volume "leaves the field to surface" (Production, trans. 313 quoted in Inglis 206). For more on this read: Inglis, David. "Auto Couture: Thinking the Car in Post-war France." Automobilities, edited by Mike Featherstone, Nigel Thrift and John Urry. London: Sage, 2005, pp. 197-220. A similar argument has been made in Verne's context too.

"êtres assiégés" ['besieged beings']; "territoire diminuant" ['lands were shrinking']; "un espace délimité" ['area bounded from all sides'].

Borges, Jorge Luis. Collected Fictions. Trans. Andrew Hurley, New York: Viking, 1998. 
For more on this read Howells and Negreiros (133-4). Howells, Richard, and Joaquim Negreiros. Visual Culture. Cambridge, U.K.: Polity Press, 2012. A large number of scholars have cited Baudrillard's use of this fable, which alone stands as a testament to Borges' influence as well as to the pertinence of this fable as a signature moment of Baudrillard's work. I am citing Howells and Negreiros because they also link Baudrillard's usage of this fable to his evocation of Disneyland, something I have explored earlier in greater detail.

58 Harvey, David. Spaces of Hope. Edinburgh: Edinburgh University Press, 2000, p. 115.

59 Pawlett, William. Jean Baudrillard: Against Banality. London: Routledge, 2007.

60 Baudrillard, Jean. Symbolic Exchange and Death. London: Sage Publications, 1993, p. 111. Quoted in Pawlett, p. 99.

${ }_{61}$ Symbolic exchange, according to Andrew Robinson, is a term that Baudrillard uses to speak of "the exchange of signs with the real." Instead of living in today's capitalist society with production as the determinative function Baudrillard finds inspiration in earlier societies that "were simply outside the logic of production." Not determined by their place in the market of signs "[s]ymbolic exchange gives objects an individuality which rips them out of sign-, use- and exchange-value. Each object becomes unique, ambivalent and reciprocal or reversible with other objects." Robinson, Andrew. "Jean Baudrillard: Symbolic Exchange." Ceasefire, 17 Feb. 2012. https://ceasefiremagazine.co.uk/in-theory-baudrillard-1/.

Pawlett also says about Symbolic Exchange: "Here there is no identity, no fixity, no value, as the bar enabling these 'things' is annulled" (Pawlett 97).

62 Seduction in Baudrillard's work is not to be understood as purposeful wooing, that involves a binary opposition of the self and the other. Seduction happens inspite of one's own self. In seduction, "Power relations, Baudrillard insists, are reversed or annulled: does the male 'seducer' seduce the woman or is he seduced by her" (Pawlett 103). Seduction "involves a play of appearances or surfaces, of signs that do not and cannot be related back to signifieds. Seduction is a 'malicious' use of signs, not only because it is a deception, but because it threatens to reveal that signs are never firmly attached to signifieds, that signs do not 'capture' referents, that the world of signs is not one of meaning and truth, but one of nothingness." (Pawlett 104) Andrew Robinson uses a production-related vocabulary to describe seduction: "Seduction is the reversal of production. Production brings things into existence, whereas seduction makes things disappear, after initiating them into a different type of existence. Seduction is governed by a secret rule, hidden behind and counterposed to the law. It renders a subject unidentifiable to him/herself." (https://ceasefiremagazine. co.uk/in-theory-baudrillard-11/)

Pawlett 98. The quotation within belongs to Baudrillard: Symbolic Exchange and Death (109). Kumar, Raksha. "Hindu Right Rewriting Indian Textbooks." Aljazeera, 4 Nov. 2014. www. aljazeera.com/indepth/features/2014/11/hindu-right-ideology-indian-textbooks-gujarat-20141147028501733.html.

Also, read Raza for the right-wing insistence on founding Indian history on Hindu dogma and myth. This article is only one among several discussions critical of the academic changes that India saw after 2014 national elections: Raza, Danish. "Saffronising Textbooks: Where Myth and Dogma Replace History." Hindustan Times, last updated 8 Dec. 2014. www.hindustantimes.com/india/saffronising-textbooks-where-myth-and-dogma-replace-history/ story-CauM4dmmsPGrjZ3APAvNxO.html. 
Bidwai, Prafful. "How the Sangh Parivar Is Taking Over Education and Culture Institutions.” Scroll, 25 Dec. 2014, http://scroll.in/article/695730/how-the-sangh-parivar-is-taking-over-education-and-culture-institutions.

For illustrative examples of a few of the controversial appointments that have been made by the Modi government, read George, Ajish. "Modi Government's Top Controversial Appointments That Were Hounded by Saffronisation Allegations." New Indian Express, 16 July 2015. www.newindianexpress.com/nation/Modi-Governments-Top-Controversial-Appointments-That-Were-Hounded-by-Saffronisation-Allegations/2015/07/16/article2923297.ece. Wayback Machine, https://tinyurl.com/tt9rjd9z. Taseer, Aatish. "Op-Ed: The Right-Wing Attack on India's Universities." New York Times, 27 Jan. 2016. www.nytimes.com/2016/01/28/opinion/the-right-wing-attack-on-indias-universities.html module $=$ ArrowsNav\&contentCollection $=$ Opinion\&action $=$ keypress\&region $=$ FixedLeft\&pgtype $=$ article.

Goel, Vindu, and Jeffrey Gettleman. "Under Modi, India's Press Is Not So Free Anymore." New York Times, 2 April 2020. https://www.nytimes.com/2020/04/02/world/asia/modiindia-press-media.html.

Bidwai, Praful. "Saffronising Culture and Education: What's Next on the Sangh's Agenda." Scroll, 26 Dec. 2014. http://scroll.in/article/695944/saffronising-culture-and-educationwhats-next-on-the-sanghs-agenda.

Radhika Desai strikes a cautious note as she states that it might be premature to claim any outright parallels with Fascist Germany. Nonetheless, echoing Bidwai, Desai points to parallels that indicate how the new government's "character and path to power evince similarities to fascism strong enough that it would be a dereliction of intellectual duty not to consider them" (48). Desai, Radhika. "A Latter-Day Fascism?” Economic \& Political Weekly, vol. 49, no. 35, 2014, pp. 48-58.

70 Kesavan, Mukul. "The Attacks on Two Delhi Universities Reveal Modi's Targets: Muslims and Their Allies." Guardian. 13 Jan. 2020. https://www.theguardian.com/commentisfree/2020/jan/13/attacks-delhi-universities-modi-muslims-allies.

71 "In his election campaign meetings, Modi harped upon the Gujarat model of development based on rapid industrialisation by providing necessary incentives to the business houses to set up industries and businesses and focusing on development of infrastructure such as roads, ports, electricity and water" (45). Palshikar, Suhas, and K. C. Suri. "India's 2014 Lok Sabha Elections: Critical Shifts in the Long Term, Caution in the Short Term." Economic \& Political Weekly, vol. 49, no. 39, 2014, pp. 39-49.

72 Gavaskar, Mahesh. "Modi’s Diaspora Nationalism." Economic \& Political Weekly, 10 Oct. 10, 2015, vol. 50, no. 41, p. 9 .

\section{Chapter 4 - Martinique: Space, Language, Gender}

All quotations in French attributed to Texaco are from the following edition: Chamoiseau, Patrick. Texaco. Paris: Gallimard, 1992.

2 All English translations of Texaco belong to: Chamoiseau, Patrick. Texaco. Trans. Rose-Myriam Réjouis and Val Vinokurov. New York: Pantheon Books, 1997.

"L'endroit était magique." (326)

"békés white Creoles of Martinique, descendants of old established colonial planter families. Fluent in Creole, they speak accented French" (Texaco. Trans. Glossary; 397). 
5 Créole, creole, Creole and créole are problematic terms that this chapter discusses. As is clear from the various experts cited in this chapter, these terms are often interchangeably used to designate either the language, the people or the culture.

6 "marqué par la trace de la muette." Coursil, Jacques. "Léloge de la muette." Linx, vol. 10, July 2012. http://linx.revues.org/989.

"Chamoiseau n’a pas fait un compromis entre le français et le créole en les mélangeant. Sa langue, c'est le français, bien que transformé ; non pas créolisé [...] mais chamoisisé.” ['Chamoiseau did not compromise by mixing French and Creole. Although transformed French is his language; not creolised [...] but chamoisified.']. Kundera, Milan. "Beau comme une rencontre multiple." Infini, vol. 34 (Summer 1991), p. 58.

N'zengou-Tayo has something similar in mind: "Chamoiseau plays with both French and Creole, stitching the two languages in linguistic 'quilt' that allows a pattern for the emergence of his own style" (94). N’zengou-Tayo, Marie-José. "Literature and Diglossia: The Poetics of French and Creole 'Interlect' in Patrick Chamoiseau's Texaco." Caribbean Quarterly, vol. 43, no. 4, 1997, pp. 81-101.

Milne, Lorna. "From Créolité to Diversalité: The Postcolonial Subject in Patrick Chamoiseau's Texaco." Subject Matters: Subject and Self in French Literature from Descartes to the Present, edited by Paul Giffort and Johnnie Gratton. Amsterdam: Rodopi, 2000, pp. 16280. 166.

One must note that duRivage sees in the Mangrove swamp, where Texaco is located, a metaphor for the Creole people: "The mangrove swamp is also the metaphor for the hybridity of Creole society. It is a place where land and sea, animal and vegetable meet. Because of these contradictions, it is a metaphor for the Creole people" (41). duRivage, Françoise. "Texaco: From the Hills to the Mangrove Swamps." Thamyris, vol. 6, no. 1, Spring 1999, pp. 35-42. Watts, Richard. Packaging Post/coloniality: The Manufacture of Literary Identity in the Francophone World. Lanham, Md.: Lexington Books, 2005.

11 It is conventional for French books to have their table of contents at the end.

12 Burton, Richard. Le Roman marron: Etudes sur la littérature martiniquaise contemporaine. Paris: L'Harmattan, 1997.

13 Delphine Perret, for instance speaks of how in some of Chamoiseau's novels the character named 'marqueur de paroles', an ethnographer, is inspired by Glissant. Perret, Delphine. La Créolité: Espace de création. Martinique: Ibis Rouge Editions, 2001, p. 13.

"...the French word geste means both "gesture" and geste as in chanson de geste, a collection of epic poems centered around the same hero." Texaco trans. Glossary, p. 399.

"Gibier" in French means "game," including birds. Glissant in addressing Chamoiseau as Gibier is playing on the presence of "Oiseau" (which in French means "bird") in the names of both Chamoiseau and Oiseau-de-Cham, the putative author of Texaco. Translators of Texaco explain the name Oiseau de Cham as: "(lit., Bird of Shem; phon., Bird of the Field) the shadowy (and unacknowledged) figure of the author. Appearing in previous works of Chamoiseau, he is always cast as a marginal character struggling with a study of martinican life (fr. Afterword). Oiseau de Cham is a word play on Chamoiseau (Cham-oiseau), the author's name. The storyteller's play on his own name is a traditional motif." Texaco trans. Glossary, p. 400.

16 Interestingly, Chamoiseau quotes Glissant in the epigraph of Texaco, and the translators of the novel point out that Glissant too names Chamoiseau "Gibier" in the epigraph of one his works: "In one of the book's epigraphs, Edouard Glissant, author of the seminal Caribbean 
Discourse, participates in that play by calling Chamoiseau (or Oiseau de Cham) 'game."' Texaco trans. Glossary, p. 400.

Although it must be pointed out that "là" could also evoke "Gibier." "'You, game....are nothing but a city-blackman: that's where you have to speak from!...' a quotation from Edouard Glissant, because of the ambiguity of the English word, 'game' gives the reader no clue that it refers here to 'gibier"" ("Translators on a Tight Rope" 93).

As a sample of research on space see: Chivallon, Christine. "Espace et identité créole chez Patrick Chamoiseau." Notre librairie: Revue du livre: Afrique, Caraïbes, Océan Indien, vol. 127 (July-Sept. 1996), pp. 86-108. For language see: N'zengou-Tayo, "Literature and Diglossia."

Chamoiseau, Patrick, Raphäl Confiant, and Jean Bernabé. Interview with Lucien Taylor. "Créolité Bites: A Conversation with Patrick Chamoiseau, Raphael Confiant, and Jean Bernabé." Transition, 74, 1997, pp. 124-61.

Chris Bongie in his Islands and Exiles situates the polemics that ensued between Le Brun and the Créolistes within the larger identitarian debate relating to the region, only to find himself "unsatisfied" (347) by the two intellectual positions. Read from pp. 341 to 347 for a nuanced understanding of their disagreements over questions of Créolité and belonging. Bongie, Chris. Islands and Exiles: The Creole Identities of Post/colonial Literature. Stanford, Calif:: Stanford University Press, 1998.

Quoted in Le Brun, Annie. Statue cou coupé. Paris: J.-M. Place, 1996. no pagination. When questioned about his reaction to Le Brun, Chamoiseau potrays it as part of an impassioned debate: "Writers and intellectuals have never been kind to each other [...] Sure, the debates are lively. Why are they lively? Because they're impassioned" ("Créolité Bites" 158). For more on the reaction of Jean Bernabé and Raphaël Confiant read the interview pp. 157-8. Price, Richard, and Sally Price. "Shadowboxing in the Mangrove." Cultural Anthropology: Journal of the Society for Cultural Anthropology, vol. 12, 1997, pp. 3-36. Read also for a detailed account of Chamoiseau's exchange with Annie Le Brun. Richard Price and Sally Price also explain how "the way the créolistes theorize gender and deploy masculinist strategies in the practice of their profession erases and silences women" (19). From an ethnographic perspective, the authors suggest "that the créolistes' masculinist position emerges directly - and uncritically - from the routine sexism of Martiniquan daily life" (16).

Gerard Genette defines "the epigraph roughly as a quotation placed en exergue [in the exergue] ... at the edge of the work, generally closest to the text" (Genette, Paratexts 144). Let us point to this "edge" as a site which "consists of commenting on the text, whose meaning it indirectly specifies or emphasizes” (157). Genette, Gérard. Paratexts: Thresholds of Interpretations. Trans. Jane E. Lewin. Cambridge, U.K.: Cambridge University Press, 1997.

"While they are outnumbered by male protagonists in Chamoiseau's novels, female characters often appear as forceful subjects of social and political action in day-to-day life, while male ones frequently appear passive and weak" (61). Milne, Lorna. "Sex, Gender and the Right to Write: Patrick Chamoiseau and the Erotics of Colonialism." Paragraph, vol. 24, no. 3, 2001, pp. 59-75.

Melas, Natalie, "Pays rêvé, pays réel. Créolité and Its Diasporas." Aftermaths: Exile, Migration, and Diaspora Reconsidered, edited by Marcus Paul Bullock and Peter Yoonsuk Paik. New Brunswick, N.J.: Rutgers University Press, 2009, pp. 103-32.

26 Soja, Edward. "The Socio-Spatial Dialectic." Annals of the Association of American Geographers, vol. 70 (June 1989), p. 210. Quoted on p. 5 in Brady, Mary P. Extinct Lands, Temporal 
Geographies: Chicana Literature and the Urgency of Space. Durham, N.C.: Duke University Press, 2002.

"une malheureuse qui vivait à côté avec sept enfants" ['a poor woman who lived next door with seven children and a series of men'] $(264 ; 239)$. "qui portait neuf enfants" ['who brought nine children'] (332; 302).

For more read: Wong, Alfred, and Roxanne Gomes. "Intractable Social-Economic Problems of Martinique." Études caribéennes, 7 March 2016. https://doi.org/10.4000/etudescaribeennes.6073.

Hoving, Isabel. "Remaining Where You Are: Kincaid and Glissant on Space and Knowledge." Mobilizing Place, Placing Mobility: The Politics of Representation in a Globalized World, edited by Ginette Verstraete and Tim Cresswell. Amsterdam: Rodopi, 2002, pp. 125-40.

Rabenarivo, Fara L. The City in Island Literature (Madagascar and Martinique): Toward a Poetics of Urban Space. University of Iowa, PhD Dissertation. 2008. Much of the reading of this section of Cahier draws from Rabenarivo's analysis of the poem.

Césaire, Aimé. Cabier d'un retour au pays natal. Paris: Présence Africaine, 1983, p. 8.

Césaire, Aimé. The Original 1939 Notebook of a Return to the Native Land: Bilingual Edition. Translated and edited by A. J. Arnold and Clayton Eshleman. Middletown, Conn.: Wesleyan University Press, 2013, p. 3.

4 McCusker discusses how Chamoiseau is "haunted" by "doudou" poets: "Chamoiseau emphasizes the strangeness of the word, its associations with the tropical, the colourful, and the exotic, and its implications in a writing lacking breadth and depth, which was oblivious of the horrors of slavery." McCusker, Maeve. "Writing against the Tide?: Patrick Chamoiseau's (Is)land Imaginary." Islanded Identities: Constructions of Postcolonial Cultural Insularity, edited by Maeve McCusker and Anthony Soares. Amsterdam: Rodopi, 2011, pp. 41-62.

Ahluwalia, Pal. Politics and Post-Colonial Theory: African Inflections. London: Routledge, 2001.

Anzaldúa, Gloria. Borderlands: The New Mestiza $=$ La Frontera. 4th ed. San Francisco: Aunt Lute Books, 2012.

Pattano, Luigia. “Sur 'L'Éloge de la Créolité': Un Entretien avec Patrick Chamoiseau.” 15 Sept. 2011. http://mondesfrancophones.com/.

Chanda, Tirthankar. "The Cultural 'Creolization' of the World: Interview with Edouard Glissant.” Label France vol. 38 (Jan. 2000). http://www.diplomatie.gouv.fr/label_france/ ENGLISH/DOSSIER/2000/15creolisation.html. Wayback Machine, https://tinyurl. com/yw33s96c.

Dash, J. Michael. Edouard Glissant. Cambridge, U.K.: Cambridge University Press, 1995.

For more on how Glissant's "political position was radically different from that of Aime Cesaire" read the first chapter of Dash's book. The chapter is titled "Contexts" (4-25).

Possible English translation for this French name - 'Antillean-Guyanese Front for Autonomy.'

For a detailed history of this organisation read pp. 26-28 of: Pojmann, Wendy A. Migration and Activism in Europe since 1945. New York: Palgrave Macmillan, 2008. Read also pp. 135-37 of: Nesbitt, Nick. Caribbean Critique: Antillean Critical Theory from Toussaint to Glissant. Liverpool: Liverpool University Press, 2013.

Murdoch, H. Adlai. "Glissant's Opacité and the Re-Conceptualization of Identity." Theorizing Glissant: Sites and Citations, edited by John E. Drabinski and Marisa Parham. London: Rowman \& Littlefield, 2015, pp. 7-28. 
Sylvia Wynter (639) quoted in Murdoch (2015; 10). Wynter, Sylvia, "Beyond the Word of Man: Glissant and the new Discourse of the Antilles," World Literature Today, vol. 63, no. 4, Edouard Glissant issue (Autumn 1989), pp. 637-48.

"pour moi la créolité c'est une mauvaise interprétation de la créolisation. La créolisation est un mouvement perpétuel d'interpénétrabilité culturelle et linguistique qui fait qu’on ne débouche pas sur une définition de l'être" ['for me créolité is a poor interpretation of créolisation. Créolisation is about a perpetual movement of cultural and linguistic interpenetrability which makes it impossible to arrive at the definition of the being'] (21). Gauvin, Lise. "L'Imaginaire des langues: Entretien avec Édouard Glissant." Études françaises, vol. 28, nos. 2-3, 1992, pp. 11-22.

Bernabé, Jean, Patrick Chamoiseau and Raphaël Confiant. Eloge de la créolité. Paris: Gallimard, 1989, pp. 21-2.

"processus qui joue dans les Antilles, joue aussi dans le monde entier. Tout le monde se créolise, toutes les cultures se créolisent à l'heure actuelle dans leurs contacts entre elles" (Gauvin 21).

"autonomie du discours scientifique des Antilles modernes" (107). Fonkoua, RomualdBlaise. "Instituer le savoir des Antilles aux îles: L'Institut Martiniquais d'études et la revue Acoma." Le Roman francophone actuel en Algérie et aux Antilles, edited by Danièle de Ruyter-Tognotti and Madeleine van Strien-Chardonneau. Amsterdam: Rodopi, 1998, pp. 103-20.

"premier embryon institutionnel d'un vrai laboratoire d'analyse antillais" (Fonkoua 111).

To see how Glissant's recently launched journal Acoma and the IME were criticized for their silence on the issue of Martinique's political status, and their general apolitical bearing read Fonkoua, pp. 109-11.

"discours et langage scientifiques" (Fonkoua 111).

Jonassaint, Jean. "Literatures in the Francophone Caribbean." Yale French Studies, vol. 103, 2003, pp. 55-63. Jean Jonaissant recognizes the historical differences that make for different pedagogical literary corpuses between Haiti on the one hand, and Martinique and Guadeloupe on the other: A "set of historical and structural differences implies differences in the delimitation or definition of the Haitian and the French Antillean literary corpuses" (56).

More specifically, Jonaissant explains how, despite the fact that at the level of secondary school, different academies decide keeping in view regional needs, at the level of other examinations for training teachers, it is always a centralized pattern of questioning that prevails: "Therefore, it is clear that a marked preference for canonical metropolitan French literature overdetermines the choice of examination topics, and even the questions in the field of comparative literature leave no room for Francophone literatures or writers from outside of Europe, or even outside of France. These examination topics, more than any other source, reveal the true state of literary studies in Martinique and Guadeloupe, which is almost entirely similar to the situation in the Hexagon, particularly in the field of teacher training" (59).

Chamoiseau, Patrick. Chronique des sept misères. Paris: Gallimard, 1986.

Chamoiseau, Patrick. Solibo Magnifique. Paris: Gallimard, 1988.

5 McCusker, Maeve. "On Slavery, Césaire, and Relating to the World: An Interview with Patrick Chamoiseau.” Trans. Rachel O'Loan and Maeve McCusker. Small Axe, vol. 13, no. 3 (30), 2009, pp. 74-83.

Quoted on p. 19 of Moudileno, Lydie. "From Pré-littérature to Littérature-monde: Postures, Neologisms, Prophecies." Antillanite, Creolite, Litterature-monde, edited by Isabelle 
Constant, Kahiudi C. Mabana and Philip Nanton. Newcastle upon Tyne: Cambridge Scholars, 2013, pp. 13-26.

57 "faussement révolutionnaire". Condé quoted in Moudileno, "Antillanité," p. 19. For more on Eloge de la Créolitês emergence and reception read Moudileno, "Antillanité."

58 Murdoch, H. Adlai. Creole Identity in the French Caribbean Novel. Gainesville: University Press of Florida, 2001.

59 "Creole." Le Trésor, http://atilf.atilf.fr/.

60 "La légitimité ou illégitimité de l'emploi du mot 'créole' en dehors de la sphère littéraire fait appel à la compétence du sujet parlant." ['The legitimacy or illegitimacy of the usage of the word 'creole' outside of the literary sphere depends on the competence of the speaking subject.'] (Coursil).

61 To understand more about connotations of the word "créole", read page 74 of: Picanço, Luciano C. Vers un concept de littérature nationale martiniquaise: Evolution de la littérature martiniquaise au XXème siècle - Une étude sur l'oeuvre d'Aimé Césaire, Edouard Glissant, Patrick Chamoiseau et Raphaël Confiant. New York: Peter Lang, 2000.

62 Chamoiseau, Patrick. Interview with Rose-Myriam Réjouis. "A Reader in the Room: Rose-Myriam Réjouis Meets Patrick Chamoiseau." Callaloo, vol. 22, no. 2, 1999, pp. 34650.

63 Dray, Susan. "Ideological Struggles on Signage in Jamaica." Semiotic Landscapes: Language, Image, Space, edited by Adam Jaworski and Crispin Thurlow. London: Continuum International, 2010, pp. 102-22.

64 Sestigiani, Sabina. Writing Colonisation: Violence, Landscape, and the Act of Naming in Modern Italian and Australian Literature. New York: Peter Lang, 2014.

65 Markus, Thomas A., and Deborah Cameron. The Words between the Spaces: Buildings and Language. London: Routledge, 2002.

66 Johnstone, Barbara. "Place, Globalization, and Linguistic Variation." Sociolinguistic Variation: Critical Reflections, edited by Carmen Fought. Oxford: Oxford University Press, 2004, pp. 65-83.

Johnstone borrows “local knowledge" from Clifford Geertz’s 1983 study: Local Knowledge: Further Essays in Interpretive Anthropology. New York: Basic Books.

67 Translators of Texaco translate this Creole sentence as: "I am going down to City, He lives in city. This fellow is from City, from Fort-de-France” (Texaco trans., 386).

68 Read Susan Gal for a more comprehensive understanding of the interrelationship between nation-states and language. Although not claiming to be exhaustive, Gal presents also an interesting array of "less familiar patterns" of relationship between language and space. Gal, Susan. "Language and Political Spaces." Language and Space: An International Handbook of Linguistic Variation, edited by Peter Auer and Jürgen Erich Schmidt. Berlin: De Gruyter Mouton, 2010, pp. 33-49.

69 Jacquemet, Marco. "Language and Transnational Spaces." Auer and Schmidt, pp. 50-69.

70 "Transidiomatic practices are the result of the co-presence of digital media and multilingual talk exercised by deterritorialized/reterritorialized speakers" (62).

71 Christian Mair provides on p. 442 a very brief explanation of Creole's link within the Caribbean with the plantation economy. Mair, Christian. "The Consequences of Migration and Colonialism I: Pidgins and Creoles.” Auer and Schmidt, pp. 440-50.

72 Speaking of how it was the movement of slave populations that resulted in the creation of various Creoles across the globe, Mair also reminds us that "creoles are languages which owe their existence to the movement of populations, and very frequently they themselves have 
become languages on the move" (442). Mair, of course, is referring to how populations of these Caribbean islands subsequently traveled across the globe, taking along with them their linguistic idiom; the literal parallel with Créolité's outward movement from the Caribbean toward the world is nonetheless interesting to note.

Foreward. Landscape in Language: Transdisciplinary Perspectives, edited by David Mark et al. Amsterdam: John Benjamins, 2011, pp. ix-x.

Janz, Bruce B. "Philosophical Issues in Ethnophysiography: Landform Terms, Disciplinarity, and the Question of Method." Landscape in Language: Transdisciplinary Perspectives, edited by David Mark et al. Amsterdam: John Benjamins, 2011, pp. 101-20.

Mark, David M. et al. "Landscape in Language: An Introduction." Landscape in Language: Transdisciplinary Perspectives, edited by David Mark et al. Amsterdam: John Benjamins, 2011, pp. 1-24.

For more on the importance of the mangrove swamp in Caribbean literature see pp. 150-1 of Prieto, Eric. "Landscaping Identity in Contemporary Caribbean Literature." Francophone Post-Colonial Cultures: Critical Essays, edited by Kamal Salhi. Lanham, Md.: Lexington Books, 2003, pp. 141-52.

Mark, David M. et al. "Landscape in Language: An Introduction," p. 7.

"The core of ethnophysiography is the investigation (for any particular language) of categories of landscape features, especially those denoted by common words (usually nouns or noun phrases). Those terms and their definitions form a research topic of considerable importance in its own right. [...] Thus, ethnophysiography is related to the study of 'place,' 'sense of place,' and 'place attachment.' Ethnophysiography examines how these significances are tied into traditional beliefs, such as those embedded in creation stories, which help to make sense of the world, of its physiographic entities, and of the relationship of such entities to everyday activities, including traditional cultural practices (ceremonies, music, art, etc.)." Mark, David M. et al. "Landscape in Language: An Introduction," p. 7.

Turk, Andrew G. "Exploring Philosophy of Place: Potential for Synergy between Phenomenology and Ethnophysiography." Landscape in Language: Transdisciplinary Perspectives, edited by David Mark et al. Amsterdam: John Benjamins, 2011, pp 47-72.

And, hasn't the body always been central to understanding the function of space? Doesn't even Jameson remind us that it is the human body which has borne the brunt of "postmodern hyperspace," the disorienting product of unbridled capitalism: "transcending the capacities of the individual human body to locate itself"? Here is the full quotation for larger context: "So I come finally to my principal point here, that this latest mutation in space - postmodern hyperspace - has finally succeeded in transcending the capacities of the individual human body to locate itself, to organize its immediate surroundings perceptually, and cognitively to map its position in a mappable external world"(Jameson, Postmodernism; 44).

François duRivage provides numerous examples of how "Texaco is the legacy of Noutéka" (38). The hills as a source of historical knowledge is important because the "hills are also a place of freedom for it is where the maroons, the slaves escaped from the plantation used to go and hide" (duRivage 36).

"Women actively and passively, through the changing nature of their everyday lives, their position in the family, the household and in the workplace, all of which have been affected by the social relations of local globalism and its associated geographic restructurings, are challenging the gendering of space as they disrupt conventional associations between 
Whiteness, masculinity and the workplace, for example, between gender and political power, between femininity and accepted definitions of sexuality. At a range of spatial scales, from the most local in the home to the global scale, women and people of colour have challenged conventional assumptions about the relationships between identity, both individual and group, and location, as well as the theoretical basis of Enlightenment thought. Old associations between a place and a people, be it a community, a region or a nation, are breaking down and are being reforged at the end of the twentieth century" (38). McDowell, Linda. "Spatializing Feminism: Geographic Perspectives." Body Space: Destabilising Geographies of Gender and Sexuality, edited by Nancy Duncan. London: Routledge, 1996, pp. 28-44.

Nnadi, Joseph. "Mémoire d'Afrique, mémoire biblique: La congruence des mythes du nègre dans Texaco de Patrick Chamoiseau." Etudes Francophones, vol. 15, no. 1, 2000, pp. 75-91.

"l'une des formes de protestation les plus rencontrées chez les romancières antillaises [...] comme le projet d'une éventuelle 'guerre de sexes" (Kemedjio 39). I am using Kemedjio summary of Condé's position: Kemedjio, Cilas. "La femme antillaise face au faubourg et à la durcification dans Texaco de Patrick Chamoiseau et Mélody des faubourgs de Lucie Julia." LittéRéalité, vol. 11, no. 2 (Autumn-Winter 1999), pp. 31-47.

McClintock, Anne. “'No Longer in a Future Heaven': Gender, Race and Nationalism." Dangerous Liaisons: Gender, Nation, and Postcolonial Perspectives, edited by Anne McClintock, Aamir Mufti and Ella Shohat. Minneapolis: University of Minnesota Press, 1997, p. 89-112. "la femme [antillaise] peut-être considérée comme le lieu où l'histoire a des possibilités de se conserver, de se perpétuer. Les femmes sont la symbolique d'une mémoire possible" (Kemedjio 43).

"le corps de la femme [martiniquaise] va devenir le lieu de formulation de la résistance aux structures d'oppression" (Kemedjio 38).

"la femme africaine subit la plus totale des agressions, qui est le viol quotidien et répété d'un équipage de marins rendus déments par l'exercice de leur métier" (297). Glissant, Edouard. Le discours antillais. Paris: Editions du Seuil, 1981.

\section{Chapter 5 - Out of Place: French Family at (Algerian) War}

1 Arendt, Hannah. Crises of the Republic: Lying in Politics; Civil Disobedience; On Violence; Thoughts on Politics and Revolution. New York: Harcourt Brace Jovanovich, 1972, p. 6. Haneke, Michael, dir. Caché: [Hidden]. Culver City, Calif: Sony Pictures Home Entertainment, 2006.

3 Original quotation is from p. 33 of article by Chris Philo: "More words, more worlds: reflections on the 'cultural turn' and human geography." Cultural Turns/geographical Turns: Perspectives on Cultural Geography, edited by I. Cook, D. Crouch, S. Naylor and J. Ryan. Harlow, U.K.: Prentice Hall, 2000, pp. 27-53. Quotation cited on p. 74 of Joanne Sharp's article: "Feminisms." A Companion to Cultural Geography, edited by James S. Duncan, Nuala C. Johnson and Richard H. Schein. Malden, Mass.: Blackwell, 2004, pp. 66-78.

$4 \quad$ Mirroring Sharp's contention, Mariusz Czepczynski also gives the example of Philo and uses the word "terrifies" to speak of how this "dematerialization of geography still worries and sometimes terrifies some of the experienced traditional researchers" (25). Czepczyński, Mariusz. Cultural Landscapes of Post-Socialist Cities: Representation of Powers and Needs. Aldershot: Ashgate, 2008. Czepczyński in the first chapter, titled "Geographical Studies of Cultural Landscape," also provides an historical account of the methodological transforma- 
tions within the discipline of geography, starting from the early days of its inception. This account helps better situate the context of the current turn in social sciences, which is variously called “'post-modern', 'spatial', 'cultural', or as identified by Foucault, 'geometric turn'” (25). Hetherington, Kevin. Expressions of Identity: Space, Performance, Politics. London: Sage, 1998.

Filimon, Monica, and Fatima Naqvi. "Variations on Themes: Spheres and Space in Haneke's Variation." A Companion to Michael Haneke, edited by Roy Grundmann. Malden, Mass.: Wiley-Blackwell, 2010, pp. 243-62.

Such is the complexity of spatial engagement in Haneke's oeuvre that Ben McCann and David Sorfa devote an entire section titled "Space" of their edited volume to questions of space and spatiality in Haneke's work. From the relevance of travel as a means of evading one's location (Justice) to the interaction between the space of the city and the ethics of hospitality toward others in Code Inconnu (Geyh), these chapters open up various ways of situating Haneke's cinema along spatial matrices. The Cinema of Michael Haneke: Europe Utopia, edited by Ben McCann and David Sorfa. London: Wallflower Press, 2011.

Justice, Christopher. "The Vacant Vacationer: Travel as Symptom and Antidote in Michael Haneke." The Cinema of Michael Haneke: Europe Utopia, pp. 94-104.

Geyh, Paula E. "Cosmopolitan Exteriors and Cosmopolitan Interiors: The City and Hospitality in Haneke's Code Unknown.” The Cinema of Michael Haneke, pp. 105-16.

Ince, Kate. "Glocal Gloom: Existential Space in Haneke's French-Language Films." The Cinema of Michael Haneke, pp. 85-93.

Gallagher, Brianne. "Policing Paris: Private Publics and Architectural Media in Michael Haneke's Caché." Journal for Cultural Research, vol. 12, no. 1, 2008, pp. 19-38.

Cowan, Michael. "Between the Street and the Apartment: Disturbing the Space of Fortress Europe in Michael Haneke." Studies in European Cinema, vol. 5, no. 2, 2009, pp. 117-29.

Schaefer, Joy C. "The Spatial-Affective Economy of (Post)colonial Paris: Reading Haneke's Caché (2005) through Octobre à Paris (1962).” Studies in European Cinema, vol. 14, no. 1, 2017, pp. 48-65.

Saxton, Libby. "Secrets and Revelations: Off-Screen Space in Michael Haneke's Caché (2005)." Studies in French Cinema, vol. 7, no. 1, 2007, pp. 5-17.

Eisenman, Peter. "Michael Haneke and the New Subjectivity: Architecture and Film." $A$ Companion to Michael Haneke, edited by Roy Grundmann. Malden, Mass.: Wiley-Blackwell, 201, pp. 124-9.

4 In the context of Haneke's Code Inconnu, Geyh briefly deploys similar spatial dynamics to explain the relationship between the inside and the outside of the human subject: the relationship between the "internal otherness" and the "external Other" (111-12).

Grosz, Elizabeth A. Space, Time, and Perversion: Essays on the Politics of Bodies. New York: Routledge, 1995.

Caillois, Roger. "Mimicry and Legendary Psychathenia." Trans. John Sheply. October, vol. 31 (Winter 1984), pp. 16-32. Quoted on p. 88 of Grosz.

McCulloch, Jock. Black Soul White Artifact: Fanon's Clinical Psychology and Social Theory. Cambridge, U.K.: Cambridge University Press, 1983.

Soja, Edward W. Thirdspace: Journeys to Los Angeles and Other Real-and-Imagined Places. Cambridge, Mass.: Blackwell, 1996, p. 16. I am building here on Soja's understanding of Foucault. 
My understanding of Arendt's writing sourced from: Young-Bruehl, Elisabeth. Why Arendt Matters. New Haven: Yale University Press, 2006.

Haneke, Michael. Interview on Caché with Serge Toubiana (DVD). All quotations by Haneke about Caché, unless otherwise stated, are taken from this interview.

Khanna, Ranjana. "From Rue Morgue to Rue des Iris." Screen, vol. 48, no. 2, 2007, pp. 237 44.

Cousins, Mark. "After the End: Word of Mouth and Caché." Screen, vol. 48, no. 2, 2007, pp. 223-6.

Ezra, Elizabeth, and Jane Sillars. “The Caché Dossier." Screen, vol. 48, no. 2, 2007, p. 211.

Szalai, Jennifer. "Habits of Seeing: The Unsettling Films of Michael Haneke." Harper's, vol. 315 , no. 1890,2007 , pp. $68-75$. On p. 74 , one can find more about how "certain critics were determined to assume the answers that Haneke so carefully withheld."

Ezra and Sillars, introduction, p. 211.

Vergès, Françoise. Monsters and Revolutionaries: Colonial Family Romance and Métissage. Durham, N.C.: Duke University Press, 1999, p. 4.

House, Jim, and Neil MacMaster. Paris 1961: Algerians, State Terror, and Memory. New York: Oxford University Press, 2006, p. 1. House and MacMaster contextualize this demonstration by explaining it as part of FLN's desire to exert pressure on de Gaulle's government: "Through a total mobilization of the Algerian community, a pacific demonstration which included women, children, and the elderly, the FLN intended to dramatically show the media and international opinion its uncontested popular support base as the unique voice of Algerian nationalism and reinforce the position of its leadership which was currently engaged in negotiations for independence with de Gaulle's government." For further information on the background and history of 17 October 1961 read House and MacMaster, pp. 1-31.

Papon, Maurice. "Proclamation of October 5, 1961." Cited in Einaudi, Jean-Luc. La Bataille de Paris: 17 octobre 1961. Paris: Seuil, 1991, p. 85.

Jacobs, Karen. The Eye's Mind: Literary Modernism and Visual Culture. Ithaca: Cornell University Press, 2001, p. 7.

"Nous savons tous, qu'est-ce qu'on [sic] peut manipuler avec, avec l' image" ['We know what we can manipulate with, with the image'].

"Ça c'était aussi le thème de plusieurs de mes films" ['This was also the theme of many of my films'].

Beugnet, Martine. "Blind Spot." Screen, vol. 48, no. 2, 2007, pp. 227-31.

"The events of 17 October 1961, when a protest against French policy in Algeria sparked a huge police operation in which hundreds of demonstrators were killed or injured, were not acknowledged at the time, nor for decades afterwards" (34). Wheatley, Catherine. "Secrets, Lies \& Videotape." Sight and Sound, vol. 16, no. 2, 2006, pp. 32-6.

Interestingly, it was not during a committee or a fact-finding mission devoted to October 1961 but during a trial against Papon for his role in the deportation of Jews during World War II that the extent of his culpability in October 1961 became known: "As the French media showed a growing interest in the events of 17 October, so there was also a demand for the opening of the state archives. A rapid shift in this direction occurred as a result of the high-profile trial of Maurice Papon (October 1997-April 1998) for crimes against humanity during the Second World War, during which the prosecution seized the opportunity to launch what the defence lawyers called the 'trial within a trial', an exposure of Papon's repressive role as Paris Prefect of Police in 1961" (Paris 8). 
While replying to a question about why only a few words in the film explicitly make the connection with the war of Algeria, Haneke says: "Je voulais pas appuyer sur ce point-là." ['I did not wish to lay stress on this point.'] I am quoting Gildea's understanding of Halbwachs. Gildea, Robert. The Past in French History. New Haven: Yale University Press, 1994, p. 10.

Laronde, Michel. "Displaced Discourses: Post(-)coloniality, Francophone Space(s), and the Literature(s) of Immigration in France." Postcolonial Theory and Francophone Literary Studies, edited by H. Adlai Murdoch, Anne Donadey and Françoise Lionnet. Gainesville: University Press of Florida, 2005, pp. 175-92. Ezra, Elizabeth, and Jane Sillars. "Hidden in Plain Sight: Bringing Terror Home." Screen, vol. 48 , no. 2, 2007, pp. 215-21.

Bayraktar also points out how, in Caché, "[m]ultiple temporalities and spaces get interwoven in these sequences, expanding into the colonial past and to various geographical locations beyond the borders of France" (88). Bayraktar, Nilgün. Mobility and Migration in Film and Moving-Image Art: Cinema Beyond Europe. New York: Routledge, 2016.

Glissant, Discours antillais, p. 132. quoted on p. 93: Coursil, Jacques. "La Catégorie de la relation dans les essais d'Edouard Glissant: Philosophie d'une politique." Chevrier, Jacques. Poétiques D'edouard Glissant: Actes du colloque international "Poétiques D'edouard Glissant", Paris-Sorbonne, 11-13 Mars 1998. Paris: Presses de l'Université de Paris-Sorbonne, 1999, pp. 85-112.

${ }_{41}$ Glissant, Edouard. Caribbean Discourse: Selected Essays. Trans. with intro. by J. Michael Dash. Charlottesville: University Press of Virginia, 1989, p. 64. Quoted on p. 104 of: Ashcroft, Bill. Post-Colonial Transformation. London: Routledge, 2001. Jacques Coursil explains this "prophétie du passê" ['prophetic vision of the past'] in greater detail. In particular read note 5 on page 93.

43 In pointing out how and why the film was attractive to a particular kind of viewer, Mark Cousins too speaks about the connection that these viewers have with its characters. Caché "made certain types of people and groupings semiconductors for its suture, mystery and anxieties [...] Not only did it intrigue, but it featured people whose social lives are organized like those of the middle-class, urban, ideas-aware groups that journalists dismissively call the chattering classes [...] Caché held a mirror up to such socio-intellectual networks and showed them anxieties which, to them, were unexpected, clever and stimulating" ("After the End" 224).

Badt, Karin. "Family Is Hell and So Is the World: Talking to Michael Haneke at Cannes 2005." Bright Lights Film Journal, 1 Nov. 2005. http://brightlightsfilm.com/ family-hellworld-talking-michael-haneke-cannes-2005/\#.V_9VYPl97IU.

Porton, R. "Collective Guilt and Individual Responsibility: An Interview with Michael Haneke." Cinéaste, vol. 31, no. 1, 2005, pp. 50-51.

Cachês "terrible realism" serves as a cinematic reminder of the spectator being an accomplice to the colonial crime. Read Celik for an interesting analysis of Cachés realism as a means of engaging with the "absence of colonial history" and with the "incomplete nature of our vision" (61).

Celik, Ipek A. "'I Wanted You to Be Present': Guilt and the History of Violence in Michael Haneke’s Caché.” Cinema Journal, vol. 50, no. 1, 2010, pp. 59-90.

47 "Alors il l'a fait. Il lui a coupé la tête... Le coq sautait... Majid était couvert de sang." ['Well, he did it. He cut its head off... The cock was bouncing around... Majid was covered in blood.']. 
48 Gilroy, Paul. “Shooting Crabs in a Barrel." Screen, vol. 48, no. 2, 2007, pp. 233-5.

49 Silverman, Max. “The Empire Looks Back.” Screen, vol. 48, no. 2, 2007, pp. $245-9$.

\section{Epilogue: Interjecting Passages}

$1 \quad$ Caldwell, Christopher. "Revolting High Rises." New York Times Magazine on the Web, 27 Nov. 2005. https://www.nytimes.com/2005/11/27/magazine/revolting-high-rises.html. Wayback Machine, https://tinyurl.com/m7d4mf27

2 Ambe J. Njoh in a book about French techniques of urbanism in foreign lands shows that right from colonial street designs, which aided "security and surveillance activities" (5), to the implementation of an outright racial segregation through urbanism, in myriad ways space management facilitated the French colonial project abroad. "By racially segregating colonial towns, officials were able to control the movement of native population. It is thanks to racial segregation that French colonial authorities were able to restrict the movement of colonial subjects despite the shoestring budgets of most colonial governments" (7). Njoh, Ambe J. French Urbanism in Foreign Lands. Cham: Springer International Publishing, 2016. ebook.

3 Ross, Kristin. Fast Cars, Clean Bodies: Decolonization and the Reordering of French Culture. Cambridge, Mass.: MIT Press, 1995.

$4 \quad$ Miłosz, Czesław. "Bypassing Rue Descartes." Trans. Renata Gorczynski and Robert Hass, Polish Poetry of the Last Two Decades of Communist Rule, edited and with translations by Stanisław Barańczak and Clare Cavanagh. Evanston, Ill.: Northwestern University Press, 1991, pp. 26-27. 


\section{BIBLIOGRAPHY}

Ahluwalia, Pal. Politics and Post-Colonial Theory: African Inflections. London: Routledge, 2001.

Alexander, Neal. “On Literary Geography." Literary Geographies, vol. 1, no. 1, 2015, pp. 3-6. Anderson, Benedict. Imagined Communities. New York: Verso, 1991.

Anzaldúa, Gloria. Borderlands: The New Mestiza = La Frontera 4th ed., San Francisco: Aunt Lute Books, 2012.

Appadurai, Arjun. "Grassroots Globalization and the Research Imagination." Globalization, edited by Arjun Appadurai. Durham, N.C.: Duke University Press, 2001, pp. 1-21.

Appadurai, Arjun. Modernity at Large: Cultural Dimensions of Globalization. Minneapolis: University of Minnesota Press, 1996.

Arendt, Hannah. Crises of the Republic: Lying in Politics; Civil Disobedience; On Violence; Thoughts on Politics and Revolution. New York: Harcourt Brace Jovanovich, 1972.

Auden, W. H. The Dyer's Hand, and Other Essays. New York: Random House, 1962.

Avrane, Patrick. "Prologue." Jules Verne. Paris: Editions Stock, 1997.

Badt, Karin. "Family Is Hell and So Is the World: Talking to Michael Haneke at Cannes 2005." Bright Lights Film Journal, 1 Nov. 2005. http://brightlightsfilm.com/ familyhell-world-talking-michael-haneke-cannes-2005/\#.V_9VYPl97IU.

Barthes, Roland. "The Nautilus and the Drunken Boat." Mythologies. Trans. Annette Lavers. New York: Noonday Press, 2007.

Bastié, Jean. "Jules Verne et la Société de Géographie." Jules Verne, voyageur extraordinaire: A la découverte des mondes connus et inconnus by Jean-Yves Paumier. Grenoble: Glénat, 2005.

Baudelaire, Charles. "Le Poison." Complete Poems. Trans. Walter Martin. New York: Routledge, 2002, pp. 128-9.

Baudelaire, Charles. Les Fleurs du mal. Paris: Poulet-Malassis et de Broise, 1857.

Bauder, Harald, and Salvatore Engle-Di Mauro, editors. Critical Geographies: A Collection of Readings. Praxis (e) Press, 2008. http://www.praxis-epress.org/CGR/contents.html. Wayback Machine, https://tinyurl.com/m7d4mf27.

Baudrillard, Jean. Simulacra and Simulation. Trans. Sheila Faria Glaser. Ann Arbor: University of Michigan Press, 1994.

Baudrillard, Jean. Symbolic Exchange and Death. London: Sage Publications, 1993.

Bayraktar, Nilgün. Mobility and Migration in Film and Moving-Image Art: Cinema Beyond Europe. New York: Routledge, 2016. 
Belugue, Geneviève, "Du lieu incontournable à la relation." Poétiques d'Édouard Glissant. Actes du colloque international Paris-Sorbonne, 11-13 mars 1998, edited by Jacques Chevrier. Paris: Presses de l'Université de Paris-Sorbonne, 1999, pp. 43-54.

Benjamin, Walter. "Work of Art in the Age of Mechanical Reproduction." Illuminations, edited with an introduction by Hannah Arendt. Trans. Harry Zohn. New York: Schocken Books, 1977.

Berdoulay, Vincent R.H. "Geography in France: Context, Practice and Text." Geography: Discipline, Profession, and Subject since 1870: An International Survey, edited by Gary S. Dunbar. Dordrecht: Springer, 2001, pp. 45-78.

Bergner, Gwen. "Who Is That Masked Woman? Or, The Role of Gender in Fanon's Black Skin, White Masks." PMLA vol. 110, no. 1, 1995, pp. 75-88.

Bernabé, Jean, Patrick Chamoiseau, and Raphaël Confiant. Eloge de la créolité. Paris: Gallimard, 1989.

Beugnet, Martine. “Blind Spot." Screen, vol. 48, no. 2, 2007, pp. 227-31.

Bhabha, Homi K. The Location of Culture. New York: Routledge, 1994.

Bidwai, Prafful. "How the Sangh Parivar Is Taking Over Education and Culture Institutions." Scroll, 25 Dec. 2014, http://scroll.in/article/695730/how-the-sangh-parivaris-taking-over-education-and-culture-institutions.

Bidwai, Praful. "Saffronising Culture and Education: What's Next on the Sangh's Agenda." Scroll, 26 Dec. 2014. http://scroll.in/article/695944/saffronising-culture-and-education-whats-next-on-the-sanghs-agenda.

Boia, Lucian. Jules Verne: Les Paradoxes d'un mythe. Paris: Belles lettres, 2005.

Bolfek-Radovani, Jasmina. Space, Place and Spatial Loss in North African and Canadian Writing in French. 2012. University of Westminster, PhD dissertation. WestminsterResearch, http://westminsterresearch.wmin.ac.uk/13283/1/Jasmina_BOLFEK-RADOVANI.pdf.

Bongie, Chris. Exotic Memories: Literature, Colonialism, and the fin de Siècle. Stanford, Calif:: Stanford University Press, 1991.

Bongie, Chris. Islands and Exiles: The Creole Identities of Post/colonial Literature. Stanford, Calif.: Stanford University Press, 1998.

Borges, Jorge Luis. Collected Fictions. Trans. Andrew Hurley. New York: Viking, 1998.

Bradbury, Ray. "Introduction." Around the World in Eighty Days by Jules Verne. Los Angeles: Plantin Press, 1962, pp vii-xii.

Brady, Mary Pat. Extinct Lands, Temporal Geographies: Chicana Literature and the Urgency of Space. Durham, N.C.: Duke University Press, 2002.

Bragard, Véronique. Transoceanic Dialogues: Coolitude In Caribbean and Indian Ocean Literatures. Brussels: P.I.E. Peter Lang, 2008.

Breyer, John, and William Butcher, "Nothing New Under the Earth." Earth Sciences History, vol. 22, no. 1, 2003 pp. 36-54.

Brosseau, Marc. “Geography's Literature." Progress in Human Geography, vol. 18, no. 3, 1994, pp. 333-53.

Brosseau, Marc. "In, Of, Out, With, and Through: New Perspectives in Literary Geography." The Routledge Handbook of Literature and Space, edited by Robert T. Tally Jr. Basingstoke: Taylor \& Francis, 2017, pp. 9-27.

Brosseau, Marc. "Literature." International Encyclopedia of Human Geography, edited by Rob Kitchin and Nigel Thrift, vol 6. Amsterdam: Elsevier, 2011, pp. 212-19. 
Brosseau, Marc. “The City in Textual Form: 'Manhattan Transfer's' New York." Ecumene, vol. 2, no. 1, 1995, pp. 89-114.

Brosseau, Marc. “The Traps: Bukowski as Interpreter of Cornered Lives." Anglia Zeitschrift für englische Philologie, vol. 126, no. 2, 2008, pp. 380-96.

Brosseau, Marc. Des Romans-Geographes: Essai. Paris: L'Harmattan, 1996.

Burton, Richard. Le Roman marron: Etudes sur la littérature martiniquaise contemporaine. Paris: L'Harmattan, 1997.

Butcher, C.W. "Graphes et graphie : Circuits et Voyages extraordinaires dans l'œuvre de Jules Verne.” http://www.ibiblio.org/julesverne/articles/Graphes.pdf. Published in print as: "Graphes et graphie." Regards sur la théorie des graphes (Actes du Colloque de Cerisy, 12-18 juin 1980). Lausanne: Presses polytechniques romandes, 1980, pp. $177-$ 82.

Butcher, W. “Un Espace vierge: Les manuscrits du 'Tour du monde”. Studi Francesi, vol. 48, no. $142,2004,108-17$.

Butcher, William. "De la ligne: Fleuves, logos et logiques dans les Voyages extraordinaires." Zvi Har'El's Jules Verne Collection, http://www.ibiblio.org/julesverne/articles/ etranges.pdf. Originally published in: Jules Verne et la modernité, edited by Jean Bessière. Université de Picardie with Presses Universitaires de France, 1988, pp. 12338.

Butcher, William. Verne's Journey to the Centre of the Self: Space and Time in the Voyages Extraordinaires. New York: St. Martin's Press, 1991.

Butcher, William, and Sarah Crozier "Verne's Underground City: The Lost Chapters from Les Indes noires." www.ibiblio.org/julesverne/articles/undergroundcity.doc. Date of access - 1 December, 2019.

Caillois, Roger. "Mimicry and Legendary Psychathenia." Trans. John Sheply. October, vol. 31 (Winter 1984), pp. 16-32.

Caldwell, Christopher. "Revolting High Rises." New York Times Magazine on the Web, 27 Nov. 2005. https://www.nytimes.com/2005/11/27/magazine/revolting-high-rises. html.

Carr, Helen. "Modernism and Travel (1880-1940)." The Cambridge Companion to Travel Writing, edited by Peter Hulme and Tim Youngs. Cambridge, U.K.: Cambridge University Press, 2002, pp. 70-86.

Carroll, Jane Suzanne. “'You Are Too Slow': Jules Verne's Around the world in 80 days.” Victorian Time: Technologies, Standardizations, Catastrophes, edited by Trish Ferguson. Basingstoke: Palgrave Macmillan, 2013, pp. 77-94.

Celik, Ipek A. "'I Wanted You to Be Present': Guilt and the History of Violence in Michael Haneke’s Caché." Cinema Journal, vol. 50, no. 1, 2010, pp. 59-90.

Césaire, Aimé. Cahier d'un retour au pays natal. Paris: Présence Africaine, 1983.

Césaire, Aimé. The Original 1939 Notebook of a Return to the Native Land: Bilingual Edition. Translated and edited by A. J. Arnold and Clayton Eshleman. Middletown, Conn.: Wesleyan University Press, 2013.

Chambers, Ross. Loiterature. Lincoln: University of Nebraska Press, 1999.

Chamoiseau, Patrick. Chronique des sept misères. Paris: Gallimard, 1986.

Chamoiseau, Patrick. Interview with Rose-Myriam Réjouis. "A Reader in the Room: Rose-Myriam Réjouis Meets Patrick Chamoiseau.” Callaloo, vol. 22, no. 2, 1999, pp. 346-50. 
Chamoiseau, Patrick. Solibo Magnifique. Paris: Gallimard, 1988.

Chamoiseau, Patrick. Texaco. Paris: Gallimard, 1992.

Chamoiseau, Patrick. Texaco. Trans. Rose-Myriam Réjouis and Val Vinokurov. New York: Pantheon Books, 1997.

Chamoiseau, Patrick, Raphaël Confiant, and Jean Bernabé. Interview with Lucien Taylor. "Créolité Bites: A Conversation with Patrick Chamoiseau, Raphael Confiant, and Jean Bernabé." Transition, 74, 1997, pp. 124-61.

Chanda, Tirthankar. “The Cultural 'Creolization' of the World: Interview with Edouard Glissant." Label France vol. 38 (Jan. 2000). http://www.diplomatie.gouv.fr/label_france/ENGLISH/DOSSIER/2000/15creolisation.html. Wayback Machine, https://tinyurl.com/yw33s96c.

Chandna, Mohit. "Re-Reading Postcolonial Women Authors." International Journal of Francophone Studies, vol. 18, no. 4, 2015, pp. 521-4.

Chandna, Mohit. "Writing Colonial Spaces." Journal of Commonwealth and Postcolonial Studies, vol. 1, no. 2, 2013, pp. 87-95.

Chandna, Mohit. "Rev. of Rewriting the Return to Africa, by Anne M. François." International Journal of Francophone Studies, vol. 15, no. 2, 2012, pp. 324-26.

Cheseneaux, Jean. The Political and Social Ideas of Jules Verne. Trans. Thomas Wikeley. London: Thames and Hudson, 1972.

Chesneaux, Jean. "Les Titres des romans verniens: Variantes, résonances et occurrences." Actes du colloque de Cerisy, Jules Verne: Cent ans après, edited by Jean-Pierre Picot and Christian Robin. Rennes: Terre de Brume, 2005, pp. 25-33.

Chivallon, Christine. "Espace et identité créole chez Patrick Chamoiseau." Notre librairie: Revue du livre: Afrique, Caraïbes, Océan Indien, vol. 127 (July-Sept. 1996), pp. 86108.

Clifford, James. The Predicament of Culture Twentieth-Century Ethnography, Literature, and Art. Cambridge, Mass.: Harvard University Press, 1988.

Collins Dictionary Online. http://www.collinsdictionary.com.

Compère, D. "Poétique de la carte." Bulletin de la Société de Jules Verne, vol. 13, no. 50, 1979, pp. 69-74.

Costello, Peter. Jules Verne, Inventor of Science Fiction. New York: Scribner, 1978.

Coursil, Jacques. "La Catégorie de la relation dans les essais d'Edouard Glissant: Philosophie d'une politique." Poétiques d'Edouard Glissant: Actes du colloque international "Poétiques d'edouard Glissant," complied by Jacques Chevrier, Paris-Sorbonne, 1113 March 1998. Paris: Presses de l'Université de Paris-Sorbonne, 1999, pp. 85-112.

Coursil, Jacques. "L'éloge de la muette." Linx, vol. 10, July 2012. http://linx.revues.org/989.

Cousins, Mark. "After the End: Word of Mouth and Caché." Screen, vol. 48, no. 2, 2007, pp. 223-6.

Cowan, Michael. "Between the Street and the Apartment: Disturbing the Space of Fortress Europe in Michael Haneke." Studies in European Cinema, vol. 5, no. 2, 2009, pp. 117 29.

Cresswell, Tim. Place: A Short Introduction. Malden, Mass.: Blackwell, 2004.

Culler, Jonathan. “'Trouver du nouveau ?': Baudelaire's Voyages.” The Poetics and Politics of the Modern Journey, edited by John Zilcosky. Toronto: University of Toronto Press, 2008, pp. 79-97. 
Czepczyński, Mariusz. Cultural Landscapes of Post-Socialist Cities: Representation of Powers and Needs. Aldershot: Ashgate, 2008.

Dash, J. M. "Rev. of Soundings in French Caribbean Writing since 1950, the Shock of Space and Time, by Mary Gallagher." International Fiction Review, vol. 32, nos. 1-2, 2005, pp. 112-14.

Dash, J. Michael. Edouard Glissant. Cambridge, U.K.: Cambridge University Press, 1995.

Desai, Radhika. “A Latter-Day Fascism?” Economic \& Political Weekly, vol. 49, no. 35, 2014, pp. 48-58.

Devi, Ananda. "Flou identitaire." Je est un autre: Pour une identité-monde, edited by M Le Bris et al. Paris: Gallimard, 2010, pp. 179-86.

Devi, Ananda. Indian Tango: Roman. Paris: Gallimard, 2007.

Devi, Ananda. Interview with www.indereunion.net. "Peut-être est-ce l'Inde mythique qui m'habite." www.indereunion.net/actu/ananda/interAnanda.htm\#Site.

Devi, Ananda. L'Ambassadeur triste: Nouvelles. Paris: Gallimard, 2015.

Devi, Ananda. L'arbre fouet: Roman. Paris, France: L'Harmattan, 1997.

Devi, Ananda. Les jours vivants: Roman. Paris: Gallimard, 2013.

Devi, Ananda. Le Voile de Draupadi. Paris: Harmattan, 1993.

Devi, Ananda. Quand la nuit consent à me parler. Paris: Bruno Doucey, 2011.

Devi, Ananda, Quand la nuit consent à me parler. Trans. Kazim Ali. When the Night Agrees to Speak to Me. Noida: Harper Collins, 2021.

Devi, Ananda. Rue la Poudrière. Abidjan: Nouvelles Editions Africaines, 1988.

Diawara, Manthia, "Reading Africa through Foucault: V. Y. Mudimbe's Reaffirmation of the Subject." Dangerous Liaisons: Gender, Nation, and Postcolonial Perspectives, edited by Anne McClintock, Aamir Mufti and Ella Shohat, Social Text Collective. Minneapolis: University of Minnesota Press, 1997, 456-67.

Diémé, Joseph. De la plantation coloniale aux banlieues: La Négritude dans le discours postcolonial francophone. Paris: L'Harmattan, 2012.

Dray, Susan. "Ideological Struggles on Signage in Jamaica." Semiotic Landscapes: Language, Image, Space, edited by Adam Jaworski and Crispin Thurlow. London: Continuum International, 2010, pp. 102-22.

Dupuy, Lionel. Jules Verne, l'homme et la terre: La mystérieuse géographie des voyages extraordinaires. Dole: Clef d'argent, 2006.

Dupuy, Lionel. "Poétique de la ruine et imaginaire géographique dans les Voyages extraordinaires de Jules Verne." Sociétés, vol. 120, no. 2, 2013, pp. 49-59.

Dupuy, Lionel, "L'imaginaire géographique au cœur d'un Voyage Extraordinaire: Le Superbe Orénoque de Jules Verne." Géographie et cultures, vol. 75, 2010, pp. 175-88. gc.revues.org/1654.

duRivage, Françoise. "Texaco: From the Hills to the Mangrove Swamps." Thamyris, vol. 6, no. 1 , Spring 1999 , pp. 35-42.

Eisenman, Peter. "Michael Haneke and the New Subjectivity: Architecture and Film." A Companion to Michael Haneke, edited by Roy Grundmann. Malden, Mass.: Wiley-Blackwell, 201, pp. 124-9.

Encyclopedia Britannica (Online) http://www.britannica.com.

Evans, Arthur. "Jules Verne's America." Extrapolation, vol. 48 no. 1, 2007, pp. 35-43.

Evans, Arthur B. , "Jules Verne and the French Literary Canon." Narratives of Modernity, edited by Edmund Smyth. Liverpool: Liverpool University Press, 2000, pp. 11-39. 
Ezra, Elizabeth, and Jane Sillars. "Hidden in Plain Sight: Bringing Terror Home." Screen, vol. 48 , no. 2, 2007, pp. 215-21.

Ezra, Elizabeth, and Jane Sillars. “The Caché Dossier." Screen, vol. 48, no. 2, 2007, p. 211.

Fanon, Frantz. Black Skin, White Masks. Trans. Charles Lam Markmann. London: Pluto Press, 1986.

Fanon, Frantz. A Dying Colonialism. Trans. Haakon Chevalier. New York: Grove Press, 1967.

Fanon, Frantz. Peau noire, masques blancs. Paris: Les Éditions du Seuil, 1952. Hosted at the Université du Québec à Chicoutimi website: http://classiques.uqac.ca/classiques/ fanon_franz/peau_noire_masques_blancs/peau_noire_masques_blancs.pdf.

Fanon, Frantz. Sociologie d'une révolution (L'an V de la révolution algérienne). Paris: François Maspero, 1972. Ebook available on the website of University of Québec at Chicoutimi. http://classiques.uqac.ca.

Ferly, Odile. A Poetics of Relation: Caribbean Women Writing at the Millennium. New York: Palgrave Macmillan, 2012.

Filimon, Monica, and Fatima Naqvi. "Variations on Themes: Spheres and Space in Haneke's Variation." A Companion to Michael Haneke, edited by Roy Grundmann. Malden, Mass.: Wiley-Blackwell, 2010, pp. 243-62.

Fonkoua, Romuald-Blaise. "Instituer le savoir des Antilles aux îles: L'Institut Martiniquais d'études et la revue Acoma." Le Roman francophone actuel en Algérie et aux Antilles, edited by Danièle de Ruyter-Tognotti and Madeleine van Strien-Chardonneau. Amsterdam: Rodopi, 1998, pp. 103-20.

Fontanabona, J. “La géographie de Jules Verne et ses cartes dans L'Île Mystérieuse.” M@ ppemonde, no. 97, 2010. http://mappemonde.mgm.fr/num25/articles/art10101. html.

Foucault, Michel. “L'Arriere-fable." L'Arc 29, 1966, pp. 5-12.

Foucault, Michel. Power/Knowledge: Selected Interviews and Other Writings 1972-77. Trans. Colin Gordon et al. New York: Pantheon Books, 1980.

Fowler's Concise Dictionary of Modern English Usage, edited by Jeremy Butterfield. Oxford: Oxford University Press, 2015.

Foxcroft, Louise. The Making of Addiction: The 'Use and Abuse' of Opium in Nineteenth-Century Britain. Aldershot : Ashgate, 2007.

François, Anne M. Rewriting the Return to Africa: Voices of Francophone Caribbean Women Writers. Lanham, Md.: Lexington Books, 2011.

Gal, Susan. "Language and Political Spaces." Language and Space: An International Handbook of Linguistic Variation, edited by Peter Auer and Jürgen Erich Schmidt. Berlin: De Gruyter Mouton, 2010, pp. 33-49.

Gallagher, Brianne. "Policing Paris: Private Publics and Architectural Media in Michael Haneke's Caché." Journal for Cultural Research, vol. 12, no. 1, 2008, pp. 19-38.

Gallagher, Mary. "Introduction: Between 'Here' and 'There', or the Hyphen of the Unfinished Things." Ici-là: Place and Displacement in Caribbean Writing in French, edited by Mary Gallagher. Amsterdam: Rodopi, 2003, pp. xiii-xxix.

Gauvin, Lise. “L'Imaginaire des langues: Entretien avec Édouard Glissant." Études françaises, vol. 28, nos. 2-3, 1992, pp. 11-22.

Gavaskar, Mahesh. "Modi's Diaspora Nationalism." Economic \& Political Weekly, 10 Oct. 10, 2015, vol. 50 , no. 41 , p. 9 . 
Geertz, Clifford. Local Knowledge: Further Essays in Interpretive Anthropology. New York: Basic Books, 1983.

Géhu. Edmond-P. “La Géographie polaire dans l'œuvre de Jules Verne: Aventures du capitaine Hatteras." Bulletin de la Société Jules Verne, vol. 9 (December 1937), pp. 181-98.

Genette, Gérard. Paratexts: Thresholds of Interpretations. Trans. Jane E. Lewin. Cambridge, U.K.: Cambridge University Press, 1997.

George, Ajish. "Modi Government's Top Controversial Appointments That Were

Hounded by Saffronisation Allegations." New Indian Express, 16 July 2015. www. newindianexpress.com/nation/Modi-Governments-Top-Controversial-Appointments-That-Were-Hounded-by-Saffronisation-Allegations/2015/07/16/article2923297.ece. Wayback Machine, https://tinyurl.com/tt9rjd9z.

Germain, Gilbert G. Spirits in the Material World: The Challenge of Technology. Lanham, Md.: Lexington Books, 2009.

Geyh, Paula E. "Cosmopolitan Exteriors and Cosmopolitan Interiors: The City and Hospitality in Haneke's Code Unknown." The Cinema of Michael Haneke: Europe Utopia, edited by Ben McCann and David Sorfa. London; New York: Wallflower Press, 2011, pp 105-16.

Gildea, Robert. The Past in French History. New Haven: Yale University Press, 1994.

Gilroy, Paul. "Shooting Crabs in a Barrel." Screen, vol. 48, no. 2, 2007, pp. 233-5.

Glissant, Edouard. Caribbean Discourse: Selected Essays. Trans. with intro. by J. Michael Dash. Charlottesville: University Press of Virginia, 1989.

Glissant, Edouard. Le discours antillais. Paris: Editions du Seuil, 1981.

Glissant, Edouard. Poetics of Relation. Trans. Betsy Wing. Ann Arbor: University of Michigan Press, 1990.

Glissant, Edouard. Poétique de la relation. Paris: Gallimard, 1990.

Glissant, Edouard. Tout-monde. Paris: Gallimard, 1993.

Glissant, Edouard. Une journée avec Édouard Glissant. Paris: Association lacanienne internationale, 2009.

Goel, Vindu, and Jeffrey Gettleman. “Under Modi, India’s Press Is Not So Free Anymore.” New York Times, 2 April 2020. https://www.nytimes.com/2020/04/02/world/asia/ modi-india-press-media.html.

Goonewardena, Kahisnka, et al. "On the Production of Henri Lefebvre." Space, Difference, Everyday Life: Reading Henri Lefebvre, edited by Kahisnka Goonewardena et al. New York: Routledge, 2008, pp. 1-24.

Grasso, June, Jay Corrin, and Michael Kort. Modernization and Revolution in China: From the Opium Wars to World Power. New York: East Gate, 2004.

Greenberg, Michael. British Trade and the Opening of China 1800-42. Cambridge, U.K.: Cambridge University Press, 1951.

Grosz, Elizabeth A. Space, Time, and Perversion: Essays on the Politics of Bodies. New York: Routledge, 1995.

Haneke, Michael, dir. Caché: [Hidden]. Culver City, Calif: Sony Pictures Home Entertainment, 2006.

Haneke, Michael. Interview on Caché with Serge Toubiana (DVD).

Hanson, Susan. "Transportation: Hooked on Speed, Eyeing Sustainability." A Companion to Economic Geography, edited by Eric Sheppard and Trevor J. Barnes. Oxford: Blackwell, 2003, pp. 468-83. 
Harpold, Terry. “Verne’s Cartographies." Science Fiction Studies, vol. 32, no. 1, 2005, pp. 18 42.

Harvey, David. Spaces of Hope. Edinburgh: Edinburgh University Press, 2000.

Harvey, David. The Condition of Postmodernity: An Enquiry into the Origins of Cultural Change. Oxford, U.K.: Blackwell, 1989.

Hawkins, Peter. "An Interview with Ananda Devi." Wasafiri, vol. 26, no. 2, 2011, pp. 8-13.

Hayward, Jennifer. Consuming Pleasures: Active Audiences and Serial Fictions from Dickens to Soap Opera. Lexington: University Press of Kentucky, 1997.

Henry, Freeman G. Geo/graphies: Mapping the Imagination in French and Francophone Literature and Film. Amsterdam: Rodopi, 2003.

Hetherington, Kevin. Expressions of Identity: Space, Performance, Politics. London: Sage, 1998.

Hones, Sheila. "Literary Geography and the Short Story: Setting and Narrative Style." Cultural Geographies, vol. 17, no. 4, 2010, pp. 473-85.

Hones, Sheila. Literary Geographies: Narrative Space in Let the Great World Spin. New York: Palgrave Macmillan, 2014.

Hones, Shiela. “Text as It Happens: Literary Geography." Geography Compass, vol. 2, 2008, pp. 1301-17.

House, Jim, and Neil MacMaster. Paris 1961: Algerians, State Terror, and Memory. New York: Oxford University Press, 2006.

Hoving, Isabel. "Remaining Where You Are: Kincaid and Glissant on Space and Knowledge." Mobilizing Place, Placing Mobility: The Politics of Representation in a Globalized World, edited by Ginette Verstraete and Tim Cresswell. Amsterdam: Rodopi, 2002, pp. 125-40.

Howells, Richard, and Joaquim Negreiros. Visual Culture. Cambridge, U.K.: Polity Press, 2012.

Humeau, D. “Les dimensions géographique dans l'œuvre de Jules Verne." Géographie et Cultures, vol. 15, 1995, pp. 21-44.

Ince, Kate. "Glocal Gloom: Existential Space in Haneke's French-Language Films.” The Cinema of Michael Haneke: Europe Utopia, edited by Ben McCann and David Sorfa. London: Wallflower Press, 2011, pp. 85-93.

Inglis, David. "Auto Couture: Thinking the Car in Post-war France." Automobilities, edited by Mike Featherstone, Nigel Thrift, and John Urry. London: Sage, 2005, pp. 197-220.

Jacobs, Karen. The Eye's Mind: Literary Modernism and Visual Culture. Ithaca: Cornell University Press, 2001.

Jacquemet, Marco. "Language and Transnational Spaces." Language and Space: An International Handbook of Linguistic Variation, edited by Peter Auer and Jürgen Erich Schmidt. Berlin: De Gruyter Mouton, 2010, pp. 50-69.

Jameson, Fredric. Postmodernism, Or, the Cultural Logic of Late Capitalism. Durham, N.C.: Duke University Press, 1991.

Janz, Bruce B. "Philosophical Issues in Ethnophysiography: Landform Terms, Disciplinarity, and the Question of Method." Landscape in Language: Transdisciplinary Perspectives, edited by David Mark et al. Amsterdam: John Benjamins, 2011, pp. 101-20.

Johnstone, Barbara. "Place, Globalization, and Linguistic Variation." Sociolinguistic Variation: Critical Reflections, edited by Carmen Fought. Oxford: Oxford University Press, 2004, 65-83. 
Jonassaint, Jean. "Literatures in the Francophone Caribbean." Yale French Studies, vol. 103, 2003, pp. 55-63.

Justice, Christopher. “The Vacant Vacationer: Travel as Symptom and Antidote in Michael Haneke." The Cinema of Michael Haneke: Europe Utopia, edited by Ben McCann and David Sorfa. London: Wallflower Press, 2011, pp 94-104.

Kalisa, Chantal. Violence in Francophone African and Caribbean Women's Literature. Nebraska: University of Nebraska Press, 2009.

Kemedjio, Cilas. "La femme antillaise face au faubourg et à la durcification dans Texaco de Patrick Chamoiseau et Mélody des faubourgs de Lucie Julia." LittéRéalité, vol. 11, no. 2 (Autumn-Winter 1999), pp. 31-47.

Kesavan, Mukul. "The Attacks on Two Delhi Universities Reveal Modi's Targets: Muslims and Their Allies." Guardian, 13 Jan. 2020. https://www.theguardian.com/commentisfree/2020/jan/13/attacks-delhi-universities-modi-muslims-allies.

Khanna, Ranjana. "From Rue Morgue to Rue des Iris." Screen, vol. 48, no. 2, 2007, pp. 237 44.

Kumar, Raksha. "Hindu Right Rewriting Indian Textbooks." Aljazeera, 4 Nov. 2014. www. aljazeera.com/indepth/features/2014/11/hindu-right-ideology-indian-textbooks-gujarat-20141147028501733.html.

Kundera, Milan. "Beau comme une rencontre multiple." Infini, vol. 34 (Summer 1991).

Landy, Frédéric. "L'Inde de Jules Verne: Une lecture de La maison à vapeur." Géographie et cultures, no. 15, Autumn 1995, pp. 45-67.

Laronde, Michel. "Displaced Discourses: Post(-)coloniality, Francophone Space(s), and the Literature(s) of Immigration in France." Postcolonial Theory and Francophone Literary Studies, edited by H. Adlai Murdoch, Anne Donadey and Françoise Lionnet. Gainesville: University Press of Florida, 2005, pp. 175-92.

Le Brun, Annie. Statue cou coupé. Paris: J.-M. Place, 1996.

Le Failler, Philippe. Monopole et prohibition de l'opium en Indochine: Le pilori des chimères. Paris: L'Harmattan, 2001.

Lefebvre, Henri. La Production de l'espace. Paris: Éditions Anthropos, 1981.

Lefebvre, Henri. The Production of Space. Trans. Donald Nicholson-Smith. Oxford: Blackwell, 1991.

Lionnet, Françoise. "Evading the Subject: Narration and the City in Ananda Devi's Rue la Poudrière." Postcolonial Representations: Women, Literature, edited by Françoise Lionnet. Ithaca: Cornell University Press, 1995, pp. 48-68.

Lionnet, Françoise. "Reframing Baudelaire Literary History, Biography, Postcolonial Theory, and Vernacular Languages." French Cultural Studies: Criticism At the Crossroads, edited by Marie-Pierre Le Hir and Dana Strand. Albany: State University of New York Press, 2000, pp. 153-83.

Lomax, Elizabeth. "Uses and Abuses of Opiates in Nineteenth Century England." Bulletin of the History of Medicine, vol. 47, no. 2, 1973, pp. 167-76.

Lyons, Martyn. Reading Culture and Writing Practices in Nineteenth-Century France. Toronto: University of Toronto Press, 2008.

Mair, Christian. "The Consequences of Migration and Colonialism I: Pidgins and Creoles." Language and Space: An International Handbook of Linguistic Variation, edited by Peter Auer and Jürgen Erich Schmidt. Berlin: De Gruyter Mouton, 2010, pp. 440-50. 
Marez, Curtis. Drug Wars: The Political Economy of Narcotics. Minneapolis: University of Minnesota Press, 2004.

Mark, David M. et al. "Landscape in Language: An Introduction." Landscape in Language: Transdisciplinary Perspectives, edited by David Mark et al. Amsterdam: John Benjamins, 2011, pp. 1-24.

Mark, David et al. Foreward. Landscape in Language: Transdisciplinary Perspectives, edited by David Mark et al. Amsterdam: John Benjamins, 2011, pp. ix-x.

Markus, Thomas A., and Deborah Cameron. The Words between the Spaces: Buildings and Language. London: Routledge, 2002.

Marx, Karl. "Free Trade and Monopoly." New York Daily Tribune, 25 Sept. 1858. http:// www.marxists.org/archive/marx/works/1858/09/25.htm.

Marx, Karl. “Trade or Opium?” New York Daily Tribune, 25 Sept. 1858. http://www.marxists.org/archive/marx/works/1858/09/20.htm.

Massey, Doreen. For Space. London: Sage, 2005.

Massey, Doreen. Space, Place, and Gender. Minneapolis: University of Minnesota Press, 1994.

Maudhuy, Roger. Jules Verne: La face cachée. Paris: Editions France-Empire, 2005.

McClintock, Anne. “'No Longer in a Future Heaven': Gender, Race and Nationalism.” Dangerous Liaisons: Gender, Nation, and Postcolonial Perspectives, edited by Anne McClintock, Aamir Mufti and Ella Shohat. Minneapolis: University of Minnesota Press, 1997, pp. 89-112.

McCulloch, Jock. Black Soul White Artifact: Fanon's Clinical Psychology and Social Theory. Cambridge, U.K.: Cambridge University Press, 1983.

McCusker, Maeve. "On Slavery, Césaire, and Relating to the World: An Interview with Patrick Chamoiseau." Trans. Rachel O’Loan and Maeve McCusker. Small Axe, vol. 13, no. 3 (30), 2009, pp. 74-83.

McCusker, Maeve. "Writing against the Tide?: Patrick Chamoiseau’s (Is)land Imaginary." Islanded Identities: Constructions of Postcolonial Cultural Insularity, edited by Maeve McCusker and Anthony Soares. Amsterdam: Rodopi, 2011, pp. 41-62.

McDowell, Linda. "Spatializing Feminism: Geographic Perspectives." Body Space: Destabilising Geographies of Gender and Sexuality, edited by Nancy Duncan. London: Routledge, 1996, pp. 28-44.

McLaughlan, Robert. Re-Imagining the "Dark Continent" in Fin de Siècle Literature. Edinburgh: Edinburgh University Press, 2012.

Melas, Natalie, "Pays rêvé, pays réel. Créolité and Its Diasporas." Aftermaths: Exile, Migration, and Diaspora Reconsidered, edited by Marcus Paul Bullock and Peter Yoonsuk Paik. New Brunswick, N.J.: Rutgers University Press, 2009, pp. 103-32.

Mercier, Guy. "Vidal de la Blache." International Encyclopedia of Human Geography, edited by Rob Kitchin and Nigel Thrift, vol. 12, 2009, pp. 147-50. Hosted on ScienceDirect. com. https://www.sciencedirect.com/science?_ob=RefWorkIndexURL\&_idxType=GI\&_cid $=278622 \& \mathrm{md} 5=32517 \mathrm{e} 01 \mathrm{fbc4a} 53788 \mathrm{~cd} 2 \mathrm{e} 200373 \mathrm{f} 986$.

Milgrom, Richard. "Lucien Kroll: Design, Difference, Everyday Life." Space, Difference, Everyday Life: Reading Henri Lefebvre, edited by Kahisnka Goonewardena et al. New York: Routledge, 2008, pp 264-81.

Milne, Lorna. "From Créolité to Diversalité: The Postcolonial Subject in Patrick Chamoiseau's Texaco." Subject Matters: Subject and Self in French Literature from Descartes to 
the Present, edited by Paul Giffort and Johnnie Gratton. Amsterdam: Rodopi, 2000, pp. 162-80.

Milne, Lorna. "Sex, Gender and the Right to Write: Patrick Chamoiseau and the Erotics of Colonialism." Paragraph, vol. 24, no. 3, 2001, pp. 59-75.

Miłosz, Czesław. "Bypassing Rue Descartes." Trans. Renata Gorczynski and Robert Hass, Polish Poetry of the Last Two Decades of Communist Rule, edited and with translations by Stanisław Barańczak and Clare Cavanagh. Evanston, Ill.: Northwestern University Press, 1991, pp. 26-27.

Mohanty, Chandra Talpade. “Under Western Eyes' Revisited: Feminist Solidarity through Anticapitalist Struggles." Signs: Journal of Women in Culture and Society, vol. 28, no. 2, 2002, pp. 499-535.

Moudileno, Lydie. “ From Pré-littérature to Littérature-monde: Postures, Neologisms, Prophecies." Antillanite, Creolite, Litterature-monde, edited by Isabelle Constant, Kahiudi C. Mabana and Philip Nanton. Newcastle upon Tyne: Cambridge Scholars, 2013, pp. 13-26.

Mukhopadhyay, Indra. "Alexandre Dumas's and Jules Verne's India: The French Republic of Letters Discusses Imperial Historiography." France’s Lost Empires: Fragmentation, Nostalgia, and La Fracture Coloniale, edited by Kate Marsh and Nicola Frith. Lanham, Md.: Lexington Books, 2011, pp. 111-23.

Murdoch, H. Adlai. Creole Identity in the French Caribbean Novel. Gainesville: University Press of Florida, 2001.

Murdoch, H. Adlai. "Glissant's Opacité and the Re-Conceptualization of Identity." Theorizing Glissant: Sites and Citations, edited by John E. Drabinski and Marisa Parham. London: Rowman \& Littlefield, 2015, pp. 7-28.

N'zengou-Tayo, Marie-José. "Literature and Diglossia: The Poetics of French and Creole 'Interlect' in Patrick Chamoiseau's Texaco." Caribbean Quarterly, vol. 43, no. 4, 1997, 81-101.

N'Zengou-Tayo, Marie-José, and Elizabeth Wilson. “Translators on a Tight Rope: The Challenges of Translating Edwidge Danticat's Breath, Eyes, Memory and Patrick Chamoiseau's Texaco." TTR: Traduction, terminologie, rédaction: Etudes sur le texte et ses transformations, vol. 13, no. 2, 2000, pp. 75-105.

Nesbitt, Nick. Caribbean Critique: Antillean Critical Theory from Toussaint to Glissant. Liverpool: Liverpool University Press, 2013.

Njoh, Ambe J. French Urbanism in Foreign Lands. Cham: Springer International, 2016. ebook.

Nnadi, Joseph. “Mémoire d'Afrique, mémoire biblique: La congruence des mythes du nègre dans Texaco de Patrick Chamoiseau." Etudes Francophones, vol. 15, no. 1, 2000, pp. 7591.

Ogborn, Miles, and Charles W. J. Withers. "Introduction: Book Geography, Book History." Geographies of the Book, edited by Miles Ogborn and Charles W. J. Withers. Farnham: Ashgate, 2010, pp. 1-28.

Owen, David Edward. British Opium Policy in China and India. Hamden, Conn.: Archon Books, 1968.

Oxford Reference Online, Pocket Fowler's Modern English Usage. Edited by Robert Allen, 1999. http://www.oxfordreference.com. 
Palshikar, Suhas, and K. C. Suri. "India's 2014 Lok Sabha Elections: Critical Shifts in the Long Term, Caution in the Short Term.” Economic \& Political Weekly, vol. 49, no. 39, 2014, pp. 39-49.

Papon, Maurice. "Proclamation of October 5, 1961." Cited in Einaudi, Jean-Luc. La Bataille de Paris: 17 octobre 1961. Paris: Seuil, 1991.

Parry, Benita. "Beginnings, Affiliations, Disavowals." Postcolonial Studies: A Materialist Critique. London: Routledge, 2004, pp. 3-12.

Parry, Benita. "Internationalism Revisited or in Praise of Internationalism." Interventions: The International Journal of Postcolonial Studies, vol. 5, no. 2 (July 2003), pp. 291-314.

Pattano, Luigia. “Sur 'L'Éloge de la Créolité': Un Entretien avec Patrick Chamoiseau." 15 Sept. 2011. http://mondesfrancophones.com/.

Pawlett, William. Jean Baudrillard: Against Banality. London: Routledge, 2007.

Perret, Delphine. La Créolité: Espace de création. Martinique: Ibis Rouge Editions, 2001.

Phillips, Richard. Mapping Men and Empire: A Geography of Adventure. London: Routledge, 1997.

Picanço, Luciano C. Vers un concept de littérature nationale martiniquaise: Evolution de la littérature martiniquaise au XXème siècle - Une étude sur l'oeuvre d'Aimé Césaire, Edouard Glissant, Patrick Chamoiseau et Raphaël Confiant. New York: Peter Lang, 2000.

Platten, David. “A Hitchhiker's Guide to Paris: Paris au XXe siècle." Jules Verne: Narratives of Modernity, edited by Edmund Smyth, Liverpool: Liverpool University Press, 2000, pp. 78-93.

Pojmann, Wendy A. Migration and Activism in Europe since 1945. New York: Palgrave Macmillan, 2008.

Porton, R. "Collective Guilt and Individual Responsibility: An Interview with Michael Haneke." Cinéaste, vol. 31, no. 1, 2005, pp. 50-1.

Price, Richard, and Sally Price. "Shadowboxing in the Mangrove." Cultural Anthropology: Journal of the Society for Cultural Anthropology, vol. 12, 1997, pp. 3-36.

Prieto, Eric. "Landscaping Identity in Contemporary Caribbean Literature." Francophone Post-Colonial Cultures: Critical Essays, edited by Kamal Salhi. Lanham, Md.: Lexington Books, 2003, pp. 141-52.

Prieto, Eric. "Phenomenology, Place, and the Spatial Turn." The Routledge Handbook of Literature and Space, edited by Robert T. Tally. Basingstoke: Taylor \& Francis, 2017, pp. 60-69.

Rabenarivo, Fara L. The City in Island Literature (Madagascar and Martinique): Toward a Poetics of Urban Space. University of Iowa, PhD Dissertation. 2008.

Raza, Danish. "Saffronising Textbooks: Where Myth and Dogma Replace History." Hindustan Times, last updated 8 Dec. 2014. www.hindustantimes.com/india/saffronising-textbooks-where-myth-and-dogma-replace-history/story-CauM4dmmsPGrjZ3APAvNxO.html.

Reclus, Elisée. L’homme et la terre. Paris: Libr. universelle, 1905.

Robinson, Andrew. "Jean Baudrillard: Symbolic Exchange." Ceasefire, 17 Feb. 2012. https://ceasefiremagazine.co.uk/in-theory-baudrillard-1/.

Ross, Kristin. Fast Cars, Clean Bodies: Decolonization and the Reordering of French Culture. Cambridge, Mass.: MIT Press, 1995. 
Ross, Kristin. "Rimbaud and Spatial History." New Formations, no. 5 (Summer 1988), pp. 53-68.

Ross, Kristin. "Rimbaud and the Transformation of Social Space." 50 Years of Yale French Studies: A Commemorative Anthology. Part 2: 1980-1998, spec. issue of Yale French Studies, vol. 97, 2000, pp. 36-54.

Ross, Kristin. "The World Literature and Cultural Studies Program.” Critical Inquiry, vol. 19, no. 4 (Summer 1993), pp. 666-76.

Saxton, Libby. "Secrets and Revelations: Off-Screen Space in Michael Haneke's Caché (2005)." Studies in French Cinema, vol. 7, no. 1, 2007, pp. 5-17.

Schaefer, Joy C. "The Spatial-Affective Economy of (Post)colonial Paris: Reading Haneke's Caché (2005) through Octobre à Paris (1962).” Studies in European Cinema, vol. 14, no. 1,2017 , pp. 48-65.

Schivelbusch, Wolfgang. The Railway Journey: The Industrialization of Time and Space in the 19th Century. Berkeley: University of California Press, 1986.

Schulman, P. "Autour de l'excentricité de Phileas Fogg et du Capitaine Nemo." Bulletin de la Société Jules Verne, vol. 123, 1997, pp. 33-6.

Sestigiani, Sabina. Writing Colonisation: Violence, Landscape, and the Act of Naming in Modern Italian and Australian Literature. New York: Peter Lang, 2014.

Sharp, Joanne. "Feminisms." A Companion to Cultural Geography, edited by James S.

Duncan, Nuala C. Johnson, and Richard H. Schein. Malden, Mass.: Blackwell, 2004, pp. 66-78.

Sharp, Joanne P. “Toward a Critical Analysis of Fictive Geographies.” Area, vol. 32, no. 3, 2000, pp. 327-34.

Shields, Rob. Lefebvre, Love, and Struggle: Spatial Dialectics. New York: Routledge, 2009.

Silverman, Max. “The Empire Looks Back." Screen, vol. 48, no. 2, 2007, pp. $245-9$.

Soja, Edward W. Thirdspace: Journeys to Los Angeles and Other Real-and-Imagined Places. Cambridge, Mass.: Blackwell, 1996.

Szalai, Jennifer. "Habits of Seeing: The Unsettling Films of Michael Haneke." Harper's, vol. 315 , no. 1890,2007 , pp. $68-75$.

Tally, Robert T., Jr. "Introduction: The Reassertion of Space in Literary Studies." The Routledge Handbook of Literature and Space, edited by Robert T. Tally Jr. Basingstoke: Taylor \& Francis, 2017, pp. 1-6.

Tally, Robert T., Jr. Literary Cartographies: Spatiality, Representation, and Narrative. New York: Palgrave Macmillan, 2015.

Tally, Robert T., Jr. Spatiality. London: Routledge, 2013.

Tally, Robert T., Jr. The Geocritical Legacies of Edward W. Said: Spatiality, Critical Humanism, and Comparative Literature. New York: Palgrave Macmillan, 2015.

Taseer, Aatish. "Op-Ed: The Right-Wing Attack on India's Universities." New York Times, 27 Jan. 2016. www.nytimes.com/2016/01/28/opinion/the-right-wing-attack-on-indias-universities.html module $=$ ArrowsNav\&contentCollection $=$ Opinion\&action=keypress\&region $=$ FixedLeft\&pgtype $=$ article.

Tavares, David, and Marc Brosseau, "The Spatial Politics of Informal Urban Citizenship: Reading the Literary Geographies of Toronto in Dionne Brand's What We All Long For." Zeitschrift für Kanada-Studien, vol. 33, no. 1, 2013, pp. 9-33.

Terrasse, Pierre. "Le Jeu de cartes de Jules Verne." Bulletin de la Société de Jules Verne (Nouvelle Série), vol. 22, no. 87, 1988, pp. 29-33. 
Thompson, Ian B. “Jules Verne, Geography and Scotland." Zvi Har'El's Jules Verne Collection, 23 Dec. 2007. julesverne.ca/jv.gilead.org.il/ithompson/geography.html. French version of the article published in: La Géographie: Acta Géographica, Dec. 2003, pp. 48-71.

Trésor de la Langue Française. Le Trésor de la Langue Française Informatisé. http://atilf. atilf.fr/tlf.htm.

Turk, Andrew G. "Exploring Philosophy of Place: Potential for Synergy between Phenomenology and Ethnophysiography." Landscape in Language: Transdisciplinary Perspectives, edited by David Mark et al. Amsterdam: John Benjamins, 2011, pp 47-72.

Tyagi, Ritu. Ananda Devi: Feminism, Narration and Polyphony. Amsterdam: Rodopi, 2013.

Tyagi, Ritu. "Rethinking Identity and Belonging: 'Mauritianness' in the Work of Ananda Devi." Islanded Identities: Constructions of Postcolonial Cultural Insularity, edited by Maeve McCusker and Anthony Soares. Amsterdam: Rodopi, 2011, pp. 91-108.

Unwin, Timothy A. Jules Verne: Journeys in Writing. Liverpool: Liverpool University Press, 2005.

Unwin, Timothy A. Jules Verne, Le tour du monde en quatre-vingts jours. Glasgow: University of Glasgow, 1992.

Unwin, Timothy. "Jules Verne: Negotiating Change in the Nineteenth Century." Science Fiction Studies, vol. 32, no. 1, 2005, pp. 5-17.

Upstone, Sara. Spatial Politics in the Postcolonial Novel. Farnham: Ashgate, 2009.

Varma, Rashmi. The Postcolonial City and Its Subjects: London, Nairobi, Bombay. New York: Routledge. 2012.

Vergès, Françoise. Monsters and Revolutionaries: Colonial Family Romance and Métissage. Durham, N.C.: Duke University Press, 1999.

Verne, Jules. Around the World in Eighty Days. Trans. William Butcher. New York: Oxford University Press, 1999.

Verne, Jules. Cinq semaines en ballon. Paris: J. Hetzel, 1863.

Verne, Jules. De la terre à la lune. Paris: J. Hetzel,1865.

Verne, Jules. Le Tour du monde en quatre-vingts jours. Paris: Librairie Générale Française, 2001.

Verne, Jules. Les enfants du capitaine Grant. Paris: Hachette, 1966.

Verne, Jules. Paris au XXe siècle. Paris: Hachette, 1994.

Verne, Jules. Voyage au centre de la terre. Paris: Hachette, 1945.

Verne, Jules. Vingt mille lieues sous les mers. Paris: J. Hetzel, 1871.

Verne, Jules. Voyages et aventures du capitaine Hatteras. Paris: J. Hetzel, 1867.

Walters, James. Baudrillard and Theology. London: T. \& T. Clark International, 2012.

Warf, Barney, and Santa Arias. "Introduction: The Reinsertion of Space into the Social Sciences and Humanities." The Spatial Turn: Interdisciplinary Perspectives, edited by Barney Warf and Santa Arias. London: Routledge, 2009, pp. 1-10.

Watts, Richard. Packaging Post/coloniality: The Manufacture of Literary Identity in the Francophone World. Lanham, Md.: Lexington Books, 2005.

Webber, Michael. "International Political Economy." A Companon to Economic Geography, edited by Eric Sheppard and Trevor J. Barnes. Oxford: Blackwell Publishers, 2003, pp. 499-518. ebook.

Wheatley, Catherine. "Secrets, Lies \& Videotape." Sight and Sound, vol. 16, no. 2, 2006, pp. 32-6. 
Wong, Alfred, and Roxanne Gomes. "Intractable Social-Economic Problems of Martinique." Études caribéennes, 7 March 2016. https://doi.org/10.4000/etudescaribeennes.6073.

Young-Bruehl, Elisabeth. Why Arendt Matters. New Haven: Yale University Press, 2006.

Youngs, Tim. Beastly Journeys: Travel and Transformation at the Fin de Siecle. Liverpool: Liverpool University Press, 2014.

Youngs, Tim. Travellers in Africa: British Travelogues, 1850-1900. Manchester: Manchester University Press, 1994. 
